QUALITY-ASSURANCE DATA FOR ROUTINE WATER

ANALYSIS IN THE NATIONAL WATER-QUALITY

LABORATORY OF THE U.S GEOLOGICAL SURVEY

FOR WATER YEAR 1989

by Thomas J. Maloney, Amy S. Ludtke, and Teresa L. Krizman

U.S. GEOLOGICAL SURVEY

Water-Resources Investigations Report 92-4075 


\section{U.S. DEPARTMENT OF THE INTERIOR \\ MANUEL LUJAN, JR., Secretary \\ U.S. GEOLOGICAL SURVEY \\ Dallas L. Peck, Director}

For additional information write to:

Chief, Branch of Quality Assurance

U.S. Geological Survey

Box 25046, Mail Stop 401

Federal Center

Denver, CO 80225-0046
Copies of this report can be purchased from:

U.S. Geological Survey

Books and Open-File Reports Section

Federal Center

Box 25425

Denver, Colorado 80225 


\section{CONTENTS}

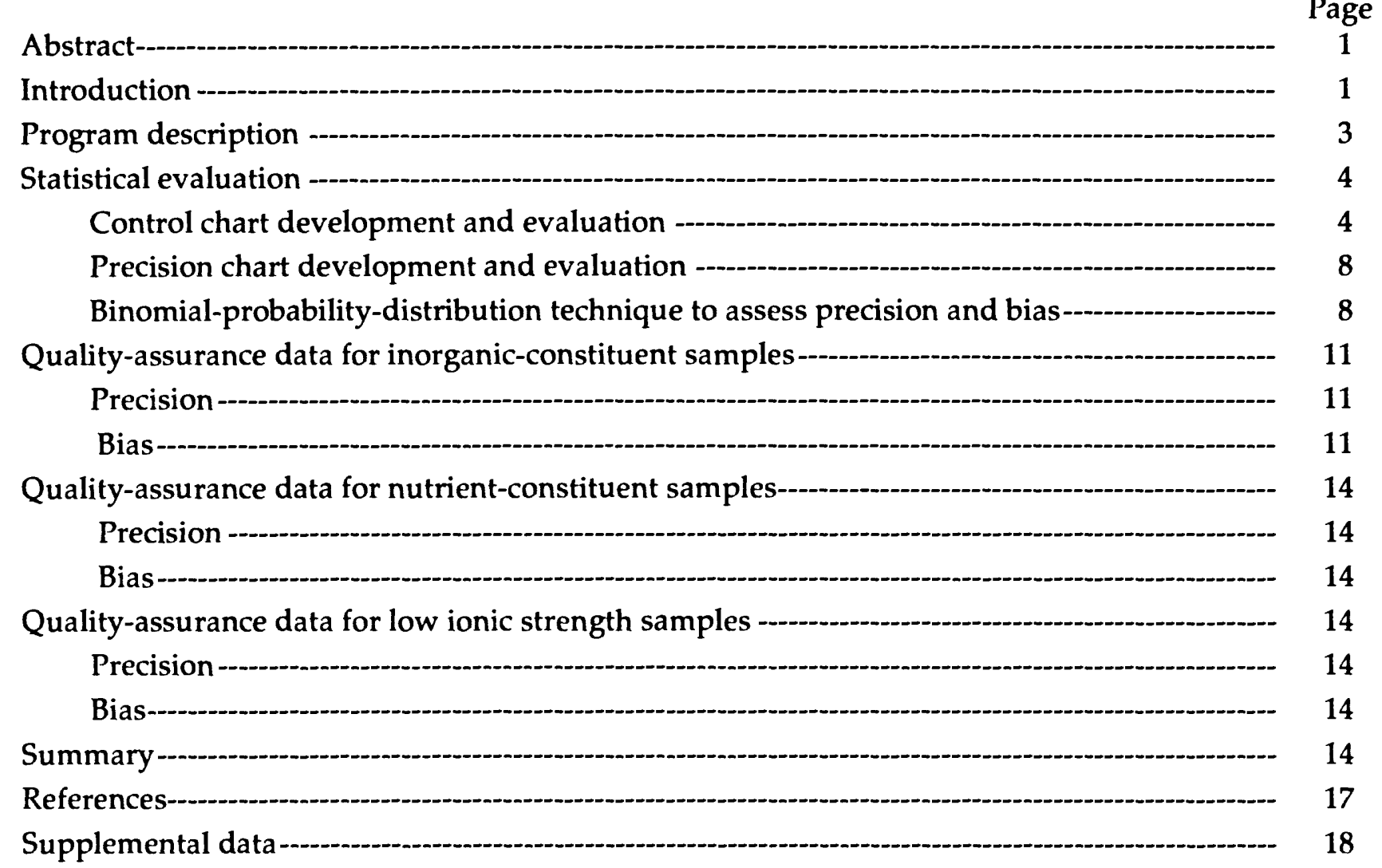

\section{FIGURES}

Figures 1-160. Graphs showing:

1. Alkalinity, total, (electrometric titration) data from the National Water

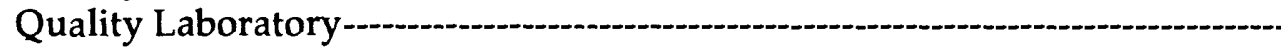

2. Aluminum, dissolved, (direct current plasma emission spectrometry) data from the National Water Quality Laboratory -

3. Aluminum, total, (direct current plasma emission spectrometry) data from the National Water Quality Laboratory

4. Antimony, dissolved, (atomic absorption spectrometry, hydride) data from the National Water Quality Laboratory

5. Arsenic, dissolved and total, (atomic absorption spectrometry, hydride) data from the National Water Quality Laboratory

6. Barium, dissolved, (inductively coupled plasma emission spectrometry) data from the National Water Quality Laboratory -

7. Barium, dissolved, (atomic absorption spectrometry) data from the National Water Quality Laboratory 
Figures 1-160. Graphs showing--Continued:

8. Barium, total recoverable, (atomic absorption spectrometry) data from the National Water Quality Laboratory

9. Beryllium, dissolved, (inductively coupled plasma emission spectrometry) data from the National Water Quality Laboratory

10. Beryllium, total recoverable, (atomic absorption spectrometry) data from the National Water Quality Laboratory -

11. Boron, dissolved, (direct current plasma emission spectrometry) data from the National Water Quality Laboratory

12. Cadmium, dissolved, (inductively coupled plasma emission spectrometry) data from the National Water Quality Laboratory --..-....

13. Cadmium, dissolved, (atomic absorption spectrometry; chelation-extraction or graphite furnace) data from the National Water Quality Laboratory --.--.--

14. Cadmium, total recoverable, (atomic absorption spectrometry; chelation extraction or graphite furnace) data from the National Water Quality Laboratory

15. Calcium, dissolved, (inductively coupled plasma emission spectrometry) data from the National Water Quality Laboratory -

16. Calcium, dissolved, (atomic absorption spectrometry) data from the National Water Quality Laboratory

17. Chloride, dissolved, (colorimetric) data from the National Water Quality Laboratory

18. Chromium, dissolved, (inductively coupled plasma emission spectrometry) data from the National Water Quality Laboratory

19. Chromium, dissolved, (direct current plasma emission spectrometry) data from the National Water Quality Laboratory -

20. Chromium, total recoverable, (direct current plasma emission spectrometry) data from the National Water Quality Laboratory

21. Cobalt, dissolved, (inductively coupled plasma emission spectrometry) data from the National Water Quality Laboratory

22. Cobalt, dissolved, (atomic absorption spectrometry; chelation-extraction or graphite furnace) data from the National Water Quality Laboratory--.---.--.---

23. Cobalt, total recoverable, (atomic absorption spectrometry; chelationextraction or graphite furnace) data from the National Water Quality Laboratory

24. Copper, dissolved, (inductively coupled plasma emission spectrometry) data from the National Water Quality Laboratory

25. Copper, dissolved, (atomic absorption spectrometry; chelation-extraction or graphite furnace) data from the National Water Quality Laboratory-

26. Copper, total recoverable, (atomic absorption spectrometry; chelationextraction or graphite furnace) data from the National Water Quality Laboratory

27. Dissolved solids, (gravimetric) data from the National Water Quality Laboratory

28. Fluoride, dissolved, (ion-selective electrode) data from the National Water Quality Laboratory 
Figures 1-160. Graphs showing--Continued:

29. Iron, dissolved, (inductively coupled plasma emission spectrometry) data from the National Water Quality Laboratory --..-.

30. Iron, dissolved, (atomic absorption spectrometry) data from the National Water Quality Laboratory-

31. Iron, total recoverable, (atomic absorption spectrometry) data from the National Water Quality Laboratory -

32. Lead, dissolved, (inductively coupled plasma emission spectrometry) data from the National Water Quality Laboratory

33. Lead, dissolved, (atomic absorption spectrometry; chelation-extraction or graphite furnace) data from the National Water Quality Laboratory-

34. Lead, total recoverable, (atomic absorption spectrometry; chelation-extraction or graphite furnace) data from the National Water Quality Laboratory -------

35. Lithium, dissolved, (inductively coupled plasma emission spectrometry) data from the National Water Quality Laboratory

36. Lithium, total recoverable, (atomic absorption spectrometry) data from the National Water Quality Laboratory

37. Magnesium, dissolved, (inductively coupled plasma emission spectrometry) data from the National Water Quality Laboratory

38. Magnesium, dissolved, (atomic absorption spectrometry) data from the National Water Quality Laboratory

39. Manganese, dissolved, (inductively coupled plasma emission spectrometry) data from the National Water Quality Laboratory

40. Manganese, dissolved, (atomic absorption. spectrometry) data from the National Water Quality Laboratory

41. Manganese, total recoverable, (atomic absorption spectrometry) data from the National Water Quality Laboratory -

42. Mercury, dissolved, (atomic absorption spectrometry) data from the National Water Quality Laboratory

43. Mercury, total, (atomic adsorption spectrometry) data from the National Water Quality Laboratory-

44. Molybdenum, dissolved, (inductively coupled plasma emission spectrometry) data from the National Water Quality Laboratory

45. Molybdenum, dissolved, (atomic absorption spectrometry) data from the National Water Quality Laboratory

46. Nickel, dissolved, (inductively coupled plasma emission spectrometry) data from the National Water Quality Laboratory -

47. Nickel, dissolved, (atomic absorption spectrometry; chelation-extraction or graphite furnace) data from the National Water Quality Laboratory

48. Nickel, total recoverable, (atomic absorption spectrometry; chelationextraction or graphite furnace) data from the National Water Quality Laboratory

49. Potassium, dissolved, (atomic absorption spectrometry) data from the National Water Quality Laboratory

Selenium, dissolved and total, (atomic absorption spectrometry, hydride) data from the National Water Quality Laboratory 
Figures 1-160. Graphs showing--Continued:

51. Silica, dissolved, (inductively coupled plasma emission spectrometry) data from the National Water Quality Laboratory --...-...-

52. Silica, dissolved, (colorimetric) data from the National Water Quality Laboratory

53. Silver, dissolved, (inductively coupled plasma emission spectrometry) data from the National Water Quality Laboratory

54. Silver, dissolved, (atomic absorption spectrometry; chelation-extraction or graphite furnace) data from the National Water Quality Laboratory -...-.-.-.-.

55. Silver, total recoverable, (atomic absorption spectrometry; chelationextraction or graphite furnace) data from the National Water Quality Laboratory

56. Sodium, dissolved, (inductively coupled plasma emission spectrometry) data from the National Water Quality Laboratory

57. Sodium, dissolved, (atomic absorption spectrometry) data from the National Water Quality Laboratory

58. Strontium, dissolved, (inductively coupled plasma emission spectrometry) data from the National Water Quality Laboratory

59. Sulfate, dissolved, (turbidimetric) data from the National Water Quality Laboratory

60. Vanadium, dissolved, (inductively coupled plasma emission spectrometry) data from the National Water Quality Laboratory

61. Zinc, dissolved, (inductively coupled plasma emission spectrometry) data from the National Water Quality Laboratory -

62. Zinc, dissolved, (atomic absorption spectrometry) data from the National Water Quality Laboratory-

63. Zinc, total recoverable, (atomic absorption spectrometry) data from the National Water Quality Laboratory

64. Ammonia as nitrogen, dissolved and total, (colorimetric) data from the National Water Quality Laboratory

65. Ammonia plus organic nitrogen, dissolved and total, (colorimetric) data from the National Water Quality Laboratory

66. Nitrate plus nitrite as nitrogen, dissolved and total, (colorimetric) data from the National Water Quality Laboratory

67. Nitrite as nitrogen, dissolved and total, (colorimetric) data from the National Water Quality Laboratory-

68. Orthophosphate as phosphorus, dissolved and total, (colorimetric) data from the National Water Quality Laboratory

69. Phosphorus, dissolved and total, (colorimetric) data from the National Water Quality Laboratory

70. Ammonia as nitrogen, dissolved and total, low ionic strength, (colorimetric) data from the National Water Quality Laboratory

71. Calcium, dissolved, low ionic strength, (atomic absorption spectrometry) data from the National Water Quality Laboratory

72. Chloride, dissolved, low ionic strength, (ion chromatography) data from the National Water Quality Laboratory 
Figures 1-160. Graphs showing--Continued:

73. Fluoride, dissolved, low ionic strength, (ion chromatography) data from the National Water Quality Laboratory ---

74. Magnesium, dissolved, low ionic strength, (atomic absorption spectrometry) data from the National Water Quality Laboratory

75. Nitrate plus nitrite as nitrogen, dissolved and total, low ionic strength, (ion chromatography) data from the National Water Quality Laboratory -

76. Orthophosphate as phosphorus, dissolved and total, low ionic strength, (ion chromatography) data from the National Water Quality Laboratory -

77. Potassium, dissolved, low ionic strength, (atomic absorption spectrometry) data from the National Water Quality Laboratory

78. Sodium, dissolved, low ionic strength, (atomic absorption spectrometry) data from the National Water Quality Laboratory

79. Specific conductance, dissolved, low ionic strength, (wheatstone bridge) data from the National Water Quality Laboratory

80. Sulfate, dissolved, low ionic strength, (ion chromatography) data from the National Water Quality Laboratory

81. Precision data for alkalinity, total, (electrometric titration) at the National Water Quality Laboratory

82. Precision data for aluminum, dissolved, (direct current plasma emission spectrometry) data from the National Water Quality Laboratory

83. Precision data for aluminum, total, (direct current plasma emission spectrometry) data from the National Water Quality Laboratory -

84. Precision data for antimony, dissolved, (atomic absorption spectrometry, hydride) data from the National Water Quality Laboratory

85. Precision data for arsenic, dissolved, (atomic absorption spectrometry, hydride) data from the National Water Quality Laboratory

86. Precision data for barium, dissolved, (inductively coupled plasma emission spectrometry) data from the National Water Quality Laboratory ---.---.--.-

87. Precision data for barium, dissolved, (atomic absorption spectrometry) data from the National Water Quality Laboratory -

88. Precision data for barium, total recoverable, (atomic absorption spectrometry) data from the National Water Quality Laboratory -.-...-.-.-

89. Precision data for beryllium, dissolved, (inductively coupled plasma emission spectrometry) data from the National Water Quality Laboratory----

90. Precision data for beryllium, dissolved, (atomic absorption spectrometry) data from the National Water Quality Laboratory

91. Precision data for boron, dissolved, (direct current plasma emission spectrometry) data from the National Water Quality Laboratory -

92. Precision data for cadmium, dissolved, (inductively coupled plasma emission spectrometry) data from the National Water Quality Laboratory----

93. Precision data for cadmium, dissolved, (atomic absorption spectrometry, graphite furnace) data from the National Water Quality Laboratory------------ 
Figures 1-160. Graphs showing--Continued:

94. Precision data for cadmium, total recoverable, (atomic absorption spectrometry; chelation-extraction and graphite furnace) data from the National Water Quality Laboratory

95. Precision data for calcium, dissolved, (inductively coupled plasma emission spectrometry) data from the National Water Quality Laboratory --.--.--.--.--.- 66

96. Precision data for calcium, dissolved, (atomic absorption spectrometry) data from the National Water Quality Laboratory

97. Precision data for chloride, dissolved, (colorimetric) data from the National Water Quality Laboratory

98. Precision data for chromium, dissolved, (inductively coupled plasma emission spectrometry) data from the National Water Quality Laboratory----

99. Precision data for chromium, dissolved, (direct current plasma emission spectrometry) data from the National Water Quality Laboratory

100. Precision data for chromium, total recoverable, (direct current plasma emission spectrometry) data from the National Water Quality Laboratory----

101. Precision data for cobalt, dissolved, (inductively coupled plasma emission spectrometry) data from the National Water Quality Laboratory

102. Precision data for cobalt, dissolved, (atomic absorption spectrometry; chelation-extraction and graphite furnace) data from the National Water Quality Laboratory

103. Precision data for cobalt, total recoverable, (atomic absorption spectrometry; chelation-extraction and graphite furnace) data from the National Water Quality Laboratory

104. Precision data for copper, dissolved, (inductively coupled plasma emission spectrometry) data from the National Water Quality Laboratory -.................

105. Precision data for copper, dissolved, (atomic absorption spectrometry; chelation-extraction and graphite furnace) data from the National Water Quality Laboratory

106. Precision data for copper, total recoverable, (atomic absorption spectrometry; chelation-extraction and graphite furnace) data from the National Water Quality Laboratory

107. Precision data for dissolved solids, (gravimetric) data from the National Water Quality Laboratory

108. Precision data for fluoride, dissolved, (ion-selective electrode) data from the National Water Quality Laboratory

109. Precision data for iron, dissolved, (inductively coupled plasma emission spectrometry) data from the National Water Quality Laboratory .................-

110. Precision data for iron, dissolved, (atomic absorption spectrometry) data from the National Water Quality Laboratory

111. Precision data for iron, total recoverable, (atomic absorption spectrometry) data from the National Water Quality Laboratory

112. Precision data for lead, dissolved, (inductively coupled plasma emission spectrometry) data from the National Water Quality Laboratory 
Figures 1-160. Graphs showing--Continued:

113. Precision data for lead, dissolved, (atomic absorption spectrometry; chelation-extraction and graphite furnace) data from the National Water Quality Laboratory

114. Precision data for lead, total recoverable, (atomic absorption spectrometry; chelation-extraction and graphite furnace) data from the National Water Quality Laboratory

115. Precision data for lithium, dissolved, (inductively coupled plasma emission spectrometry) data from the National Water Quality Laboratory -...-.-.-.-.-.

116. Precision data for lithium, total recoverable, (atomic absorption spectrometry) data from the National Water Quality Laboratory

117. Precision data for magnesium, dissolved, (inductively coupled plasma
emission spectrometry) data from the National Water Quality Laboratory

117. Precision data for magnesium, dissolved, (inductively coupled plasma
emission spectrometry) data from the National Water Quality Laboratory----

118. Precision data for magnesium, dissolved, (atomic absorption spectrometry) data from the National Water Quality Laboratory

119. Precision data for manganese, dissolved, (inductively coupled plasma emission spectrometry) data from the National Water Quality Laboratory----

120. Precision data for manganese, dissolved, (atomic absorption spectrometry) data from the National Water Quality Laboratory

121. Precision data for manganese, total recoverable, (atomic absorption spectrometry) data from the National Water Quality Laboratory

122. Precision data for mercury, dissolved, (atomic absorption spectrometry) data from the National Water Quality Laboratory

123. Precision data for mercury, total, (atomic absorption spectrometry) data from the National Water Quality Laboratory

124. Precision data for molybdenum, dissolved, (inductively coupled plasma emission spectrometry) data from the National Water Quality Laboratory--.-

125. Precision data for molybdenum, dissolved, (atomic absorption spectrometry) data from the National Water Quality Laboratory

126. Precision data for nickel, dissolved, (inductively coupled plasma emission spectrometry) data from the National Water Quality Laboratory

127. Precision data for nickel, dissolved, (atomic absorption spectrometry; chelation-extraction and graphite furnace) data from the National Water Quality Laboratory

128. Precision data for nickel, total recoverable, (atomic absorption spectrometry; chelation-extraction and graphite furnace) data from the National Water Quality Laboratory

129. Precision data for potassium, dissolved, (atomic absorption spectrometry) data from the National Water Quality Laboratory

130. Precision data for selenium, dissolved, (atomic absorption spectrometry; chelation-extraction and graphite furnace) data from the National Water Quality Laboratory

131. Precision data for silica, dissolved, (inductively coupled plasma emission spectrometry) data from the National Water Quality Laboratory 
Figures 1-160. Graphs showing--Continued:

153. Precision data for fluoride, dissolved, low ionic strength, (ion chromatography) from the National Water Quality Laboratory

154. Precision data for magnesium, dissolved, low ionic strength, (atomic absorption spectrometry) data from the National Water Quality Laboratory

155. Precision data for nitrate plus nitrite as nitrogen, dissolved and total, low ionic strength, (ion chromatography) data from the National Water Quality Laboratory

156. Precision data for orthophosphate as phosphorus, dissolved and total, low ionic strength, (ion chromatography) data from the National Water Quality Laboratory

157. Precision data for potassium, dissolved, low ionic strength, (atomic absorption spectrometry) data from the National Water Quality Laboratory

158. Precision data for sodium, dissolved, low ionic strength, (atomic absorption spectrometry) data from the National Water Quality Laboratory

159. Precision data for specific conductance, low ionic strength, (wheatstone bridge) data from the National Water Quality Laboratory

160. Precision data for sulfate, dissolved, low ionic strength, (ion chromatography) data from the National Water Quality Laboratory

\section{TABLES}

Table 1. Linear least-squared equations for determining the most probable deviation

2. Total number of analyses from quality-assurance samples during water year 1989 with number greater than two and six standard deviations from the most probable value

3. Results of statistical testing for lack of precision in inorganic constituent data -.....

4. Results of statistical testing for bias in inorganic constituent data

5. Results of statistical testing for lack of precision in nutrient constituent data --..-.--

6. Results of statistical testing for bias in nutrient constituent data

7. Results of statistical testing for lack of precision in low ionic strength constituent data

8. Results of statistical testing for bias in low ionic strength constituent data 
Figures 1-160. Graphs showing--Continued:

132. Precision data for silica, dissolved, (colorimetric) data from the National Water Quality Laboratory-

133. Precision data for silver, dissolved, (inductively coupled plasma emission spectrometry) data from the National Water Quality Laboratory --.---.-----

134. Precision data for silver, dissolved, (atomic absorption spectrometry; chelation-extraction and graphite furnace) data from the National Water Quality Laboratory

135. Precision data for silver, total recoverable, (atomic absorption spectrometry; chelation-extraction and graphite furnace) data from the National Water Quality Laboratory

136. Precision data for sodium, dissolved, (inductively coupled plasma emission spectrometry) data from the National Water Quality Laboratory

137. Precision data for sodium, dissolved, (atomic absorption spectrometry) data from the National Water Quality Laboratory

138. Precision data for strontium, dissolved, (inductively coupled plasma emission spectrometry) data from the National Water Quality Laboratory

139. Precision data for sulfate, dissolved, (turbidimetric) data from the National Water Quality Laboratory

140. Precision data for vanadium, dissolved (inductively coupled plasma emission spectrometry) data from the National Water Quality Laboratory----

141. Precision data for zinc, dissolved, (inductively coupled plasma emission spectrometry) data from the National Water Quality Laboratory

142. Precision data for zinc, dissolved, (atomic absorption spectrometry) data from the National Water Quality Laboratory

143. Precision data for zinc, total recoverable, (atomic absorption spectrometry) data from the National Water Quality Laboratory

144. Precision data for ammonia as nitrogen, dissolved and total, (colorimetric) data from the National Water Quality Laboratory

145. Precision data for ammonia plus organic nitrogen, dissolved and total, (colorimetric) data from the National Water Quality Laboratory-

146. Precision data for nitrate plus nitrite as nitrogen, dissolved and total, (colorimetric) data from the National Water Quality Laboratory-

147. Precision data for nitrite as nitrogen, dissolved and total, (colorimetric) data from the National Water Quality Laboratory

148. Precision data for orthophosphate as phosphorus, dissolved and total, (colorimetric) data from the National Water Quality Laboratory

149. Precision data for phosphorus, dissolved and total, (colorimetric) data from the National Water Quality Laboratory

150. Precision data for ammonia as nitrogen, dissolved and total, low ionic strength, (colorimetric) data from the National Water Quality Laboratory -.-

151. Precision data for calcium, dissolved, low ionic strength, (atomic absorption spectrometry) data from the National Water Quality Laboratory --.---.--.-.

152. Precision data for chloride, dissolved, low ionic strength, (ion chromatography) data from the National Water Quality Laboratory 


\section{ABBREVIATIONS}

\section{Units of measure}

C

$\mathrm{mg} / \mathrm{L}$

$\mu \mathrm{g} / \mathrm{L}$

$\mu \mathrm{S} / \mathrm{cm}$

AA

COL

DCP

GRAV

IC

ICP

ISE

TITR

TOT

TURB

LOP

MPD

MPV

$\mathrm{N}$

NWQL

$P$

QL

SD

SRWS

WATSTORE
Celsius

milligrams per liter

micrograms per liter

microsiemens per centimeter

\section{Analytical Methods}

atomic absorption spectrometry

colorimetric

direct current plasma emission spectrometry

gravimetric

ion chromatography

inductively coupled plasma emission spectrometry

ion-selective electrode

electrometric titration

total recoverable

turbidimetric

\section{Others}

statistically significant lack of precision

most probable deviation

most probable value

negative bias

National Water Quality Laboratory

positive bias

quantitation limit bias

standard deviation

standard reference water samples

national Water Data Storage and Retrieval System 


\title{
QUALITY-ASSURANCE DATA FOR ROUTINE WATER ANALYSIS IN \\ THE NATIONAL WATER-QUALITY LABORATORY OF THE U.S. GEOLOGICAL SURVEY FOR WATER YEAR 1989
}

\author{
By Thomas J. Maloney, Amy S. Ludtke, and Teresa L. Krizman
}

\section{ABSTRACT}

The U.S. Geological Survey maintains a quality-assurance program based on the analyses of reference samples for its National Water-Quality Laboratory located in Arvada, Colorado. Reference samples containing selected inorganic, nutrient, and low-ionic strength constituents are prepared and disguised as routine samples. The program goal is to submit blind reference samples at a rate of approximately 5 percent of the annual environmental sample load for each analytical procedure. The samples are distributed to the laboratory throughout the year. The results are stored permanently in the national Water Data Storage and Retrieval System (WATSTORE), the Survey's data base for all water data. These data are analyzed statistically for precision and bias and the results are discussed for data collected during water year 1989.

An overall evaluation of the inorganic quality-assurance data for water year 1989 indicated a lack of precision in the National Water-Quality Laboratory for 8 out of 63 analytical procedures: aluminum, total recoverable (atomic absorption spectrometry), boron (direct current plasma emission spectrometry), copper, total recoverable (atomic absorption spectrometry; chelationextraction or graphite furnace), iron, total recoverable (atomic absorption spectrometry), sodium dissolved (inductively coupled plasma emission spectrometry), zinc, dissolved (inductively coupled plasma emission spectrometry), zinc, dissolved (atomic absorption spectrometry), and zinc, total recoverable (atomic absorption spectrometry). The results for 37 of 63 analytical procedures had positive or negative bias during water year 1989.

Lack of precision was indicated in the determination of one of the six nutrient procedures: nitrate plus nitrite as nitrogen. Lack of precision for this procedure has been attributed to limitations of the analytical method for low $\mathrm{pH}$ samples. A biased condition was indicated in the determination of ammonia as nitrogen and orthophosphate as phosphorus.

There was acceptable precision for determinations of all 11 low-ionic strength analytical procedures. Results for chloride and fluoride indicated a biased condition.

\section{INTRODUCTION}

The Water Resources Division of the U.S. Geological Survey performs numerous hydrologic investigations that require analyses of water, suspended sediment, and bed sediment materials for inorganic constituents, nutrients, some physical properties, and priority pollutants as defined by the U.S. Environmental Protection Agency (Keith and Telliard, 1979). The National Water Quality Laboratory (NWQL) in Arvada, Colorado, is the primary source of analytical services for these hydrologic investigations. Results of the quality-assurance program used to monitor the quality of work at the NWQL are described in this report. Previous reports (Peart and Thomas, 1983a, 1983b, 1984; Peart and Sutphin, 1987; Lucey and Peart, 1988, 1989a, 
1989b; and Lucey, 1989) document results from February 1981 through September 1988. Some of the previous reports contained quality assurance information for organic determinations.

Factors that need to be considered for data interpretation for this period in conjunction with the results presented in this report include the following:

1. No effort was made to correct nonanalytical errors, even when it was obvious which corrective measures were appropriate, so the data are presented as originally produced by the laboratory. These errors include sample login errors, transcription errors by the analyst, datatransmission errors by laboratory instruments, and manual data-entry errors. Therefore, if the data reviewer in the office that collected the sample detects non-analytical errors, the errors can be corrected to improve the quality of the data in the local water quality data base compared to the data presented in this report. For example, two samples from different sites are submitted to the laboratory on the same day and are misidentified in a way that the analytical data reported for one would actually belong to the other. A data reviewer familiar with one of the sites or its historical data usually could detect the problem and make necessary corrections.

2. Analysis rerun requests are commonly made for determinations that exceed control limits set at $+/-2$ standard deviations of the reference sample concentration. The purpose of rerun requests is to identify reference samples that may be deteriorating or that may have been incorrectly bottled. If the analysis rerun confirms that one of these nonanalytical problems has occurred, the quality assurance data base is updated. However, the majority of analysis reruns confirm laboratory problems, such as: analytical errors, internal bottle mixups, or data transmission errors. If a laboratory problem is confirmed by the analysis rerun, the originally released data remains in the quality-assurance data base. However, if the quality-control section of the laboratory identifies problems with an analytical line and requires that updated analyses be released, then the qualityassurance data base is updated with the new values. The results of the rerun analyses are not used to update the quality assurance data base. Data reviewers in the offices that collect environmental samples are expected to scrutinize analytical data for discrepancies and make requests for analysis reruns. District re-analysis requests may result in the detection of analytical and non-analytical errors. If these errors are detected and data base corrections are made then the districts overall data quality would improve when compared to data quality presented in this report. Therefore, this report presents a conservative quality assurance evaluation of NWQL analytical data which a district office would have in its environmental data base.

3. Control charts included in this report may be used to determine analytical conditions at any given time for water year 1989. A chart may show an analytical process to be out of statistical control for a short period of time, but in general, in statistical control for most of the year. The data for the short period may impact the statistical tests for the entire year such that they would indicate lack of precision or significant bias. The data for the period when the analytical process was in statistical control can be considered on its own to evaluate precision and bias. An interactive quality assurance data base is available that allows laboratory users to select specific analytes and time periods of interest. Lucey (1990) describes the use of the program to retrieve information from the data base.

4. Incorrectly applied dilution factors account for some analytical errors. Sample 
dilutions are routinely made in the laboratory to bring sample concentrations into analytical range. If the dilution factor is not applied or is applied incorrectly, the reported value will be in error. For example, if a nutrient sample has a phosphorus concentration of $1.2 \mathrm{mg} / \mathrm{L}$ and an analysis is reported at $0.12 \mathrm{mg} / \mathrm{L}$, a $10 \mathrm{X}$ dilution may have been used and not applied to the final result. These kinds of errors are difficult to confirm. Their detection, confirmation through rerun requests, and correction in the field offices will improve the data quality in the district's local water quality data base compared to that indicated in this report.

5. Non-analytical errors for nutrient analyses can result when the samples are not maintained at the ideal temperature of $4^{\circ} \mathrm{C}$ during shipping and receiving.

During the 1989 water year, 80 analytical procedures were evaluated at the NWQL. The following categories list the analytes included in the 1989 NWQL Blind Sample Program. The low Ionic strength category lists analytes determined by methods adapted to detect low level concentrations.

Inorganic constituents: alkalinity, aluminum, antimony, arsenic, barium, beryllium, boron, cadmium, calcium, chloride, chromium, cobalt, copper, dissolved solids (residue on evaporation at $180^{\circ} \mathrm{C}$ ), fluoride, iron, lead, lithium, magnesium, manganese, mercury, molybdenum, nickel, potassium, selenium, silica, silver, sodium, strontium, sulfate, vanadium, and zinc.

Nutrient constituents: ammonia as nitrogen; ammonia plus organic nitrogen; nitrate plus nitrite as nitrogen; nitrite as nitrogen; orthophosphate as phosphorus; and phosphorus.

Low-ionic strength constituents: ammonia as nitrogen; calcium; chloride; fluoride; magnesium; nitrate plus nitrite as nitrogen; orthophosphate as phosphorus; potassium; sodium; specific conductance; and sulfate.

\section{PROGRAM DESCRIPIION}

Standard reference water samples (SRWS) (Skougstad and Fishman, 1975; Schroder and others, 1980; Janzer, 1985) are used to prepare the reference samples used in this program. The SRWS are diluted with deionized water, mixed in varying proportions with other SRWS, or used undiluted. A large range of concentrations of chemical constituents is achieved, thereby increasing the number of unique samples available for qualityassurance purposes. This, in turn, decreases the probability that quality-assurance samples will be recognized in the laboratory because of frequency of analyses or unique sample characteristics.

The Blind Sample Program's reference samples are made to appear as much like environmental samples as possible. Analytical request forms are completed to ensure that appropriate analyses have been requested for the samples. The samples and the forms are shipped to selected U.S. Geological Survey offices across the country. These offices send the quality-assurance samples for the Blind Sample Program to the NWQL with their regular environmental samples.

The number of quality-assurance determinations requested for each analytical procedure is in direct proportion to the number of requests for the procedure from all environmental samples submitted. The program goal is to have quality-assurance samples submitted for each analytical procedure at a rate of approximately 5 percent of the environmental sample load.

SRWS are filtered during preparation, therefore all constituents in the Blind Reference Samples are in the dissolved phase. Those analytical procedures in this report that are designated as "total recoverable" have actually been evaluated using reference 
samples that have undergone a digestion process (Fishman and Friedman, 1985, p. 8788) during analysis, rather than from unfiltered or whole-water samples. Differences that appear in this report between the dissolved analyses and the total recoverable analyses are caused by the digestion process rather than by any difference in the sampling techniques or sample source.

The Blind Sample Program qualityassurance samples pass through the NWQL as routine samples, undergoing the normal laboratory quality-control and qualityassurance procedures. The data released by the laboratory are stored in the national Water Data Storage and Retrieval System (WATSTORE). Having passed through the laboratory in this manner, data from these quality-assurance samples reflect the quality of the analytical data that the NWQL produces for environmental samples.

Beginning in the 1989 water year, four new constituents were added to the NWQL blind sample quality-assurance program. The new constituents are aluminum total recoverable (TOT, AA), mercury (TOT,AA), vanadium by inductively coupled plasma emission spectrometry (ICP), and low-ionic strength specific conductance determinations.

\section{STATISTICAL EVALUATION}

\section{Control Chant Development and Evaluation}

The SRWS samples are analyzed through a round-robin evaluation program by about 150 laboratories throughout the United States. The results are compiled and a statistical summary is prepared. Until 1988, the SRWS program used parametric statistics, mean and standard deviation, for statistical summaries. Since then, the program has used non-parametric statistics, median and f-pseudosigma (nonparametric statistic equivalent to the standard deviation), for the statistical summaries.
Resultant mean or median values are used to estimate the most probably correct values or the most probable values (MPV's). These MPV's are used in this quality-assurance program for comparison against analytical results. For reference samples composed of a mixture of two SRWS's or an SRWS and deionized water, the volume weighted average of the SRWS's is used to determine the constituent MPV's for the mixture.

A deviation regression equation was determined by using linear least-squares regression of the MPV for each constituent obtained from all the SRWS's analyzed during the last 7 years against the corresponding standard deviation or f-pseudosigma value for those constituents. The 7-year period was selected to account for general improvements in analytical methods over time and to provide enough data to prepare the regressions. These regression equations enable an estimation of a most probable deviation (MPD) for each constituent at various concentrations. The difference between the analysis concentration and the MPV was compared against the MPD to determine whether an analysis was statistically in or out of control. An individual reported value was considered in statistical control if it was within two MPD's of the MPV. In this report, the term "standard deviations" will be used when comparing individual determinations against the MPV.

MPV data for the SRWS program are often reported with more significant figures than reported by the NWQL for environmental sample analyses. Because the MPD regression equations are based on SRWS data that are reported to a more accurate level, they may produce MPD values, especially at lower concentrations, with tolerances too tight to be met by the reporting criteria set for release of normal environmental analyses. This was true for fluoride, lithium, nitrite as nitrogen, and selenium; for cadmium, chromium, copper, lead, molybdenum, nickel, and silver when determined by inductively coupled plasma emission spectrometry; for barium, cadmium, manganese, molybdenum, and zinc when 
determined by atomic absorption spectrometry; for aluminum, barium, beryllium, cadmium, lead, lithium, manganese, nickel, and zinc when determined by total recoverable digestion; and for aluminum when determined by direct current plasma emission spectrometry. An administrative decision was made to establish a minimum standard deviation for each of these constituents equal to three-quarters of the value of the reporting level to allow at least one reportable value less than or greater than the MPV. For example, barium, by atomic adsorption spectrometry, has a minimum reporting level of $100 \mathrm{mg} / \mathrm{L}$ (micrograms per liter). Many SRWS reference mixes have an MPV well below this minimum reporting level such that a reference with an MPV for barium of $20 \mathrm{mg} / \mathrm{L}$ would be rounded to $100 \mathrm{mg} / \mathrm{L}$. The regression equation, in table 1 , provides an MPD value of $21 \mathrm{mg} / \mathrm{L}$ for a reference with an MPV of 20. Therefore, data for the reference sample reported at $100 \mathrm{mg} / \mathrm{L}$ is 3.81 standard deviations high. In order to allow values one reporting unit less than or greater than the MPV to be acceptable, the minimum MPD for barium, by atomic adsorption spectrometry, has been set to $75 \mathrm{mg} / \mathrm{L}$. The equations for determining the MPD for each constituent and the established minimum MPD, if any, are listed in table 1.

The number of standard deviations (NSD) that an analysis differs from the MPV was calculated by dividing the difference between the reported value and the MPV by the MPD. For each ion, the NSD values were plotted against the date samples were logged into the laboratory to prepare control charts. The results for each constituent are shown on control charts in figures 1 through 80 in the "Supplemental Data" section of this report.

Control charts for inorganic reference samples are presented in figures 1 through 63 . Three symbols are used in these figures to indicate results from the lower $(+)$, middle $(\Delta)$, and upper $(\mathrm{O})$ one-thirds of the potential analytical range tested in this program for inorganic constituents. This range does not necessarily correspond with the analytical capabilities of the laboratory instrumentation or methods, but rather corresponds with the analytical range tested using the available SRWS or other reference samples. The three parts of this range are based on the MPV's of the quality-assurance samples and not on the reporting policy; for example, available resources limit the maximum MPV for boron (DCP) to be $367 \mathrm{mg} / \mathrm{L}$ (fig. 11) and still allow a correctly reported value of $370 \mathrm{mg} / \mathrm{L}$, based on the policy to report boron to the nearest 10 $\mathrm{mg} / \mathrm{L}$ at this concentration. Not all figures will show all three parts of the analytical range because of concentration ranges in the available SRWS.

Control charts for nutrient constituents are shown in figures 64 through 69 and control charts for low-ionic strength samples are shown in figures 70 through 80 . Because of the low concentrations of these constituents, symbols on these charts represent the entire potential analytical range tested.

On figures $1-80$, points for values greater than 6 standard deviations or less than -6 standard deviations are plotted at the top or bottom edge of the figure. The number of standard deviations is indicated adjacent to the point except on figure 66 (nitrate plus nitrite as nitrogen) Numerous points on this chart were equal to or less than the -6 standard deviation limit for the analysis of SRWS sample N-20 (fig. 66).

Beginning July 1989, SRWS specifically prepared for mercury were incorporated into this program. Control charts for dissolved mercury (fig. 42) and total mercury (Fig. 43) indicate excellent precision for these determinations using the new SRWS. Mercury determinations obtained before July 1989 were from trace metal SRWS that were later preserved with nitric acid/potassium dichromate solution. Data from these solutions are not representative of the analytical capabilities of the NWQL and the data has been removed from the quality- 
Table 1.--Linear least-squared equations for determining the most probable deviation

[MPD, most probable deviation; TITR, electrometric titration; $\mathrm{mg} / \mathrm{L}$, milligrams per liter; MPV, most probable value; *, not applicable; DCP, direct current plasma emission spectrometry; $\mathrm{mg} / \mathrm{L}$, micrograms per liter; TOT, total recoverable; AA, atomic absorption spectrometry; ICP, inductively coupled plasma emission spectrometry; COL, colorimetric; GRAV, gravimetric; ISE, ion-selective electrode; TURB, turbidimetric; IC, ion chromatography; $\mathrm{mS} / \mathrm{cm}$, microsiemens per centimeter]

\section{Constituent (dissolved} except as indicated) or property

\section{Units}

Equation to determine MPD
Minimum MPD

\author{
Alkalinity (TITR) \\ Aluminum (DCP) \\ Aluminum (TOT,DCP) \\ Antimony (AA) \\ Arsenic (AA) \\ Barium (ICP) \\ Barium (AA) \\ Barium (TOT,AA) \\ Beryllium (ICP) \\ Beryllium (TOT,AA) \\ Boron (DCP) \\ Cadmium (ICP) \\ Cadmium (AA) \\ Cadmium (TOT,AA) \\ Calcium (ICP) \\ Calcium (AA) \\ Chloride (COL) \\ Chromium (ICP) \\ Chromium (DCP) \\ Chromium (TOT,DCP) \\ Cobalt (ICP) \\ Cobalt (AA) \\ Cobalt (TOT,AA) \\ Copper (ICP) \\ Copper (AA) \\ Copper (TOT,AA) \\ Dissolved solids (GRAV) \\ Fluoride (ISE) \\ Iron (ICP) \\ Iron (AA) \\ Iron (TOT,AA) \\ Lead (ICP) \\ Lead (AA) \\ Lead (TOT,AA) \\ Lithium (ICP) \\ Lithium (TOT,AA) \\ Magnesium (ICP) \\ Magnesium (AA) \\ Manganese (ICP)
}

\section{Inorganic constituents}

\begin{tabular}{|c|c|c|}
\hline $\mathrm{mg} / \mathrm{L}$ & $(0.024 \times \mathrm{MPV})+0.72$ & $*$ \\
\hline$\mu \mathrm{g} / \mathrm{L}$ & $(0.022 \times M P V)+6.73$ & 7.5 \\
\hline$\mu \mathrm{g} / \mathrm{L}$ & $(0.022 \times M P V)+6.73$ & 7.5 \\
\hline$\mu g / L$ & $(0.065 \times \mathrm{MPV})+1.29$ & $*$ \\
\hline$\mu \mathrm{g} / \mathrm{L}$ & $(0.11 \times \mathrm{MPV})+0.86$ & * \\
\hline$\mu \mathrm{g} / \mathrm{L}$ & $(0.05 \times \mathrm{MPV})+1.61$ & * \\
\hline$\mu \mathrm{g} / \mathrm{L}$ & $(0.15 \times M P V)+18.0$ & 75 \\
\hline$\mu g / L$ & $(0.15 \times \mathrm{MPV})+18.0$ & 75 \\
\hline$\mu \mathrm{g} / \mathrm{L}$ & $(0.058 \times \mathrm{MPV})+0.93$ & $*$ \\
\hline$\mu \mathrm{g} / \mathrm{L}$ & $(0.058 \times \mathrm{MPV})+0.93$ & 7.5 \\
\hline$\mu \mathrm{g} / \mathrm{L}$ & $(0.016 \times \mathrm{MPV})+5.0$ & $*$ \\
\hline$\mu \mathrm{g} / \mathrm{L}$ & $(0.12 \times \mathrm{MPV})+0.49$ & 0.75 \\
\hline$\mu \mathrm{g} / \mathrm{L}$ & $(0.12 \times \mathrm{MPV})+0.49$ & 0.75 \\
\hline$\mu \mathrm{g} / \mathrm{L}$ & $(0.12 \times \mathrm{MPV})+0.49$ & 0.75 \\
\hline $\mathrm{mg} / \mathrm{L}$ & $(0.044 \times$ MPV $)+0.09$ & $*$ \\
\hline $\mathrm{mg} / \mathrm{L}$ & $(0.044 \times$ MPV $)+0.09$ & $*$ \\
\hline $\mathrm{mg} / \mathrm{L}$ & $(0.025 \times M P V)+0.70$ & $*$ \\
\hline$\mu g / L$ & $(0.16 \times \mathrm{MPV})+1.25$ & 2.5 \\
\hline$\mu \mathrm{g} / \mathrm{L}$ & $(0.16 \times \mathrm{MPV})+1.25$ & $*$ \\
\hline$\mu \mathrm{g} / \mathrm{L}$ & $(0.16 \times \mathrm{MPV})+1.25$ & $*$ \\
\hline$\mu \mathrm{g} / \mathrm{L}$ & $(0.17 \times \mathrm{MPV})+0.84$ & * \\
\hline$\mu g / L$ & $(0.17 \times \mathrm{MPV})+0.84$ & $*$ \\
\hline$\mu g / L$ & $(0.17 \times \mathrm{MPV})+0.84$ & * \\
\hline$\mu \mathrm{g} / \mathrm{L}$ & $(0.029 \times \mathrm{MPV})+3.38$ & 7.5 \\
\hline$\mu \mathrm{g} / \mathrm{L}$ & $(0.029 \times \mathrm{MPV})+3.38$ & $*$ \\
\hline$\mu g / L$ & $(0.029 \times M P V)+3.38$ & * \\
\hline $\mathrm{mg} / \mathrm{L}$ & $(0.014 \times M P V)+10.2$ & $*$ \\
\hline $\mathrm{mg} / \mathrm{L}$ & $(0.07 \times \mathrm{MPV})+0.02$ & 0.05 \\
\hline$\mu g / L$ & $(0.035 \times M P V)+9.58$ & $*$ \\
\hline$\mu \mathrm{g} / \mathrm{L}$ & $(0.035 \times M P V)+9.58$ & * \\
\hline$\mu \mathrm{g} / \mathrm{L}$ & $(0.035 \times M P V)+9.58$ & * \\
\hline$\mu \mathrm{g} / \mathrm{L}$ & $(0.24 \times \mathrm{MPV})+1.48$ & 7.5 \\
\hline$\mu \mathrm{g} / \mathrm{L}$ & $(0.24 \times \mathrm{MPV})+1.48$ & $*$ \\
\hline$\mu \mathrm{g} / \mathrm{L}$ & $(0.24 \times \mathrm{MPV})+1.48$ & 3.75 \\
\hline$\mu \mathrm{g} / \mathrm{L}$ & $(0.11 \times \mathrm{MPV})+2.07$ & 7.5 \\
\hline$\mu g / L$ & $(0.11 \times \mathrm{MPV})+2.07$ & 7.5 \\
\hline $\mathrm{mg} / \mathrm{L}$ & $(0.043 \times \mathrm{MPV})+0.09$ & $*$ \\
\hline $\mathrm{mg} / \mathrm{L}$ & $(0.043 \times \mathrm{MPV})+0.09$ & * \\
\hline$\mu \mathrm{g} / \mathrm{L}$ & $(0.049 \times \mathrm{MPV})+2.51$ & * \\
\hline
\end{tabular}


Table 1.--Linear least-squared equations for determining the most probable deviation--Continued

\begin{tabular}{|c|c|c|c|}
\hline $\begin{array}{l}\text { Constituent (dissolved } \\
\text { except as indicated) } \\
\text { or property }\end{array}$ & Units & $\begin{array}{l}\text { Equation to } \\
\text { determine MPD }\end{array}$ & $\begin{array}{l}\text { Minimum } \\
\text { MPD }\end{array}$ \\
\hline Manganese (AA) & $\mu \mathrm{g} / \mathrm{L}$ & $(0.049 \times \mathrm{MPV})+2.51$ & 7.5 \\
\hline Manganese (TOT,AA) & $\mu \mathrm{g} / \mathrm{L}$ & $(0.049 \times \mathrm{MPV})+2.51$ & 7.5 \\
\hline Mercury (AA) & $\mu \mathrm{g} / \mathrm{L}$ & $(0.11 \times \mathrm{MPV})+0.12$ & $*$ \\
\hline Mercury (TOT,AA) & $\mu g / L$ & $(0.11 \times \mathrm{MPV})+0.12$ & $*$ \\
\hline Molybdenum (ICP) & $\mu \mathrm{g} / \mathrm{L}$ & $(0.055 \times \mathrm{MPV})+3.30$ & 7.5 \\
\hline Molybdenum (AA) & $\mu \mathrm{g} / \mathrm{L}$ & $(0.055 \times \mathrm{MPV})+3.30$ & $*$ \\
\hline Nickel (ICP) & $\mu g / L$ & $(0.092 \times \mathrm{MPV})+4.14$ & 7.5 \\
\hline Nickel (AA) & $\mu g / L$ & $(0.092 \times \mathrm{MPV})+4.14$ & $*$ \\
\hline Nickel (TOT,AA) & $\mu \mathrm{g} / \mathrm{L}$ & $(0.092 \times \mathrm{MPV})+4.14$ & 7.5 \\
\hline Potassium (AA) & $\mathrm{mg} / \mathrm{L}$ & $(0.11 \times \mathrm{MPV})+0.00$ & $*$ \\
\hline Selenium (AA) & $\mu g / L$ & $(0.21 \times \mathrm{MPV})+0.42$ & 0.75 \\
\hline Silica (ICP) & $\mathrm{mg} / \mathrm{L}$ & $(0.065 \times \mathrm{MPV})+0.13$ & $*$ \\
\hline Silica (COL) & $\mathrm{mg} / \mathrm{L}$ & $(0.065 \times \mathrm{MPV})+0.13$ & $*$ \\
\hline Silver (ICP) & $\mu g / L$ & $(0.13 \times \mathrm{MPV})+0.97$ & $*$ \\
\hline Silver (AA) & $\mu \mathrm{g} / \mathrm{L}$ & $(0.13 \times \mathrm{MPV})+0.97$ & $*$ \\
\hline Silver (TOT,AA) & $\mu \mathrm{g} / \mathrm{L}$ & $(0.13 \times \mathrm{MPV})+0.97$ & $*$ \\
\hline Sodium (ICP) & $\mathrm{mg} / \mathrm{L}$ & $(0.039 \times \mathrm{MPV})+0.05$ & $*$ \\
\hline Sodium (AA) & $\mathrm{mg} / \mathrm{L}$ & $(0.039 \times \mathrm{MPV})+0.05$ & $*$ \\
\hline Strontium (ICP) & $\mu \mathrm{g} / \mathrm{L}$ & $(0.052 \times \mathrm{MPV})+0.00$ & $*$ \\
\hline Sulfate (TURB) & $\mathrm{mg} / \mathrm{L}$ & $(0.045 \times \mathrm{MPV})+1.0$ & $*$ \\
\hline Vanadium (ICP) & $\mu \mathrm{g} / \mathrm{L}$ & $(0.21 \times \mathrm{MPV})+1.58$ & $*$ \\
\hline Zinc (ICP) & $\mu \mathrm{g} / \mathrm{L}$ & $(0.039 \times \mathrm{MPV})+4.33$ & $*$ \\
\hline Zinc (AA) & $\mu \mathrm{g} / \mathrm{L}$ & $(0.039 \times \mathrm{MPV})+4.33$ & 7.5 \\
\hline Zinc (TOT) & $\mu \mathrm{g} / \mathrm{L}$ & $(0.039 \times \mathrm{MPV})+4.33$ & 7.5 \\
\hline \multicolumn{4}{|c|}{ Nutrient constituents } \\
\hline Ammonia as nitrogen (COL) & $\mathrm{mg} / \mathrm{L}$ & $(0.1 \times \mathrm{MPV})+0.033$ & $*$ \\
\hline Ammonia plus organic nitrogen (COL) & $\mathrm{mg} / \mathrm{L}$ & $(0.5 \times \mathrm{MPV})-0.01$ & * \\
\hline Nitrate plus nitrite as nitrogen (COL) & $\mathrm{mg} / \mathrm{L}$ & $(0.04 \times \mathrm{MPV})+0.034$ & $*$ \\
\hline Nitrite as nitrogen(COL) & $\mathrm{mg} / \mathrm{L}$ & $(0.069 \times \mathrm{MPV})+0.005$ & .0075 \\
\hline Orthophosphate as phosphorus (COL) & $\mathrm{mg} / \mathrm{L}$ & $(0.058 \times \mathrm{MPV})+0.009$ & * \\
\hline Phosphorus (COL) & $\mathrm{mg} / \mathrm{L}$ & $(0.068 \times \mathrm{MPV})+0.008$ & $*$ \\
\hline \multicolumn{4}{|c|}{ Constituents in low-ionic strength samples } \\
\hline Ammonia as nitrogen (COL) & $\mathrm{mg} / \mathrm{L}$ & $(0.32 \times \mathrm{MPV})+0.008$ & * \\
\hline Calcium (AA) & $\mathrm{mg} / \mathrm{L}$ & $(0.065 \times \mathrm{MPV})+0.05$ & * \\
\hline Chloride (IC) & $\mathrm{mg} / \mathrm{L}$ & $(0.078 \times \mathrm{MPV})+0.17$ & $*$ \\
\hline Fluoride (IC) & $\mathrm{mg} / \mathrm{L}$ & $(0.169 \times \mathrm{MPV})+0.19$ & * \\
\hline Magnesium (AA) & $\mathrm{mg} / \mathrm{L}$ & $(0.047 \times \mathrm{MPV})+0.01$ & $*$ \\
\hline Nitrate as nitrogen (IC) & $\mathrm{mg} / \mathrm{L}$ & $(0.23 \times \mathrm{MPV})+0.018$ & $*$ \\
\hline Orthophosphate as phosphorus (COL) & $\mathrm{mg} / \mathrm{L}$ & $(0.058 \times \mathrm{MPV})+0.009$ & $*$ \\
\hline Potassium (AA) & $\mathrm{mg} / \mathrm{L}$ & $(0.11 \times \mathrm{MPV})+0.02$ & $*$ \\
\hline Sodium (AA) & $\mathrm{mg} / \mathrm{L}$ & $(0.043 \times \mathrm{MPV})+0.04$ & * \\
\hline Specific conductance & $\mu \mathrm{S} / \mathrm{cm}$ & $(0.091 \times \mathrm{MPV})+0.21$ & $*$ \\
\hline Sulfate (IC) & $\mathrm{mg} / \mathrm{L}$ & $(0.037 \times \mathrm{MPV})+0.03$ & * \\
\hline
\end{tabular}


assurance data base maintained by this program.

Control charts for cadmium (AA) (fig. 13), cadmium (TOT, AA) (fig. 14), cobalt (AA) (fig. 22), cobalt (TOT, AA) (fig. 23), copper (AA) (fig. 25), copper (TOT, AA) (fig. 26), lead (AA) (fig. 33), lead (TOT, AA) (fig. 34), nickel (AA) (fig. 47), nickel (TOT, AA) (fig. 48), silver (AA) (fig. 54), and silver (TOT, AA) (fig. 55) have a vertical line on May 15, 1989, when the methods of analyses for these constituents changed from atomic absorption chelationextraction to atomic absorption graphite furnace. Analytical results may have been affected by the change in methodology.

Control charts for aluminum (TOT, DCP) (fig. 3), barium (AA) (fig. 7), chromium (DCP) (fig. 19), cobalt (AA) (fig. 22), iron (AA) (fig. 30), lead (ICP) (fig. 32), lead (AA) (fig. 33), lithium (ICP) (fig. 35), manganese (ICP) (fig. 39), manganese (AA) (fig. 40), molybdenum (ICP) (fig. 44), molybdenum (AA) (fig. 45), nickel (ICP) (fig. 46), nickel (AA) (fig. 47), silver (ICP) (fig. 53), strontium (ICP) (fig. 58), vanadium (ICP) (fig. 60), zinc (ICP) (fig. 61), and zinc (AA) (fig. 62) have an uneven temporal distribution of data points, with several months where reference samples were not submitted for these constituents.

\section{Precision Chart Development and Evaluation}

Replicate determinations of reference samples were used to provide a measure of precision. For each sample mixture having at least 3 determinations, the mean, standard deviation, and relative standard deviation was calculated for each constituent. The relative standard deviation provides an estimate of error at the concentrations of the reference samples. Replicate sample results as measured by this procedure provides an estimate of long-term laboratory precision.

Precision data charts (figs. 81 through 160 in the "Supplemental data" section of this report) were prepared by plotting the relative standard deviations for inorganic, nutrient, and low-ionic strength constituents as a percent against their mean concentrations. These plots allow a data reviewer to estimate precision at any concentration shown for a constituent. For example, the precision of the total alkalinity values from the NWQL are estimated to be $+/-2.5$ percent for the analyzed range of concentrations (fig. 81). To allow the precision charts to be used to estimate an expected error from the analytical results, outliers were deleted from the data set. An outlier was defined as a value that is greater than 6 or less than -6 standard deviations from the MPV. The total number of analyses for each constituent processed during the water year, the number of analyses with standard deviations greater than 2 or less than -2 from the MPV, and the number of analyses with standard deviations greater than 6 or less than -6 from the MPV are listed in table 2 . If the relative standard deviation for a given mix has a value of zero, the data point will plot on the horizontal axis of the precision data chart, as in figures 87 and 90 . A relative standard deviation of zero occurs when all values reported by the laboratory for a constituent in a unique mix are the same. Although this suggests that the results are from a reproducible analytical method, repetitive results can be an artifact of small sample size or reporting level. For example, the minimum reporting level for barium (AA) is 100 micrograms per liter and, because the mixes used during the 1989 water year have MPV's less than this value (fig. 7), the precision chart (fig. 87) shows a relative standard deviation of 0.0 at a mean concentration of 100 micrograms per liter.

\section{Binomial-Probability-Distribution Technique To Assess Precision and Bias}

Measures of precision and bias were determined from the control chart data by applying binomial-probability-distribution equations using procedures described by 
Table 2.--Total number of analyses from quality-assurance samples during water year 1989 with number greater than two and six standard deviations from the most probable value

[ $>2 \mathrm{SD}$, number of analyses greater than 2 or less than -2 standard deviations from the most probable value; $>6 \mathrm{SD}$, number of analyses greater than 6 or less than -6 standard deviations from the most probable value; TITR, electrometric titration; DCP, direct current plasma emission spectrometry; AA, atomic absorption spectrometry; ICP, inductively coupled plasma emission spectrometry; TOT, total recoverable; $\mathrm{COL}$, colorimetric; GRAV, gravimetric; ISE, ion-selective electrode; TURB, turbidimetric; IC, ion chromatography; $\mathrm{mS} / \mathrm{cm}$, microsiemens per centimeter]

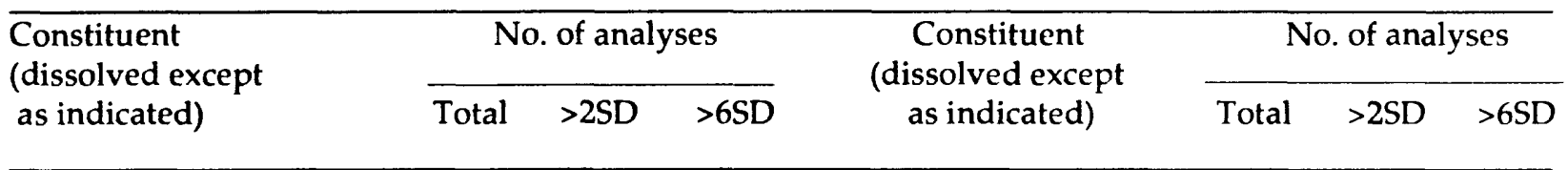

$\begin{array}{lrrllrrr}\text { Alkalinity (TITR) } & 323 & 1 & 1 & \text { Lead (AA) } & 110 & 3 & 1 \\ \text { Aluminum (DCP) } & 122 & 7 & 2 & \text { Lead (TOT, AA) } & 55 & 2 & 0 \\ \text { Aluminum (TOT, DCP) } & 20 & 11 & 5 & \text { Lithium (ICP) } & 160 & 2 & 1 \\ \text { Antimony (AA) } & 78 & 1 & 0 & \text { Lithium (TOT, AA) } & 33 & 0 & 0 \\ \text { Arsenic (AA) } & 227 & 6 & 3 & \text { Magnesium (ICP) } & 278 & 10 & 0 \\ \text { Barium (ICP) } & 160 & 3 & 2 & \text { Magnesium (AA) } & 44 & 10 & 0 \\ \text { Barium (AA) } & 21 & 0 & 0 & \text { Manganese (ICP) } & 160 & 7 & 2 \\ \text { Barium (TOT, AA) } & 55 & 1 & 0 & \text { Manganese (AA) } & 94 & 0 & 0 \\ \text { Beryllium (ICP) } & 60 & 5 & 0 & \text { Manganese (TOT, AA) } & 55 & 5 & 0 \\ \text { Beryllium (TOT, AA) } & 33 & 0 & 0 & \text { Mercury (AA) } & 55 & 0 & 0 \\ \text { Boron (DCP) } & 115 & 18 & 3 & \text { Mercury (TOT, AA) } & 18 & 0 & 0 \\ \text { Cadmium (ICP) } & 160 & 15 & 2 & \text { Molybdenum (ICP) } & 160 & 3 & 0 \\ \text { Cadmium (AA) } & 110 & 6 & 1 & \text { Molybdenum (AA) } & 72 & 2 & 0 \\ \text { Cadmium (TOT, AA) } & 55 & 5 & 0 & \text { Nickel (ICP) } & 82 & 5 & 0 \\ \text { Calcium (ICP) } & 278 & 3 & 0 & \text { Nickel (AA) } & 95 & 3 & 0 \\ \text { Calcium (AA) } & 44 & 2 & 0 & \text { Nickel (TOT, AA) } & 55 & 1 & 0 \\ \text { Chloride (COL) } & 323 & 7 & 2 & \text { Potassium (AA) } & 332 & 7 & 4 \\ \text { Chromium (ICP) } & 159 & 5 & 1 & \text { Selenium (AA) } & 156 & 4 & 1 \\ \text { Chromium (DCP) } & 24 & 3 & 0 & \text { Silica (ICP) } & 278 & 4 & 4 \\ \text { Chromium (TOT, DCP) } & 55 & 1 & 1 & \text { Silica (COL) } & 44 & 0 & 0 \\ \text { Cobalt (ICP) } & 160 & 5 & 0 & \text { Silver (ICP) } & 82 & 2 & 1 \\ \text { Cobalt (AA) } & 38 & 5 & 0 & \text { Silver (AA) } & 99 & 2 & 0 \\ \text { Cobalt (TOT, AA) } & 55 & 6 & 0 & \text { Silver (TOT, AA) } & 55 & 1 & 0 \\ \text { Copper (ICP) } & 160 & 3 & 1 & \text { Sodium (ICP) } & 278 & 23 & 0 \\ \text { Copper (AA) } & 110 & 5 & 3 & \text { Sodium (AA) } & 44 & 5 & 2 \\ \text { Copper (TOT, AA) } & 55 & 14 & 0 & \text { Strontium (ICP) } & 160 & 4 & 2 \\ \text { Dissolved solids (GRAV) } & 323 & 9 & 1 & \text { Sulfate (TURB) } & 323 & 4 & 0 \\ \text { Fluoride (ISE) } & 207 & 10 & 2 & \text { Vanadium (ICP) } & 158 & 2 & 0 \\ \text { Iron (ICP) } & 160 & 14 & 3 & \text { Zinc (ICP) } & 160 & 41 & 3 \\ \text { Iron (AA) } & 94 & 3 & 0 & \text { Zinc (AA) } & 94 & 11 & 3 \\ \text { Iron (TOT, AA) } & 55 & 15 & 3 & \text { Zinc (TOT, AA) } & 55 & 16 & 4 \\ \text { Lead (ICP) } & 160 & 9 & 0 & & & & \\ & & & & & & \\ & & 5 & & & & \\ \end{array}$


Table 2.--Total number of analyses from quality-assurance samples during water year 1989 with number greater than two and six standard deviations from the most probable value--Continued

\begin{tabular}{|c|c|c|c|c|c|c|c|}
\hline \multirow{2}{*}{$\begin{array}{l}\text { Constituent } \\
\text { (dissolved except } \\
\text { as indicated) }\end{array}$} & \multicolumn{3}{|c|}{ No. of analyses } & \multirow{2}{*}{$\begin{array}{l}\text { Constituent } \\
\text { (dissolved except } \\
\text { as indicated) }\end{array}$} & \multicolumn{3}{|c|}{ No. of analyses } \\
\hline & Total & $>2 S D$ & $>6 \mathrm{SD}$ & & Total & $>2 \mathrm{SD}$ & $>6 S D$ \\
\hline \multicolumn{8}{|c|}{ Nutrient constituents } \\
\hline Ammonia as nitrogen (COL) & 436 & 9 & 2 & Nitrite as nitrogen (COL) & 249 & 7 & 4 \\
\hline $\begin{array}{l}\text { Ammonia plus organic } \\
\text { nitrogen (COL) }\end{array}$ & 358 & 6 & 2 & $\begin{array}{l}\text { Orthophosphate } \\
\text { as phosphorus (COL) }\end{array}$ & 271 & 35 & 2 \\
\hline $\begin{array}{l}\text { Nitrate plus nitrite } \\
\text { as nitrogen (COL) }\end{array}$ & 435 & 120 & 64 & Phosphorus (COL) & 402 & 18 & 8 \\
\hline \multicolumn{8}{|c|}{ Constituents in low-ionic strength samples } \\
\hline Ammonia as nitrogen (COL) & 10 & 0 & 0 & Orthophosphate as & 49 & 2 & 1 \\
\hline Calcium (AA) & 59 & 0 & 0 & phosphorus (COL) & & & \\
\hline Chloride (IC) & 59 & 2 & 1 & Potassium (AA) & 59 & 3 & 1 \\
\hline Fluoride (IC) & 59 & 2 & 1 & Sodium (AA) & 59 & 4 & 4 \\
\hline Magnesium (AA) & 59 & 3 & 1 & Specific conductance & 59 & 6 & 2 \\
\hline $\begin{array}{l}\text { Nitrate plus nitrite } \\
\text { as nitrogen (IC) }\end{array}$ & 38 & 0 & 0 & Sulfate (IC) & 59 & 2 & 1 \\
\hline
\end{tabular}

Friedman, Bradford, and Peart, (1983); and by Peart and Thomas, (1983a).

The precision analysis is based on whether or not the analytical process could produce results within $+/-2$ standard deviations of the theoretical values. The binomial equation identifies the maximum number of determinations that could exceed the control limit at a confidence level of 99 percent. A comparison is then made between the number of analytical determinations exceeding control limits and the results of the binomialprobability-distribution equation for the total number of analytical determinations. Analytes exhibit lack of precision if they have more determinations outside the control limits than the result of the binomial equation. The binomial-probability-distribution procedure to measure precision allows tracking of short term variations in analytical measurements. However, this statistical test may fail to identify periods of serious imprecision of laboratory methods because it is based on MPV's from inter-laboratory multiple-method round robin testing, rather than analysis means of determinations from the individual laboratories.

The bias analysis is made by tabulating the total number of analyses and the number of determinations above, below, and at the MPV concentration. A binomial equation is used to determine the maximum number of determinations above or below the MPV at a confidence level of 99 percent. Analyses exhibit a positive bias if the number of determinations above the MPV exceeded the result of the binomial equation. Likewise, analyses exhibit a negative bias if the number of determinations below the MPV exceeded the result of the binomial equation. 


\section{QUALITY-ASSURANCE DATA FOR INORGANIC-CONSTITUENT SAMPLES}

\section{Precision}

The results of statistical testing for lack of precision for each inorganic constituent are presented in table 3 . For each constituent, this table indicates statistically significant lack of precision at the 95-percent confidence level (indicated by "LOP") as well as all acceptable results (indicated by "+").

Data for water year 1989 for aluminum (TOT, DCP), boron (DCP), copper (TOT, AA), iron (TOT, AA), sodium (ICP), zinc (ICP), zinc (AA), and zinc (TOT, AA) indicated lack of precision in the NWQL. Sodium (ICP) and iron (TOT, AA) failed the precision criteria during water year 1988 (Lucey, 1989) and again in 1989.

In the NWQL during water year 1989, calcium (ICP), fluoride (ISE), iron (AA), magnesium (AA), manganese (TOT, AA), and potassium (AA) had acceptable results after failing the precision tests during water year 1988 (Lucey, 1989).

\section{Bias}

Table 4 presents the results of statistical tests for bias for each inorganic constituent. Analytical bias is indicated for 37 constituents for water year 1989 compared to only 30 for water year 1988 (Lucey, 1989). The degree of bias is evident through review of control charts. Constituents that showed negative bias for water years 1989 and 1988 were: cadmium (ICP), chromium (ICP), cobalt (ICP), lithium (TOT, AA), molybdenum (AA), nickel (ICP), nickel (AA), and silver (ICP). In addition, antimony (AA), beryllium (ICP), chloride (COL), chromium (DCP), chromium (TOT, AA), molybdenum (ICP), potassium (AA), and vanadium (ICP) had negative bias for water year 1989.

Positively biased constituents for water years 1989 and 1988 were: arsenic (AA), iron (ICP), magnesium (ICP), selenium (AA), sodium (ICP); sulfate (TURB), zinc (AA), and zinc (TOT, AA). Additional constituents that had a positive bias for 1989 but did not during water year 1988 were: alkalinity (TITR), aluminum (DCP), aluminum (TOT, DCP), barium (ICP), cadmium (AA), iron (AA), iron (TOT, AA), lead (TOT, AA), manganese (TOT, AA), silica (ICP), silica (COL), strontium (ICP), and zinc (ICP).

In addition to the 37 analytes which showed statistical bias, an apparent positive bias is evident on the control charts for barium (AA), barium (TOT, AA), beryllium (TOT, AA), and lead (ICP). This apparent bias occurred because the minimum reporting levels (barium (AA), $100 \mathrm{mg} / \mathrm{L}$; beryllium (TOT, AA), $10 \mathrm{mg} / \mathrm{L}$; and, lead (ICP), $10 \mathrm{mg} / \mathrm{L}$ ) were greater than the MPV's of most or all reference samples. Table 4 designates these constituents as a quantitation limit (QL) bias.

Results for arsenic, iron (ICP), magnesium (ICP), selenium (AA), sodium (ICP), sulfate (TURB), and zinc (AA) have indicated a positive bias for each of the last three years (1987, 1988, 1989). Nickel (AA) and silver (ICP) have indicated a negative bias for 1987 (Lucey and Peart, 1989b), 1988 (Lucey, 1989), and 1989.

Several factors may have affected the results for other constituents that indicated occasional bias; the factors may include deterioration of standard calibrating solutions or reagents, improper or inaccurate reagent or standard-solution preparation, undetected problems with analytical instrumentation, undefined matrix effects caused by mixing together two very different SRWS, reporting levels being higher or lower than the MPV's or undetected contamination of the SRWS. 
Table 3.--Results of statistical testing for lack of precision in inorganic constituent data

[TITR, electrometric titration; +, acceptable results; TOT, total recoverable; DCP, direct current plasma emission spectrometry; LOP, statistically significant lack of precision; AA, atomic absorption spectrometry; ICP, inductively coupled plasma emission spectrometry; COL, colorimetric; GRAV, gravimetric; ISE, ion-selective electrode; TURB, turbidimetric]

\begin{tabular}{|c|c|c|c|}
\hline $\begin{array}{l}\text { Constituent } \\
\text { (dissolved, } \\
\text { except as } \\
\text { indicated) }\end{array}$ & $\begin{array}{c}\text { Results from } \\
\text { Oct. } 1988- \\
\text { Sept. } 1989\end{array}$ & $\begin{array}{l}\text { Constituent } \\
\text { (dissolved, } \\
\text { except as } \\
\text { indicated) }\end{array}$ & $\begin{array}{c}\text { Results from } \\
\text { Oct. 1988- } \\
\text { Sept. } 1989\end{array}$ \\
\hline Alkalinity (TITR) & + & Lead $(\mathrm{AA})$ & + \\
\hline Aluminum (DCP) & + & Lead (TOT, AA) & + \\
\hline Aluminum (TOT, DCP) & LOP & Lithium(ICP) & + \\
\hline Antimony (AA) & + & Lithium (TOT, AA) & + \\
\hline Arsenic $(\mathrm{AA})$ & + & Magnesium (ICP) & + \\
\hline Barium (ICP) & + & Magnesium (AA) & + \\
\hline Barium (AA) & + & Manganese (ICP) & + \\
\hline Barium (TOT, AA) & + & Manganese (AA) & + \\
\hline Beryllium (ICP) & + & Manganese (TOT, AA) & + \\
\hline Beryllium (TOT, AA) & + & Mercury (AA) & + \\
\hline Boron (DCP) & LOP & Mercury (TOT, AA) & + \\
\hline Cadmium (ICP) & + & Molybdenum (ICP) & + \\
\hline Cadmium (AA) & + & Molybdenum (AA) & + \\
\hline Cadmium (TOT, AA) & + & Nickel (ICP) & + \\
\hline Calcium (ICP) & + & Nickel (AA) & + \\
\hline Calcium (AA) & + & Nickel (TOT, AA) & + \\
\hline Chloride (COL) & + & Potassium (AA) & + \\
\hline Chromium (ICP) & + & Selenium (AA) & + \\
\hline Chromium (DCP) & + & Silica (ICP) & + \\
\hline Chromium (TOT, DCP) & + & Silica (COL) & + \\
\hline Cobalt (ICP) & + & Silver (ICP) & + \\
\hline Cobalt (AA) & + & Silver (AA) & + \\
\hline Cobalt (TOT, AA) & + & Silver (TOT, AA) & + \\
\hline Copper (ICP) & + & Sodium (ICP) & LOP \\
\hline Copper (AA) & + & Sodium (AA) & + \\
\hline Copper (TOT, AA) & LOP & Strontium (ICP) & + \\
\hline Dissolved solids (GRAV) & + & Sulfate (TURB) & + \\
\hline Fluoride (ISE) & + & Vanadium (ICP) & + \\
\hline Iron (ICP) & + & Zinc (ICP) & LOP \\
\hline Iron $(\mathrm{AA})$ & + & Zinc (AA) & LOP \\
\hline Iron (TOT, AA) & LOP & Zinc (TOT, AA) & LOP \\
\hline Lead (ICP) & + & & \\
\hline
\end{tabular}


Table 4.--Results of statistical testing for bias in inorganic constituent data

[TITR, electrometric titration; $P$, positive bias; DCP, direct current plasma emission spectrometry; TOT, total recoverable; $A A$, atomic absorption spectrometry; $N$, negative bias; ICP, inductively coupled plasma emission spectrometry; $\mathrm{QL}$, quantitation limit; +, acceptable results; COL, colorimetric; GRAV, gravimetric; ISE, ion-selective electrode; TURB, turbidimetric]

\begin{tabular}{lclc}
\hline $\begin{array}{l}\text { Constituent } \\
\text { (dissolved, }\end{array}$ & Results from & Constituent & Results from \\
except as & Oct. 1988- & Oct. 1988- \\
indicated) & Sept. 1989 & $\begin{array}{l}\text { except as } \\
\text { indicated) }\end{array}$ & Sept. 1989
\end{tabular}

\begin{tabular}{|c|c|c|c|}
\hline Alkalinity (TITR) & $P$ & Lead (AA) & + \\
\hline Aluminum (DCP) & $\mathbf{P}$ & Lead (TOT, AA) & $\mathrm{P}$ \\
\hline Aluminum (TOT, DCP) & $P$ & Lithium (ICP) & + \\
\hline Antimony (AA) & $\mathbf{N}$ & Lithium (TOT, AA) & $\mathbf{N}$ \\
\hline Arsenic (AA) & $\mathrm{P}$ & Magnesium (ICP) & $P$ \\
\hline Barium (ICP) & $\mathrm{P}$ & Magnesium (AA) & + \\
\hline Barium (AA) & $\mathrm{QL}^{1}$ & Manganese (ICP) & + \\
\hline Barium (TOT, AA) & $\mathrm{QL}^{1}$ & Manganese (AA) & + \\
\hline Beryllium (ICP) & $\mathrm{N}$ & Manganese (TOT, AA) & $\mathrm{P}^{2}$ \\
\hline Beryllium (TOT, AA) & $\mathrm{QL}^{1}$ & Mercury (AA) & + \\
\hline Boron (DCP) & + & Mercury (TOT, AA) & $N$ \\
\hline Cadmium (ICP) & $\mathbf{N}$ & Molybdenum (ICP) & $\mathbf{N}$ \\
\hline Cadmium (AA) & $\mathrm{P}$ & Molybdenum (AA) & $\mathrm{N}$ \\
\hline Cadmium (TOT, AA) & + & Nickel (ICP) & $N$ \\
\hline Calcium (ICP) & + & Nickel (AA) & $\mathbf{N}$ \\
\hline Calcium (AA) & + & Nickel (TOT, AA) & + \\
\hline Chloride (COL) & $N$ & Potassium (AA) & $\mathbf{N}$ \\
\hline Chromium (ICP) & $\mathbf{N}$ & Selenium (AA) & $P$ \\
\hline Chromium (DCP) & $\mathbf{N}$ & Silica (ICP) & $\mathrm{P}$ \\
\hline Chromium (TOT, DCP) & $N$ & Silica (COL) & $\mathbf{P}$ \\
\hline Cobalt (ICP) & $N$ & Silver (ICP) & $N$ \\
\hline Cobalt (AA) & + & Silver (AA) & + \\
\hline Cobalt (TOT, AA) & + & Silver (TOT, AA) & + \\
\hline Copper (ICP) & + & Sodium (ICP) & $\mathbf{P}$ \\
\hline Copper (AA) & + & Sodium (AA) & + \\
\hline Copper (TOT, AA) & + & Strontium (ICP) & $P$ \\
\hline Dissolved solids (GRAV) & + & Sulfate (TURB) & $\mathbf{P}$ \\
\hline Fluoride (ISE) & + & Vanadium (ICP) & $\mathbf{N}$ \\
\hline Iron (ICP) & $\mathrm{P}$ & Zinc (ICP) & $\mathbf{P}$ \\
\hline Iron $(A A)$ & $P$ & $\operatorname{Zinc}(A A)$ & $\mathbf{P}$ \\
\hline Iron (TOT, AA) & $\mathrm{P}$ & Zinc (TOT, AA) & $\mathbf{P}$ \\
\hline Lead (ICP) & $\mathrm{QL}^{1}$ & & \\
\hline
\end{tabular}

\footnotetext{
${ }^{1}$ Positive bias is indicated because the most probable values of most or all reference samples were below the quantitation limit of the method.

${ }^{2}$ Bias position may be influenced because some most probable values are less than the lowest reporting limit.
} 


\section{QUALITY-ASSURANCE DATA FOR NUTRIENT-CONSTITUENT SAMPLES}

\section{Precision}

The results of statistical testing for lack of precision for each nutrient constituent are presented in table 5 . Results for nitrate plus nitrite nitrogen as nitrogen failed the precision test at the NWQL for the 1989 water year. This is the third consecutive year that nitrate plus nitrite nitrogen as $\mathrm{N}$ has failed the precision test (Lucey and Peart, 1989b; and Lucey, 1989). The control chart for nitrate plus nitrite as nitrogen (COL) (fig. 66) shows many points below the control limit throughout the year. The lack of precision indicated on this chart has been attributed to a limitation of the analytical method for determinations of nitrate plus nitrite in water with low $\mathrm{pH}$. A SRWS reference sample with an approximate $\mathrm{pH}$ of 1.8 had been used for the entire water year. The NWQL could not meet control limits in the determination of this standard. Another SRWS reference sample, that had a $\mathrm{pH}$ of 7.1, was used in the blind sample program during the 1989 water year. The NWQL showed good analytical precision in the determination of this second standard. The $\mathrm{pH}$ at which analytical precision began to fail was not determined but there may be concern about nitrate plus nitrite as nitrogen (COL) analyses for environmental samples collected from wetlands and bogs that have a lower $\mathrm{pH}$. A method change was made in February 1990 by the NWQL so that low pH samples could be determined.

\section{Bias}

Results of the statistical tests for bias are presented in table 6 . Results for ammonia as nitrogen (COL) indicated a positive bias, whereas the results for phosphorus (COL), indicated a negative bias. During water year 1988 , ammonia plus organic nitrogen (COL) also indicated a positive bias (Lucey, 1989).

\section{QUALITY-ASSURANCE DATA FOR LOW-IONIC STRENGTH SAMPLES}

\section{Precision}

The results for statistical testing for lack of precision for each constituent in the low-ionic strength samples are presented in table 7. Results for all of the constituents in the lowionic strength samples indicated acceptable precision for water year 1989, as they did in water year 1988 (Lucey, 1989).

\section{Bias}

The results for statistical testing for bias for each constituent in the low-ionic strength samples are presented in table 8 . The results for chloride (IC) indicate a positive bias and results for fluoride (IC) a negative bias. Fluoride data also indicated a negative bias in water year 1988 (Lucey, 1989).

\section{SUMMARY}

Reference water samples with established MPV's were disguised as regular samples and submitted with environmental water samples by U.S. Geological Survey offices to the National Water-Quality Laboratory in Arvada, Colorado. The resulting analytical data are stored in the WATSTORE data base.

For each constituent, control charts were prepared based on the difference between the analytical results and the most probable value of the reference samples. To allow the data for all reference mixes to be plotted on the same chart, the difference from the above calculations was divided by each sample's most probable deviation, which was determined from a linear regression technique. Replicate sample determinations allowed the preparation of precision charts for each constituent. Data for inorganic, nutrient, and low-ionic strength constituent samples then were evaluated statistically for precision and 
Table 5.--Results of statistical testing for lack of precision in nutrient constituent data [COL, colorimetric); +, acceptable results; LOP, statistically significant lack of precision]

\begin{tabular}{|c|c|c|c|}
\hline $\begin{array}{l}\text { Constituent } \\
\text { (dissolved) }\end{array}$ & $\begin{array}{c}\text { Results from } \\
\text { Oct. 1988- } \\
\text { Sept. } 1989\end{array}$ & $\begin{array}{l}\text { Constituent } \\
\text { (dissolved) }\end{array}$ & $\begin{array}{c}\text { Results from } \\
\text { Oct. 1988- } \\
\text { Sept. } 1989\end{array}$ \\
\hline Ammonia as nitrogen (COL) & + & Nitrite as nitrogen (COL) & + \\
\hline $\begin{array}{l}\text { Ammonia plus organic } \\
\text { nitrogen (COL) }\end{array}$ & + & $\begin{array}{l}\text { Orthophosphate as } \\
\text { phosphorus (COL) }\end{array}$ & + \\
\hline $\begin{array}{l}\text { Nitrate plus nitrite as } \\
\text { nitrogen (COL) }\end{array}$ & LOP & Phosphorus (COL) & + \\
\hline
\end{tabular}

Table 6.--Results of statistical testing for bias in nutrient constituent data

[COL, colorimetric; $P$, positive bias; + , acceptable results; $N$, negative bias]

\begin{tabular}{lccc}
\hline Constituent & Results from & Constituent & Results from \\
(dissolved) & Oct. 1988- & (dissolved) & Oct. 1988- \\
& Sept. 1989 & & Sept. 1989 \\
\hline
\end{tabular}

\begin{tabular}{|c|c|c|c|}
\hline Ammonia as nitrogen (COL) & $\bar{P}$ & Nitrite as nitrogen (COL) & + \\
\hline $\begin{array}{l}\text { Ammonia plus organic) } \\
\text { nitrogen (COL) }\end{array}$ & + & $\begin{array}{l}\text { Orthophosphate as } \\
\text { phosphorus (COL) }\end{array}$ & + \\
\hline $\begin{array}{l}\text { Nitrate plus nitrite as) } \\
\text { nitrogen (COL) }\end{array}$ & + & Phosphorus (COL) & $\mathrm{N}$ \\
\hline
\end{tabular}

Table 7.--Results of statistical testing for lack of precision in low-ionic strength constituent data [COL, colorimetric; +, acceptable results; AA, atomic absorption spectrometry; IC, ion chromatography; $\mathrm{mS} / \mathrm{cm}$, microsiemens per centimeter]

\begin{tabular}{|c|c|c|c|}
\hline $\begin{array}{l}\text { Constituent } \\
\text { (dissolved) }\end{array}$ & $\begin{array}{c}\text { Results from } \\
\text { Oct. 1988- } \\
\text { Sept. } 1989\end{array}$ & $\begin{array}{l}\text { Constituent } \\
\text { (dissolved) }\end{array}$ & $\begin{array}{c}\text { Results from } \\
\text { Oct. 1988- } \\
\text { Sept. } 1989\end{array}$ \\
\hline $\begin{array}{l}\text { Ammonia as nitrogen (COL) } \\
\text { Calcium (AA) } \\
\text { Chloride (IC) } \\
\text { Fluoride (IC) } \\
\text { Magnesium (AA) } \\
\text { Nitrate as nitrogen (IC) }\end{array}$ & $\begin{array}{l}+ \\
+ \\
+ \\
+ \\
+ \\
+\end{array}$ & $\begin{array}{l}\text { Orthophosphate as } \\
\text { phosphorus (IC) } \\
\text { Potassium (AA) } \\
\text { Sodium (AA) } \\
\text { Specific conductance }(\mu \mathrm{S} / \mathrm{cm}) \\
\text { Sulfate (IC) }\end{array}$ & $\begin{array}{l}+ \\
+ \\
+ \\
+ \\
+\end{array}$ \\
\hline
\end{tabular}


Table 8.--Results of statistical testing for bias in low-ionic strength constituent data

[COL, colorimetric; +, acceptable results; AA, atomic absorption spectrometry; IC, ion chromatography; $P$, positive bias; $\mathrm{N}$, negative bias; $\mathrm{mS} / \mathrm{cm}$, microsiemens per centimeter]

\begin{tabular}{|c|c|c|c|}
\hline $\begin{array}{l}\text { Constituent } \\
\text { (dissolved) }\end{array}$ & $\begin{array}{c}\text { Results from } \\
\text { Oct. } 1988- \\
\text { Sept. } 1989\end{array}$ & $\begin{array}{l}\text { Constituent } \\
\text { (dissolved) }\end{array}$ & $\begin{array}{c}\text { Results from } \\
\text { Oct. 1988- } \\
\text { Sept. } 1989\end{array}$ \\
\hline Ammonia as nitrogen (COL) & + & Orthophosphate as & + \\
\hline Chloride (IC) & $\mathbf{P}$ & Potassium (AA) & + \\
\hline Fluoride (IC) & $\mathrm{N}$ & Sodium (AA) & + \\
\hline Magnesium (AA) & + & Specific conductance $(\mu \mathrm{S} / \mathrm{cm})$ & + \\
\hline Nitrate as nitrogen (IC) & + & Sulfate (IC) & + \\
\hline
\end{tabular}

bias by using a binomial-probabilitydistribution equation.

An overall evaluation of the inorganic constituent data for water year 1989 indicates a lack of precision in results from the NWQL for aluminum (TOT, AA), boron (DCP), copper (TOT, AA), iron (TOT, AA), sodium (ICP), zinc (ICP), zinc (AA), and zinc (TOT, $A A)$. Iron (TOT, AA) and sodium (TOT, AA) failed the precision criteria for both water years 1988 and 1989.

An overall evaluation of the inorganic constituent data for water year 1989 indicates a significant bias in results from the NWQL for alkalinity (TITR), aluminum (DCP), aluminum (TOT, DCP), antimony (AA), arsenic (AA), barium (ICP), beryllium (ICP), cadmium (ICP), cadmium (AA), chloride (COL), chromium (ICP), chromium (DCP), chromium (TOT, DCP), cobalt (ICP), iron (ICP), iron (AA), iron (TOT, AA), lead (TOT, AA), lithium (TOT, AA), magnesium (ICP), manganese (TOT, AA), molybdenum (ICP), molybdenum (AA), nickel (ICP), nickel (AA), potassium (AA), selenium (AA), silica (ICP), silica (COL), silver (ICP), sodium (ICP), strontium (ICP), sulfate (TURB), vanadium (ICP), zinc (ICP), zinc (AA), and zinc (TOT, AA).
Constituents with results that showed negative bias for water years 1988 and 1989 were: cadmium (ICP), chromium (ICP), cobalt (ICP), lithium (TOT, AA), molybdenum (AA), nickel (ICP), nickel (AA), and silver (ICP). Constituents with results that showed positive bias for water years 1988 and 1989 were: arsenic (AA), iron (ICP), magnesium (ICP), selenium (AA), sodium (ICP), sulfate (TURB), zinc (AA), and zinc (TOT, AA). Results for arsenic (AA), iron (ICP), magnesium (ICP), selenium (AA), sodium (ICP), sulfate (TURB), and zinc (AA) have indicated a positive bias for each of the last 3 years. Nickel (AA) and silver (ICP) have each indicated a negative bias for the past 3 years.

For nutrient constituents, results for nitrate plus nitrite as nitrogen (COL), failed the precision test at the NWQL for water year 1989. Nitrate plus nitrite as nitrogen (COL) also failed the precision test for water years 1987 and 1988. Results for ammonia as nitrogen (COL) indicate a positive bias; whereas results for phosphorus (COL) indicate a negative bias. Only ammonia as nitrogen (COL) indicated a positive bias in 1988 and 1989.

Results for all constituents in low-ionic strength samples indicate acceptable precision. 
Results for chloride (IC) indicate a positive bias, while results for fluoride (IC) indicate a negative bias. Fluoride (IC) had a negative bias for water years 1988 and 1989.

\section{REFERENCES}

Fishman, M.J., and Friedman, L.C., 1985, Methods for determination of inorganic substances in water and fluvial sediments: Techniques of Water-Resources Investigations of the U.S. Geological Survey, Book 5, Chapter A1, Open-File Report 85-496, 709 p.

Friedman, L.C., Bradford, W.L., and Peart, D.B., 1983. Application of binomial distributions to quality-assurance of quantitative chemical analyses: Journal of Environmental Science and Health, v. A18, no. 4, p. 561-570.

Janzer, V.J., 1985, The use of natural waters as U.S. Geological Survey reference samples, in Taylor, J.K., and Stanley, T.W., eds., Quality assurance for environmental measurements, ASTM STP 867,: American Society for Testing and Materials, Philadelphia, p. 319333.

Keith, L.H., and Telliard, W.A., 1979, Priority pollutants, I.- A perspective view: Environmental Science and Technology, v. 13 no. 4 , p. $416-423$.

Lucey, K.J., 1989, Quality-assurance data for routine water analysis in the National Water Quality Laboratory of the U.S. Geological Survey for water year 1988: U.S. Geological Survey Water-Resources Investigations Report 89-4166, 96 p.

1990, QADATA user's manual: An interactive computer program for the retrieval and analysis of the results from the external blind sample quality-assurance project of the U.S. Geological Survey: U.S. Geological Survey Open-File Report 90-162, $53 \mathrm{p}$.

Lucey, K.J., and Peart, D.B., 1988, Qualityassurance data for routine water analysis in the laboratories of the U.S. Geological Survey for water year 1985: U.S. Geological Survey Water-Resources Investigations Report 88-4109, 121 p.

1989a, Quality-assurance data for routine water analysis in the laboratories of the U.S. Geological Survey for water year 1986: U.S.
Geological Survey Water-Resources Investigations Report 89-4009, 145 p.

$1989 \mathrm{~b}$, Quality-assurance data for routine water analysis in the laboratories of the U.S. Geological Survey for water year 1987: U.S. Geological Survey Water-Resources Investigations Report 89-4049, 90 p.

Peart, D.B., and Sutphin, H.B., 1987, Qualityassurance data for routine water analysis in the laboratories of the U.S. Geological Survey for water year 1984: U.S. Geological Survey Water-Resources Investigations Report 87-4077, 125 p.

Peart, D.B., and Thomas, Nancy, 1983a, Qualityassurance data for routine water analysis in the laboratories of the U.S. Geological Survey 1981 annual report: U.S. Geological Survey Water-Resources Investigations Report 83-4090, 112 p.

1983b, Quality-assurance data for routine water analysis in the laboratories of the U.S. Geological Survey for water year 1982: U.S. Geological Survey Water-Resources Investigations Report 83-4264, 112 p.

1984, Quality-assurance data for routine water analysis in the laboratories of the U.S. Geological Survey for water year 1983: U.S. Geological Survey Water-Resources Investigations Report 84-4234, $112 \mathrm{p}$.

Schroder, L.J., Fishman, M.J., Friedman, L.C., and Darlington, G.W., 1980, The use of standard reference water samples by the U.S. Geological Survey: U.S. Geological Survey Open-File Report 80-738, 11 p.

Skougstad, M.W., and Fishman, M.J., 1975, Standard reference water samples: American Water Works Association Water Quality Technology Conference, Dallas, 1974, Proceedings, p. XIX-1 -XIX-6. 
SUPPLEMENTAL DATA

18 


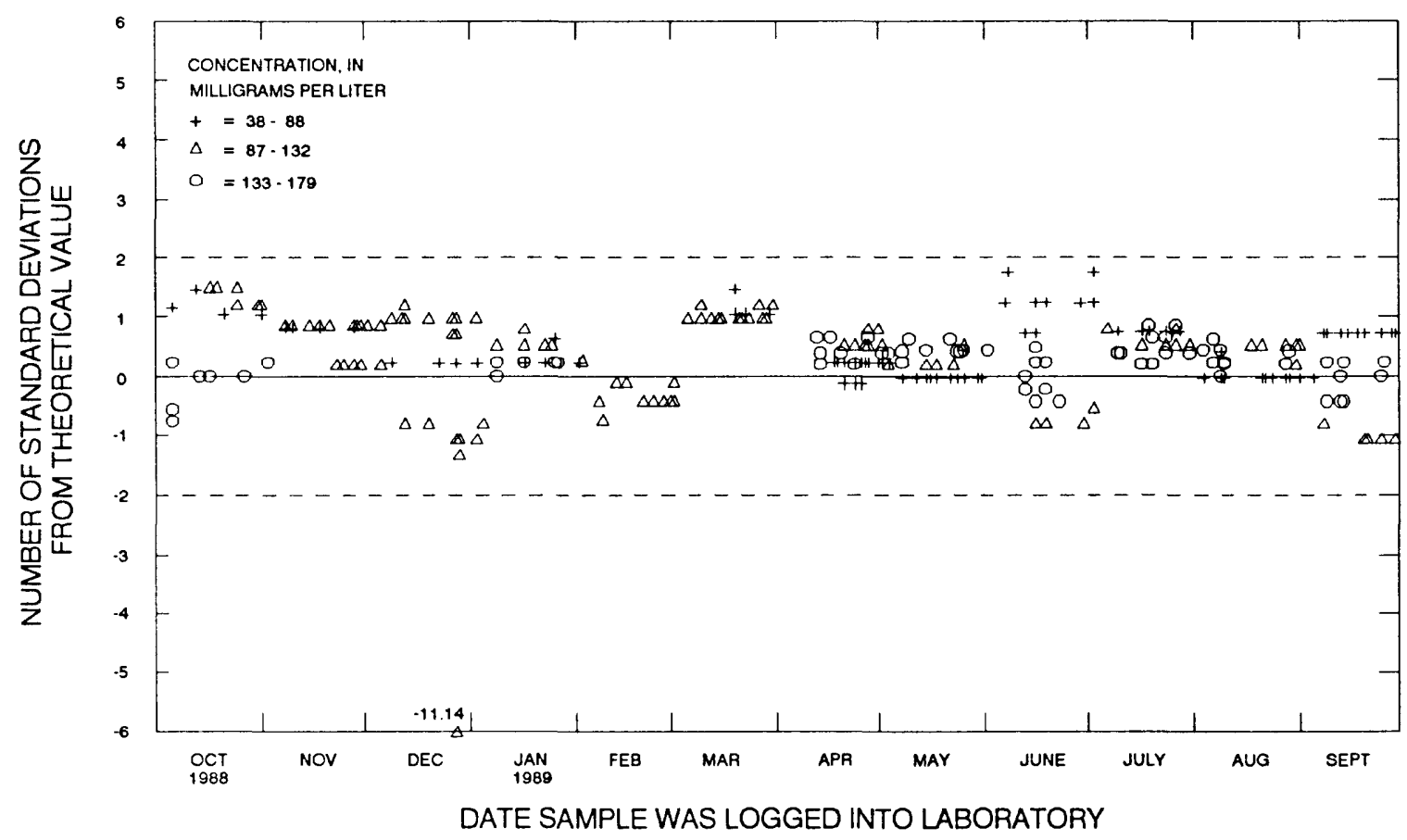

Figure 1.-- Alkalinity, total, (electrometric titration) data from the National Water Quality Laboratory.

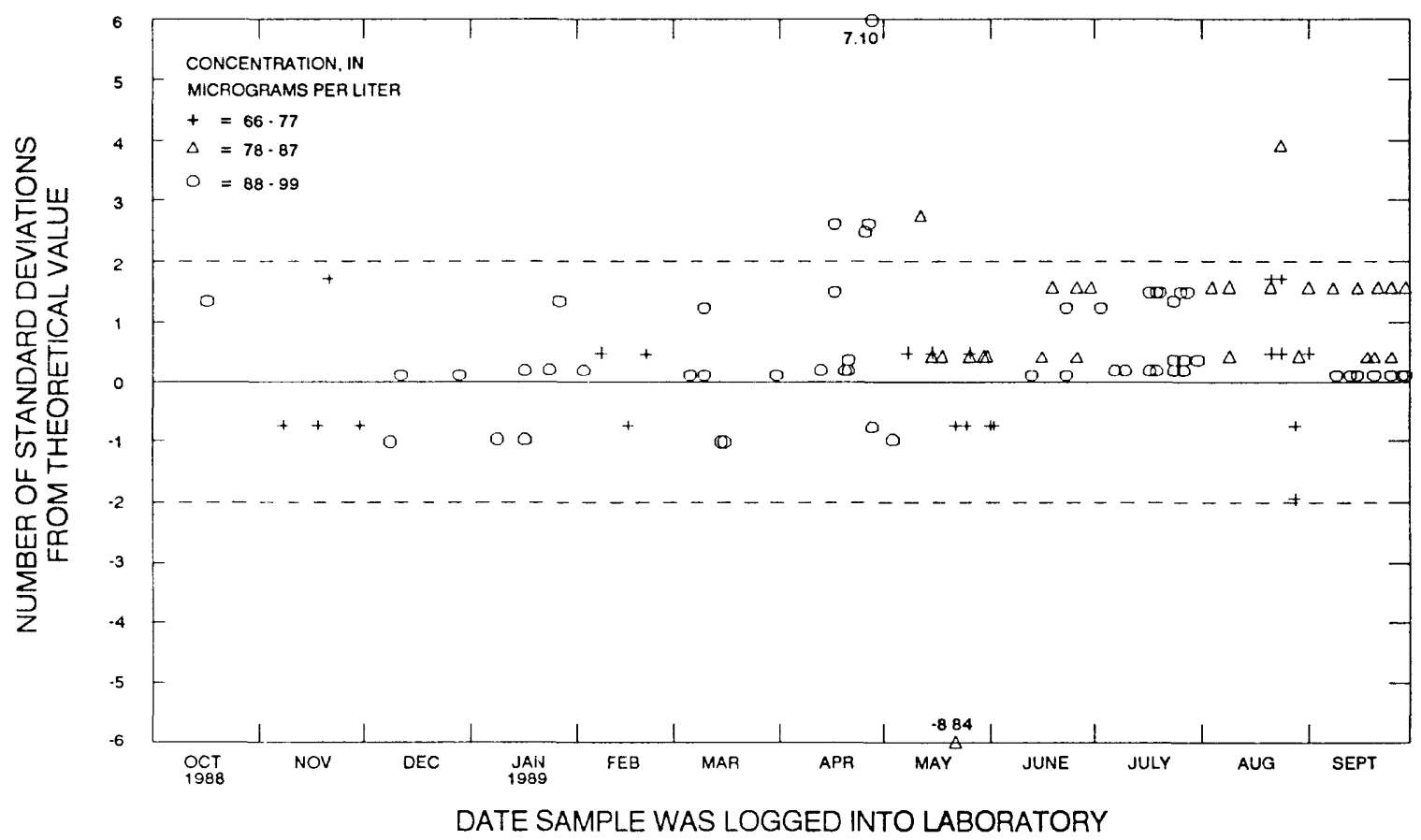

Figure 2.--Aluminum, dissolved, (direct current plasma emission spectrometry) data from the National Water Quality Laboratory. 


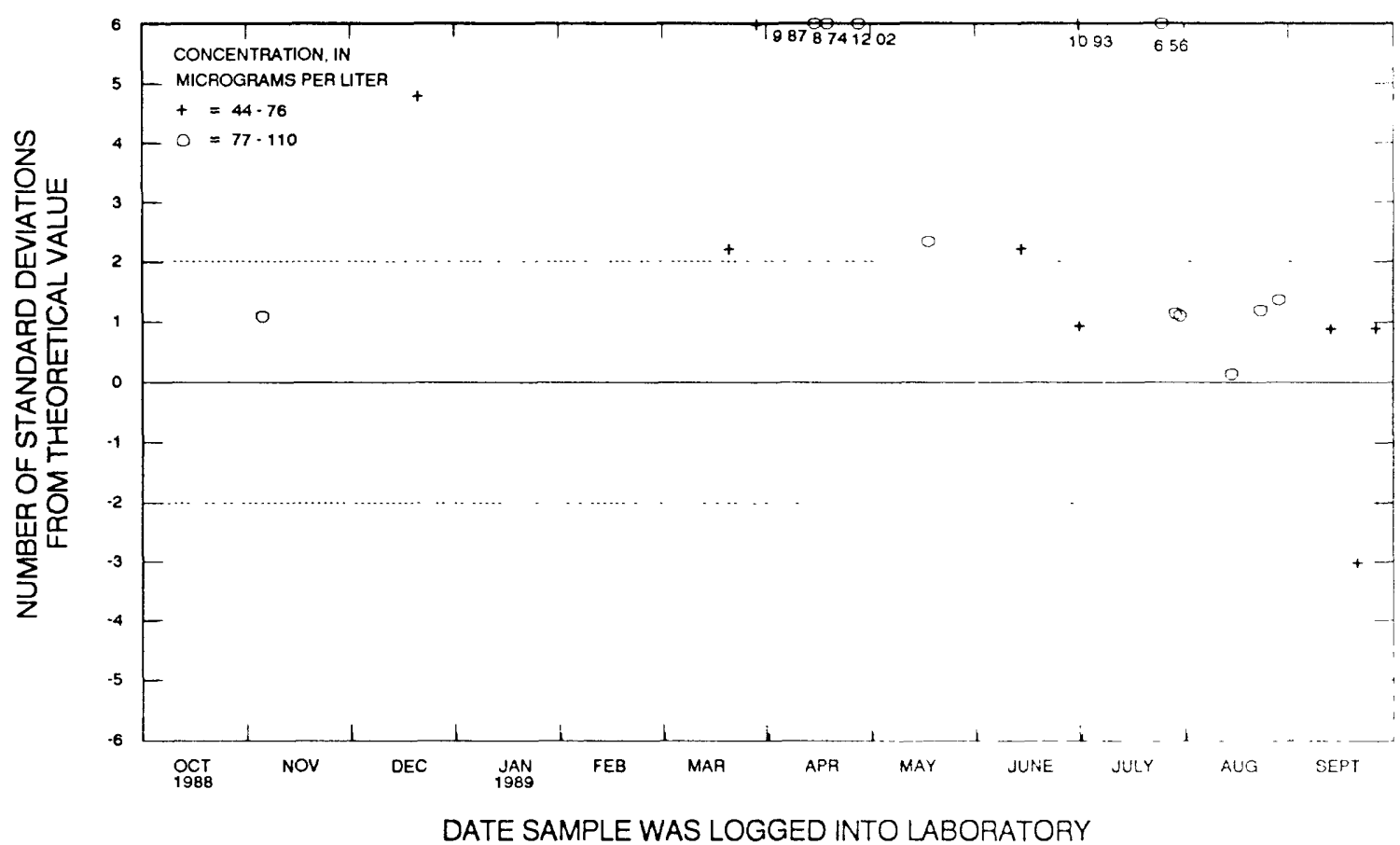

Figure 3-- Aluminum, total, (direct current plasma emission spectrometry) data from the National Water Quality Laboratory.

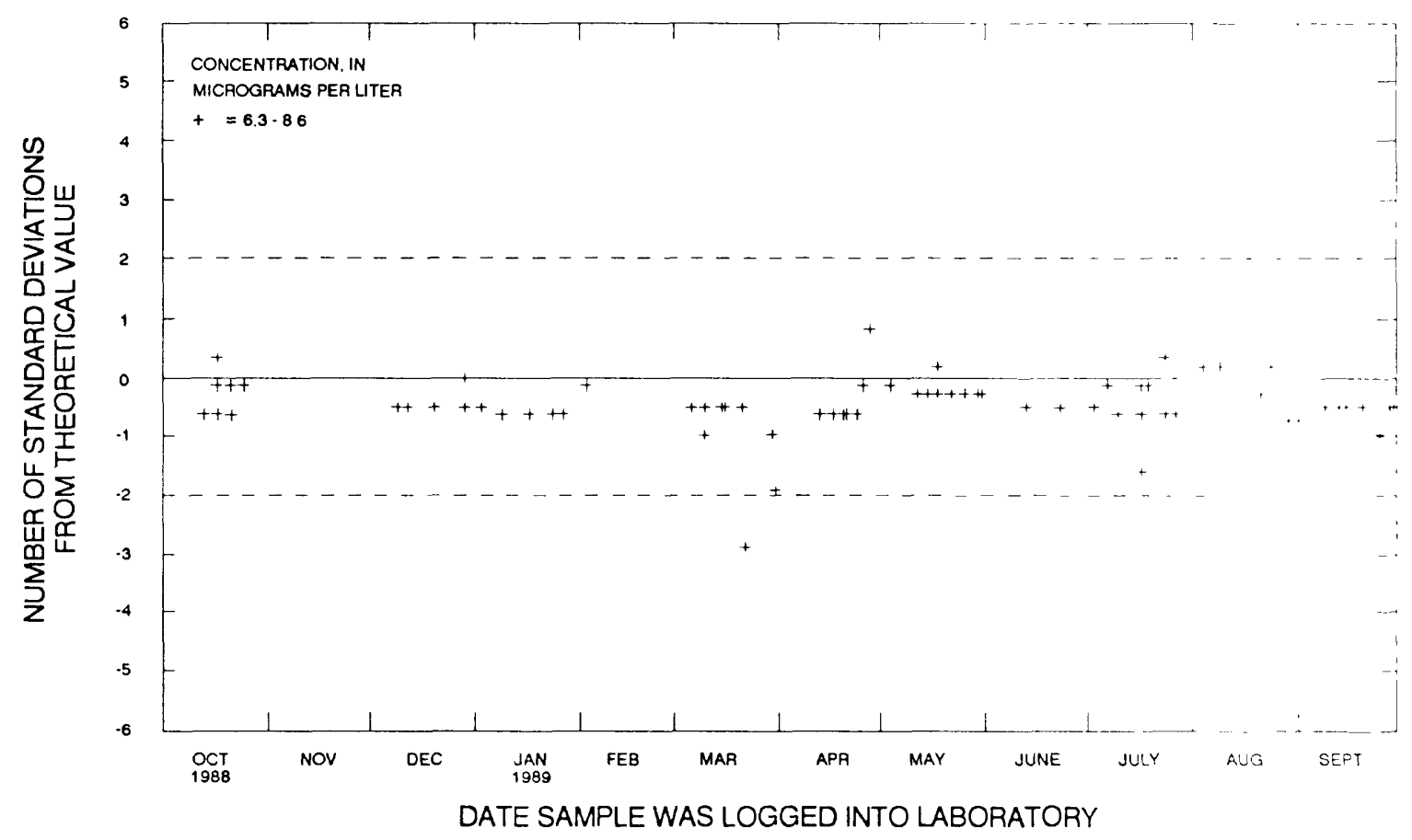

Figure 4.-- Antimony, dissolved and total, (atomic absorption spectrometry, hydride) data from the National Water Quality Laboratory. 


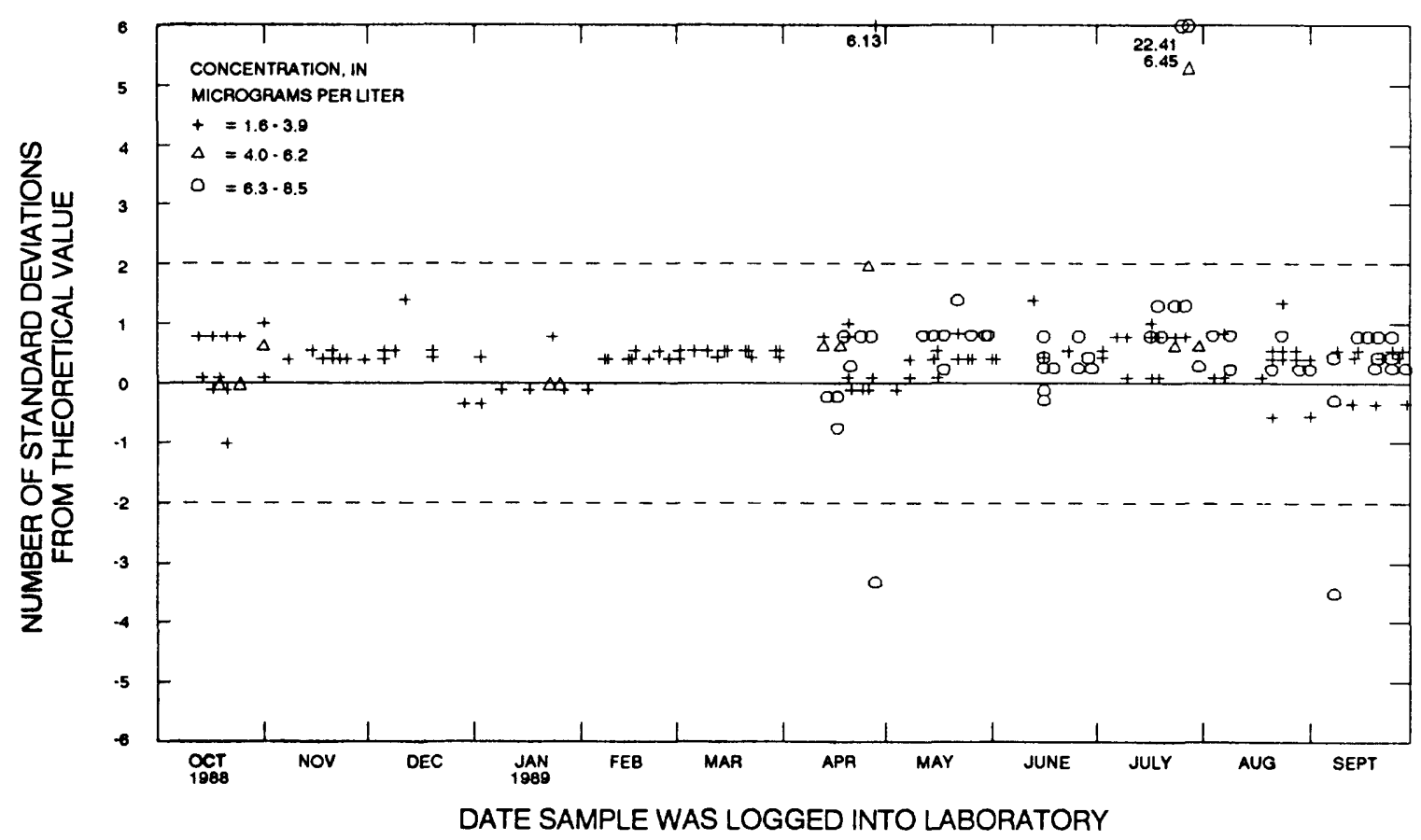

Figure 5.--Arsenic, dissoived and totai, (atomic absorption spectrometry, hydride) data from the National Water Quality Laboratory.

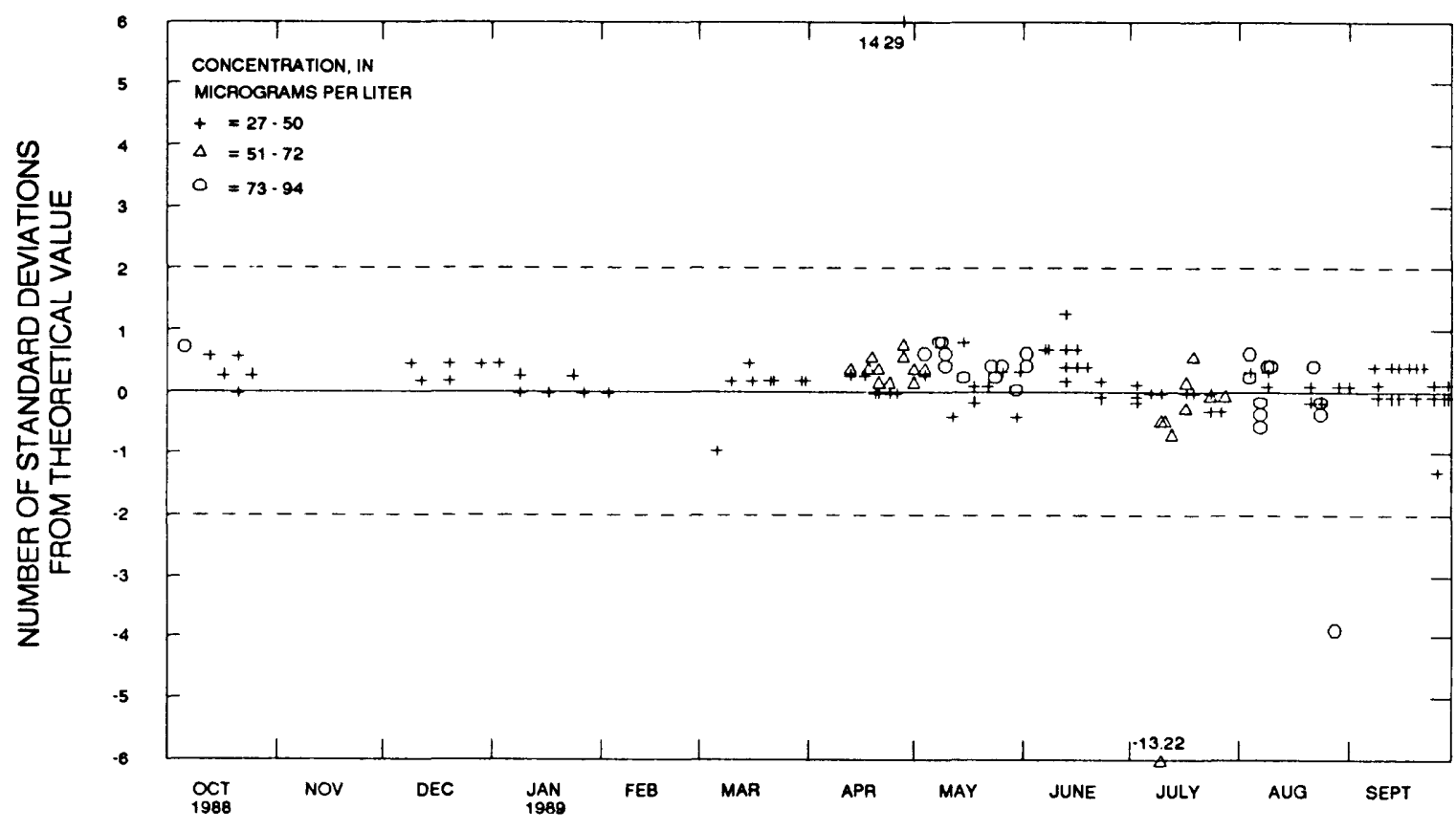

DATE SAMPLE WAS LOGGED INTO LABORATORY

Figure 6.-- Barium, dissoived, (inductively coupied plasma emission spectrometry) data from the Nationai Water Quality Laboratory. 


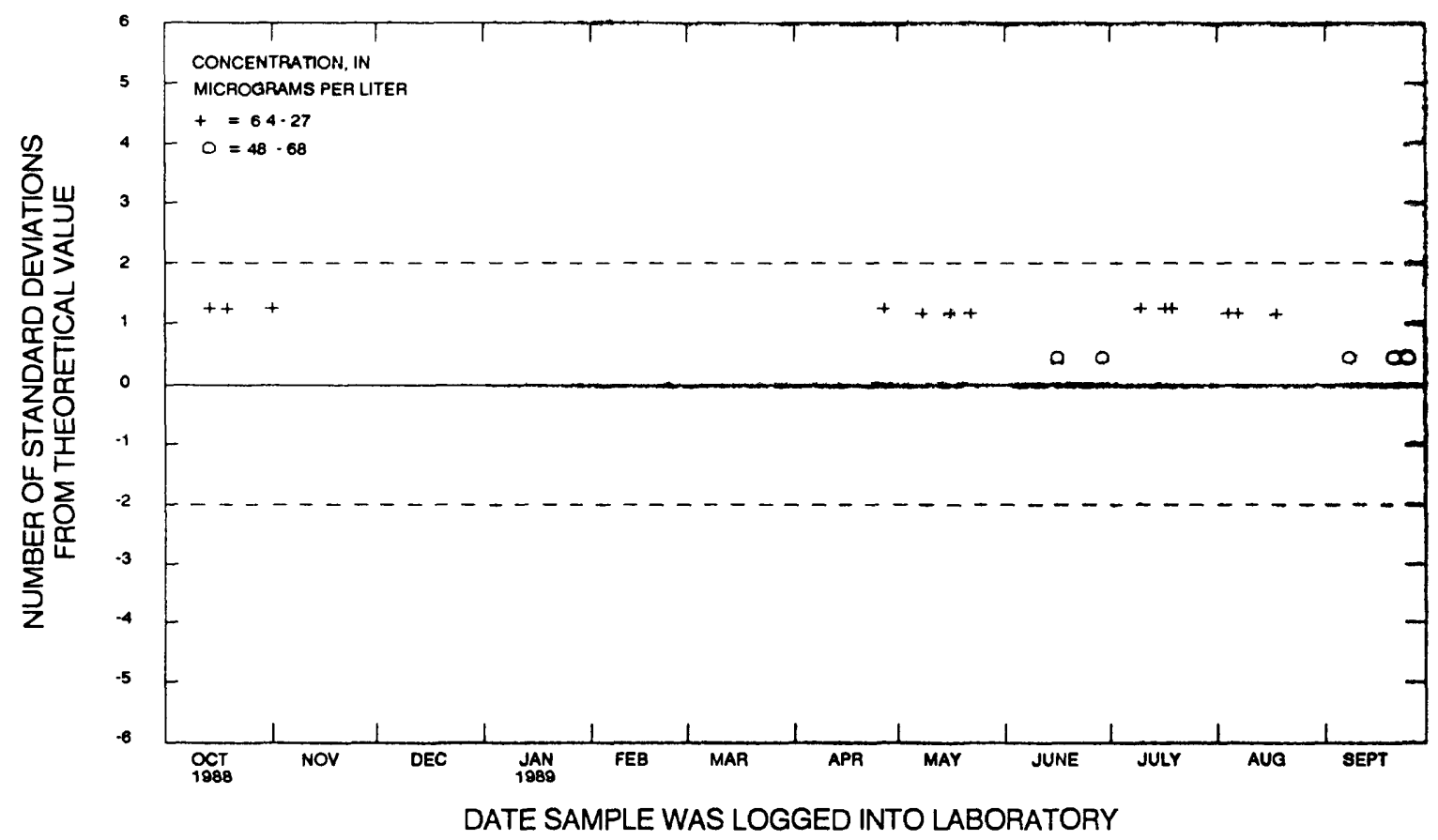

Figure 7.--Barium, dlssolved,

(atomic absorption spectrometry)

data from the National Water Quality Laboratory.

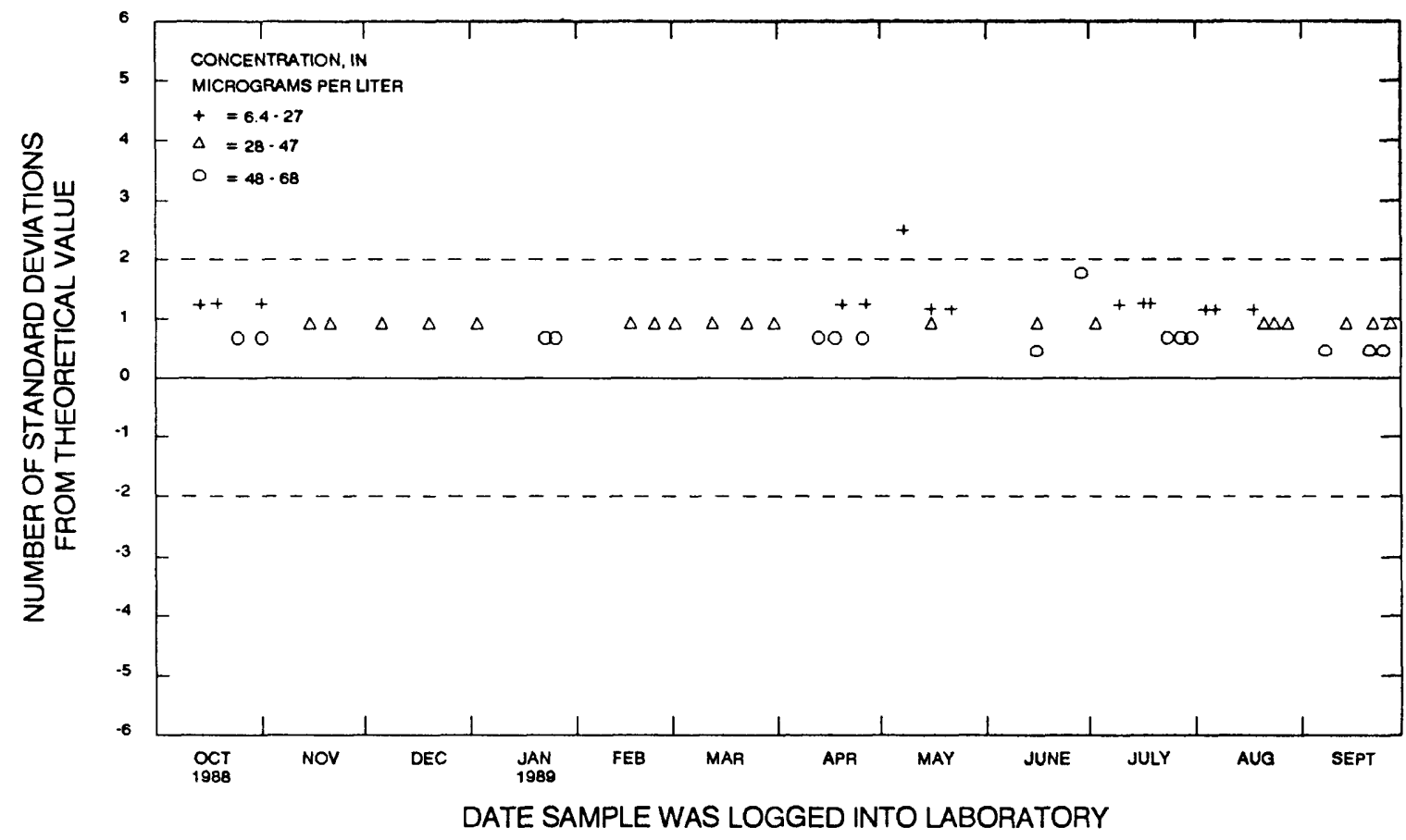

Figure 8.-- Barium, total recoverable, (atomic absorption spectrometry) data from the National Water Quality Laboratory. 


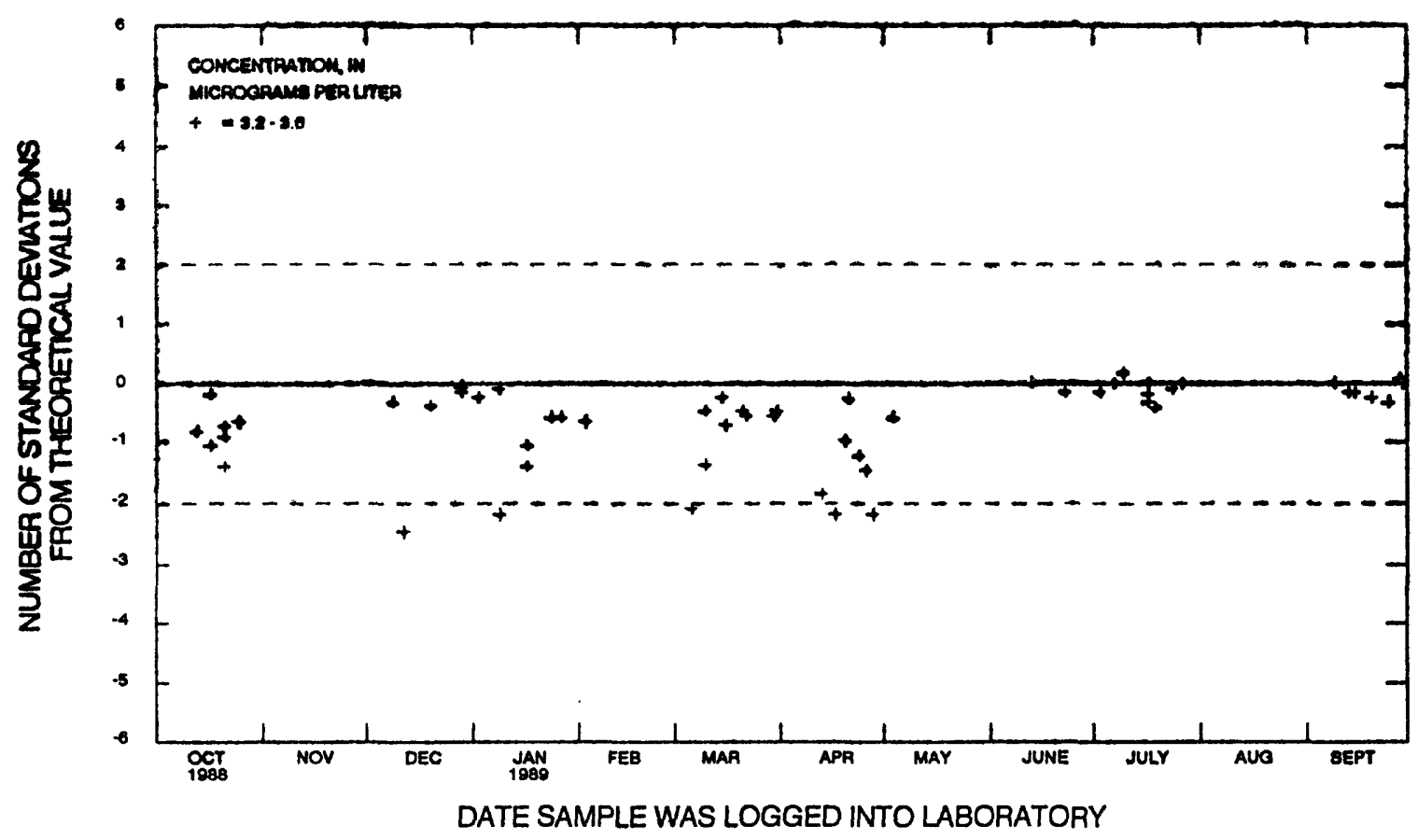

Figure 9.--Beryllium, dlssolved, (Inductively coupled plasma emission spectrometry) data from the National Water Quality Laboratory.

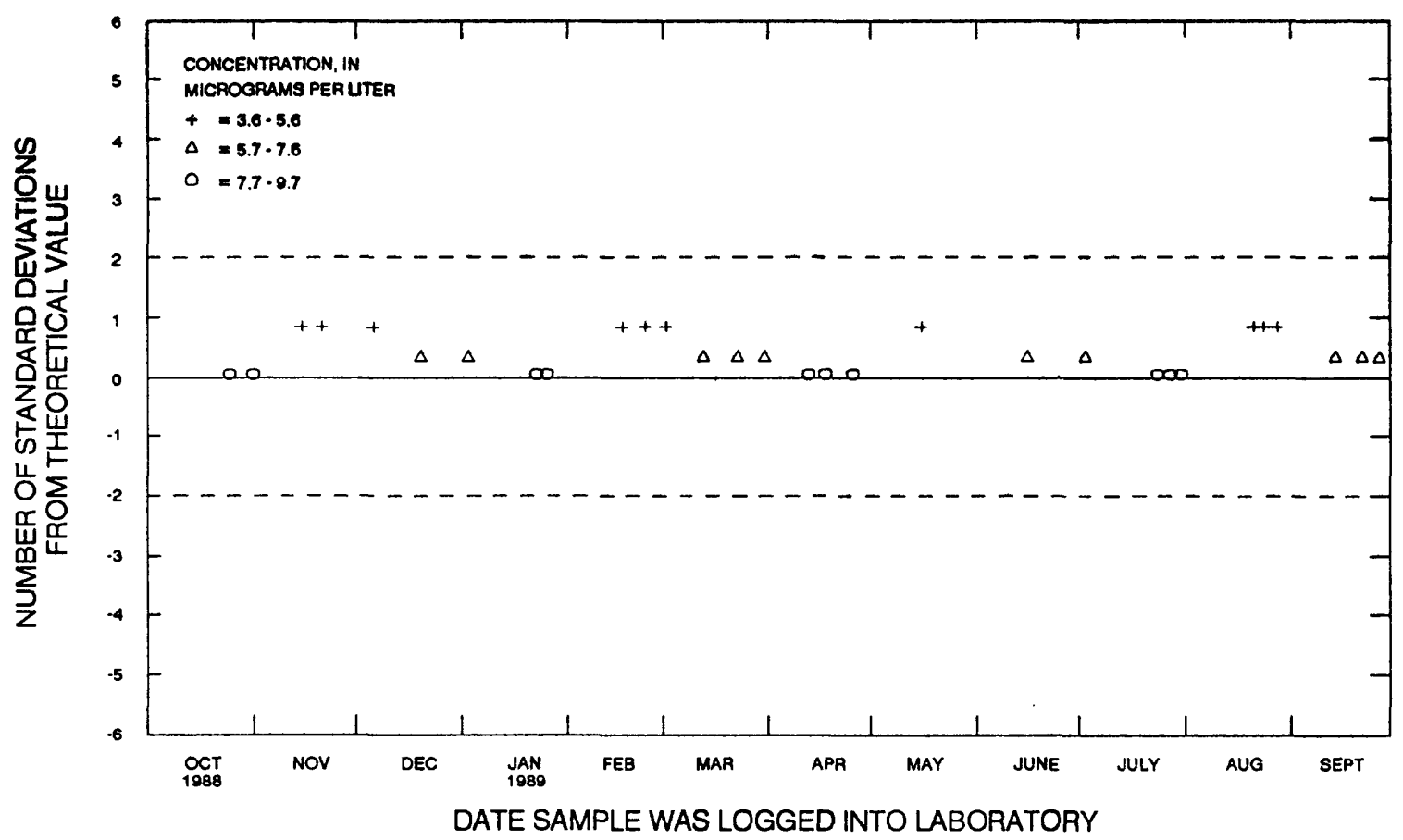

Figure 10.--Beryllium, total recoverabie, (atomic absorption spectrometry) data from the National Water Quality Laboratory. 


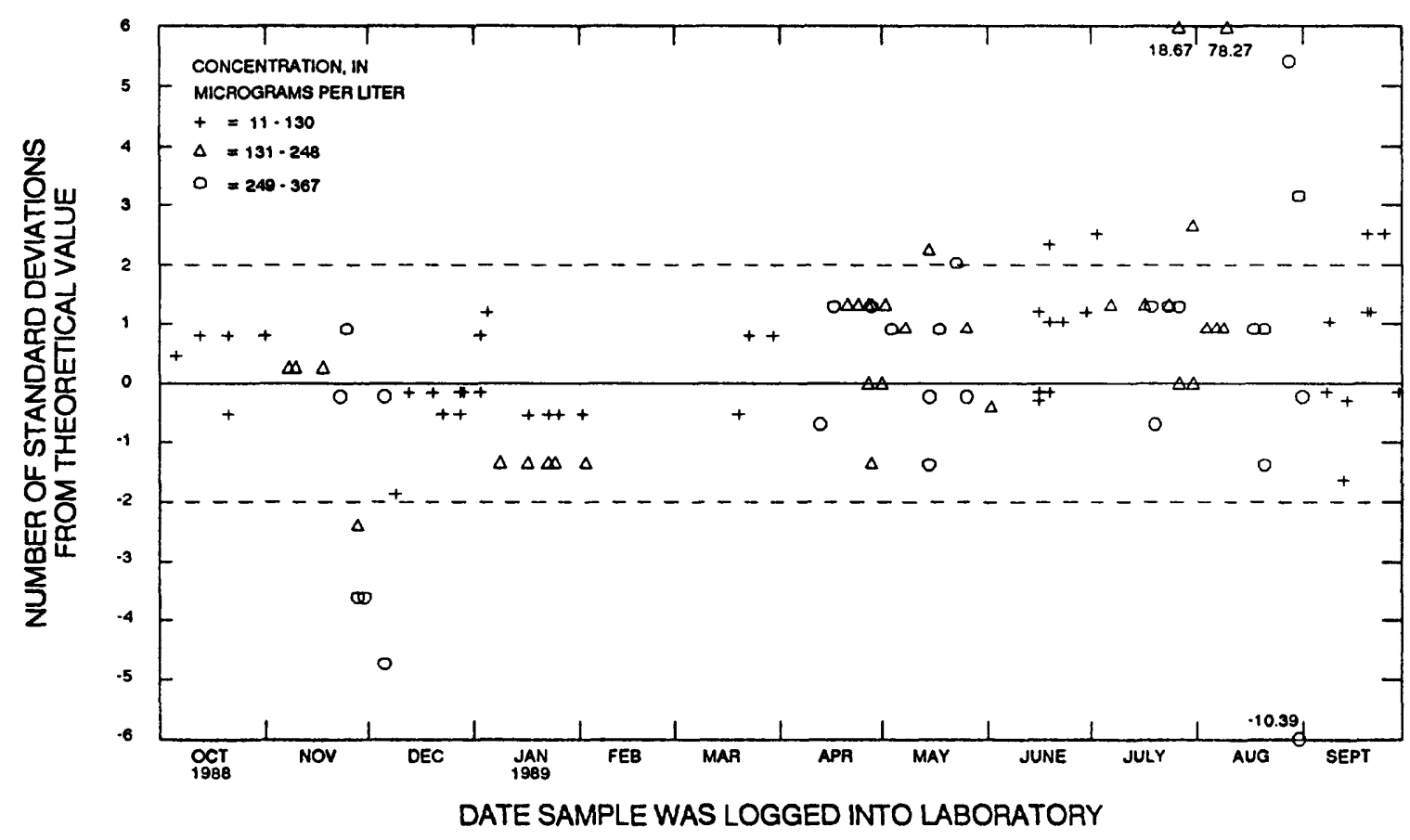

Figure 11.-- Boron, dissolved, (direct current plasma emission spectrometry) data from the National Water Quality Laboratory.

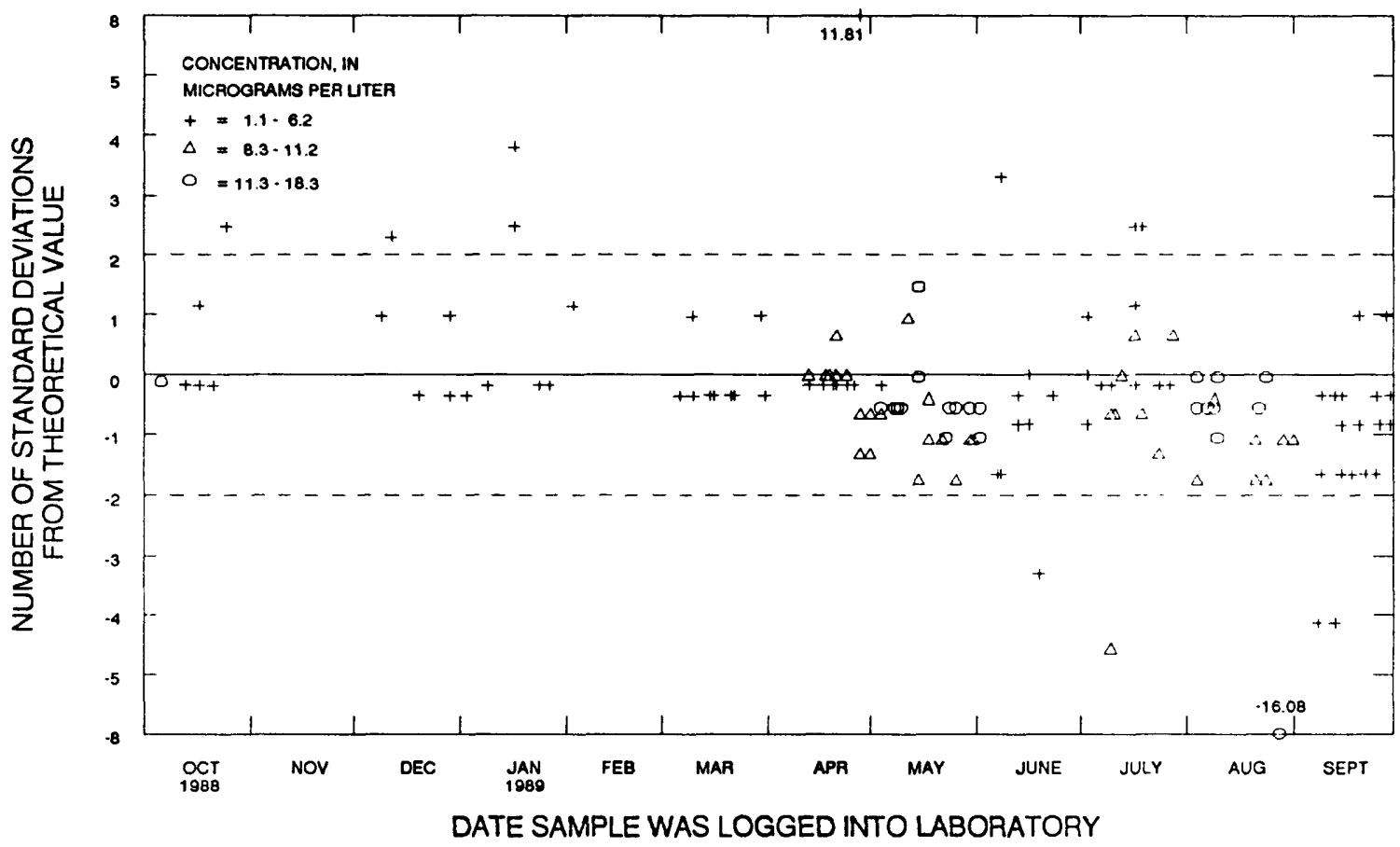

Figure 12.-- Cadmium, dissolved, (inductively coupled plasma emlssion spectrometry) data from the National Water Quality Laboratory. 


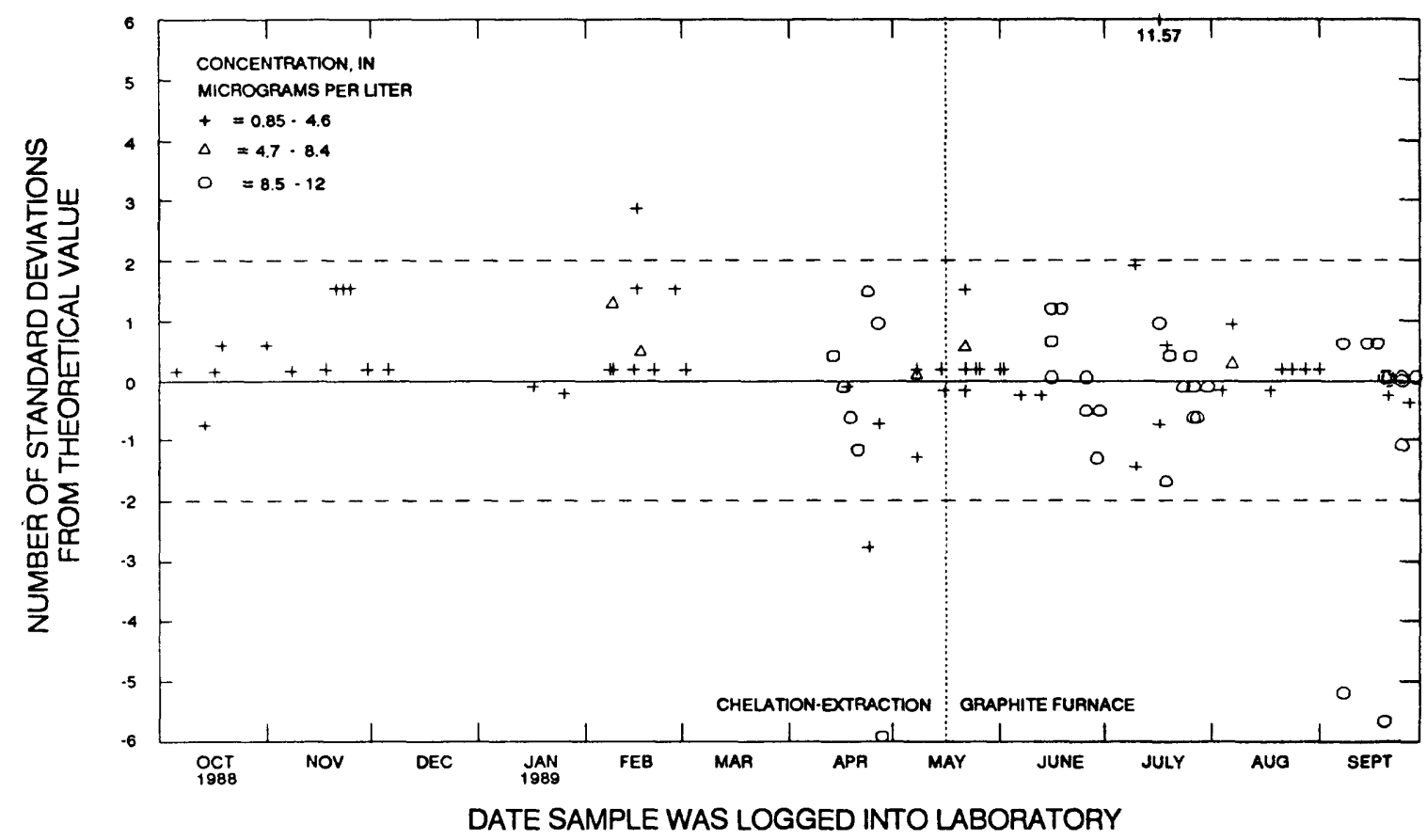

Figure 13.-- Cadmlum, dlssolved, (atomic absorption spectrometry; chelation-extraction or graphlte furnace) data from the Natlonal Water Quality Laboratory.

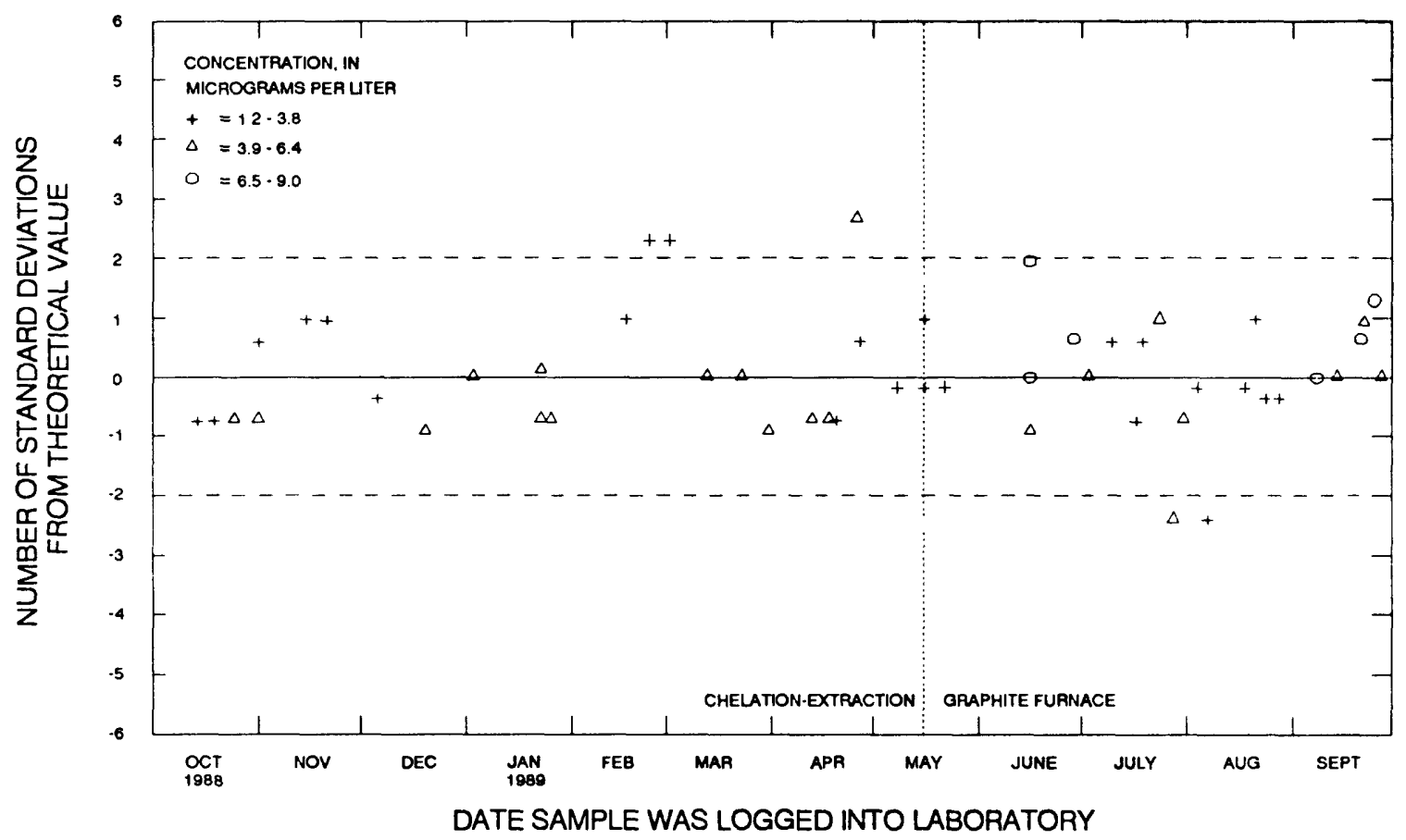

Figure 14.-- Cadmium, total recoverabie, (atomlc absorption spectrometry; chelation-extraction or graphite furnace) data from the Natlonal Water Quality Laboratory. 


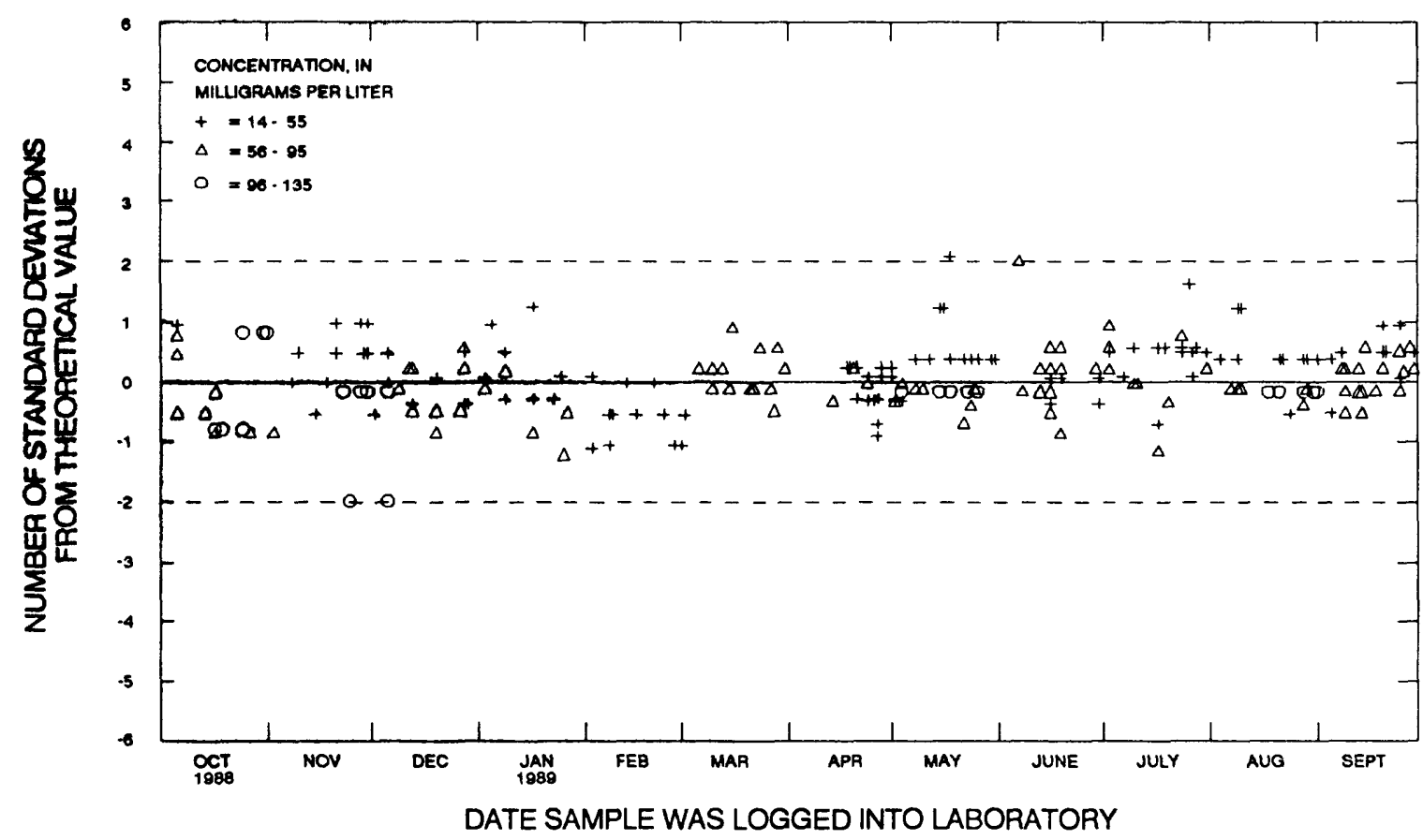

Figure 15.-- Calcium, dissolved, (Inductively coupled plasma emission spectrometry) data from the Natlonal Water Quality Laboratory.

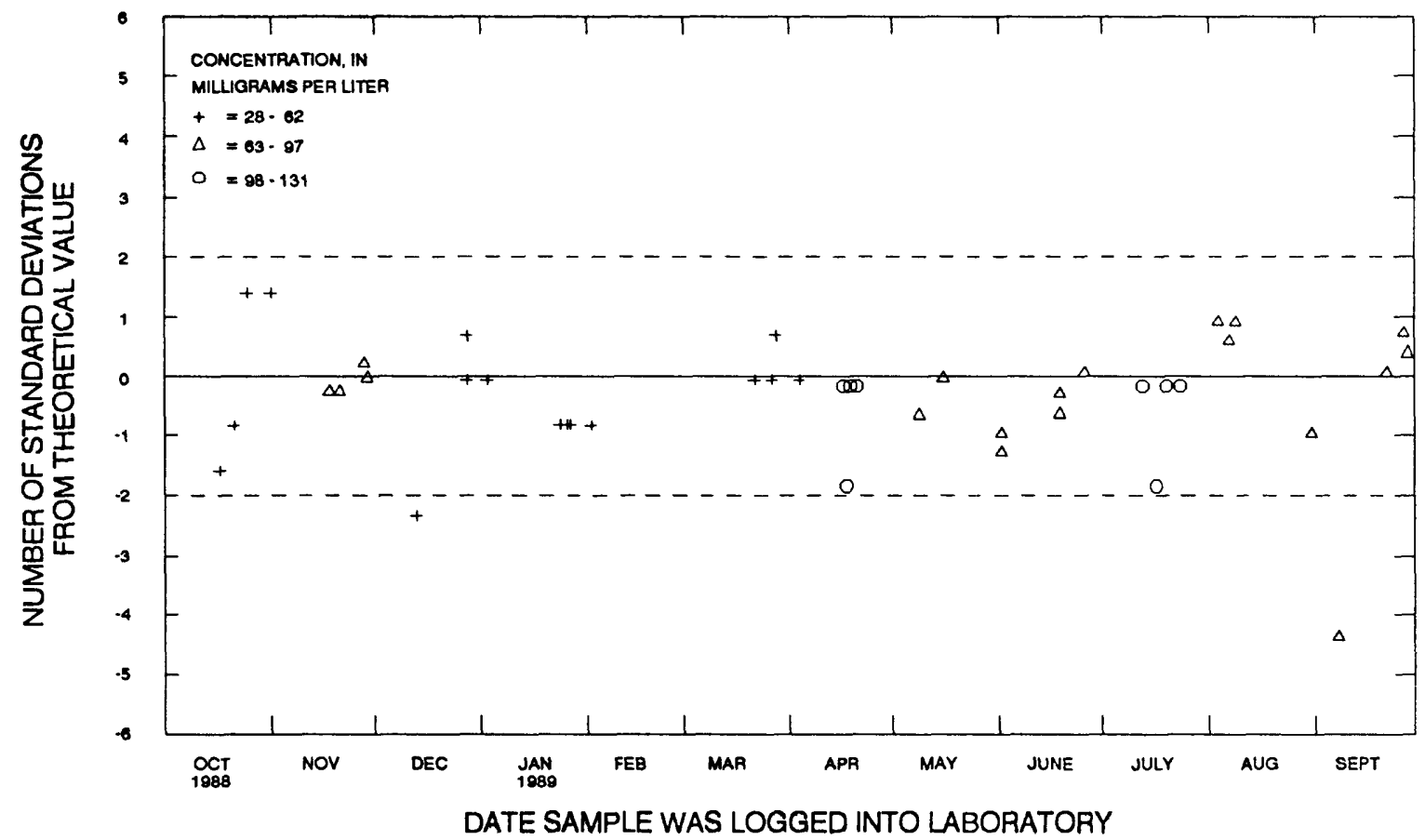

Figure 16.-- Calclum, dissolved, (atomic absorption spectrometry)

data from the National Water Quality Laboratory. 


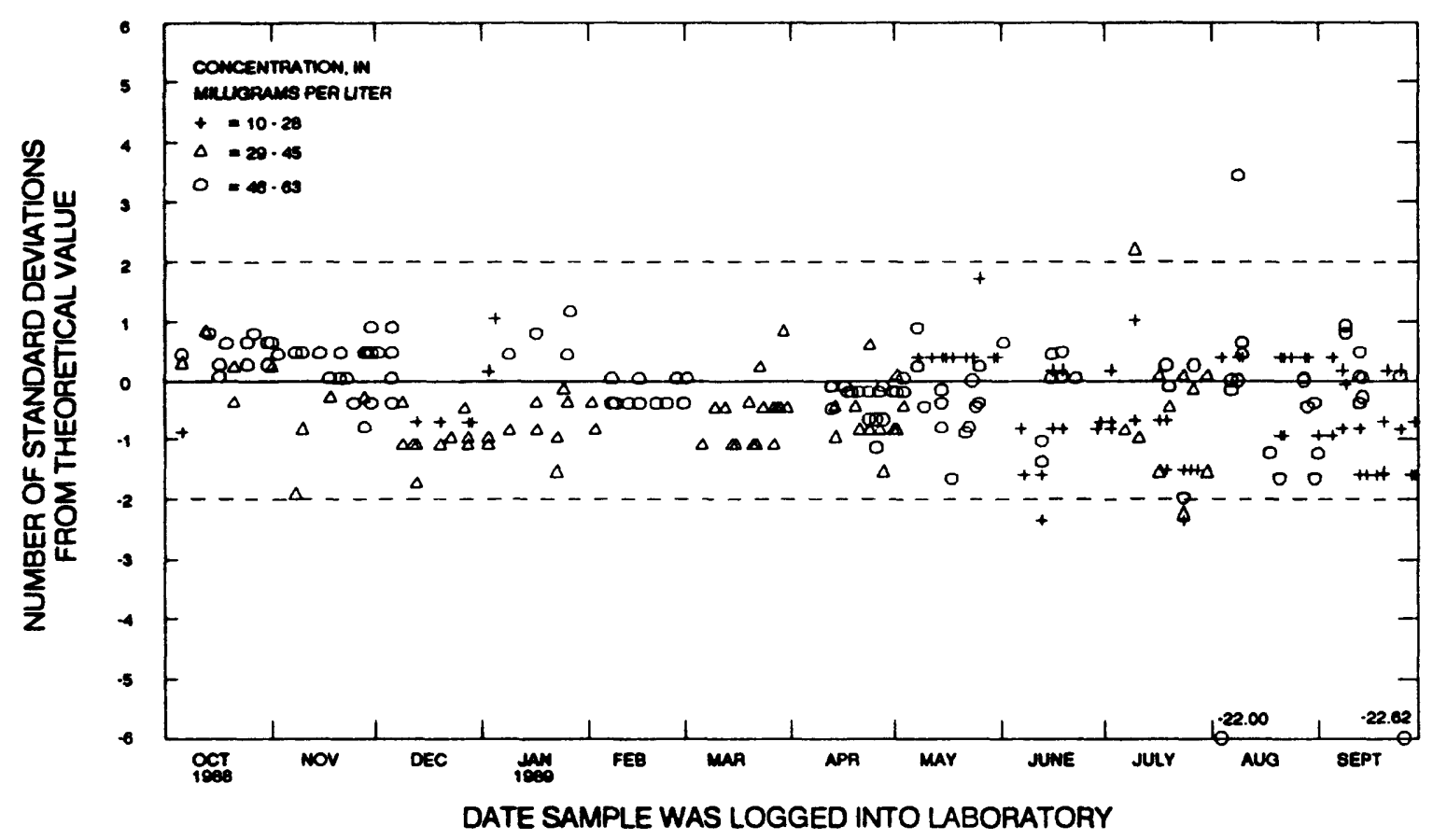

Flgure 17.-- Chlorlde, dissolved, (colorimetric)

data from the National Water Quality Laboratory.

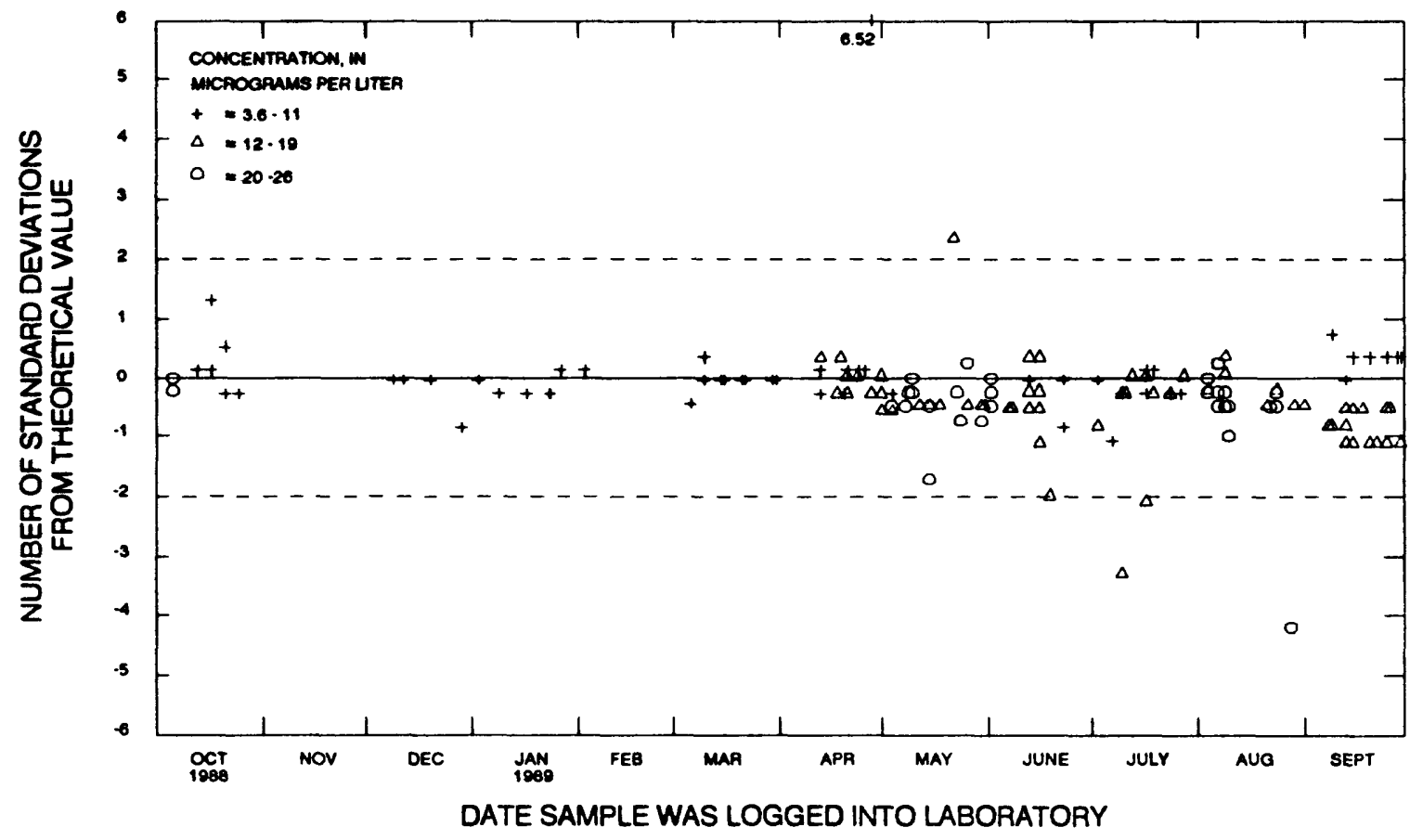

Figure 18.-- Chromium, dissolved, (Inductlvely coupled plasma emission spectrometry) data from the National Water Quality Laboratory. 


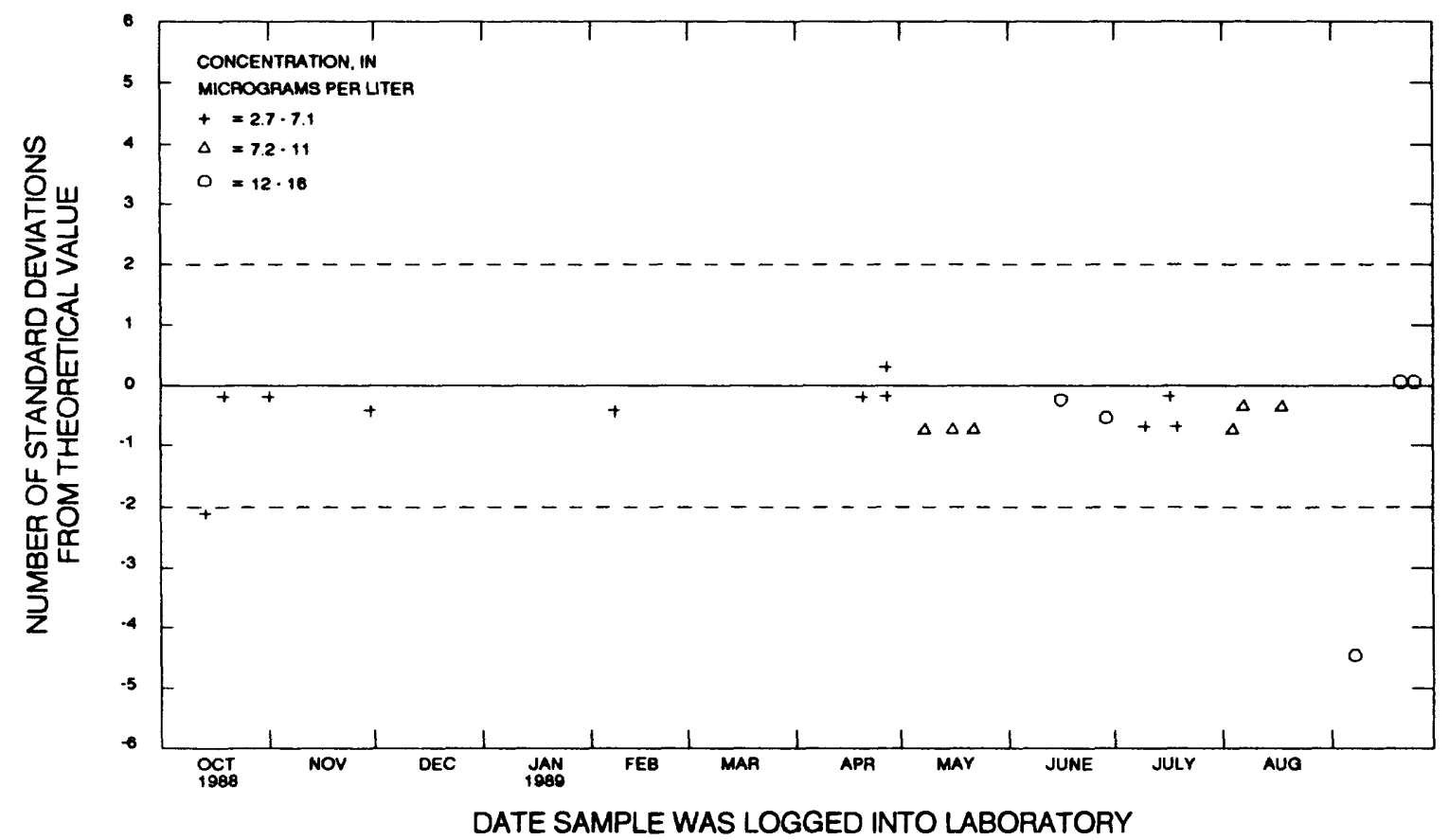

Figure 19.-- Chromium, dissolved, (direct current plasma emission spectrometry) data from the National Water Quality Laboratory.

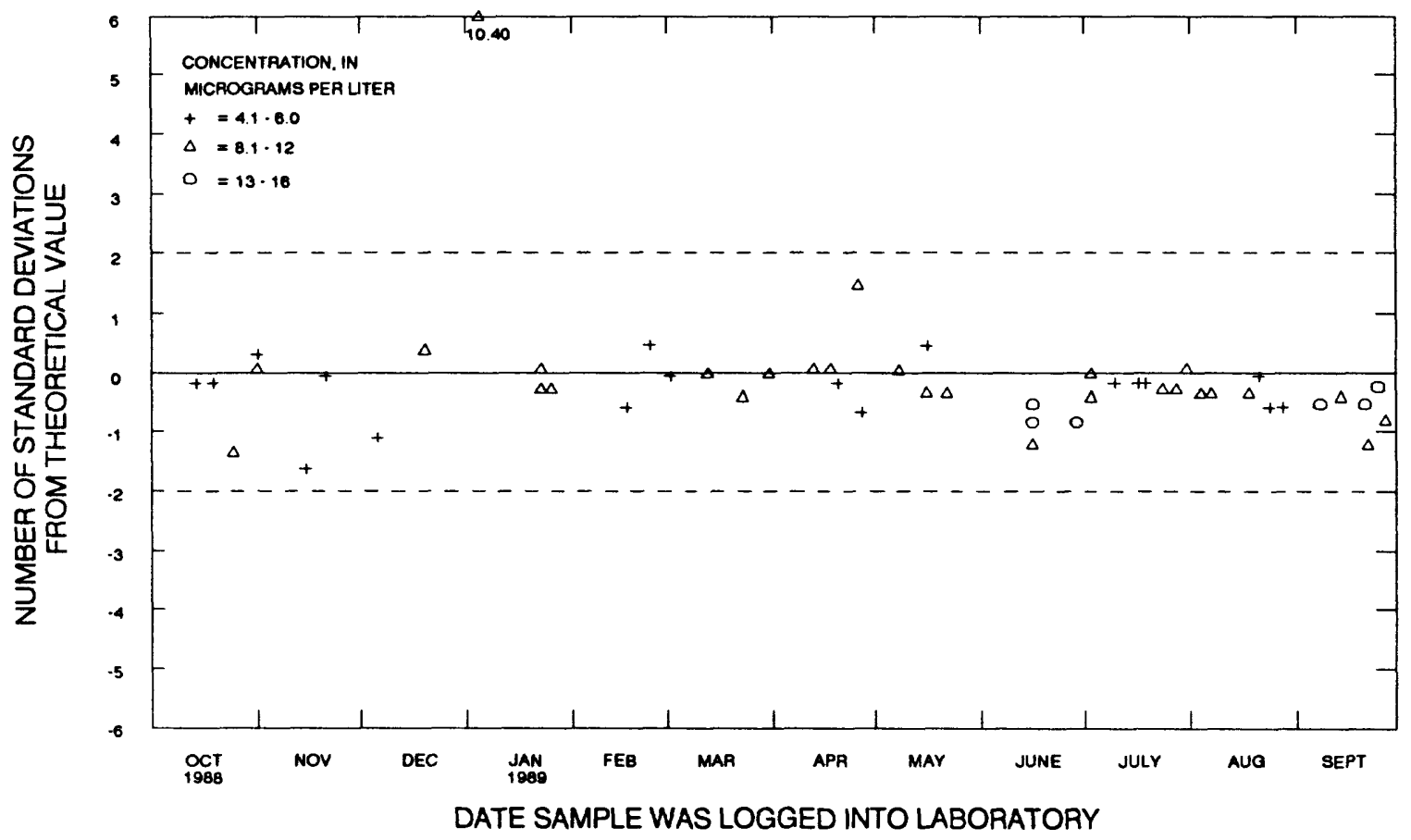

Figure 20.-- Chromium, total recoverable, (direct current plasma emission spectrometry) data from the National Water Quality Laboratory. 


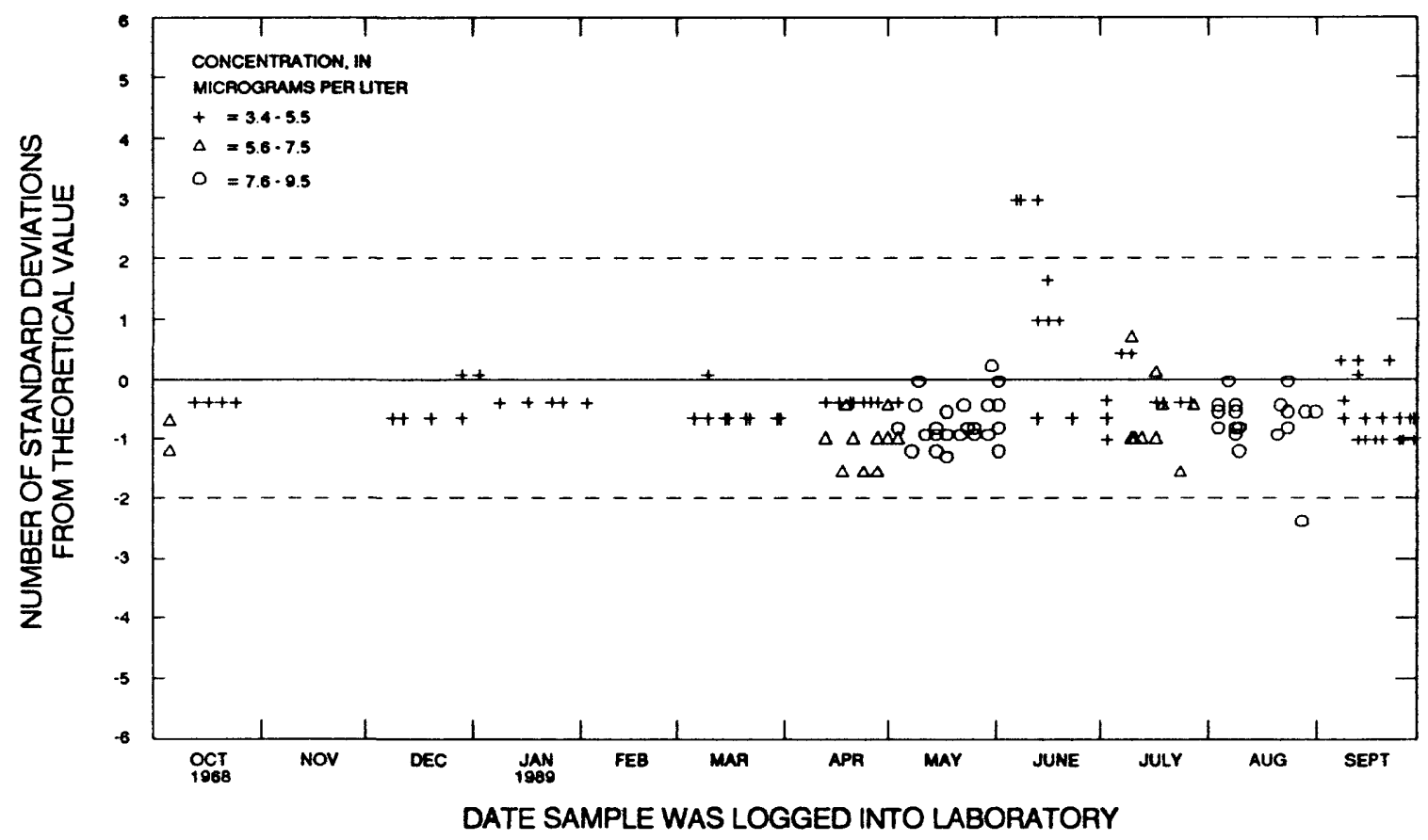

Figure 21.-- Cobalt, dissolved (inductlvely coupled plasma emission spectrometry) data from the National Water Quality Laboratory.

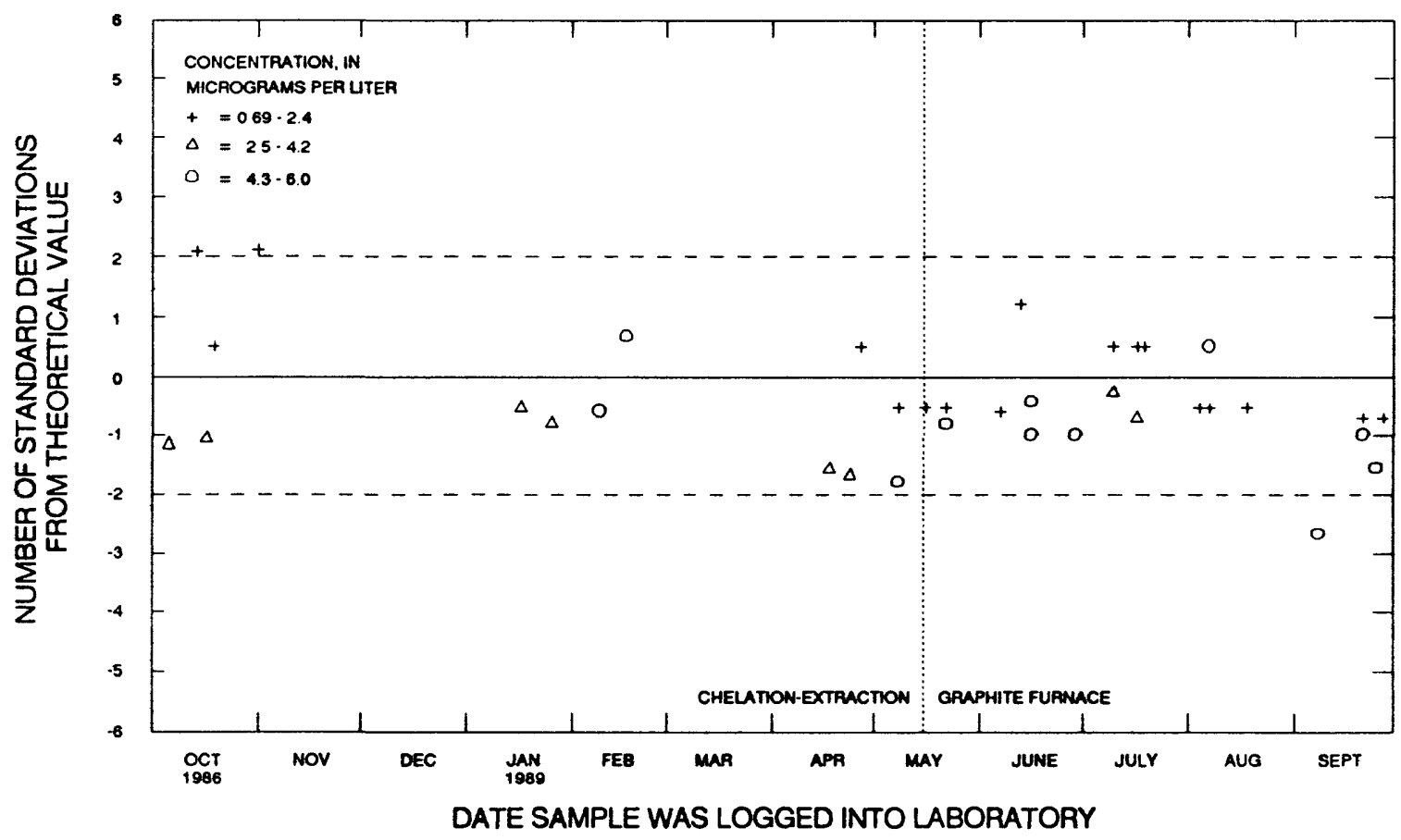

Figure 22.-- Cobalt, dissolved, (atomic absorption spectrometry; chelation-extraction or graphite furnace) data from the National Water Quality Laboratory. 


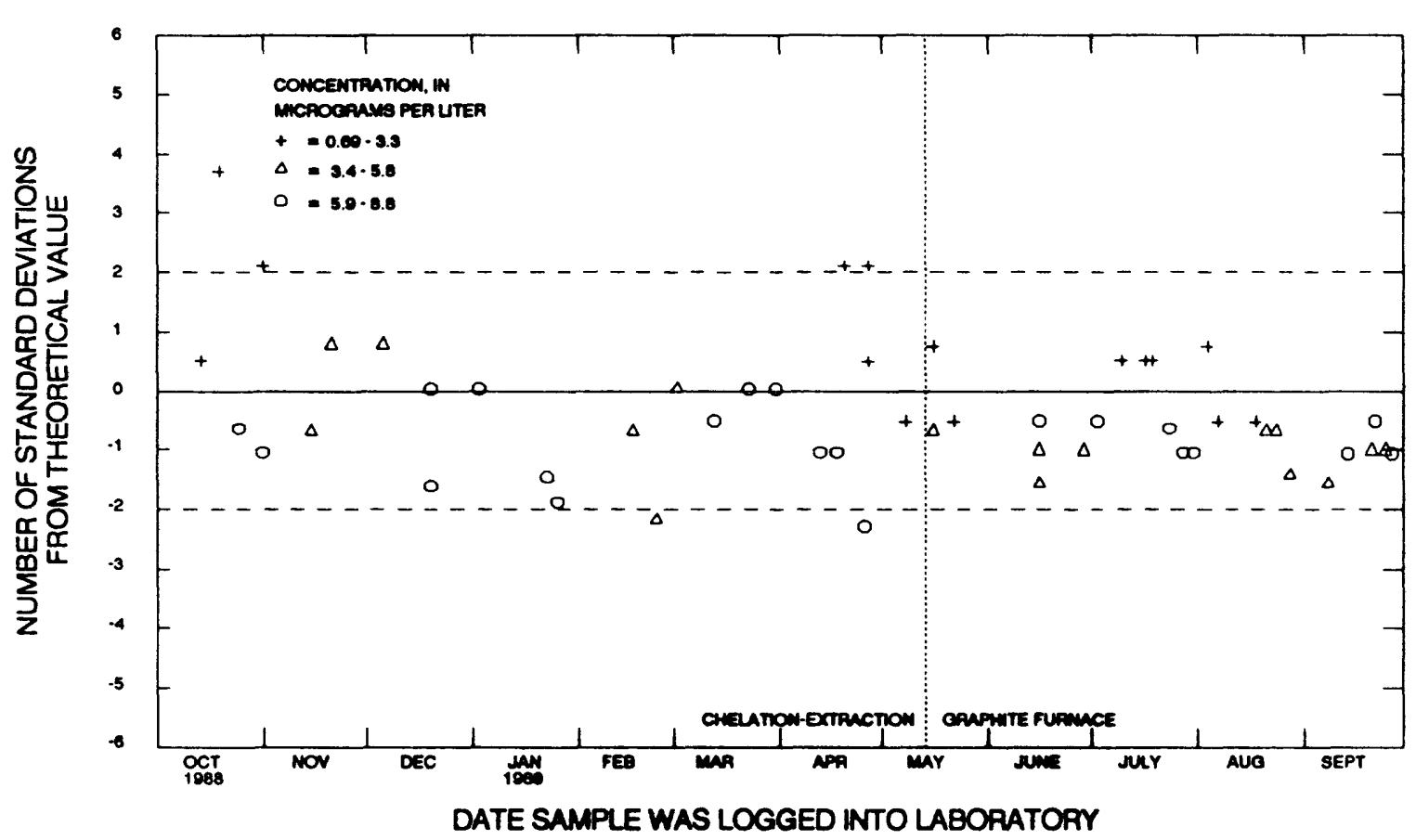

Figure 23.-- Cobalt, total recoverable,

(atomic absorption epectrometry; chelation-extraction or graphite furnace)

data from the National Water Quality Laboratory.

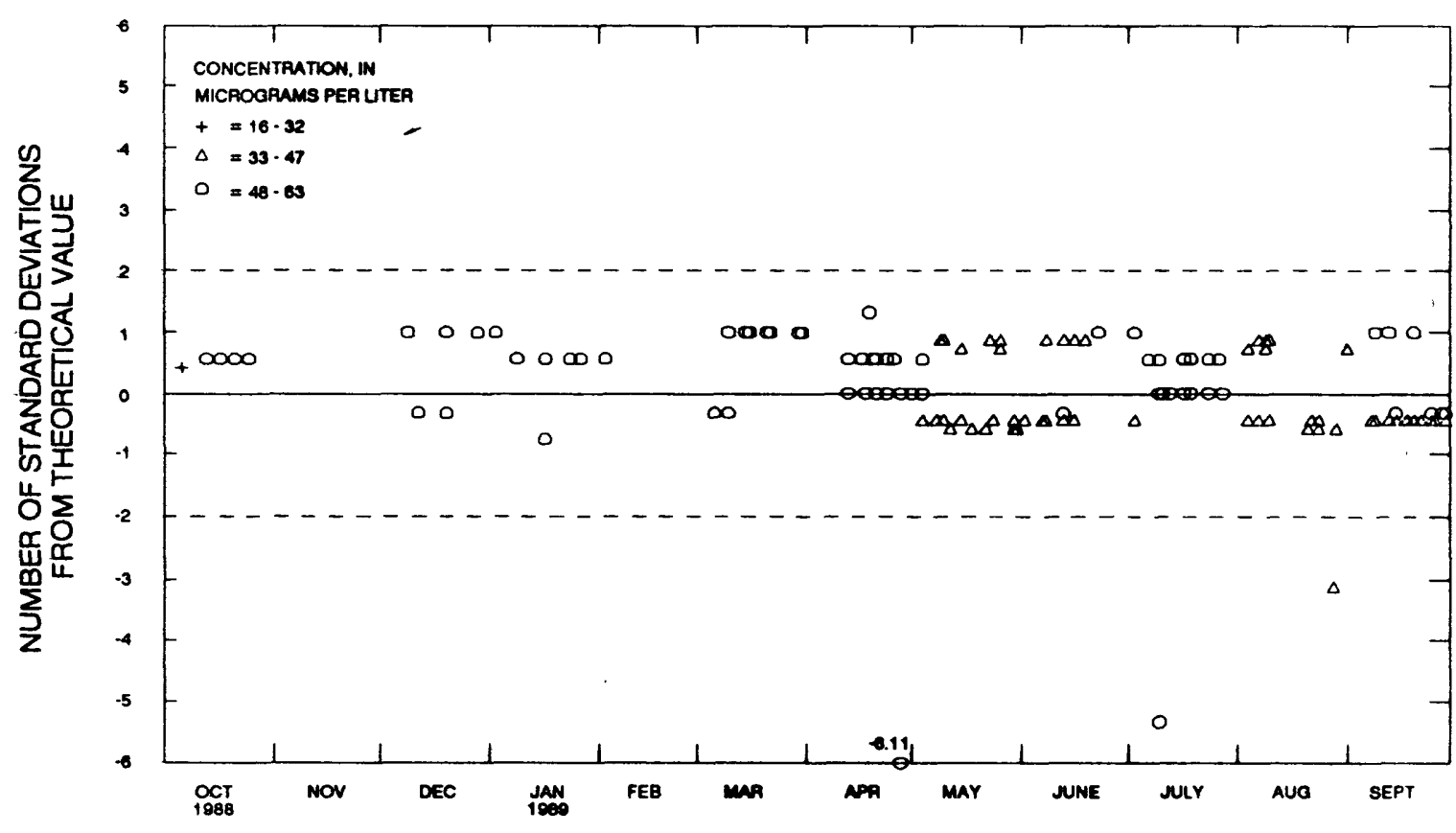

DATE SAMPLE WAS LOGGED INTO LABORATORY

Figure 24,- Copper, dissolved, (inductively coupled plasma emission spectrometry) data from the Natlonal Water Quality Laboratory. 


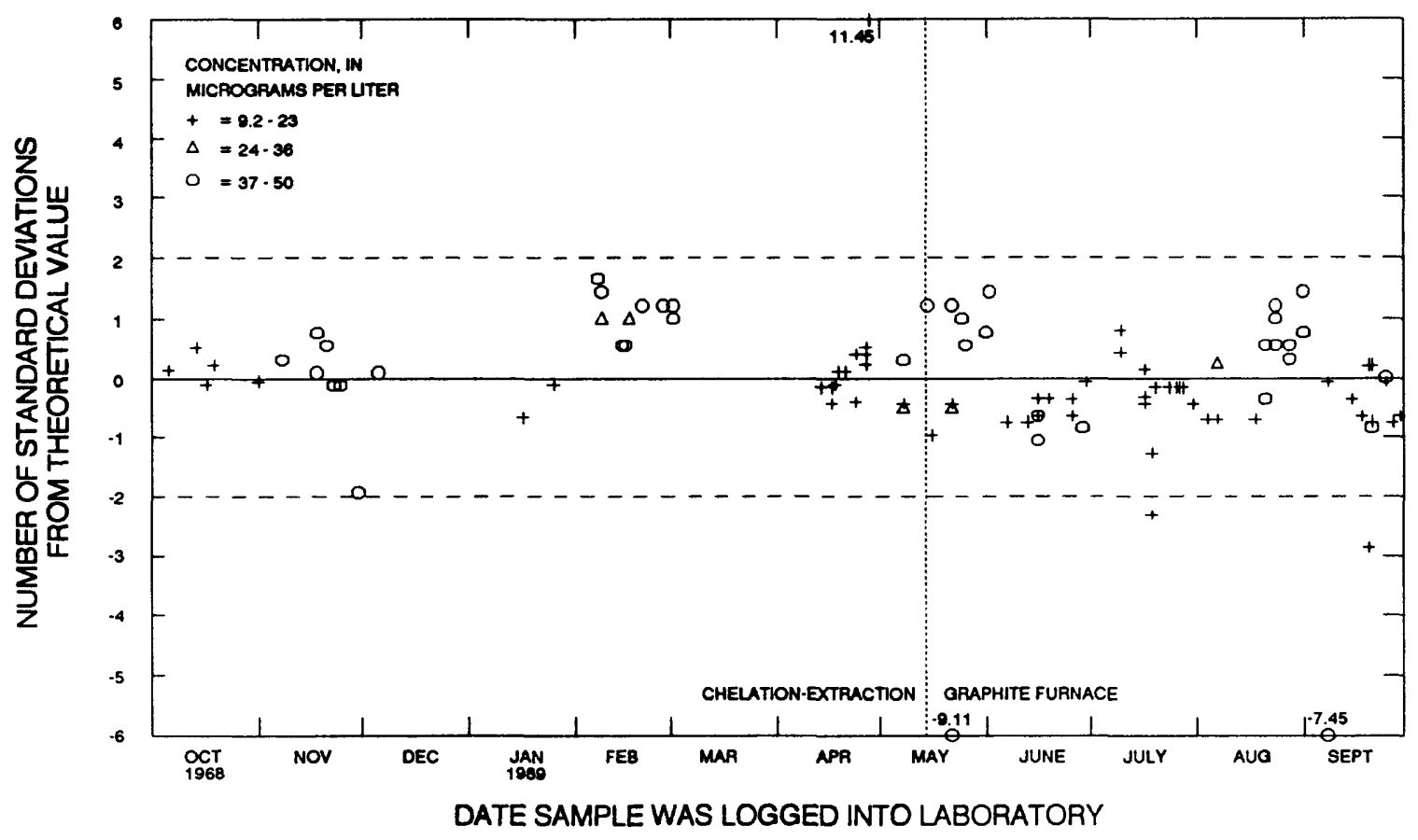

Figure 25.-- Copper, dlssolved, (atomlc absorption spectrometry; chelation-extraction or graphlte furnace)

data from the Natlonal Water Quality Laboratory.

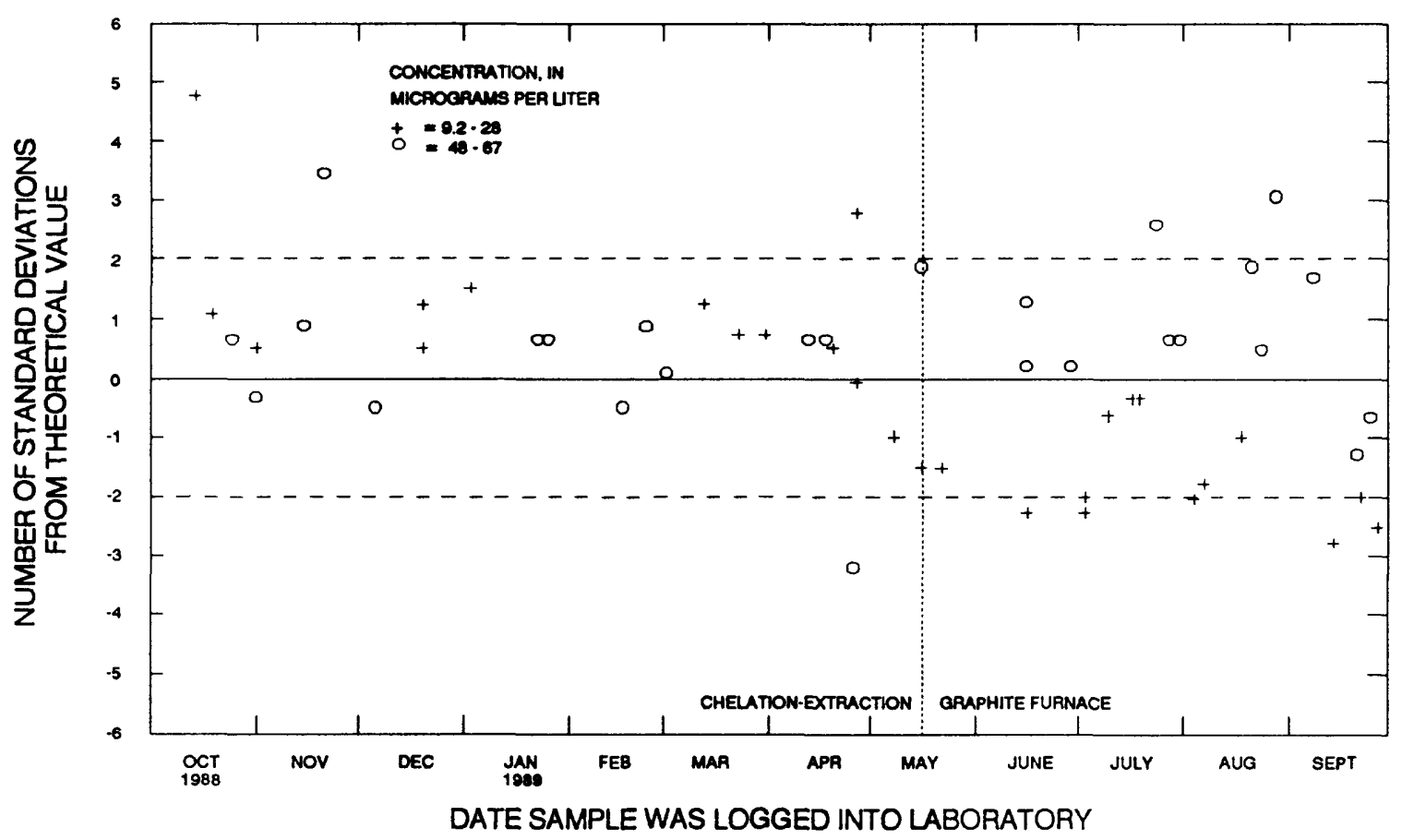

Figure 26.-- Copper, total recoverable,

(atomlc absorption spectrometry; chelation-extraction or graphlte furnace)

data from the National Water Quality Laboratory. 


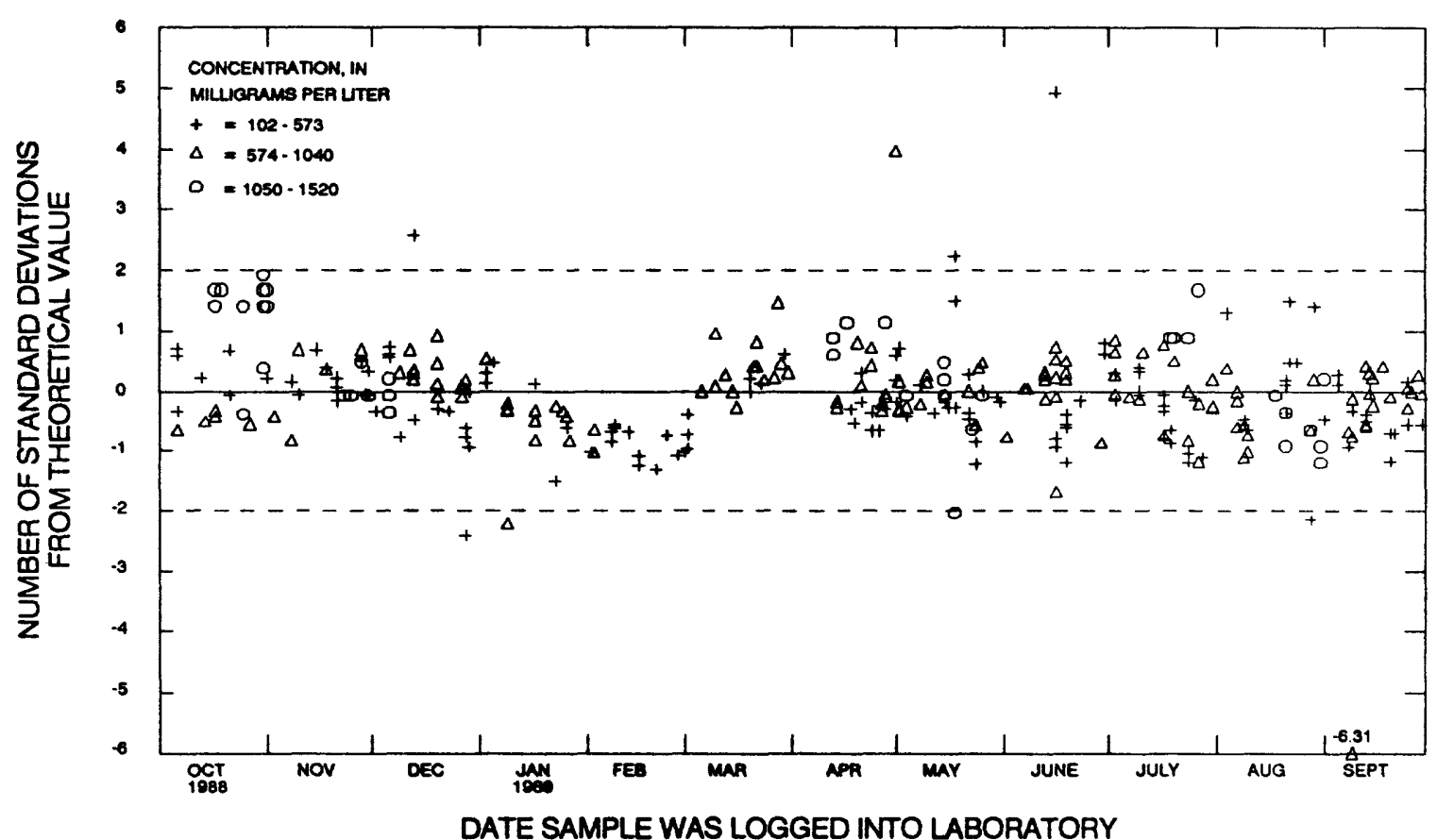

Figure 27.--Dissolved sollds, (gravlmetric)

data from the National Water Quality Laboratory.

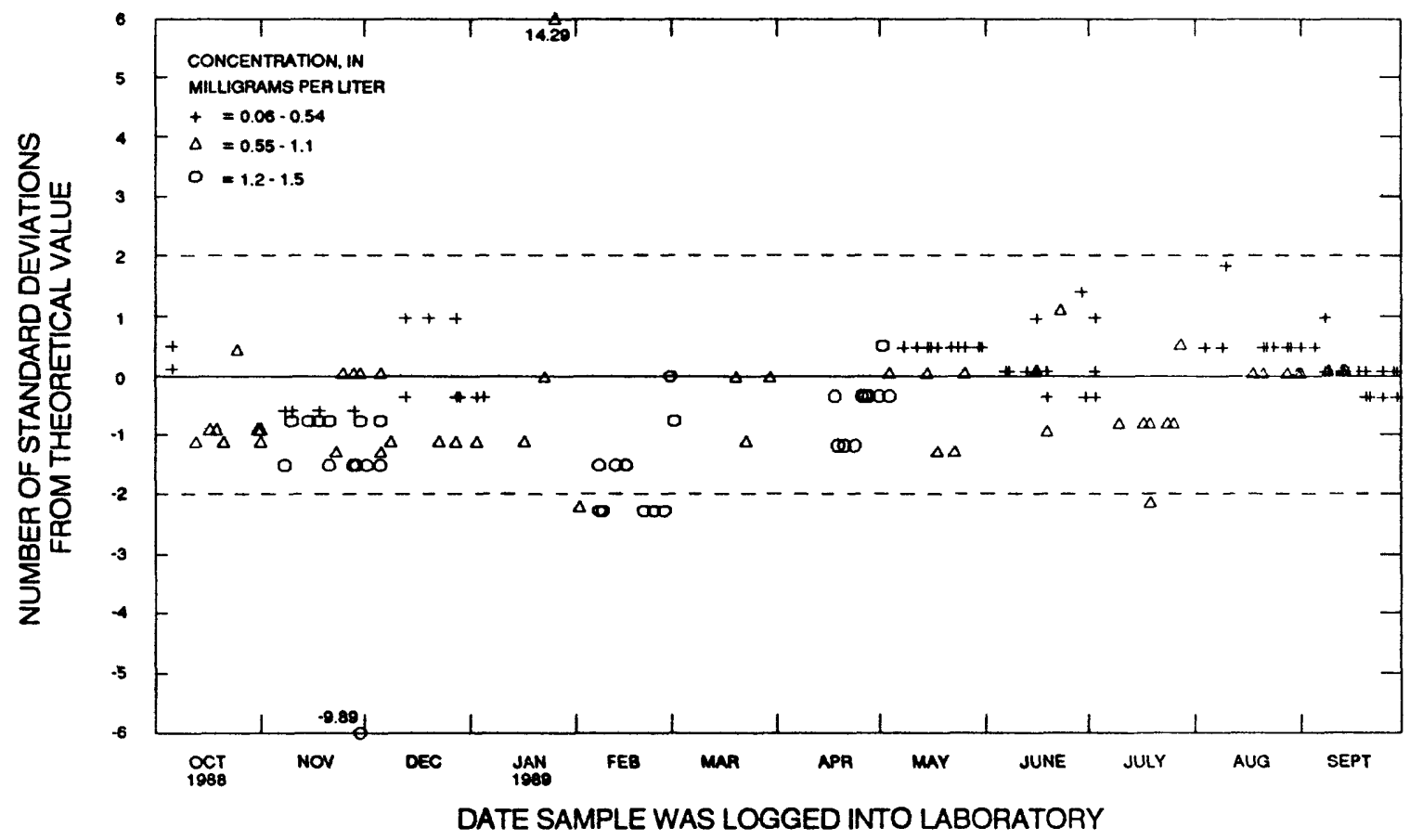

Figure 28.-- Fluoride, dissolved, (ion selective electrode) data from the National Water Quality Laboratory. 


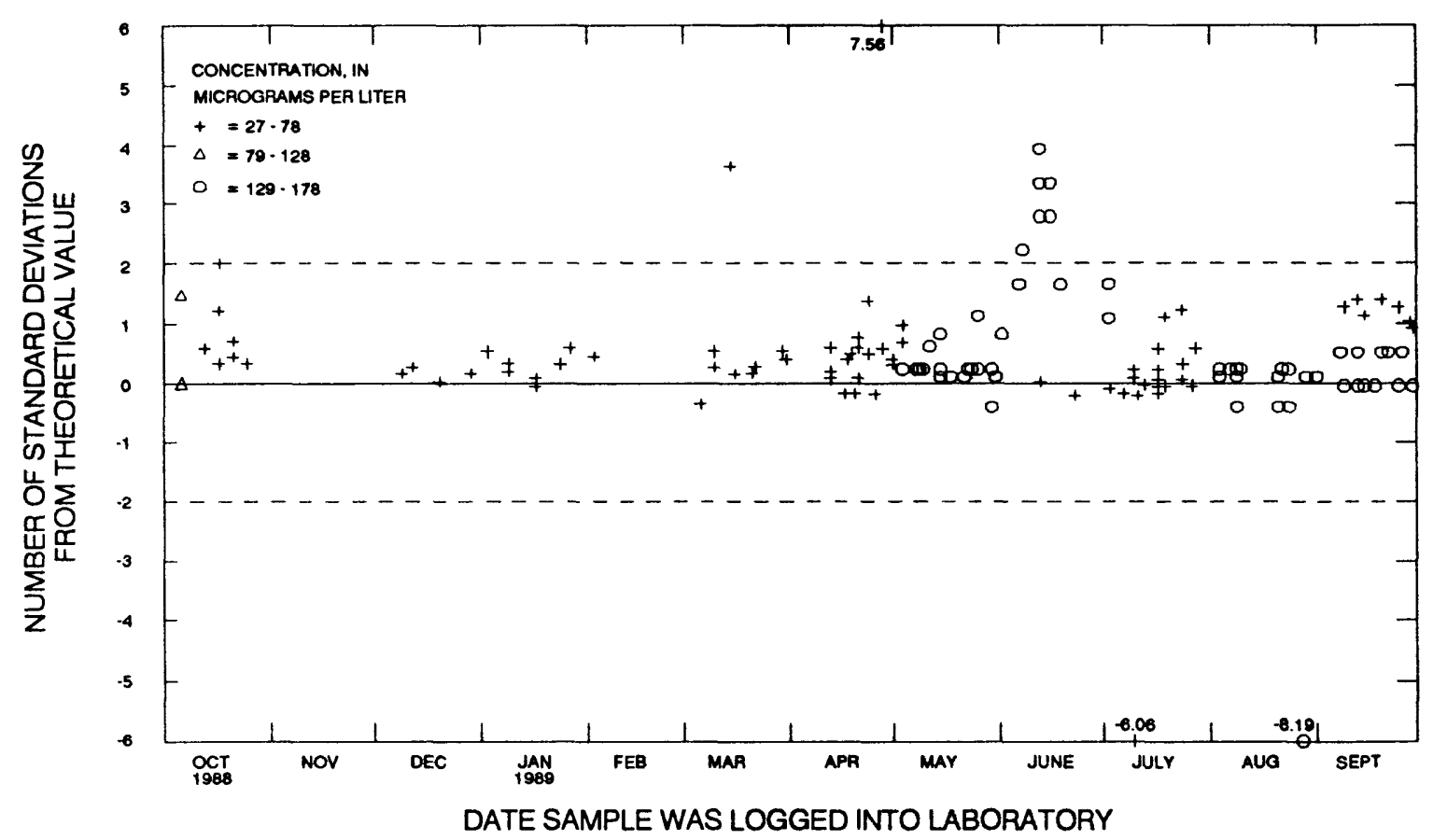

Figure 29.-- Iron, dlssolved, (inductlvely coupled plasma emission spectrometry) data from the National Water Quality Laboratory.

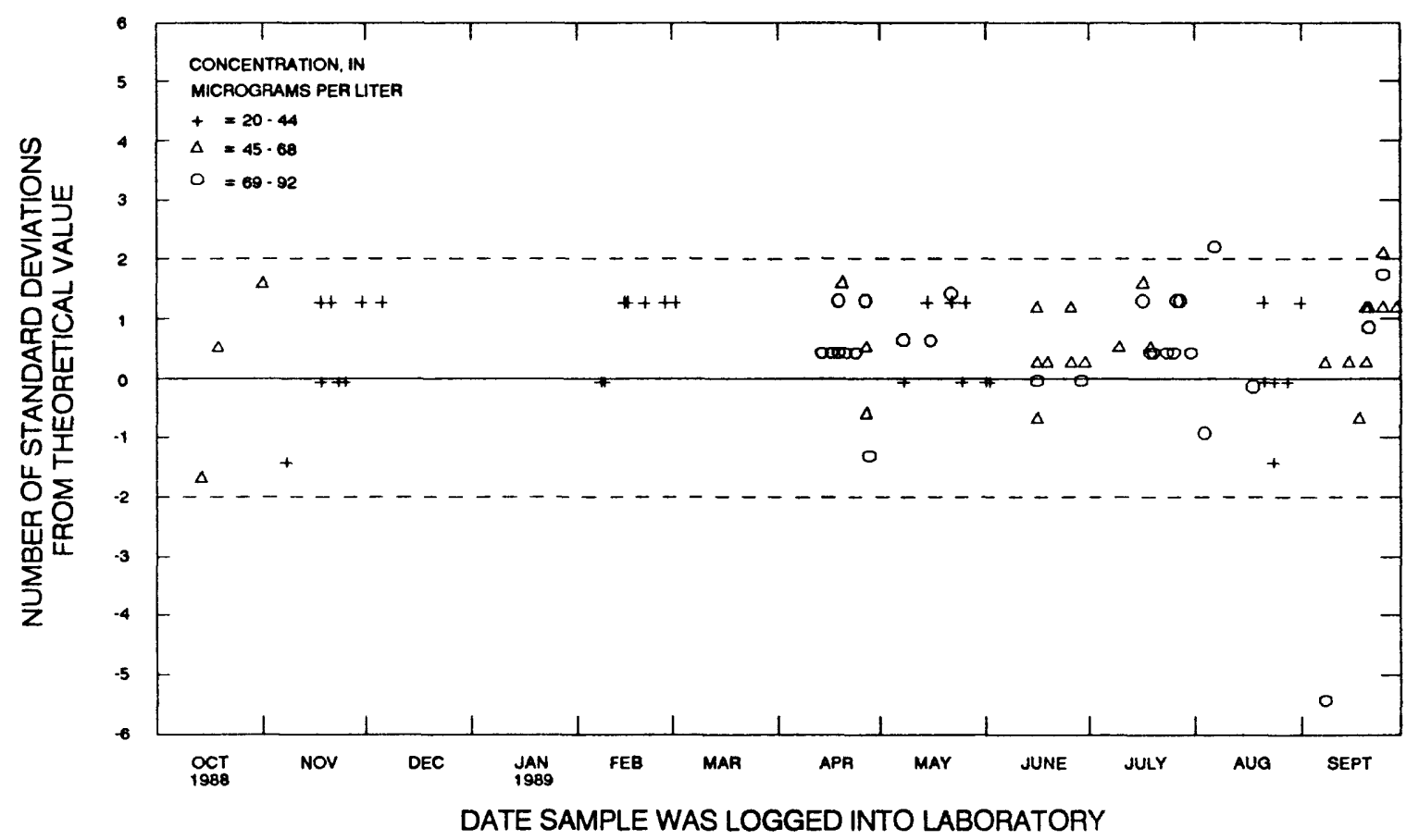

Figure 30.-- Iron, dissolved, (atomlc absorptlon spectrometry) data from the Natlonal Water Quality Laboratory. 


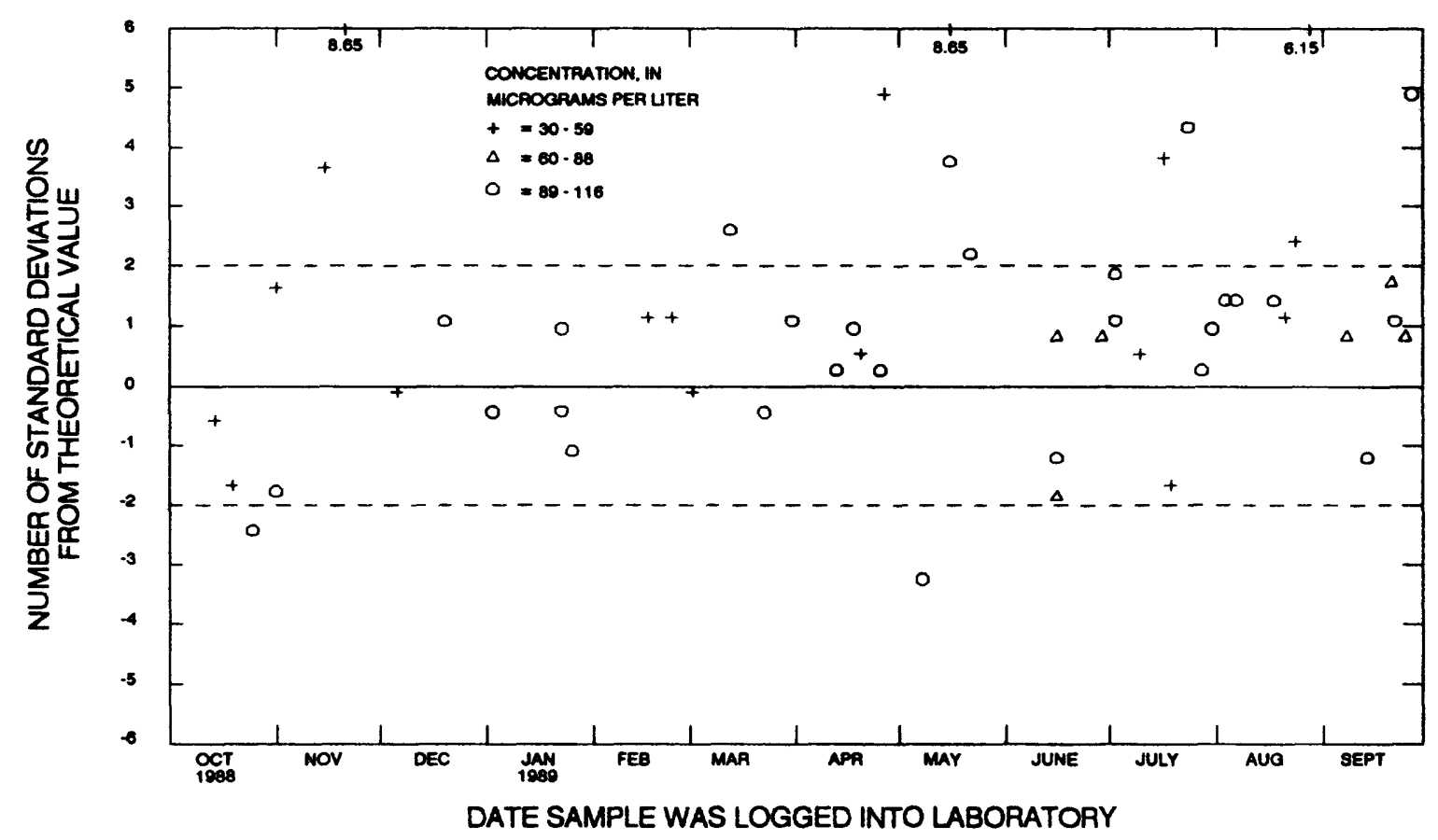

Figure 31.-- Iron, total recoverable, (atomic absorption spectrometry) data from the National Water Quality Laboratory.

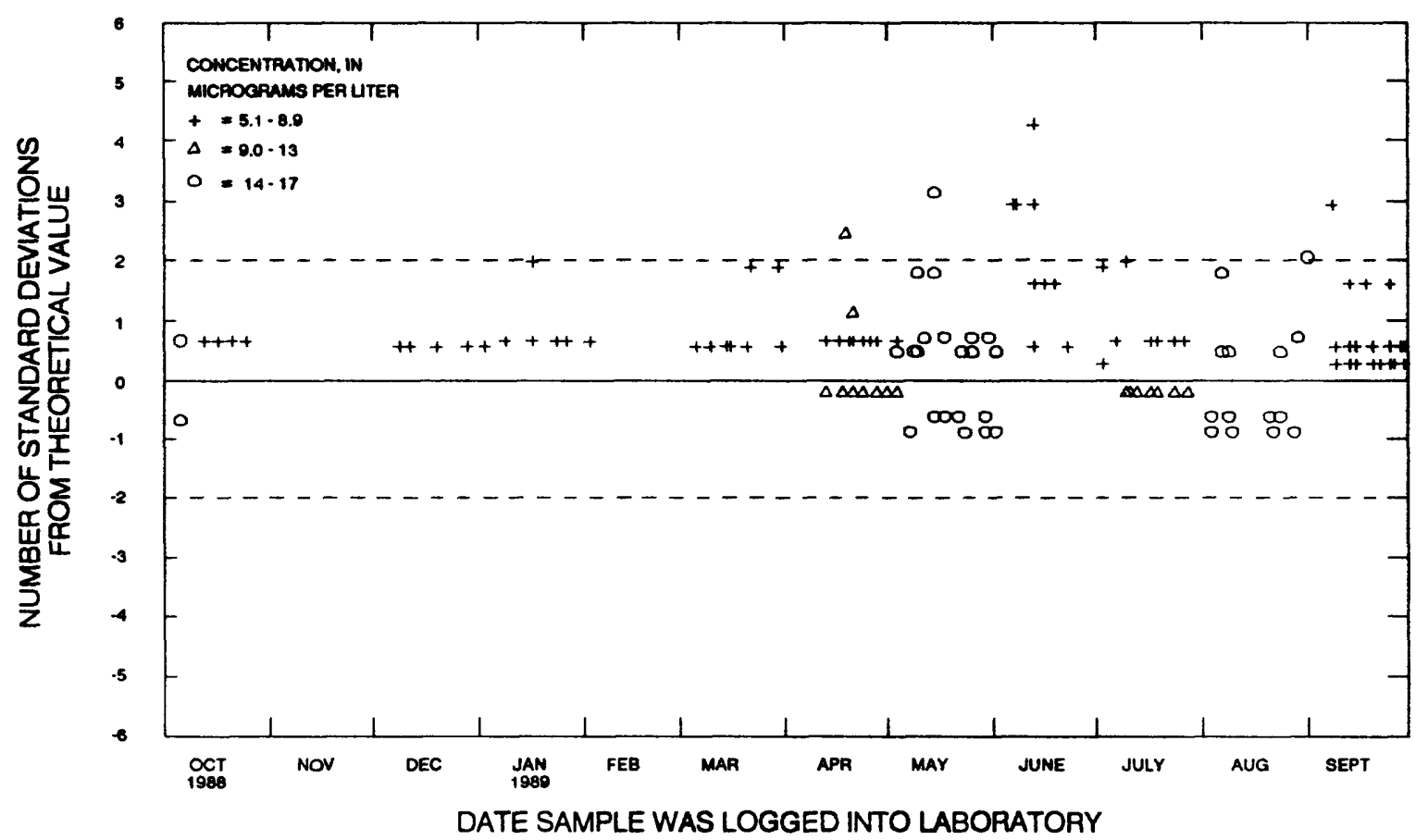

Figure 32.-- Lead, dissoived, (inductively coupled plasma emission spectrometry) data from the National Water Quality Laboratory. 


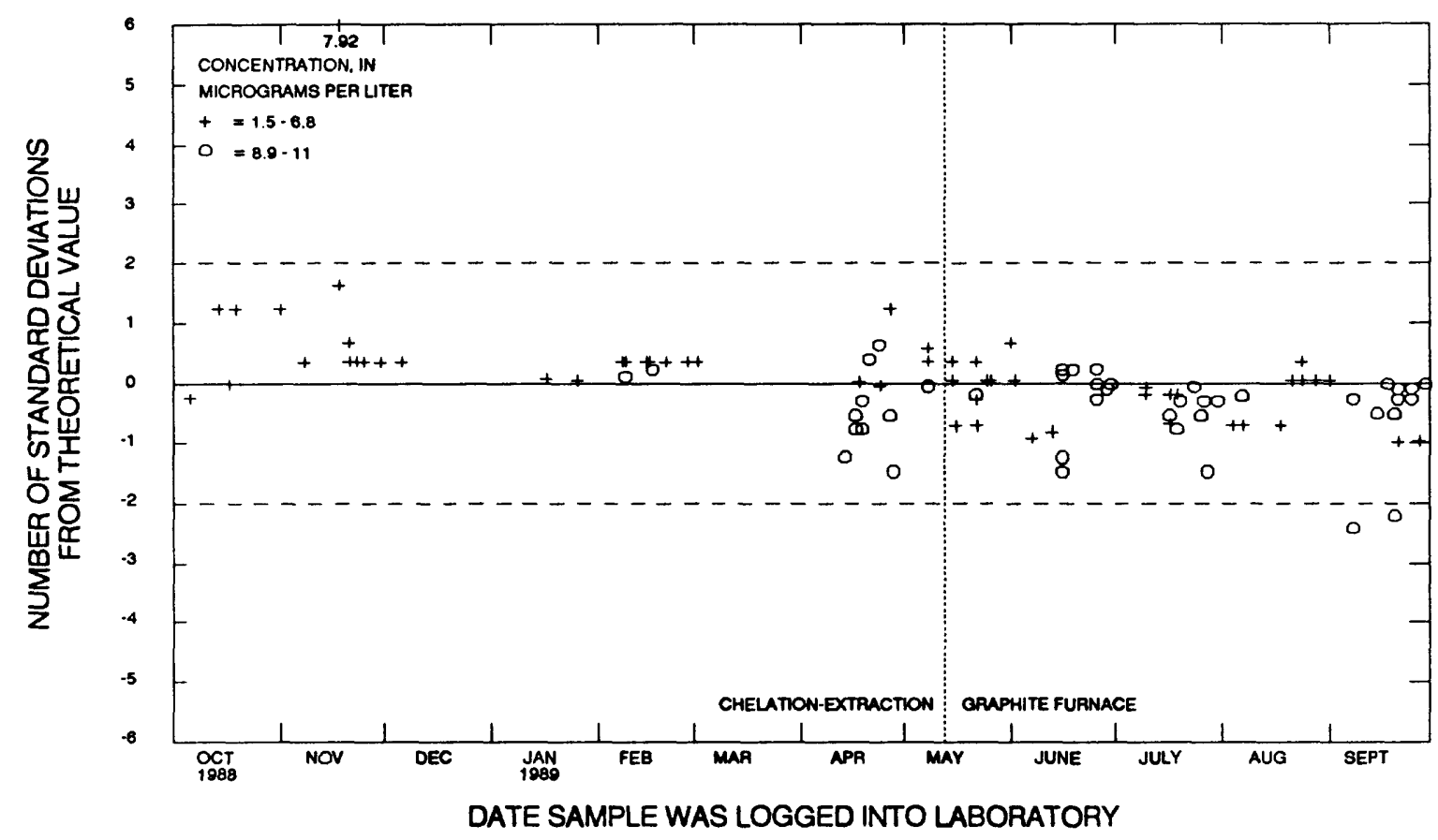

Figure 33.-- Lead, dissolved, (atomic absorption spectrometry; chelation-extraction or graphite furnace) data from the National Water Quality Laboratory.

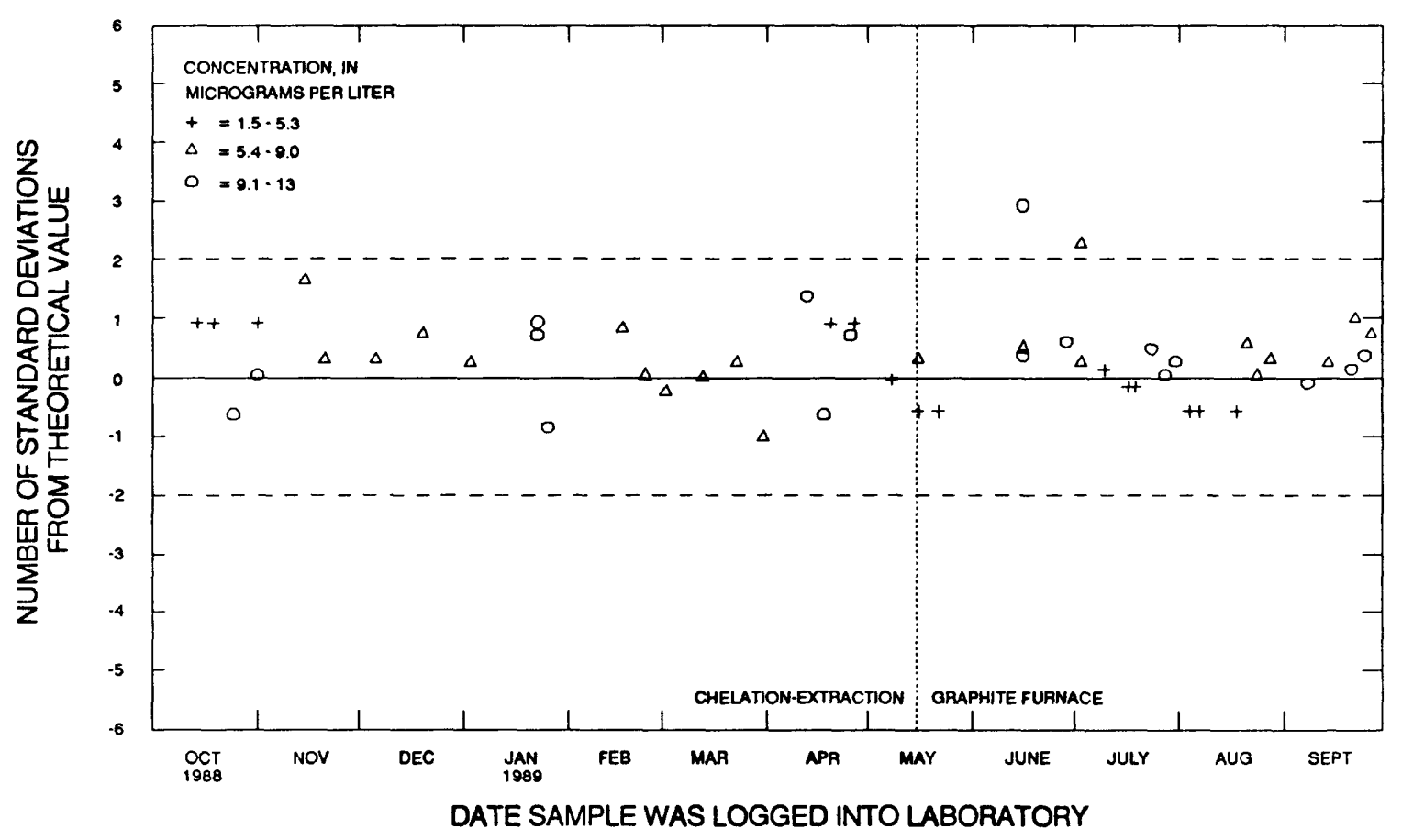

Figure 34.-- Lead, total recoverable, (atomic absorptlon spectrometry; chelation-extraction or graphite furnace) data from the National Water Quality Laboratory. 


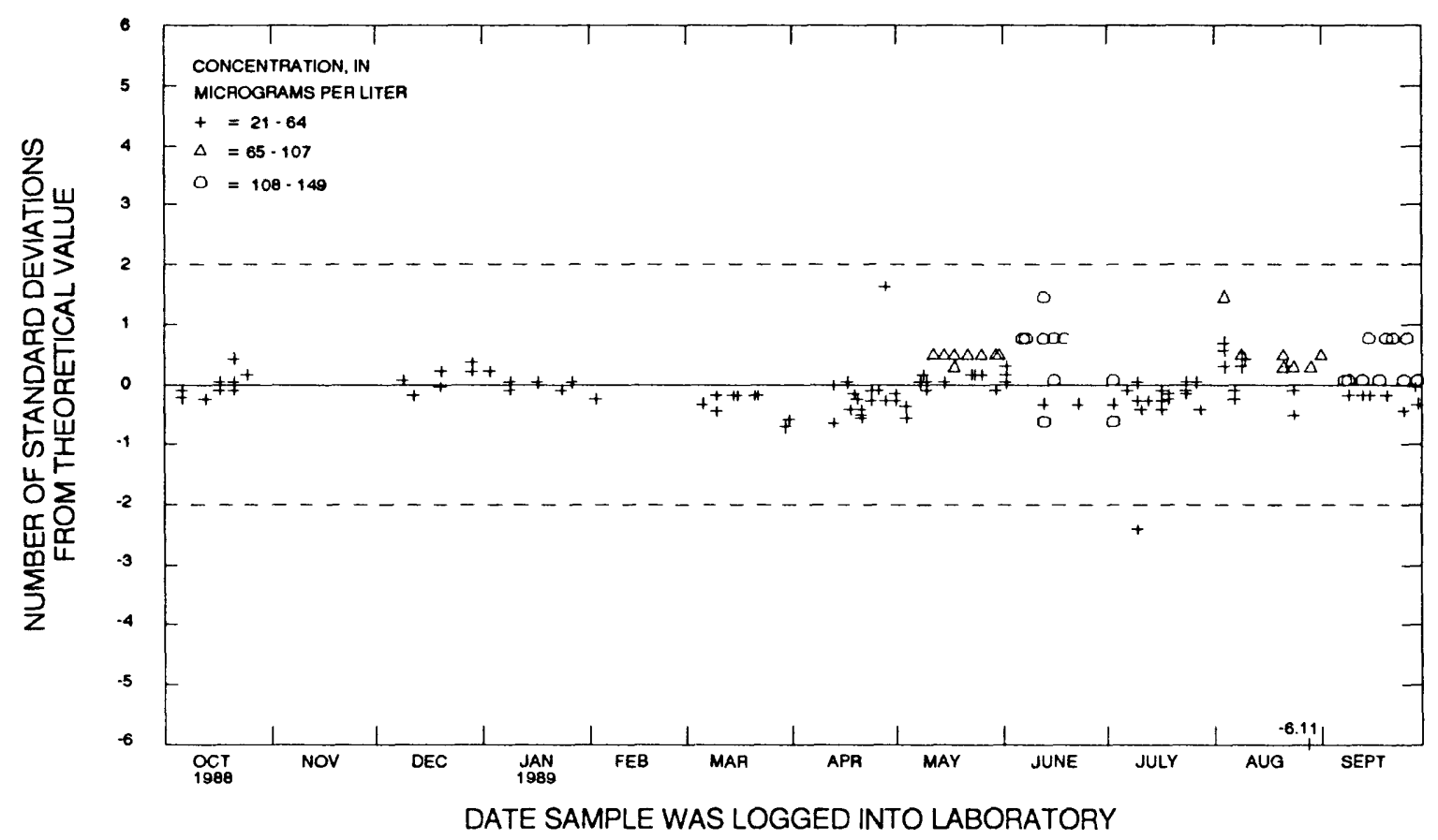

Figure 35.-- Lithium, dissolved, (inductively coupled plasma emission spectrometry) data from the National Water Quality Laboratory.

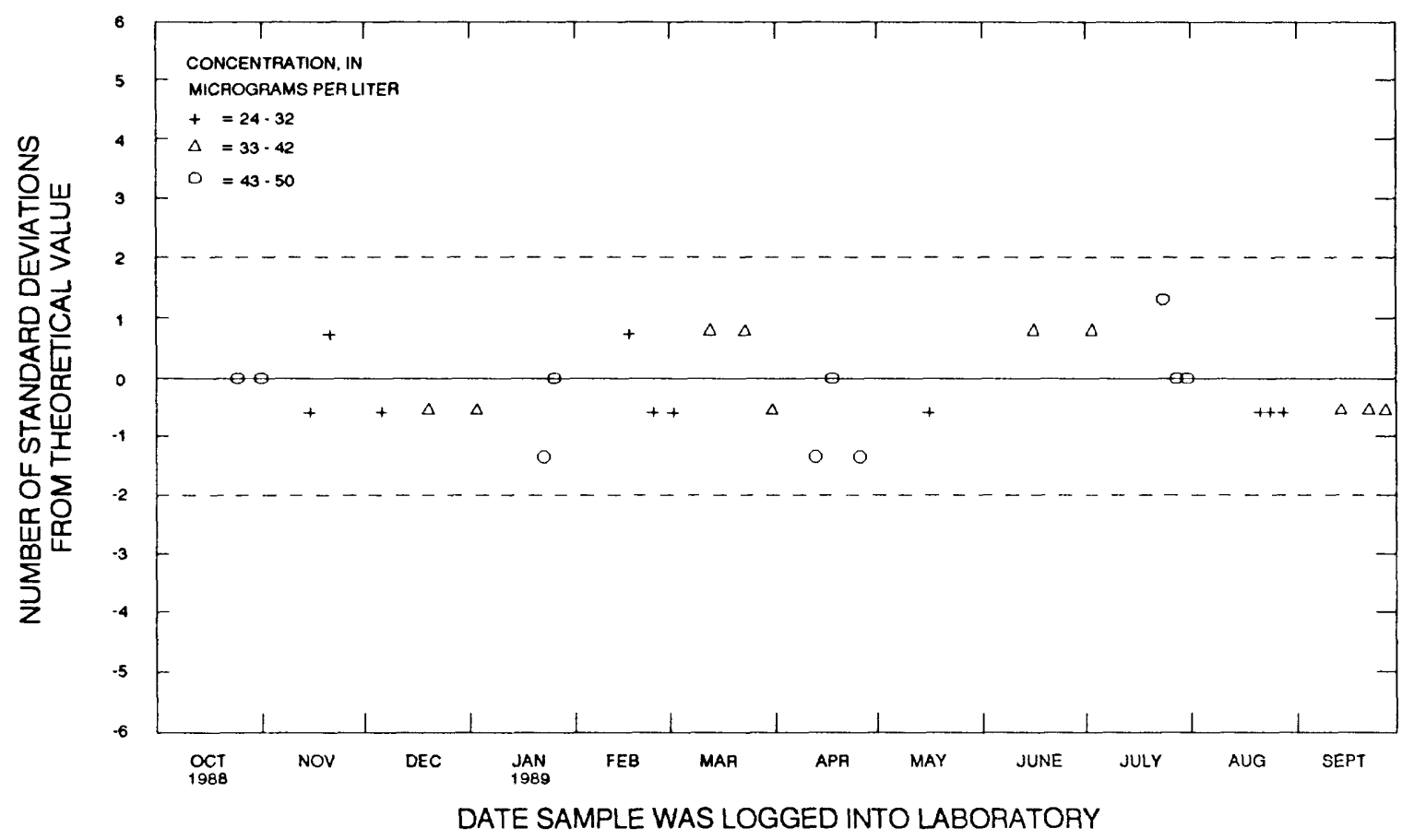

Figure 36.-- Lithium, total recoverable, (atomic absorption spectrometry) data from the Natlonal Water Quality Laboratory. 


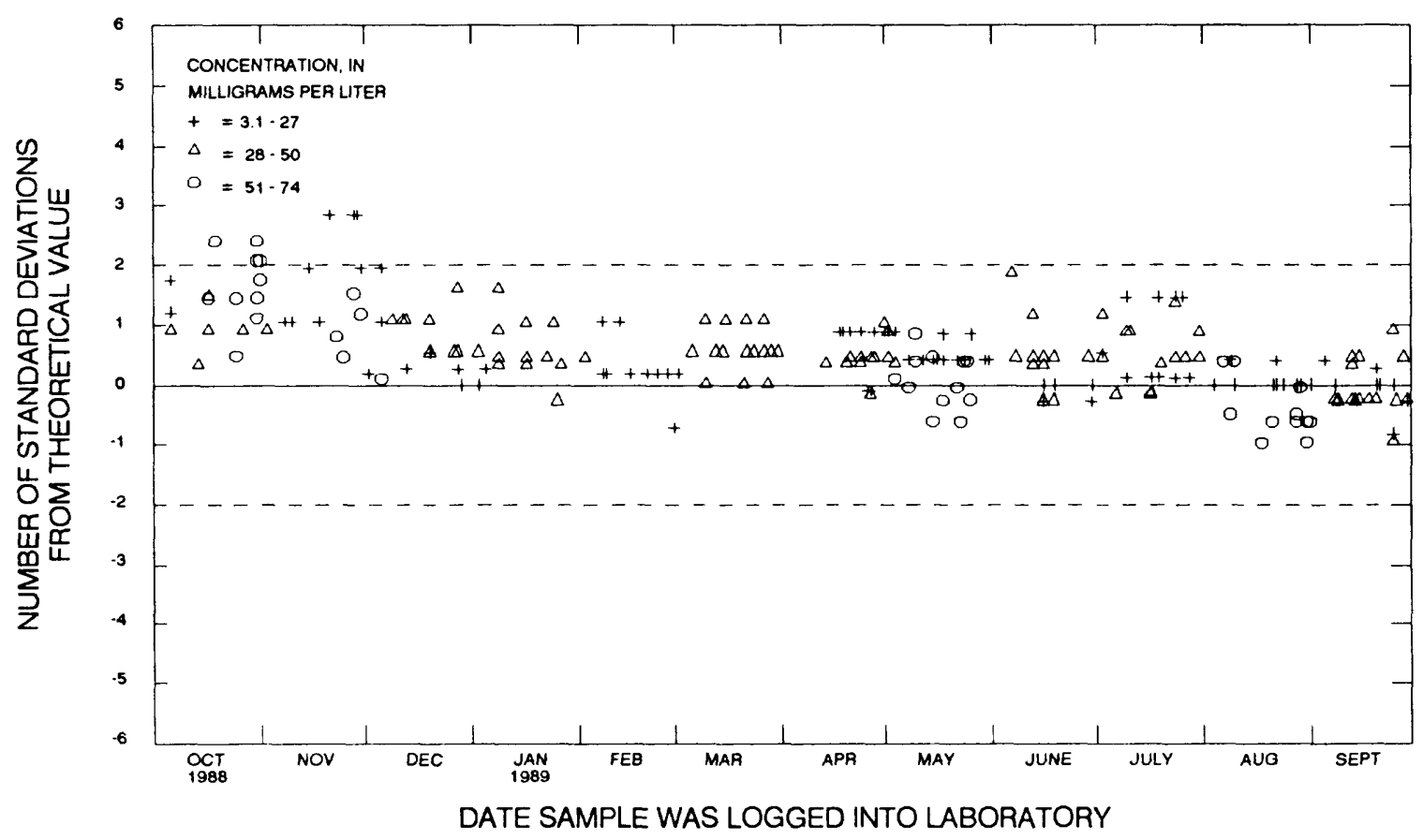

Figure 37.-- Magnesium, dissolved, (inductively coupled plasma emission spectrometry) data from the National Water Quallty Laboratory.

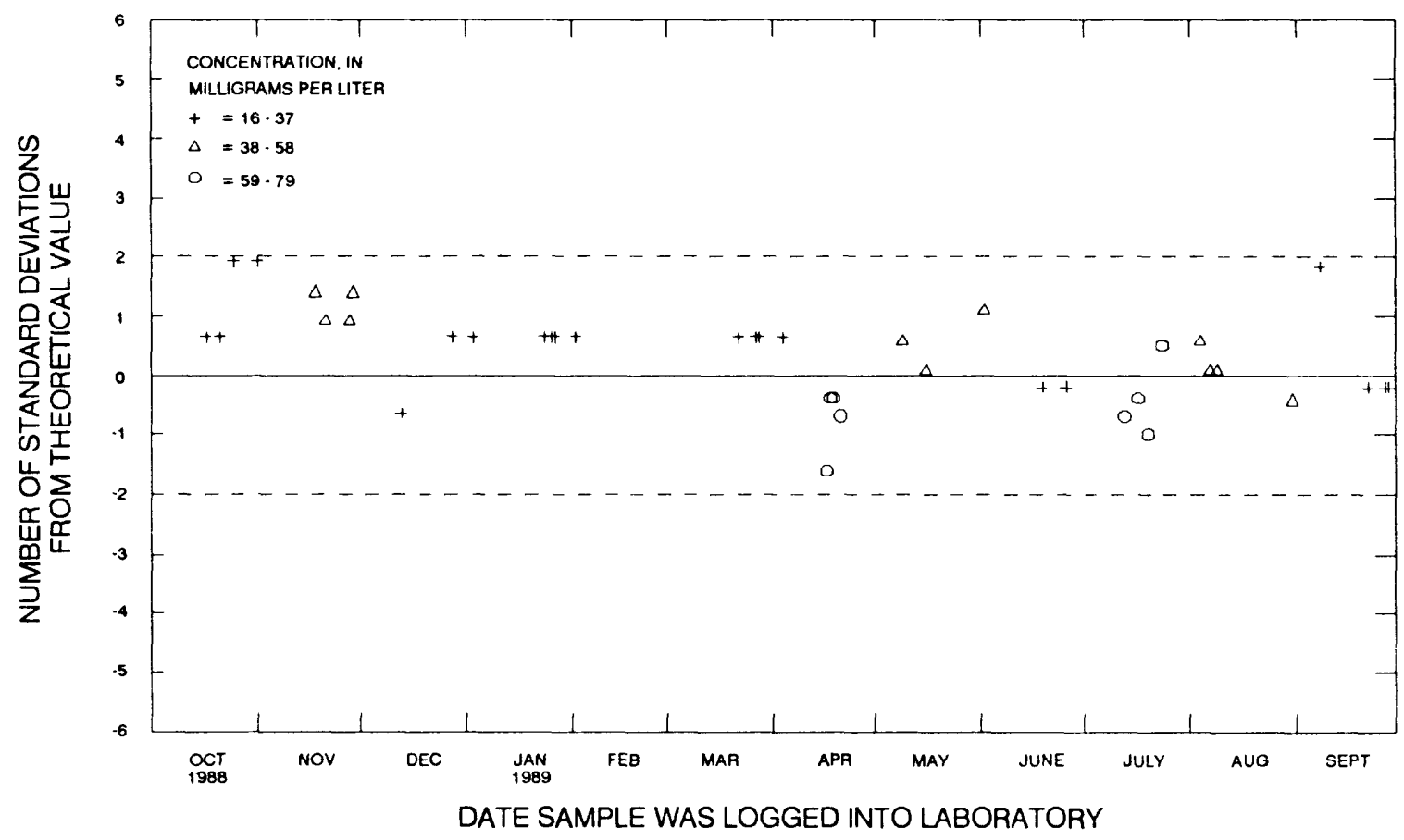

Figure 38.-- Magnesium, dissolved, (atomic absorption spectrometry) data from the National Water Quality Laboratory. 


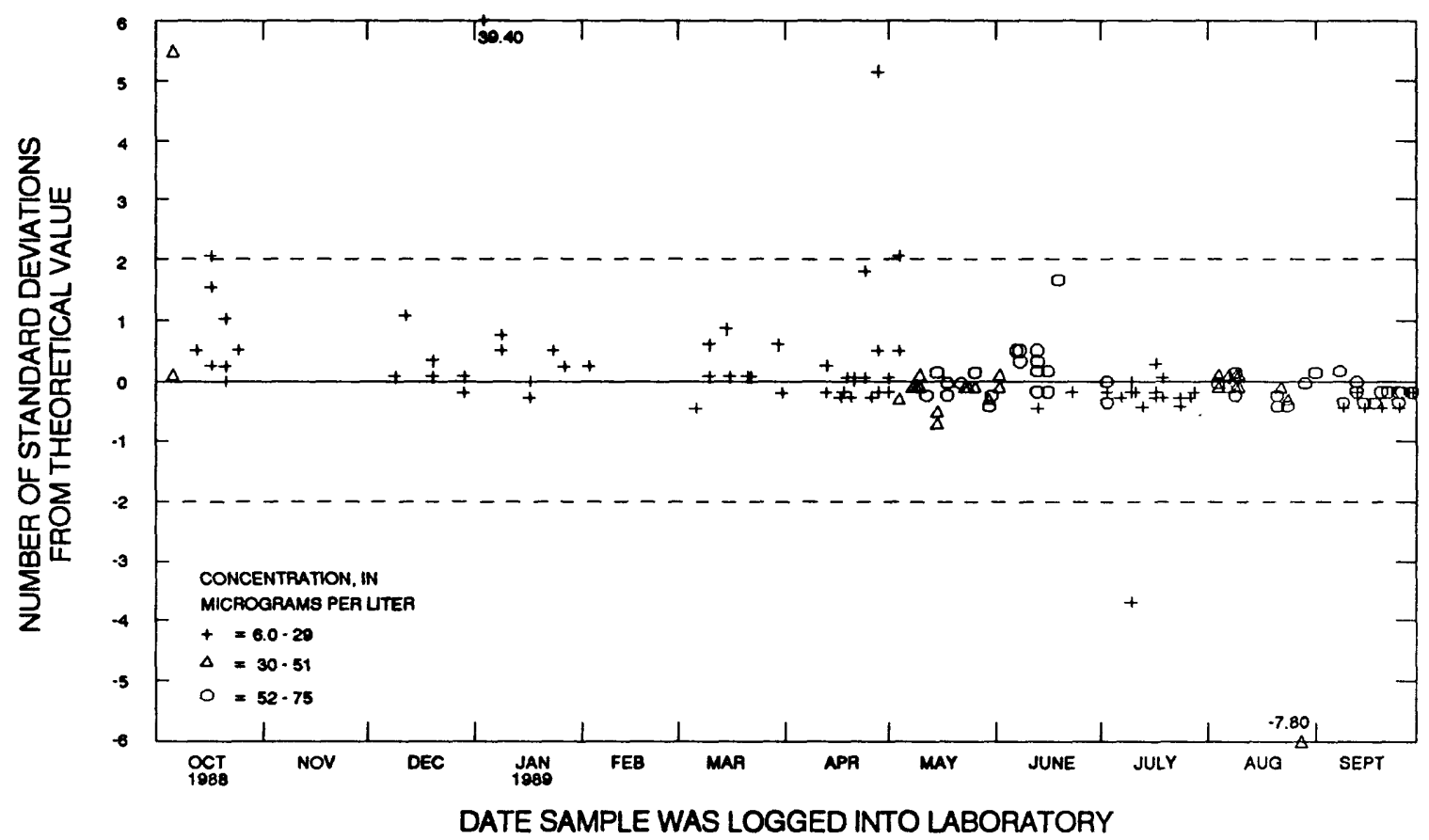

Figure 39.-- Manganese, dissolved, (inductively coupled plasma emission spectrometry) data from the National Water Quality Laboratory.

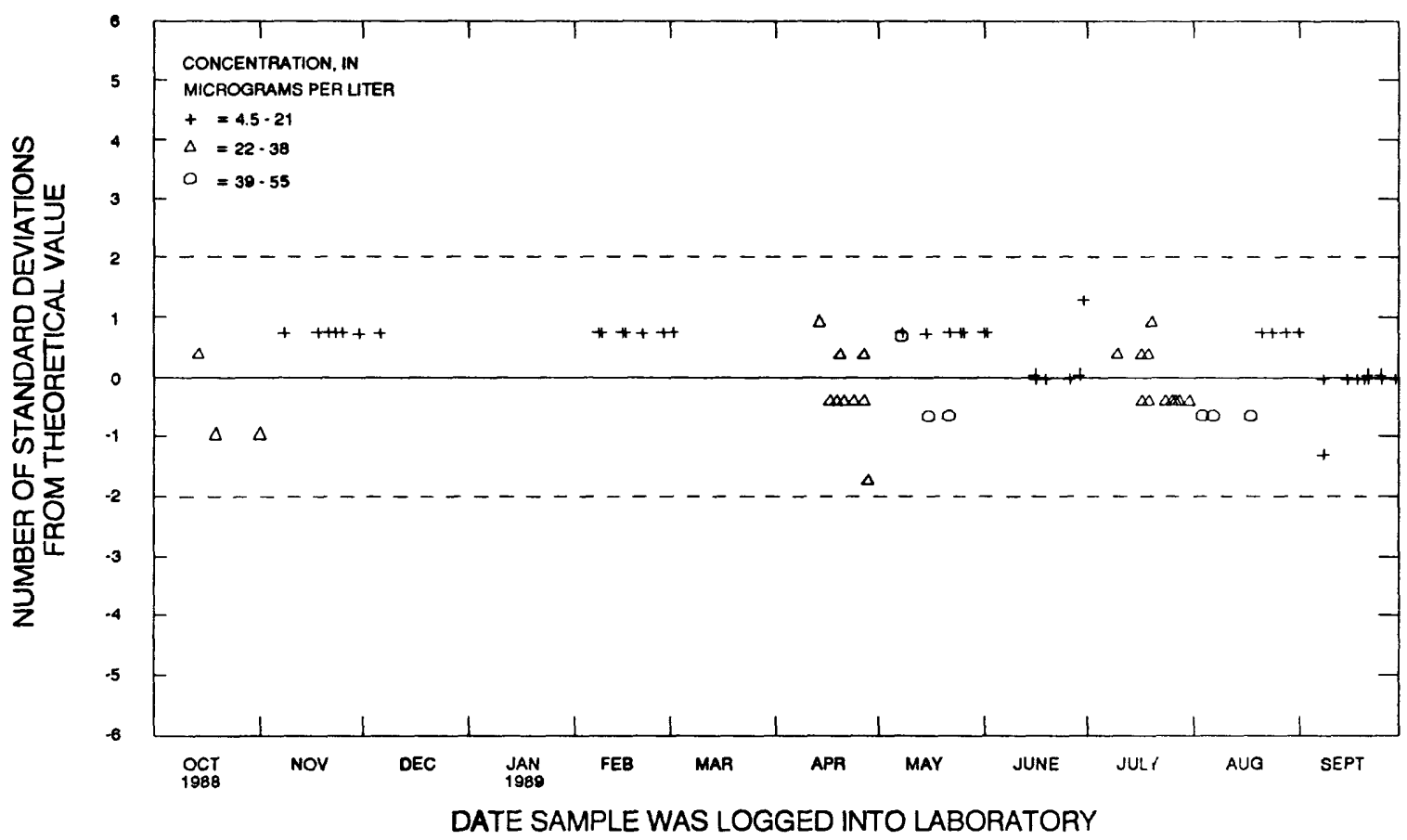

Figure 40.-- Manganese, dissolved, (atomic absorption spectrometry) data from the National Water Quality Laboratory. 


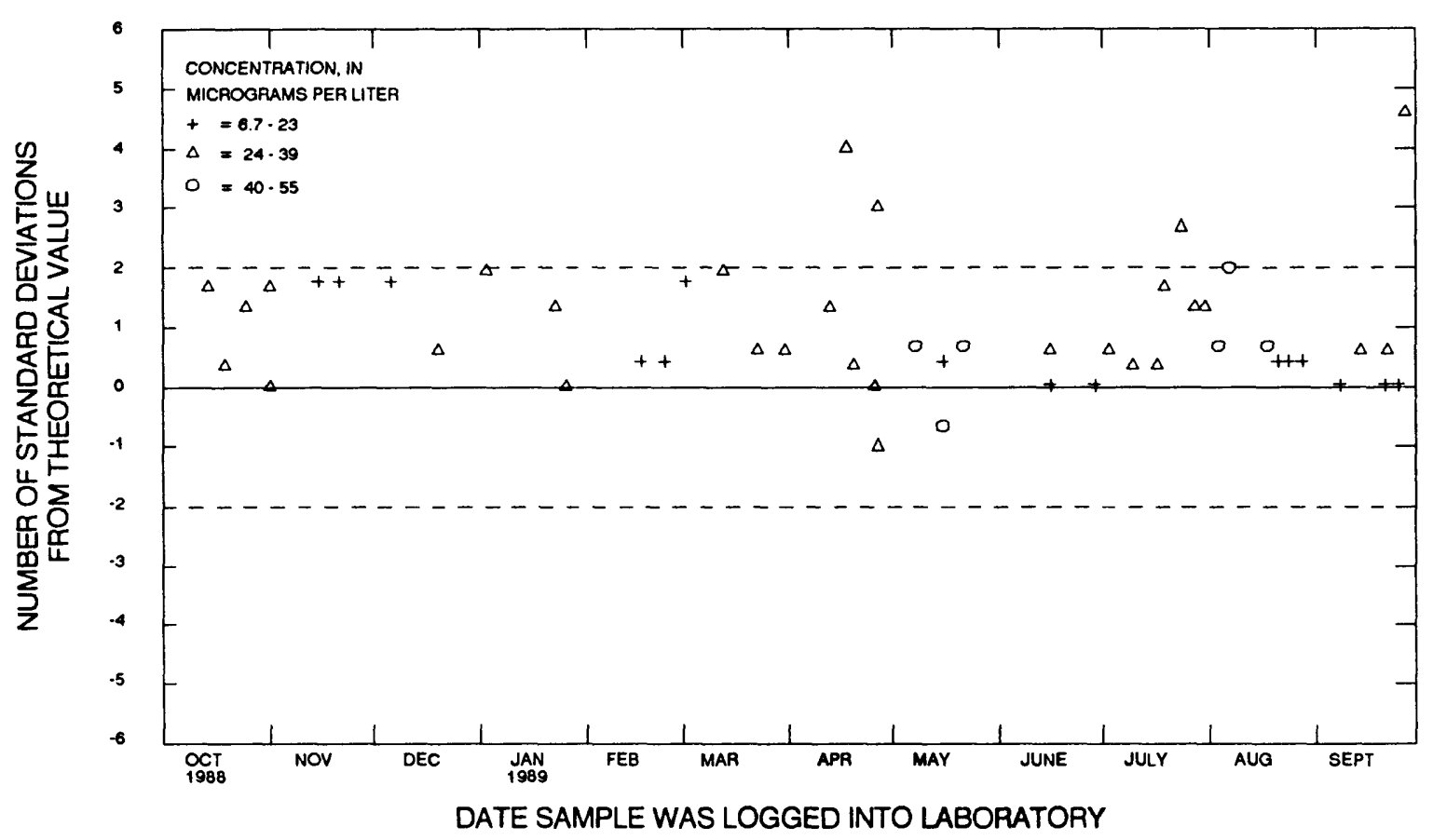

Flgure 41.-- Manganese, total recoverable, (atomic absorption spectrometry) data from the Natlonal Water Quallty Laboratory.

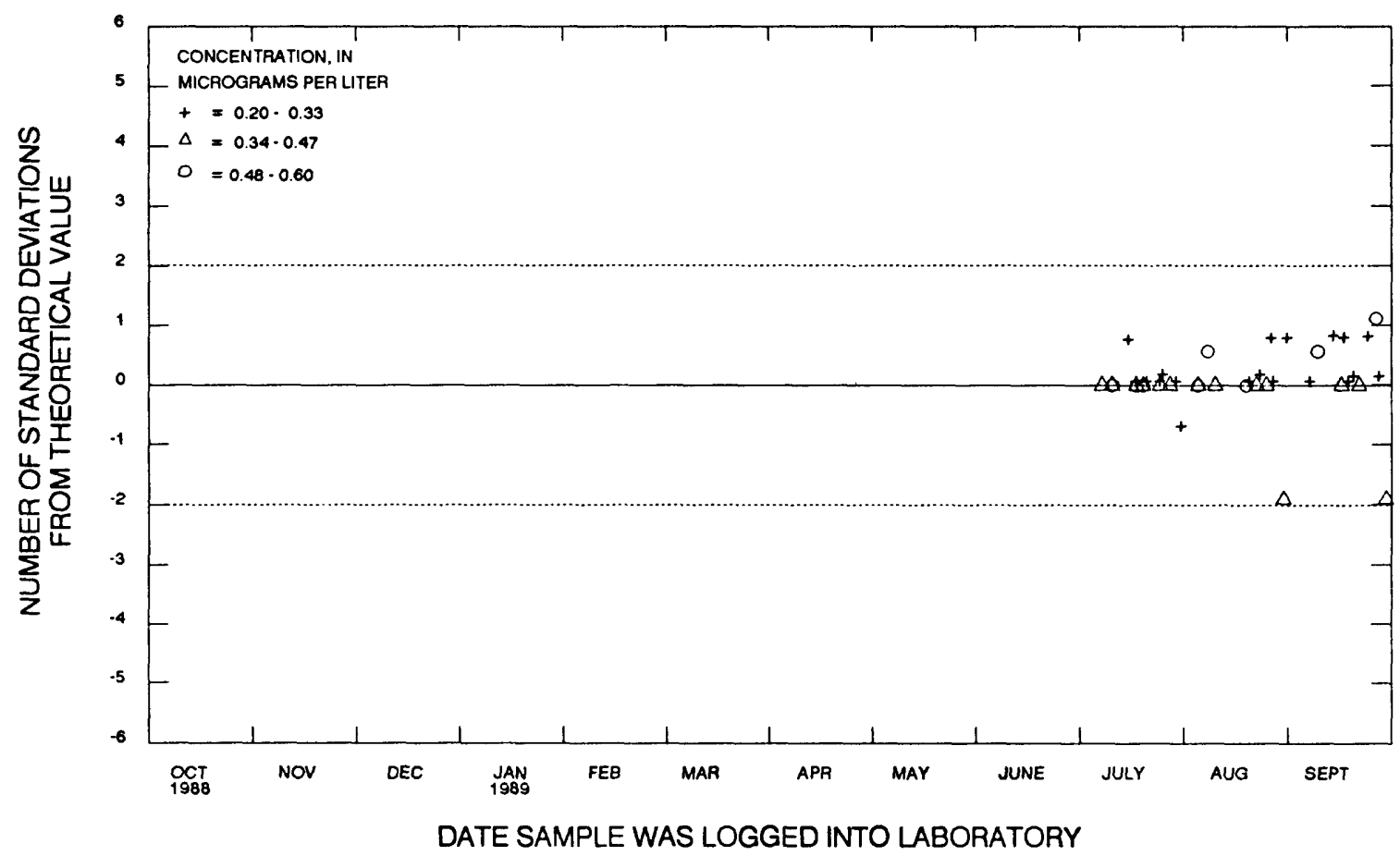

Figure 42.-- Mercury, dissolved, (atomic absorption spectrometry) data from the Natlonal Water Quailty Laboratory. 

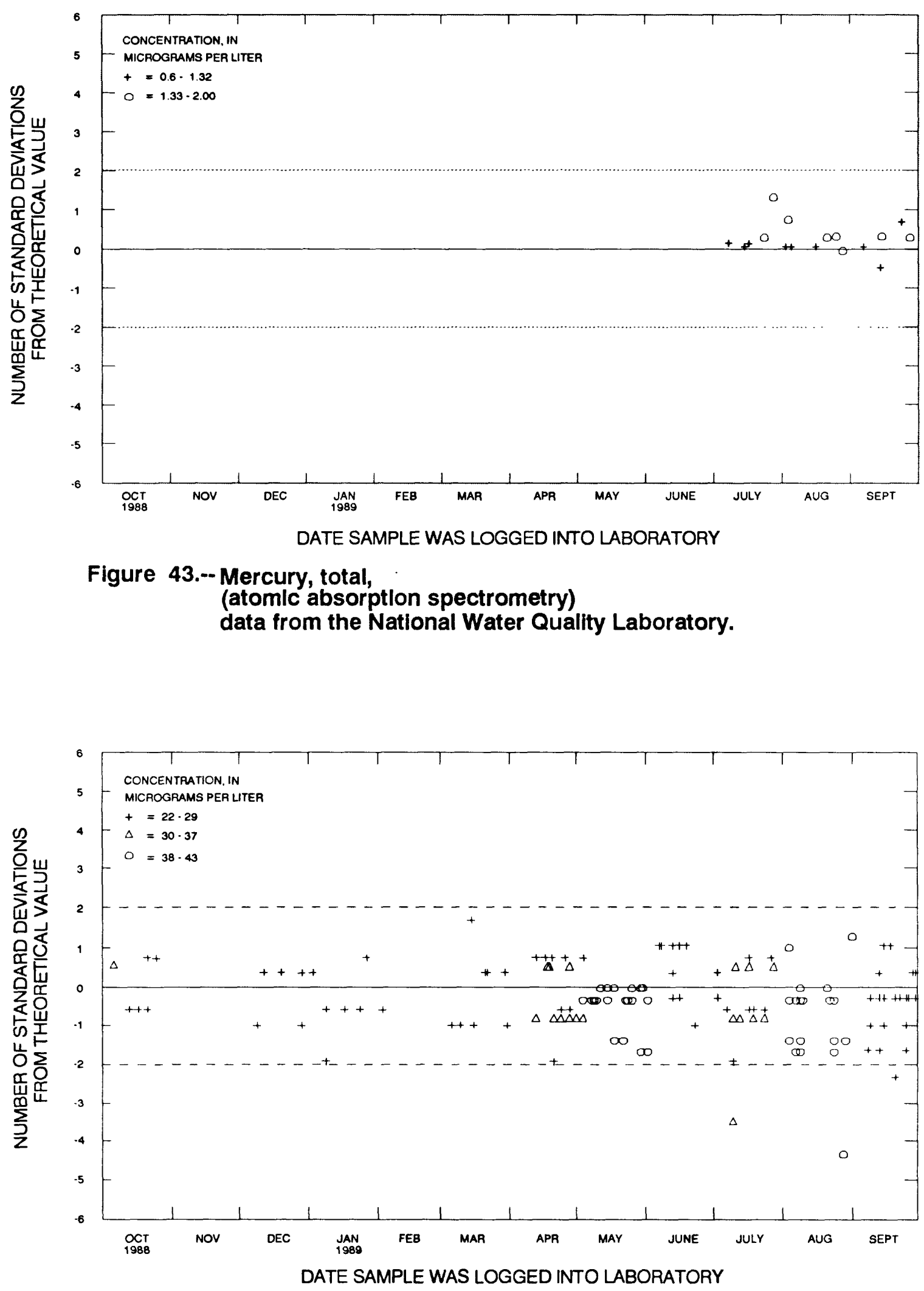

Figure 44.-- Molybdenum, dlssolved, (inductively coupled plasma emission spectrometry) data from the National Water Quality Laboratory. 


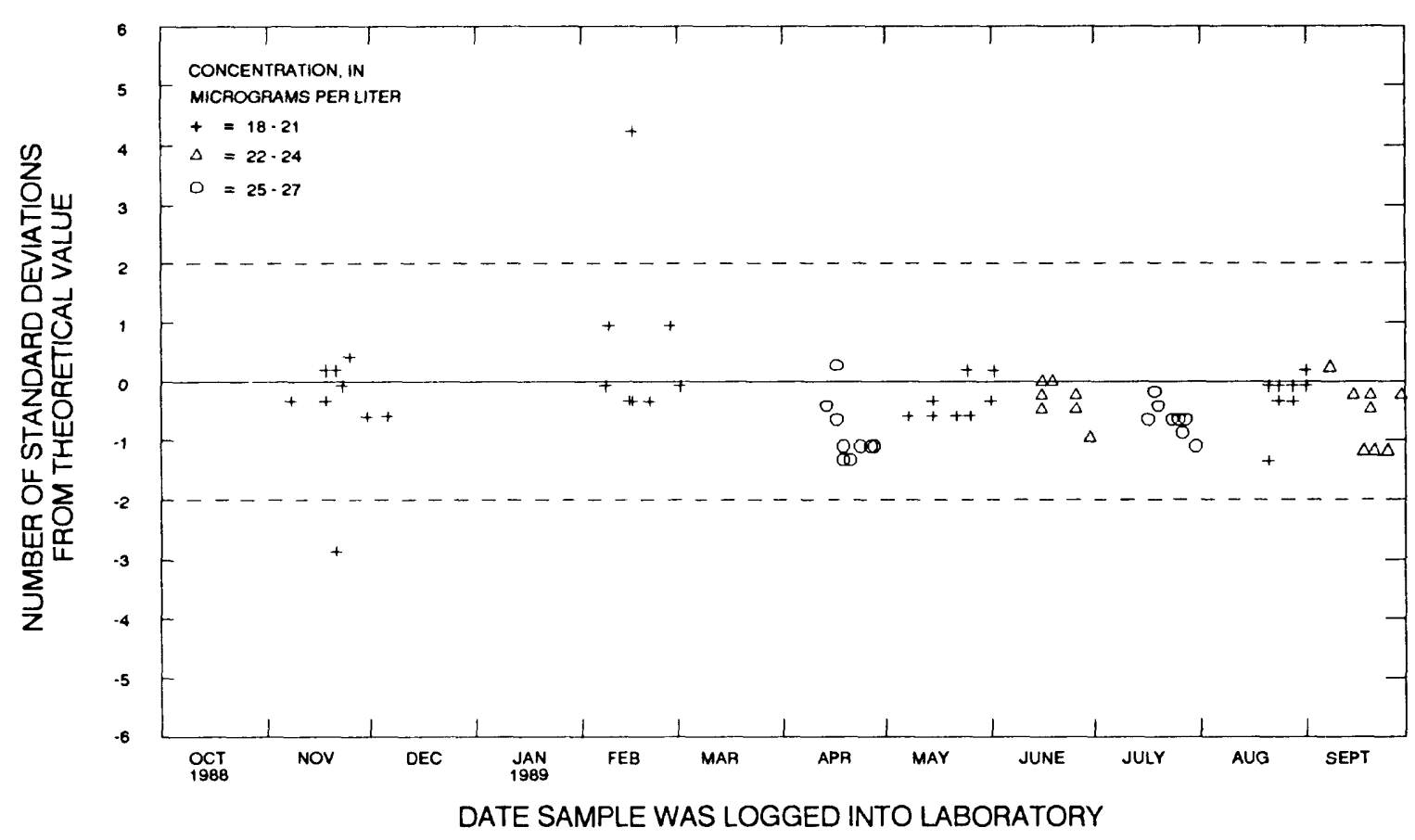

Flgure 45.-- Molybdenum, dissolved, (atomic absorption spectrometry) data from the National Water Quality Laboratory.

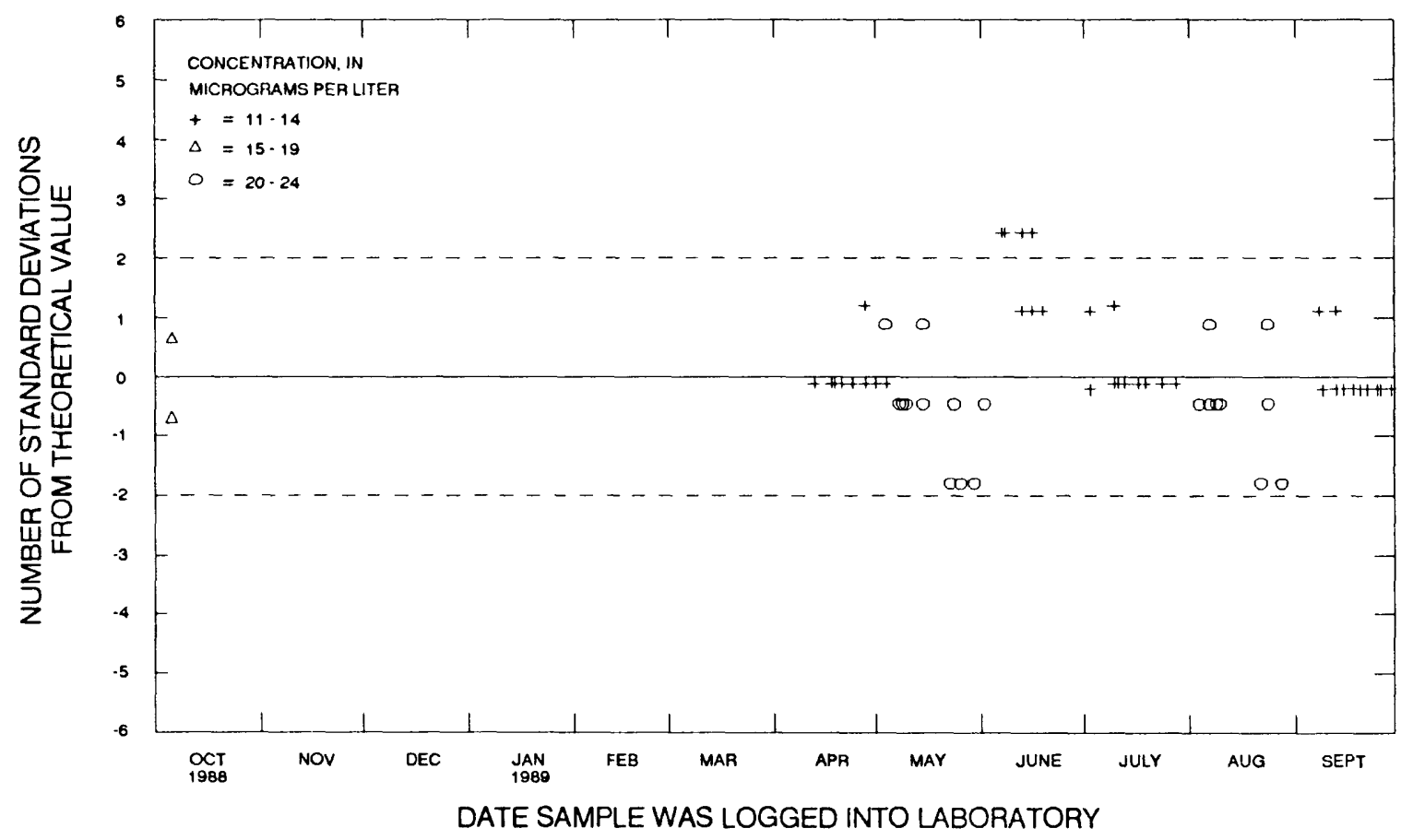

Figure 46.-- Nickel, dissolved, (inductively coupled plasma emission spectrometry) data from the National Water Quality Laboratory. 


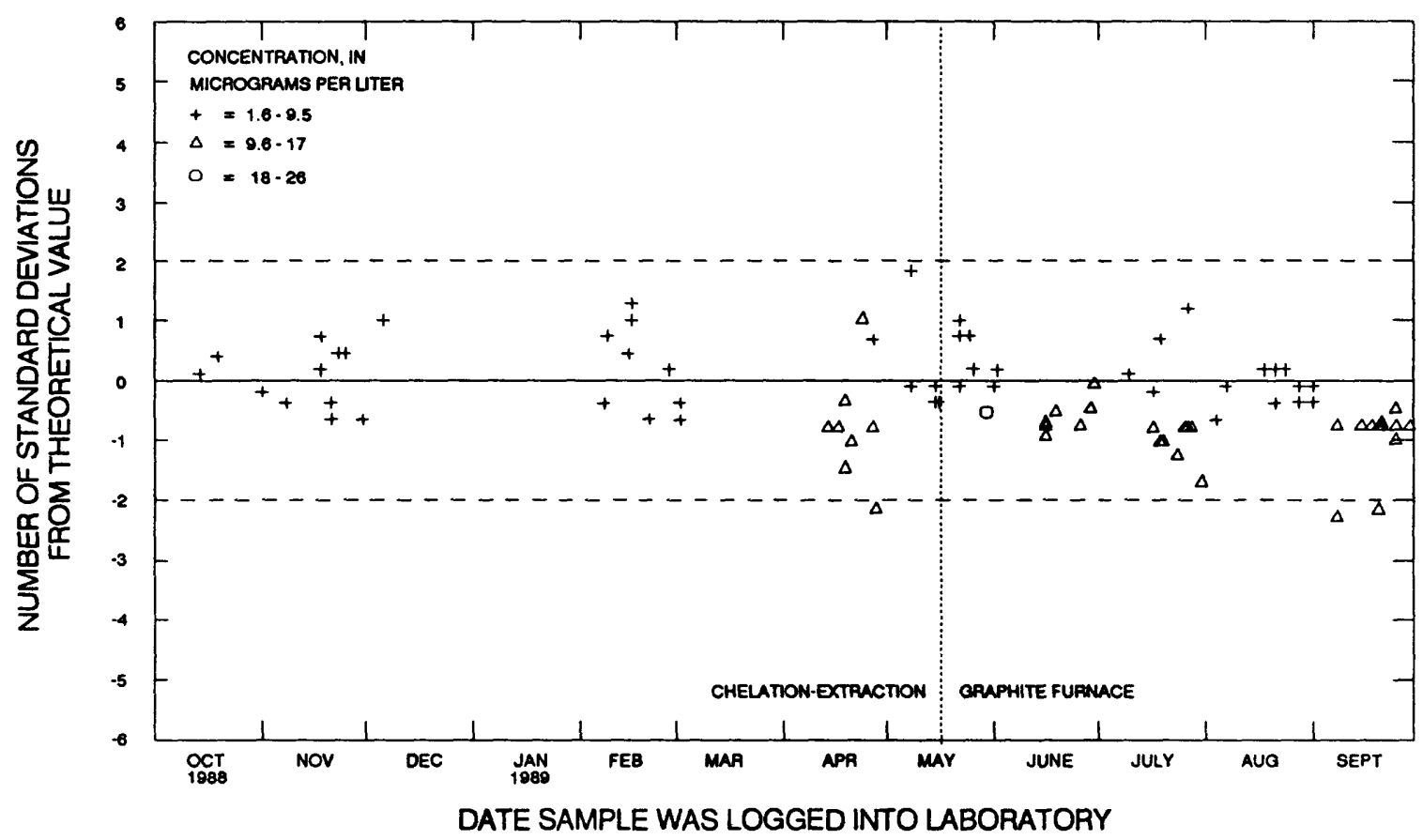

Figure 47.-- Nickei, dissolved, (atomic absorption spectrometry, chelation-extraction or graphite furnace) data from the National Water Quality Laboratory.

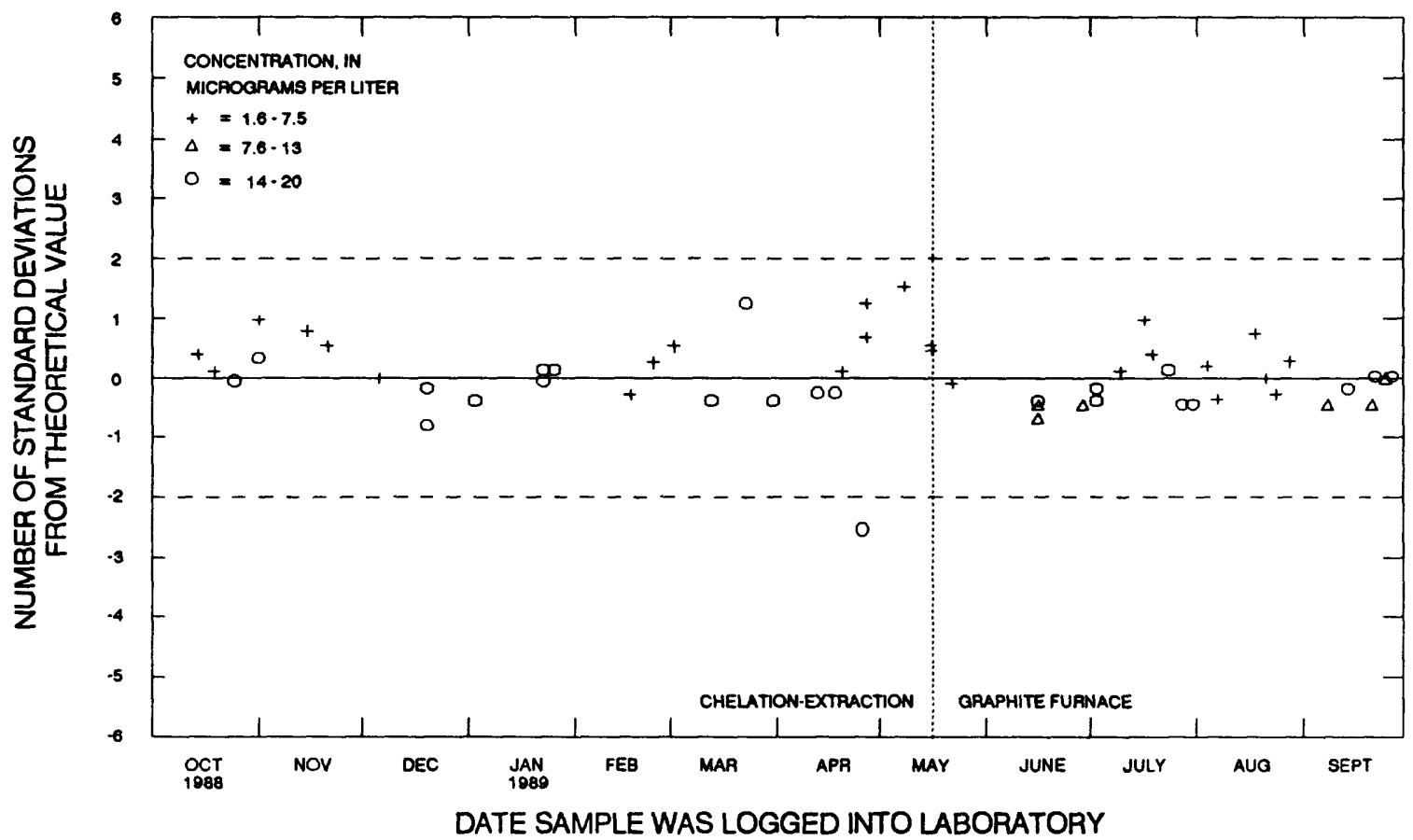

Figure 48.--NIckel, total recoverable, (atomic absorption spectrometry, chelation-extraction or graphlte furnace) data from the National Water Quailty Laboratory. 


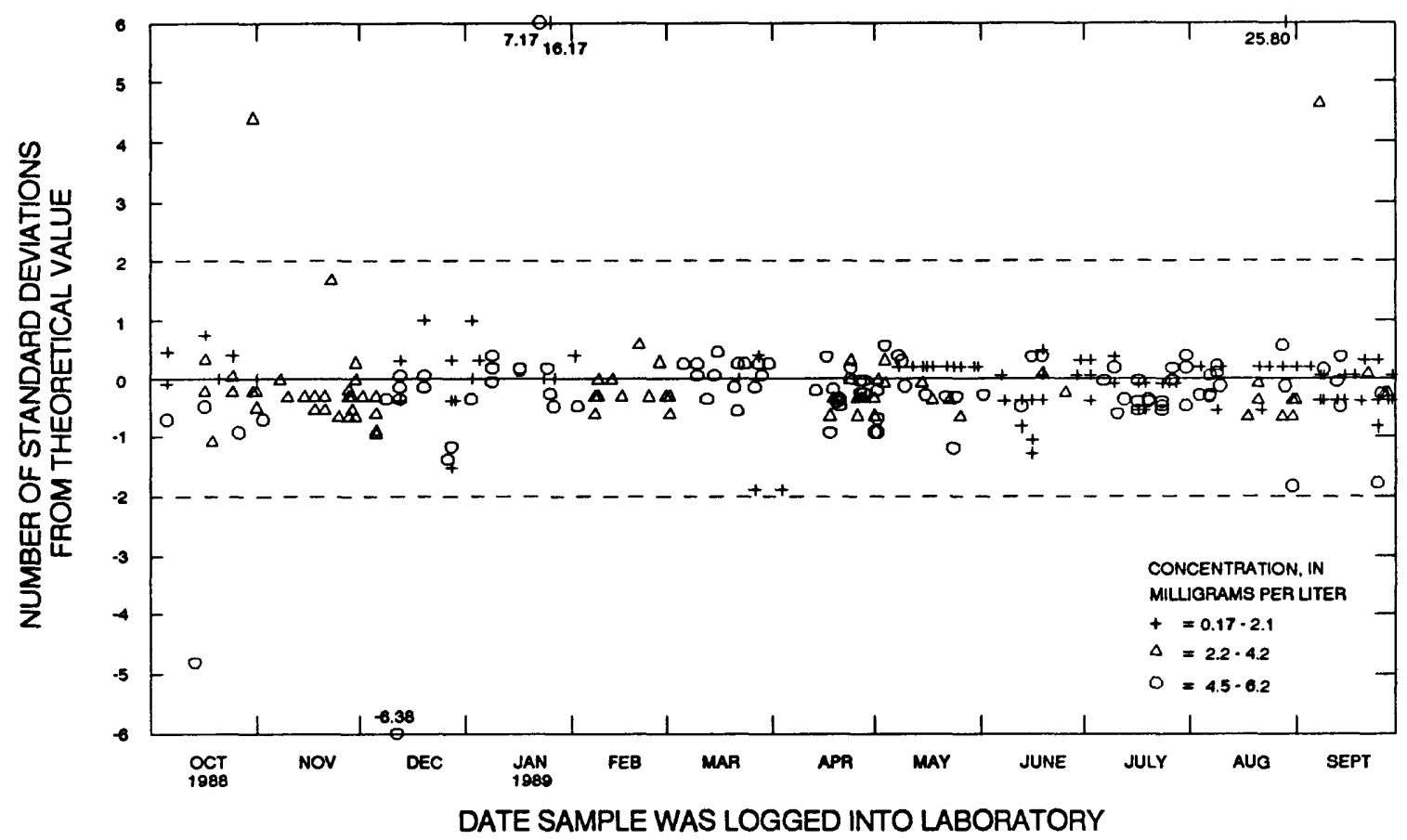

Figure 49.-- Potassium, dissolved, (atomlc absorptlon spectrometry) data from the National Water Quallty Laboratory.

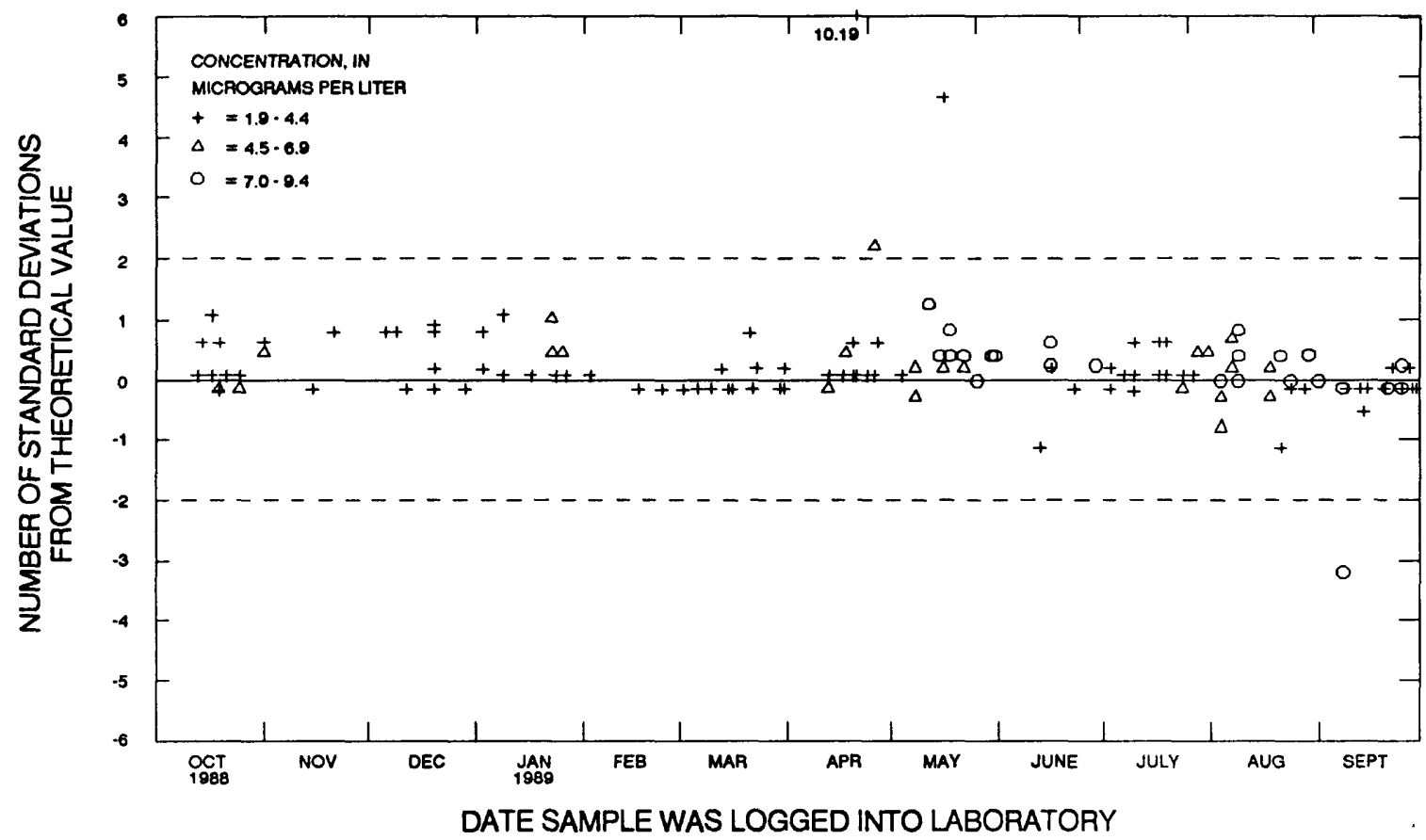

Figure 50.--Selenium, dlssolved and total, (atomic absorptlon spectrometry, hydride) data from the National Water Quality Laboratory. 


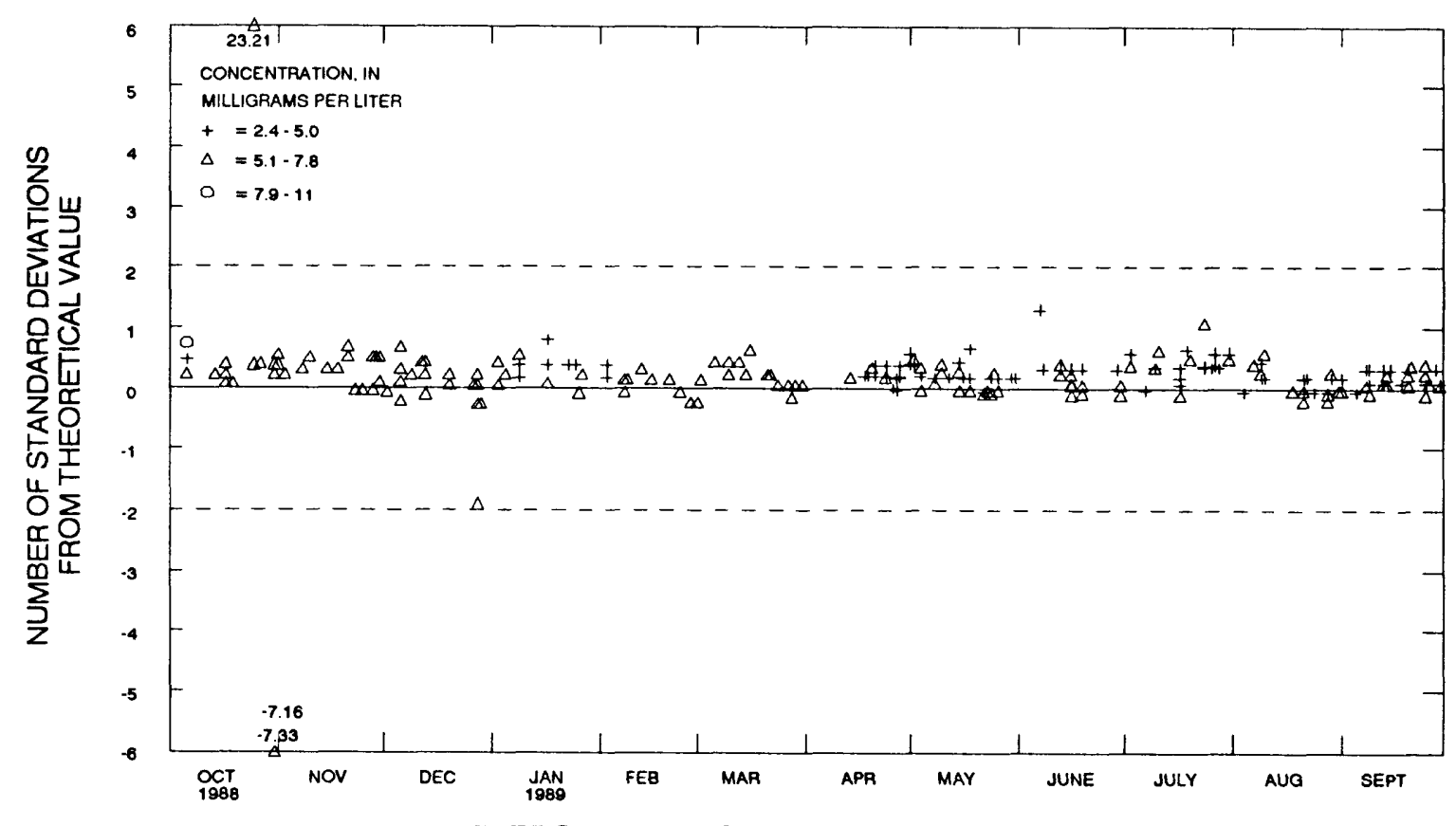

DATE SAMPLE WAS LOGGED INTO LABORATORY

Figure 51.-- Silica, dissolved, (inductively coupled plasma emission spectrometry) data from the National Water Quallty Laboratory.

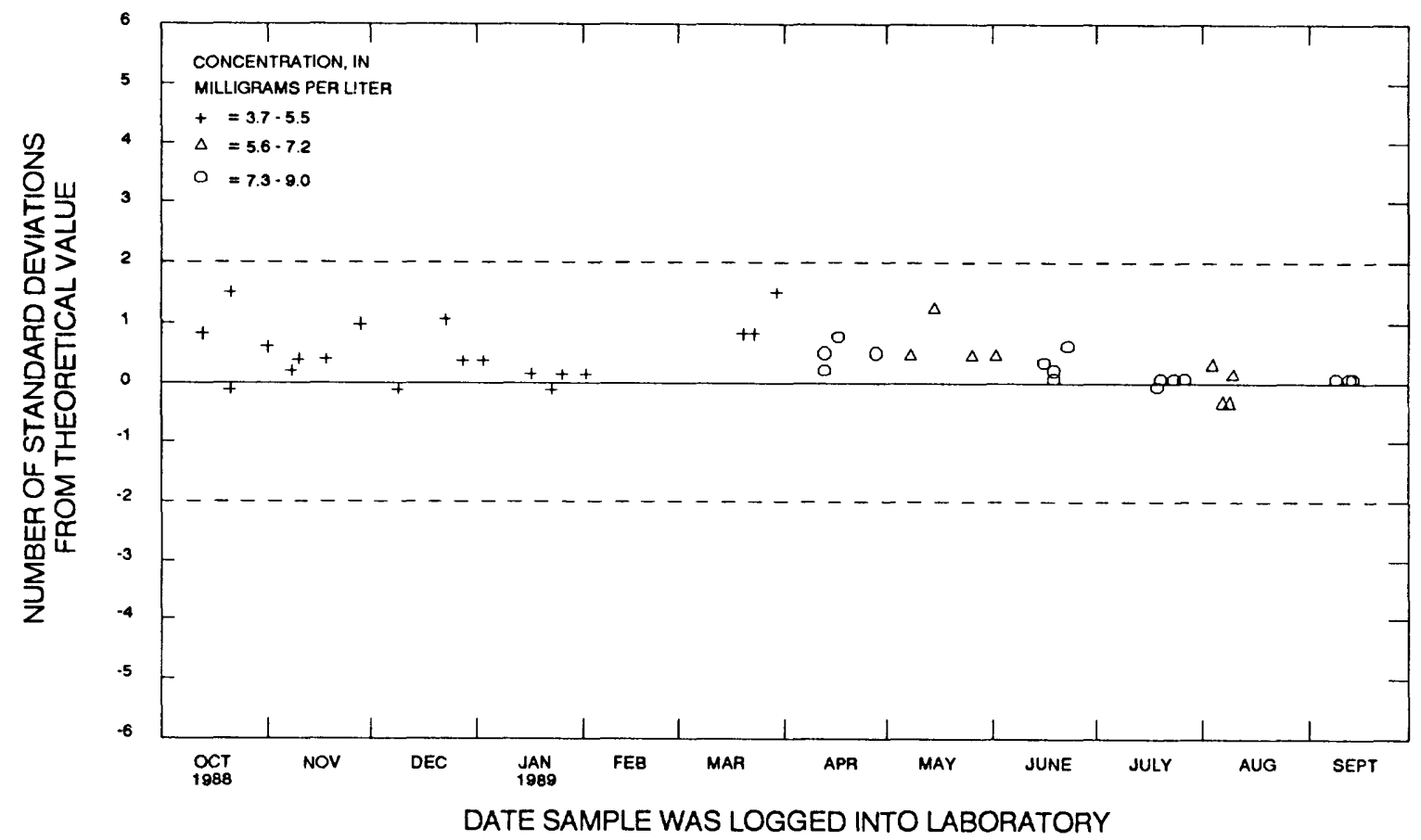

Figure 52.--Silica, dissolved, (colorimetric)

data from the National Water Quality Laboratory. 


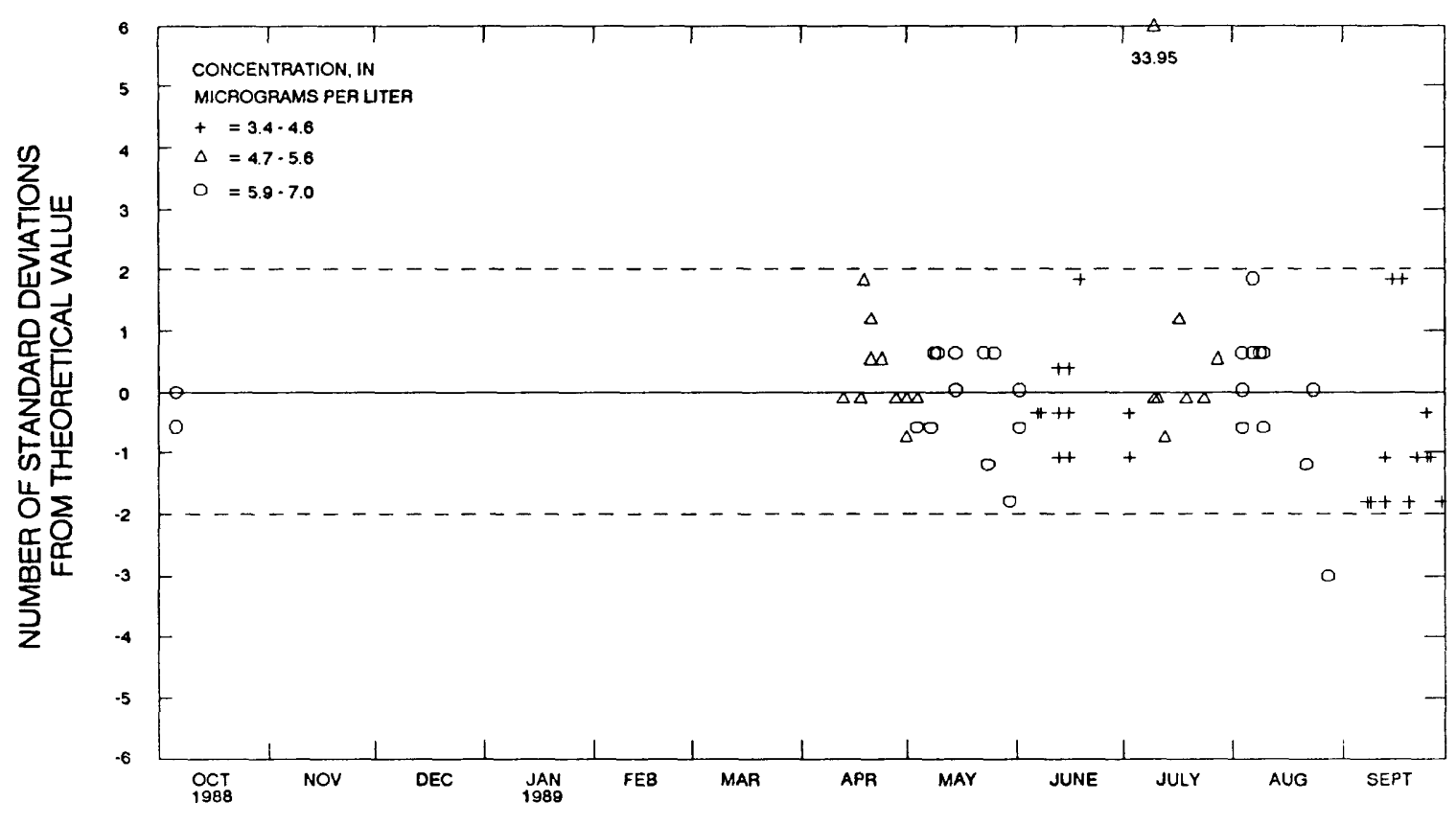

DATE SAMPLE WAS LOGGED INTO LABORATORY

Figure 53.-- Silver, dissolved, (inductively coupled plasma emission spectrometry) data from the National Water Quality Laboratory.

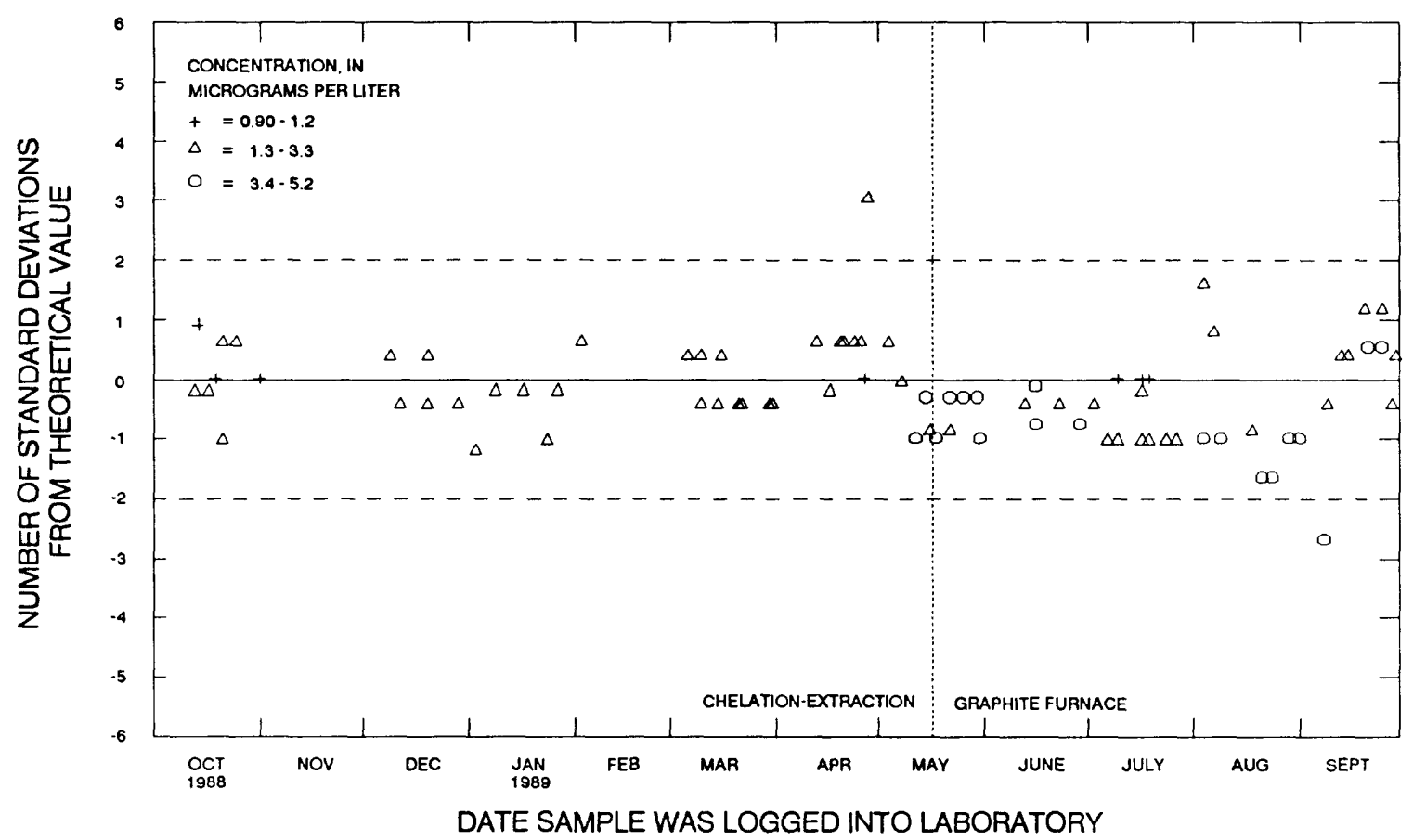

Figure 54.-- Silver, dissolved, (atomic absorption spectrometry; chelation-extraction or graphite furnace) data from the National Water Quality Laboratory. 


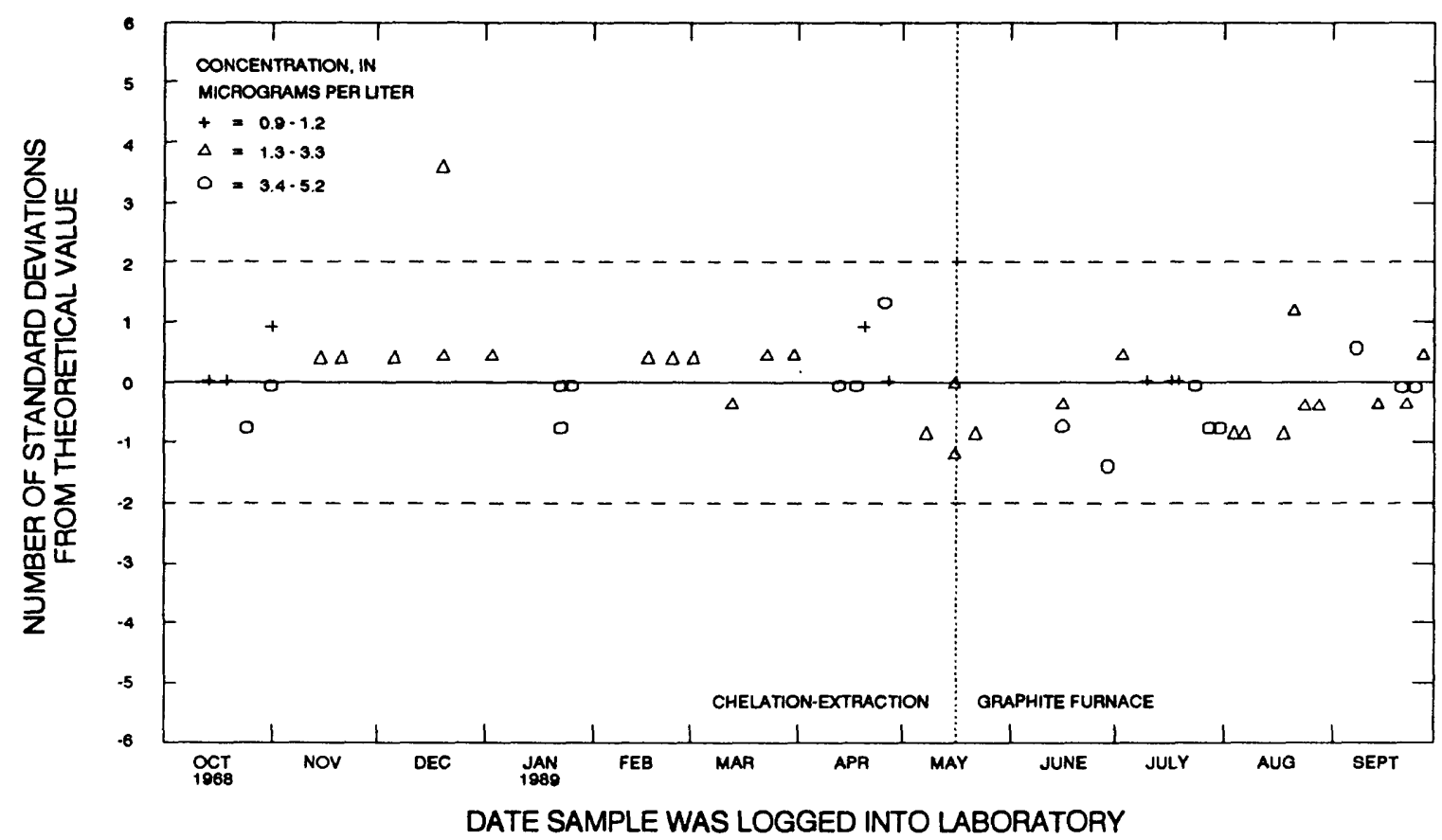

Figure 55 --Silver, total recoverable, (atomic absorption spectrometry; chelation-extraction or graphite furnace) data from the Nationai Water Quality Laboratory.

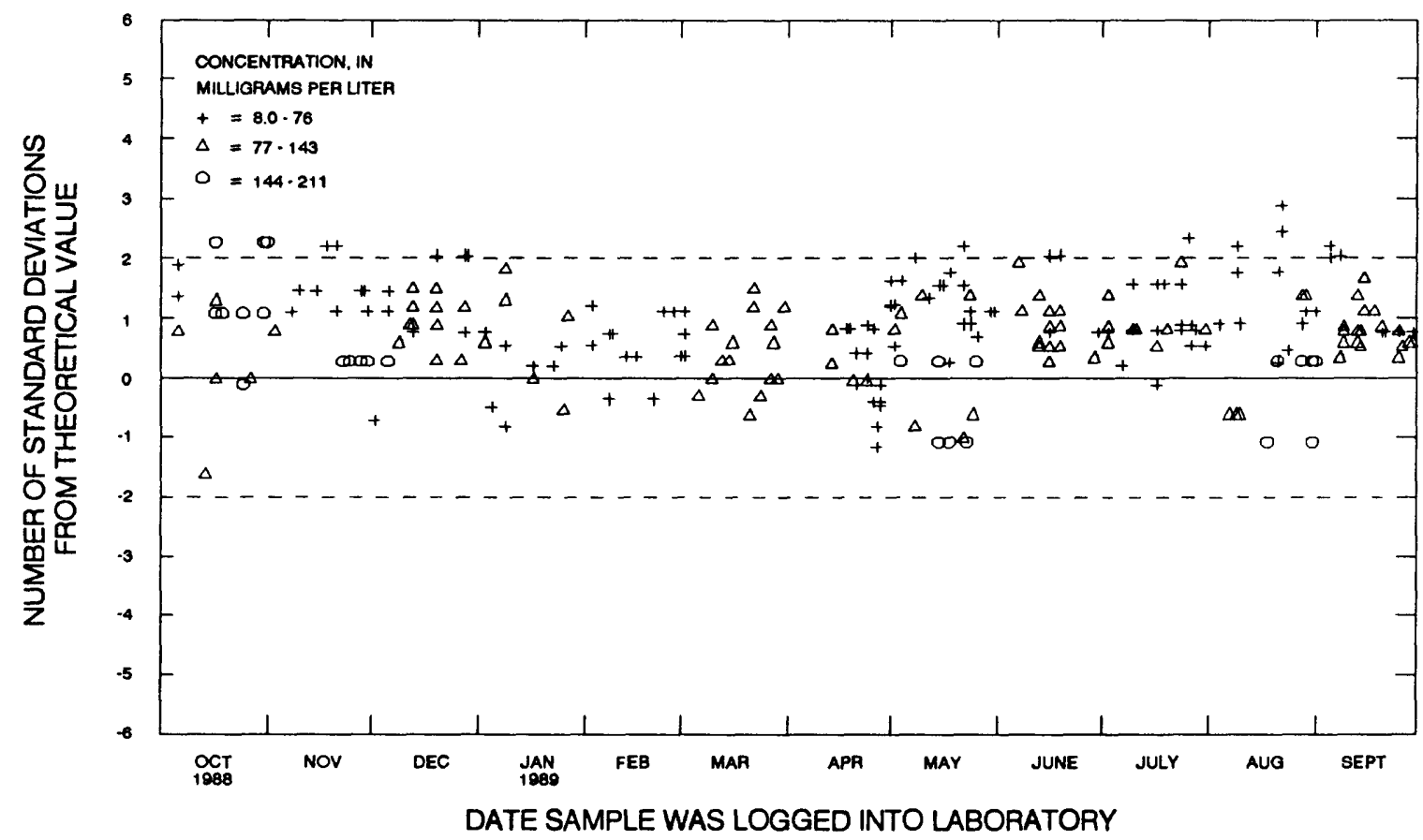

Figure 56.-- Sodium, dissolved, (inductiveiy coupled plasma emission spectrometry) data from the Natlonal Water Quality Laboratory. 


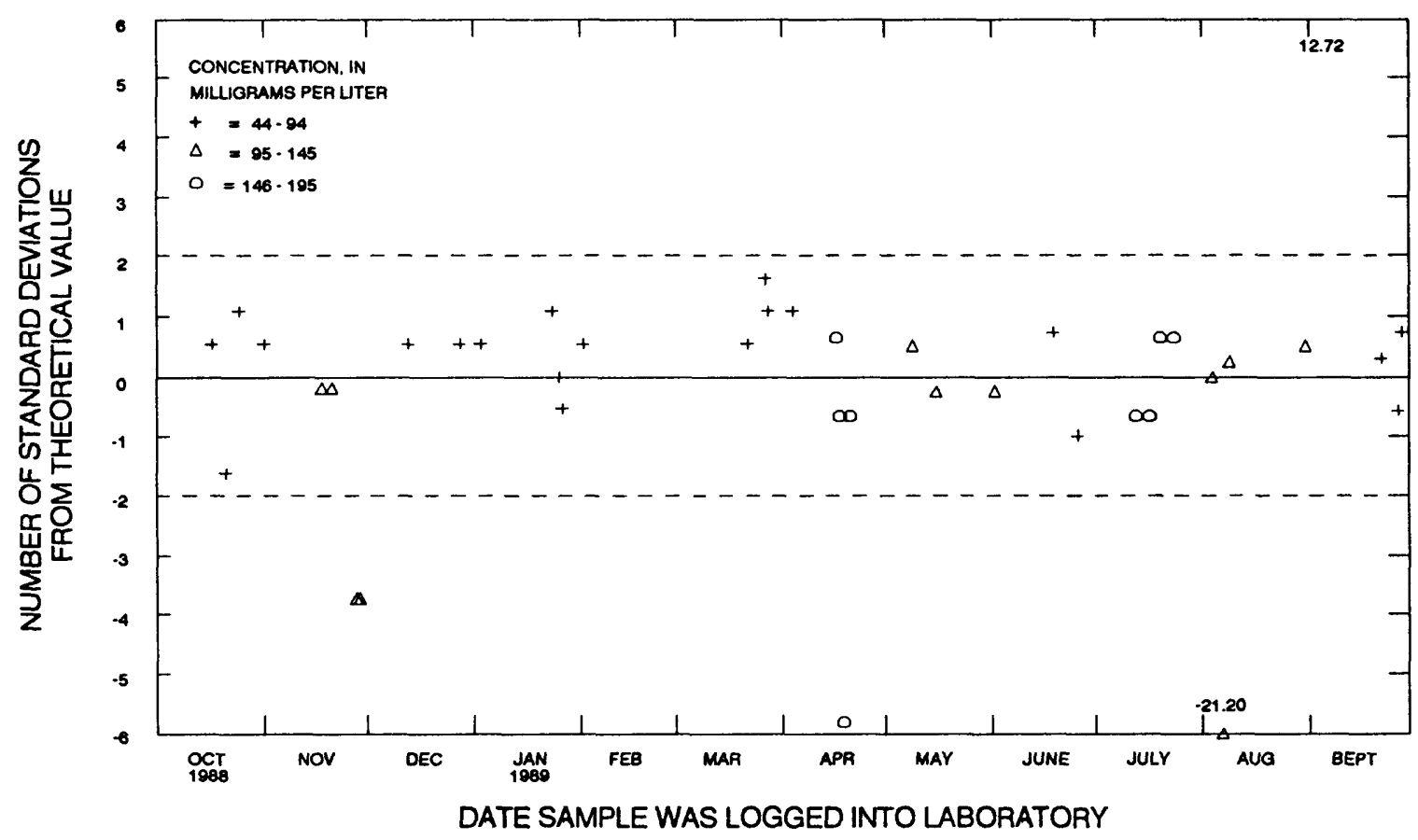

Figure 57.-- Sodium, dissolved, (atomic absorption spectrometry) data from the National Water Quality Laboratory.

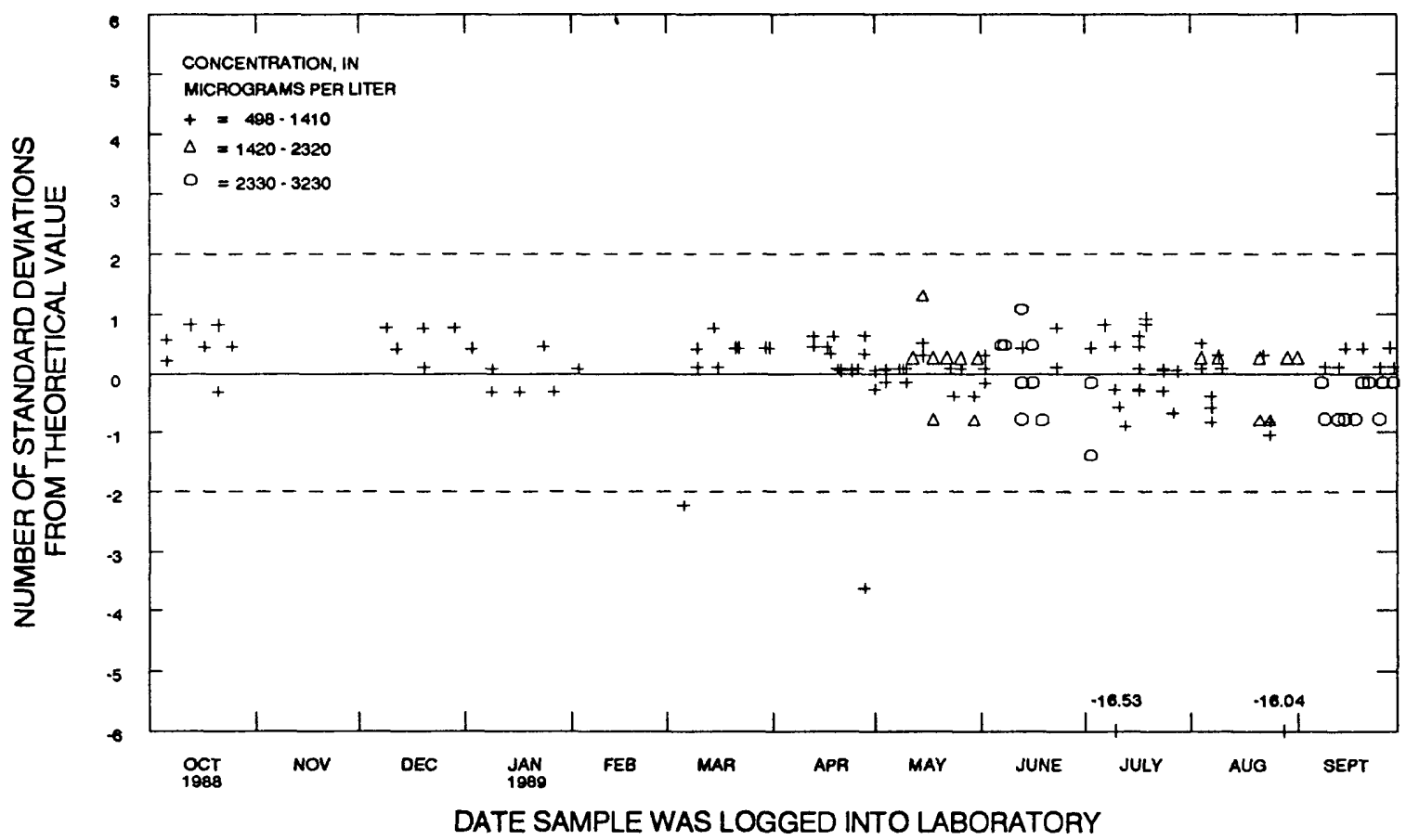

Flgure 58.-- Strontlum, dissolved, (inductively coupled plasma emission spectrometry) data from the National Water Quailty Laboratory. 


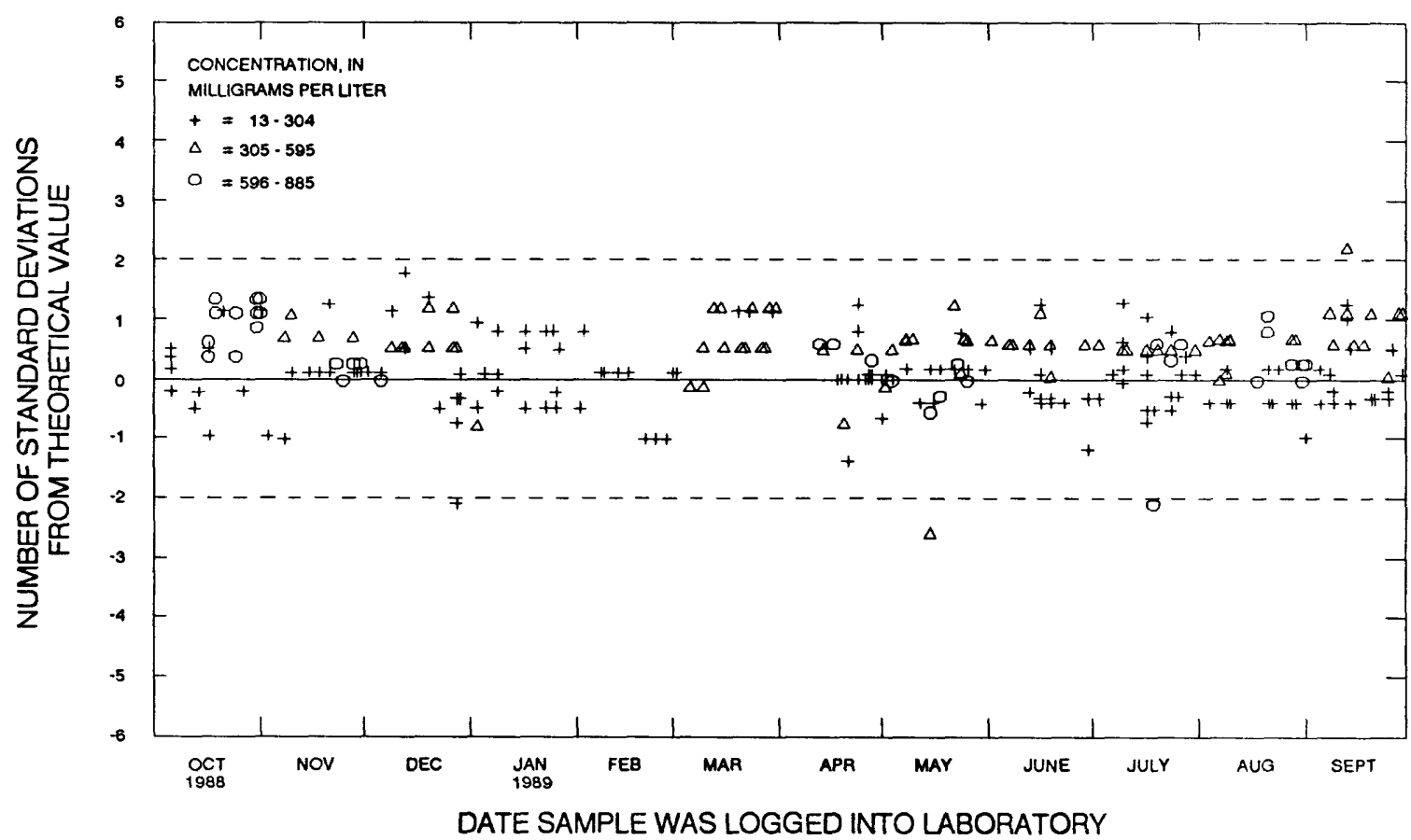

Figure 59.-- Suifate, dissolved, (turbidimetric)

data from the National Water Quality Laboratory.

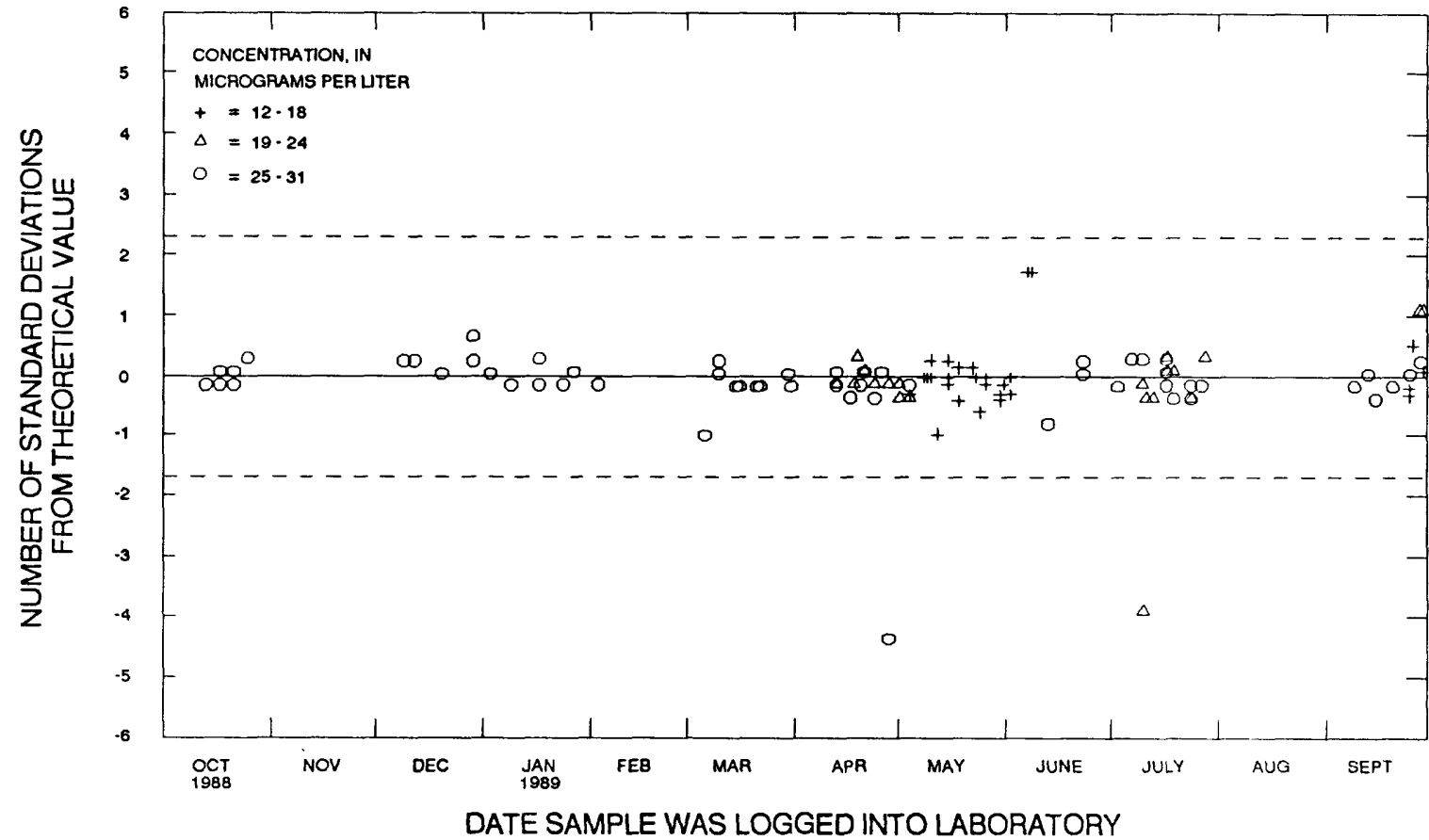

Figure 60.-- Vanadium, dissoived, (Inductively coupled plasma emission spectrometry) data from the National Water Quality Laboratory. 


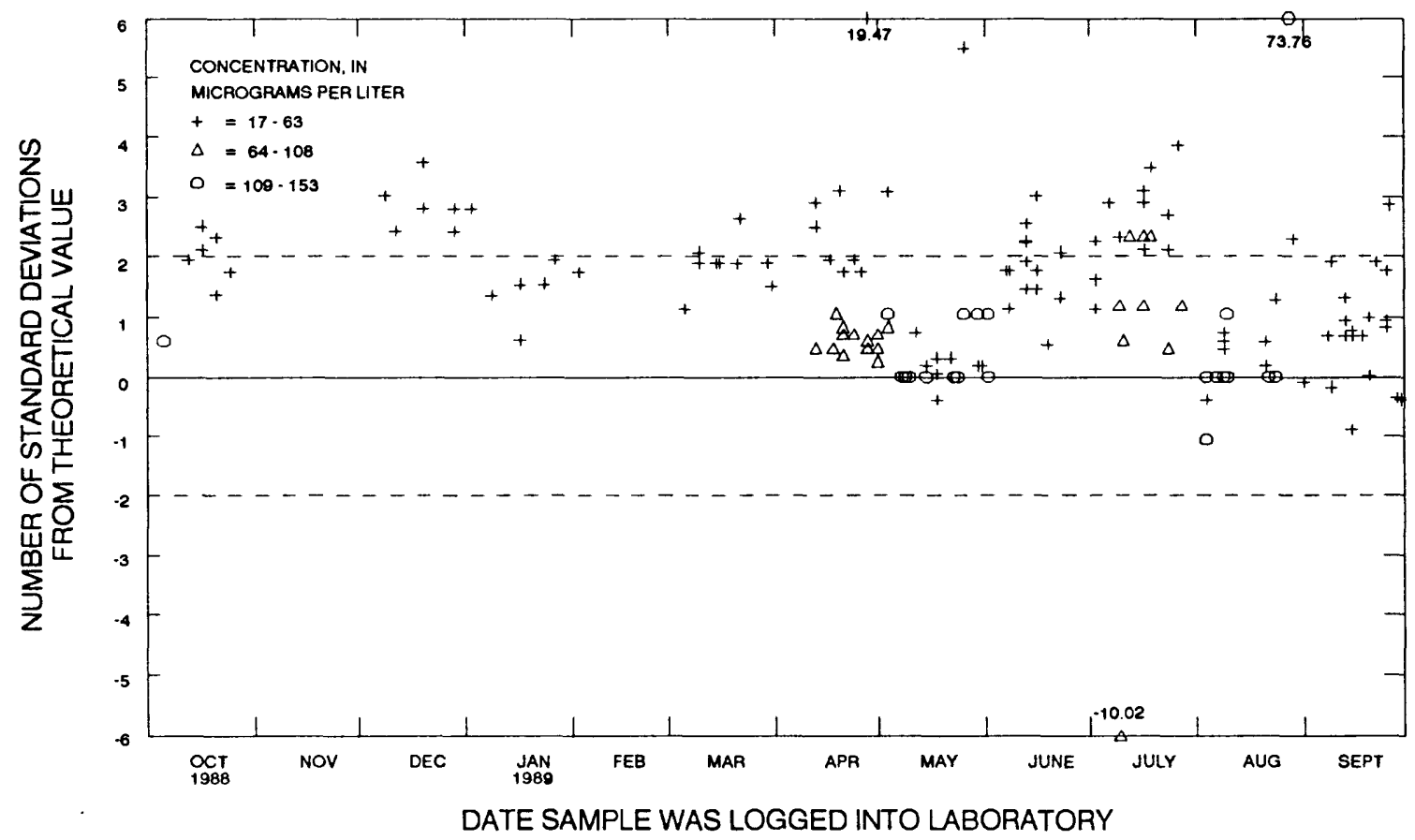

Figure 61.--Zinc, dissolved, (inductively coupled plasma emission spectrometry) data from the National Water Quality Laboratory.

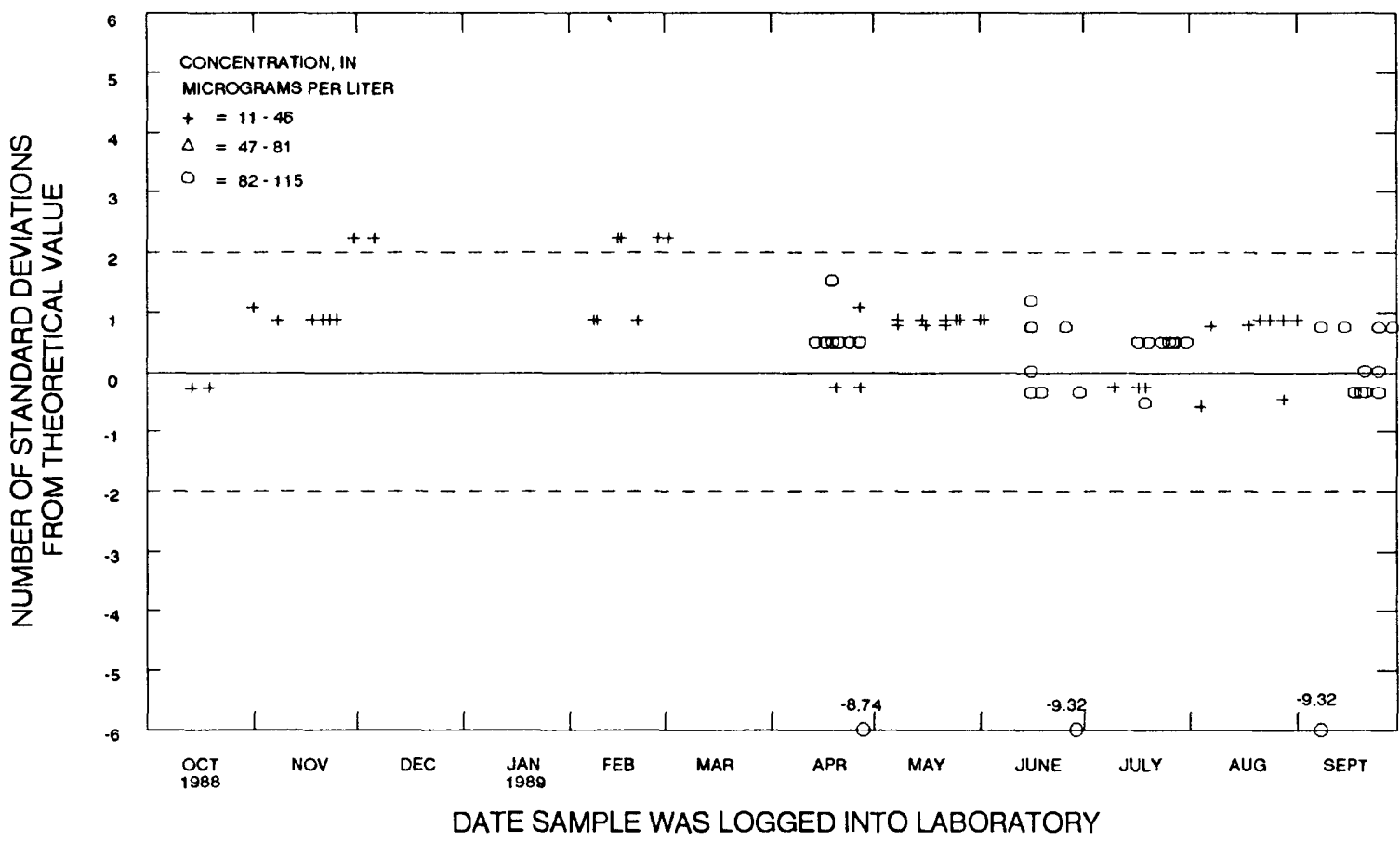

Figure 62.-- Zinc, dissolved, (atomic absorption spectrometry) data from the National Water Quailty Laboratory. 


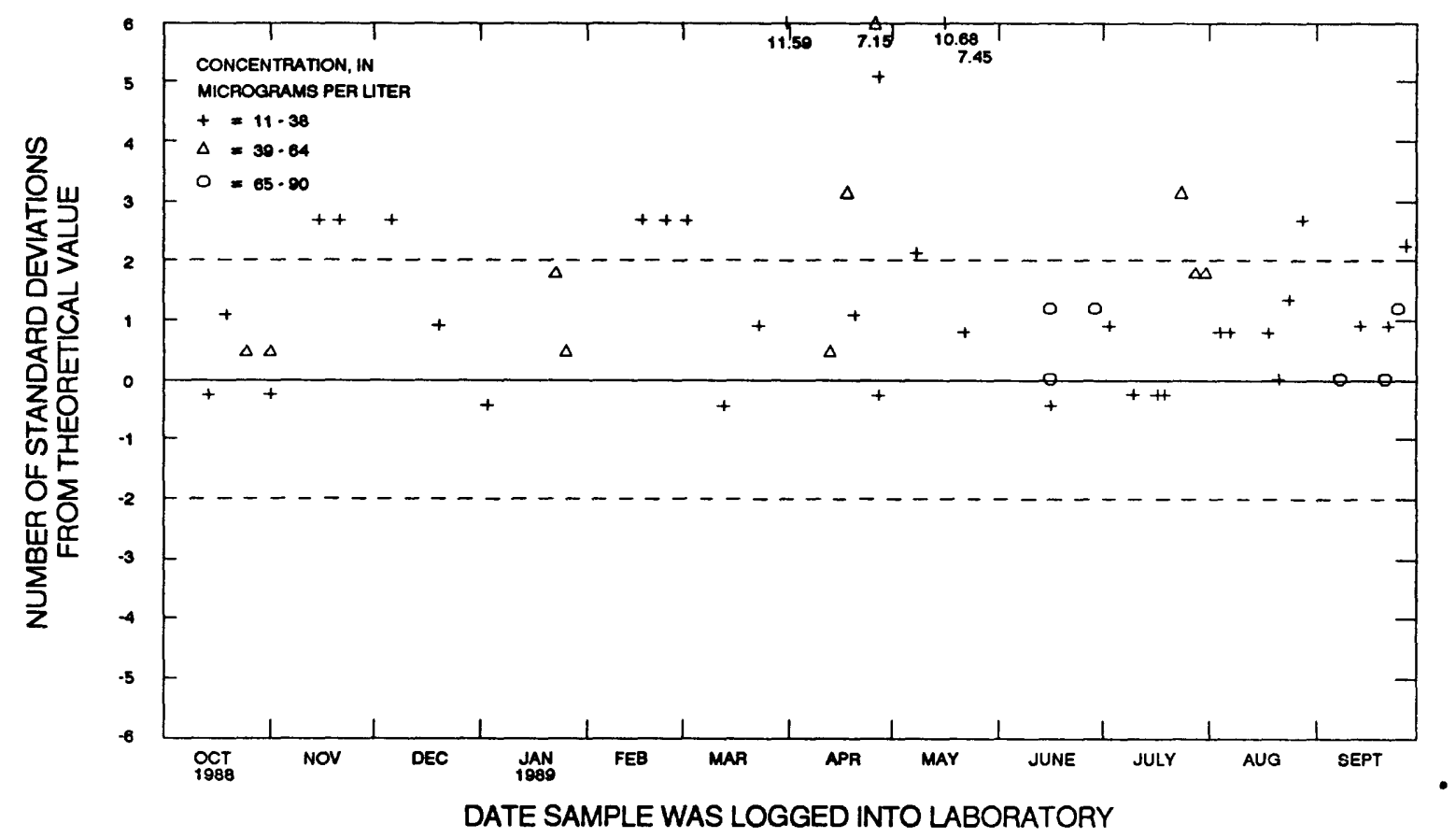

Figure 63.-- Zinc, total recoverable, (atomic absorption spectrometry) data from the National Water Quality Laboratory.

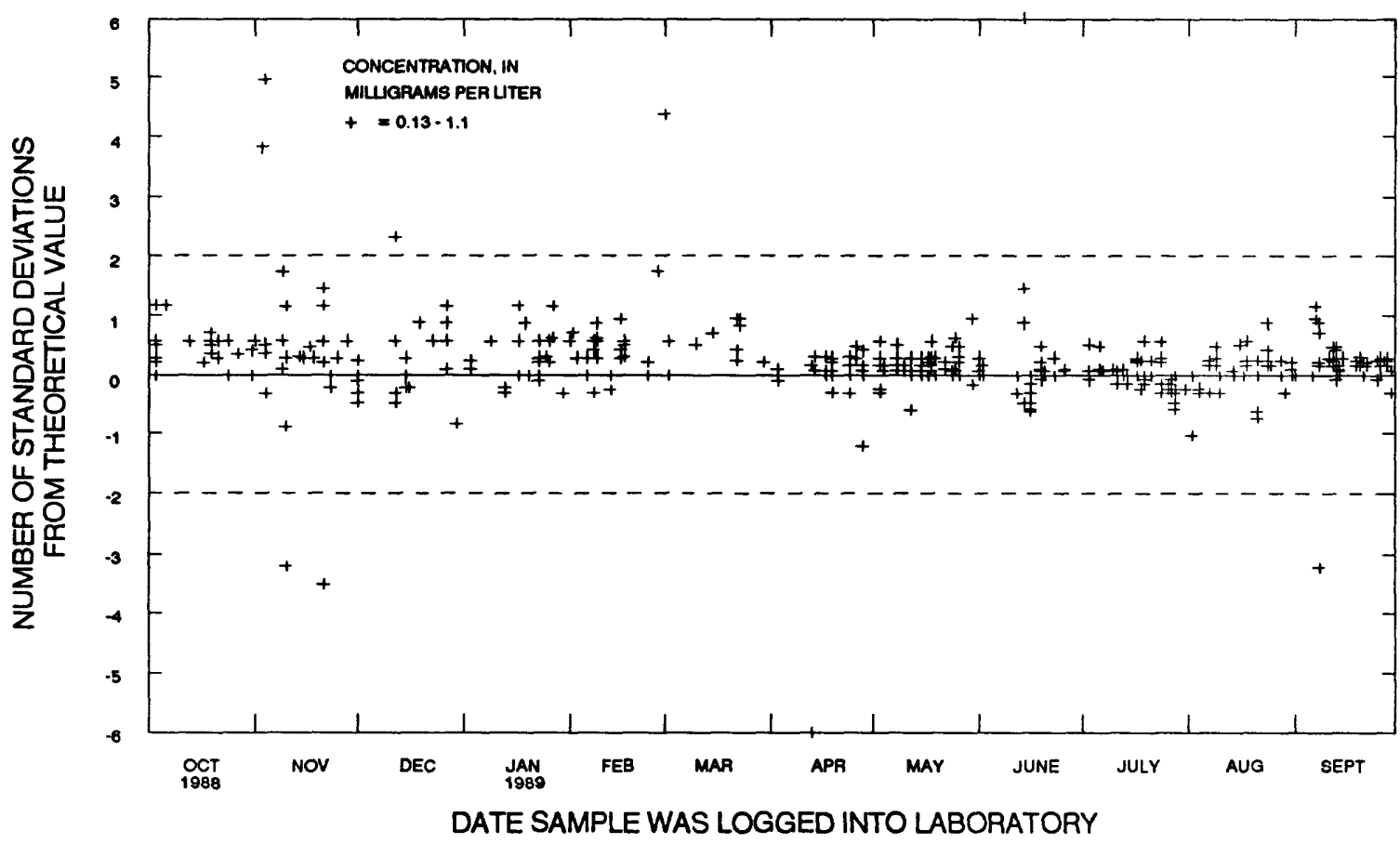

Figure 64.-- Ammonla as nitrogen, dissolved and total, (colorimetric)

data from the Natlonal Water Quality Laboratory. 


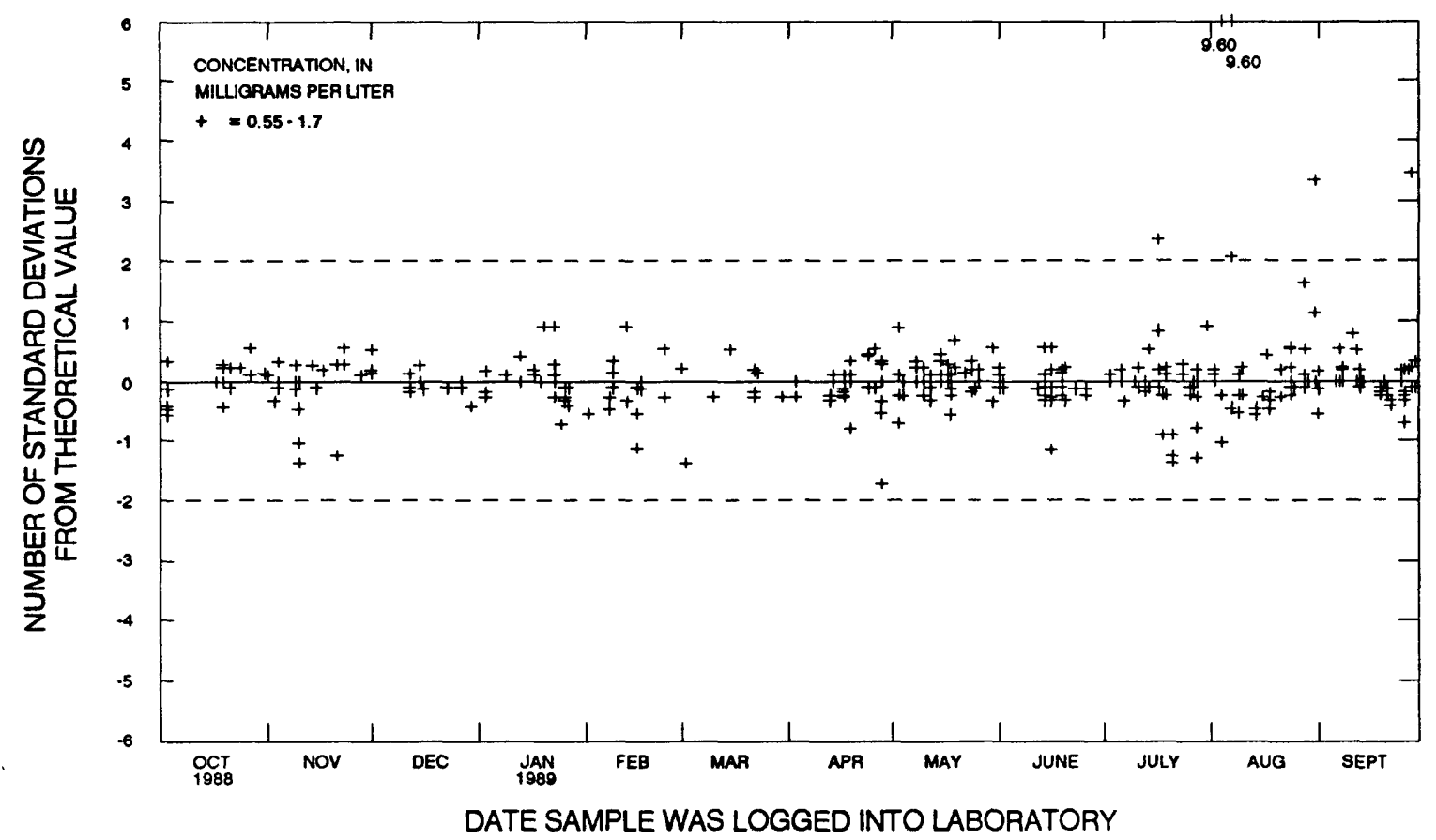

Figure 65.--Ammonla plus organic nitrogen, dissolved and total, (colorimetric) data from the National Water Quality Làboratory.

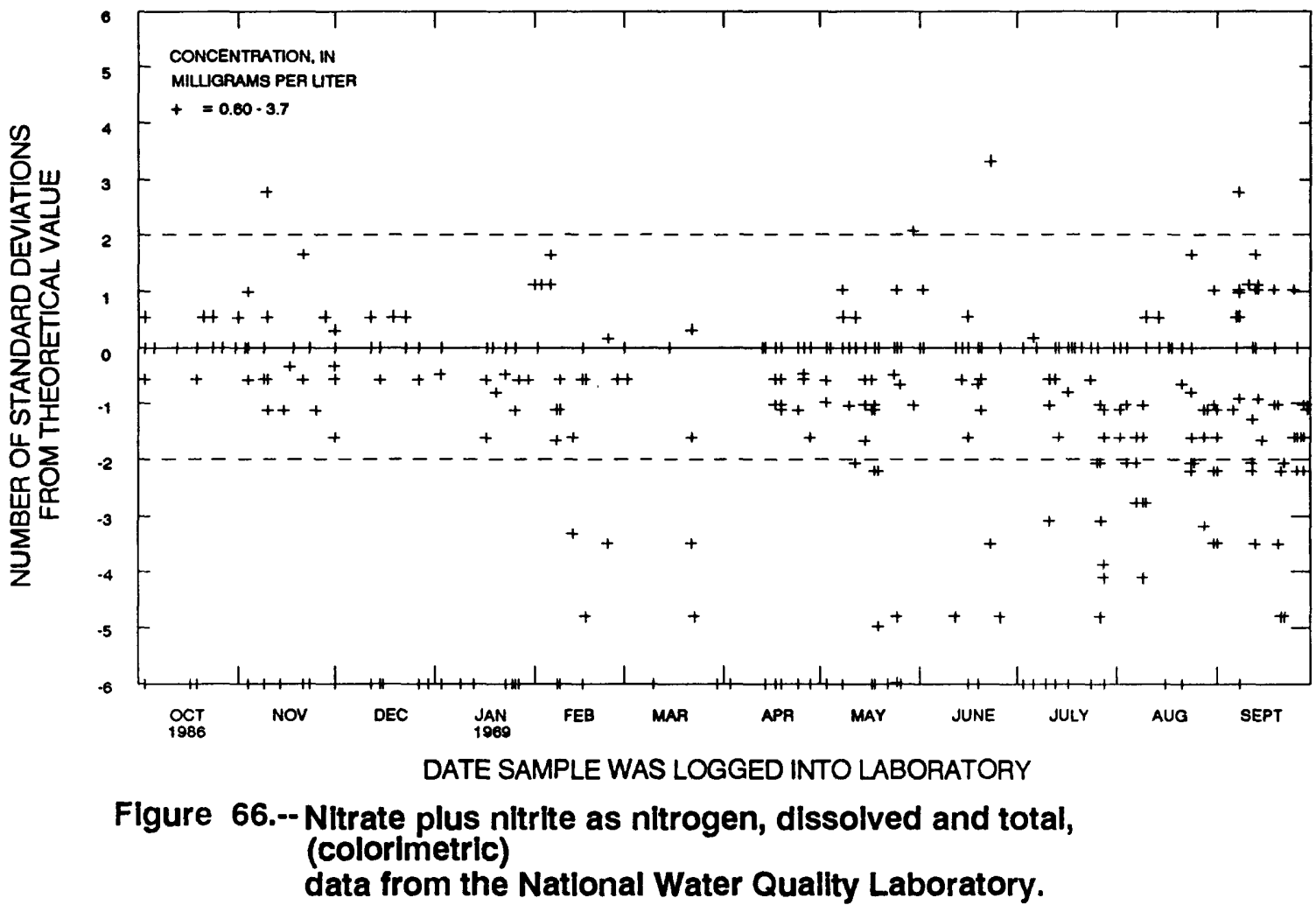




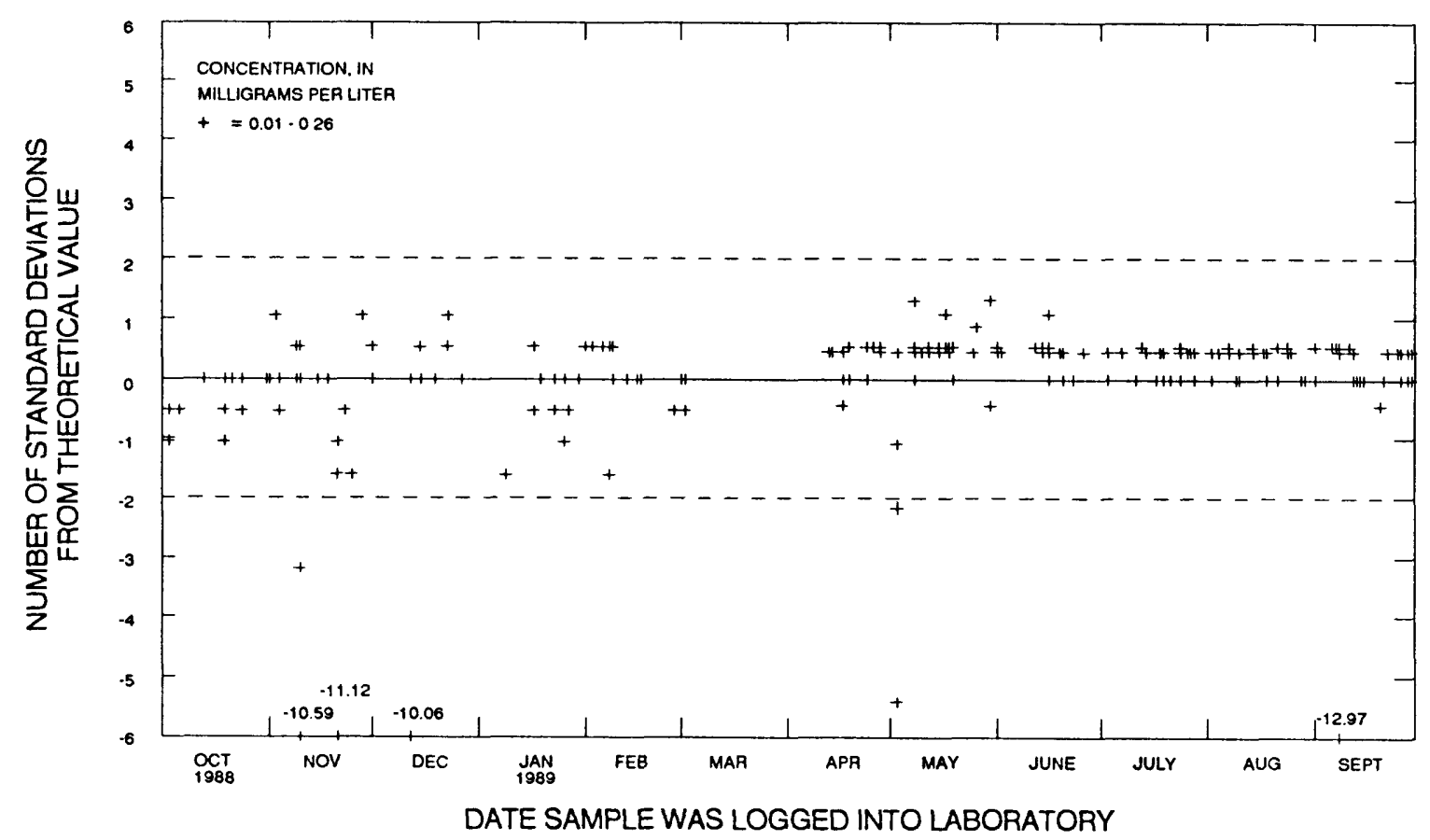

Figure 67.-- Nitrite as nitrogen, dissolved and total, (colorimetric)

data from the National Water Quality Laboratory.

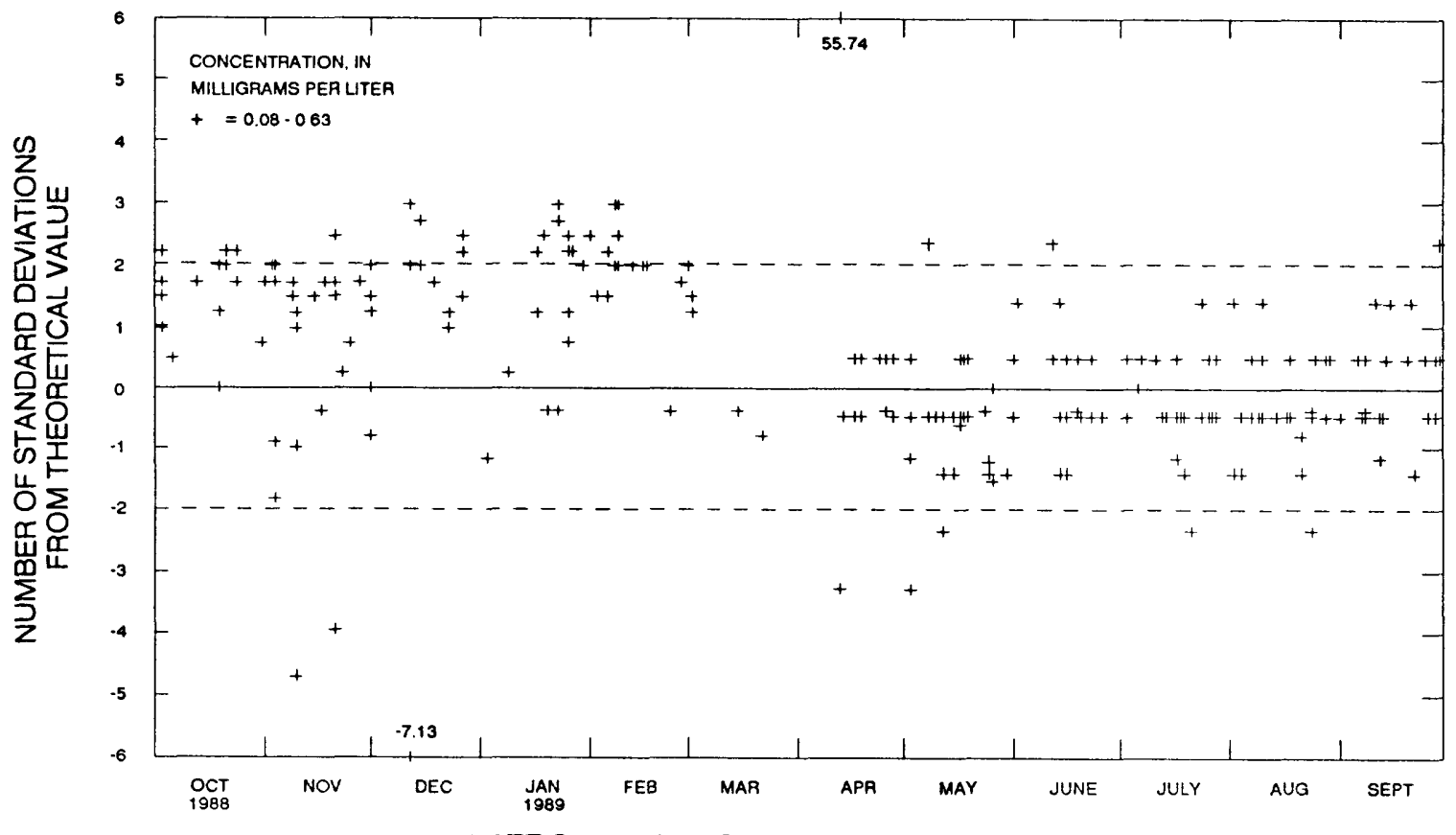

DATE SAMPLE WAS LOGGED INTO LABORATORY

Figure 68.-- Orthophosphate as phosphorus, dissolved and total, (colorimetric)

data from the National Water Quality Laboratory. 


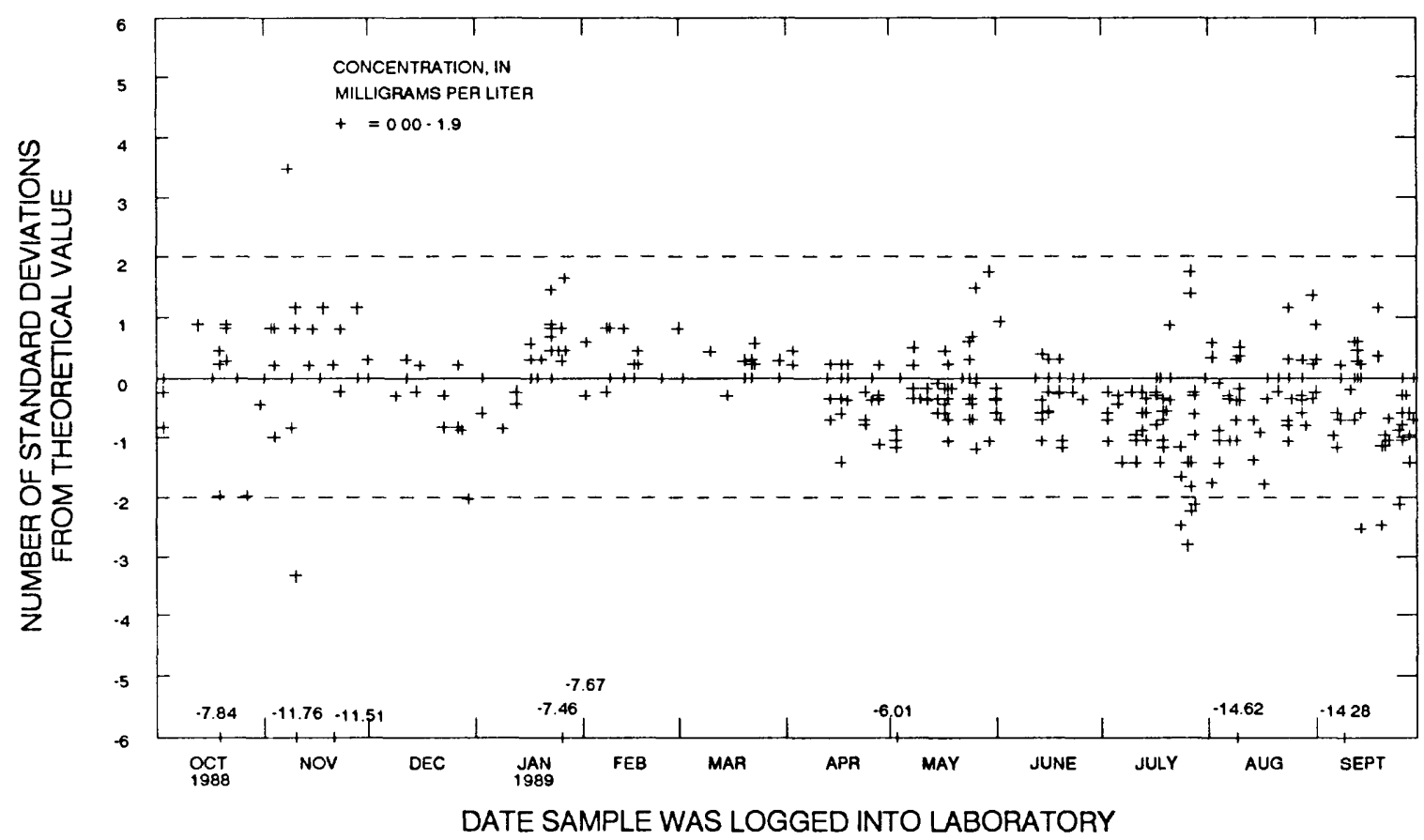

Figure 69.--Phosphorus, dissolved and total, (colorimetric)

data from the National Water Quality Laboratory.

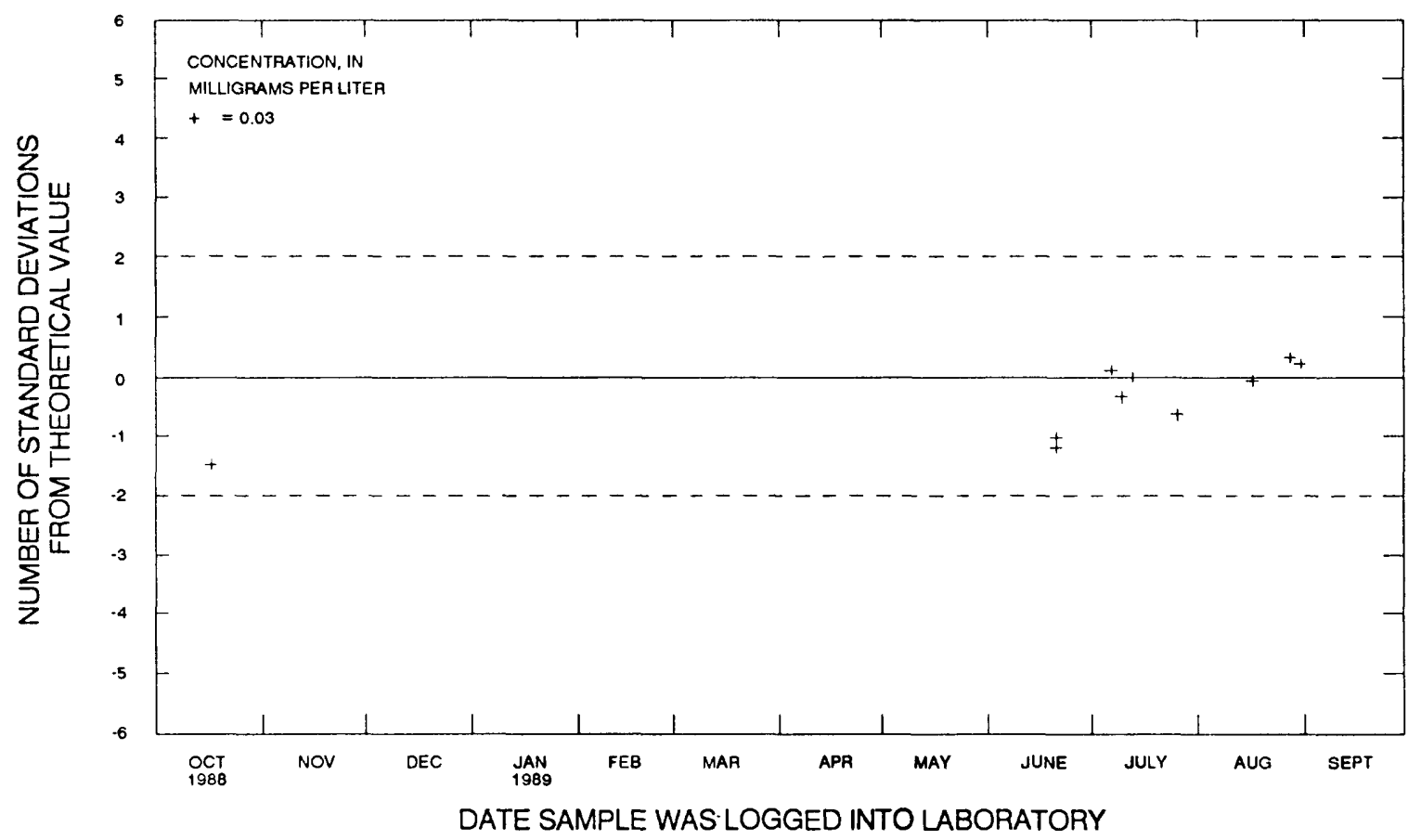

Figure 70.--Ammonia as nitrogen, dissolved and total, low ionic strength, (colorimetric) data from the National Water Quality Laboratory. 


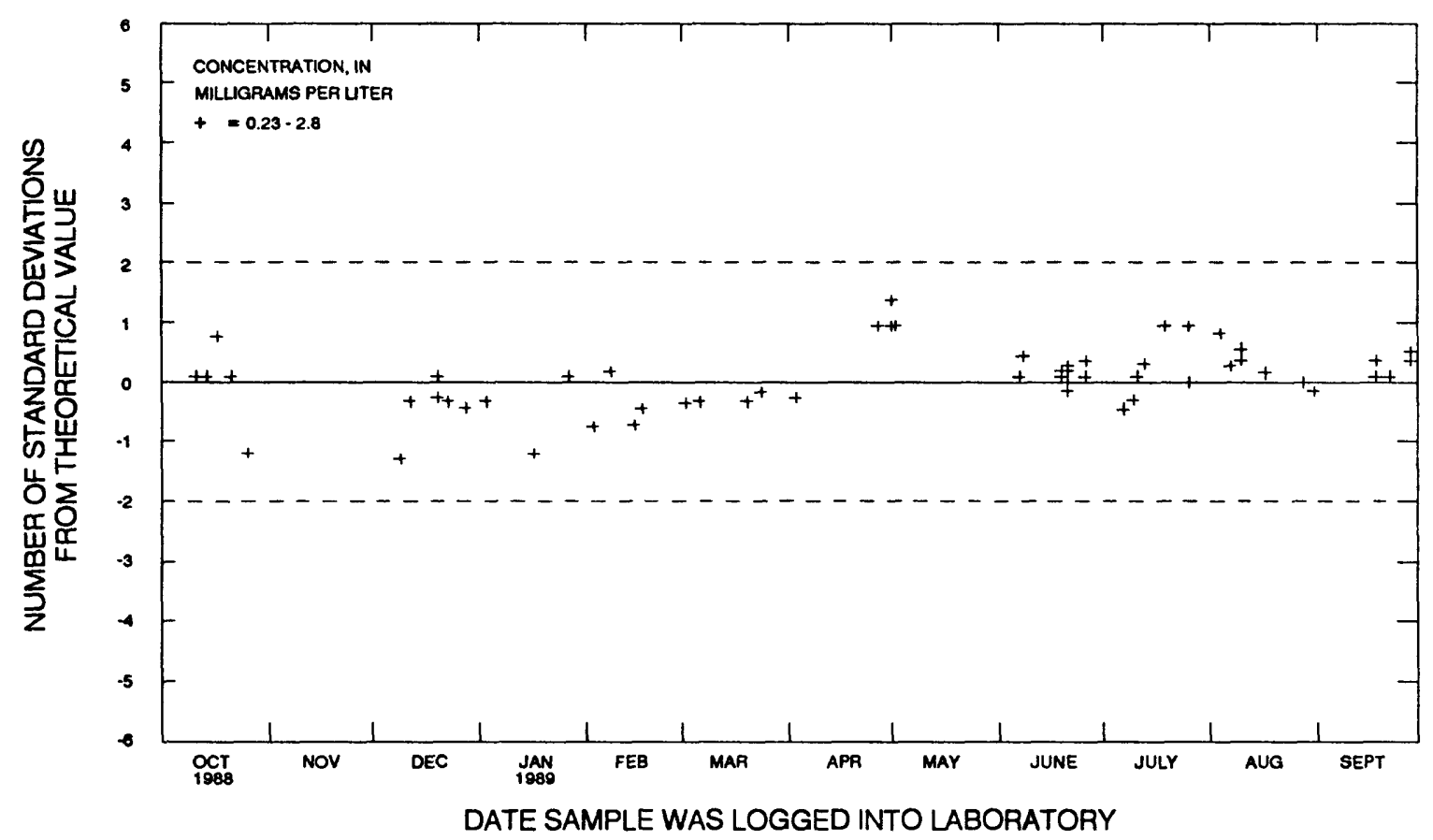

Figure 71.-- Calclum, dlssolved, low lonic strength, (atomlc absorptlon spectrometry) data from the National Water Quality Laboratory.

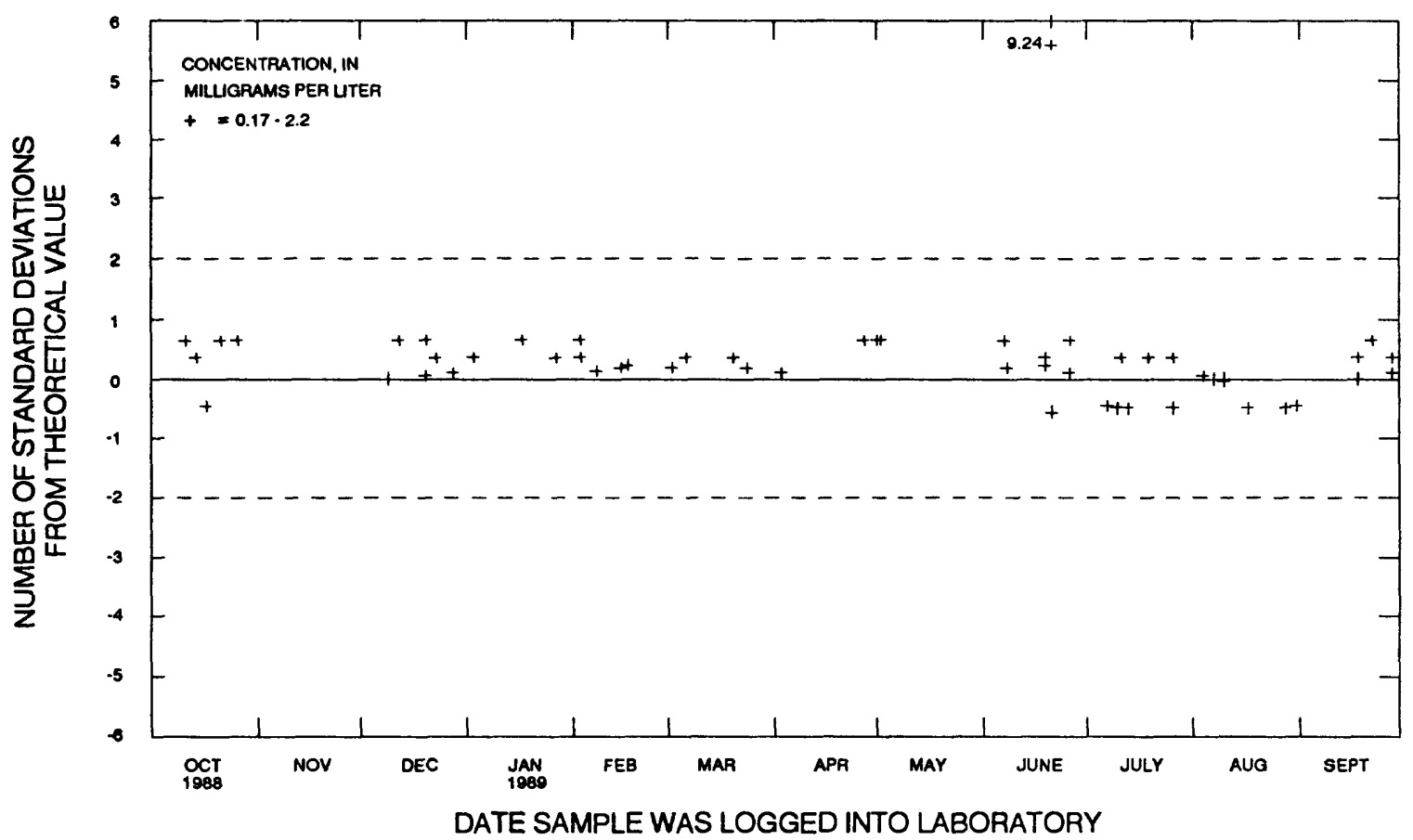

Flgure 72.-- Chloride, dlssolved, low lonlc strength, (lon chromatography)

data from the Natlonal Water Quality Laboratory. 


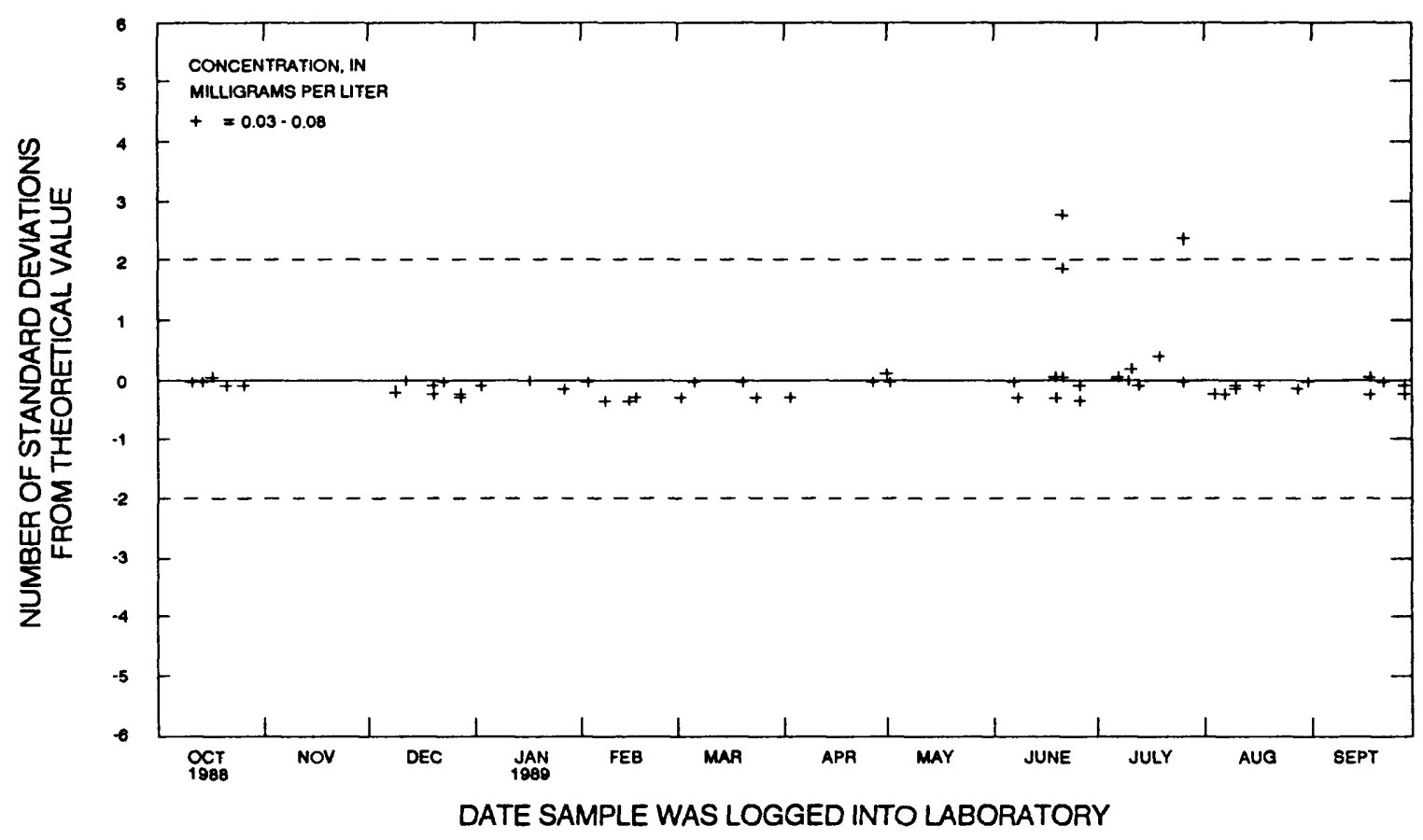

Figure 73.-- Fluoride, dissolved, low lonic strength, (ion chromatography)

data from the National Water Quality Laboratory.

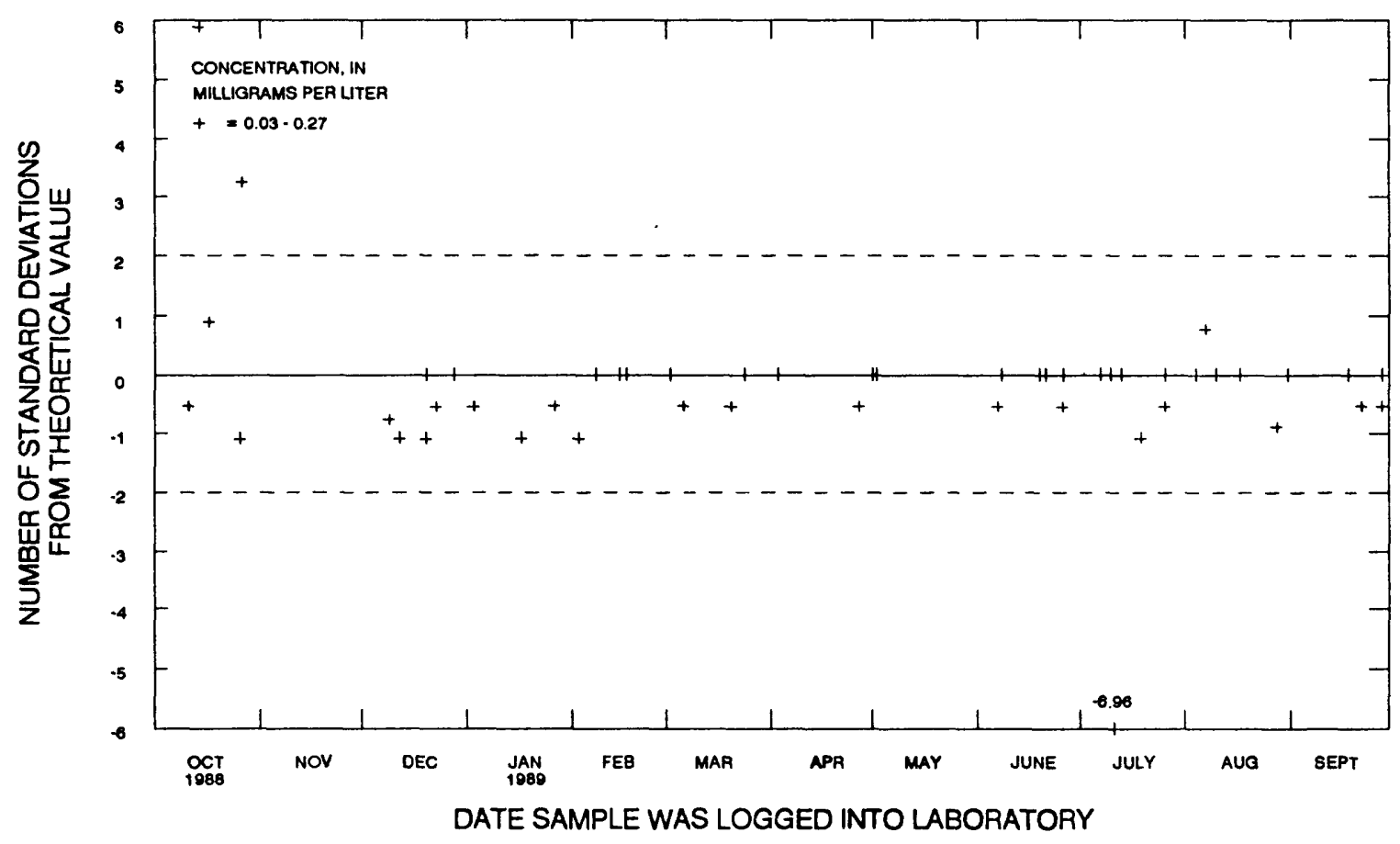

Figure 74.-- Magneslum, dissolved, low lonlc strength, (atomic absorption spectrometry) data from the National Water Quality Laboratory. 


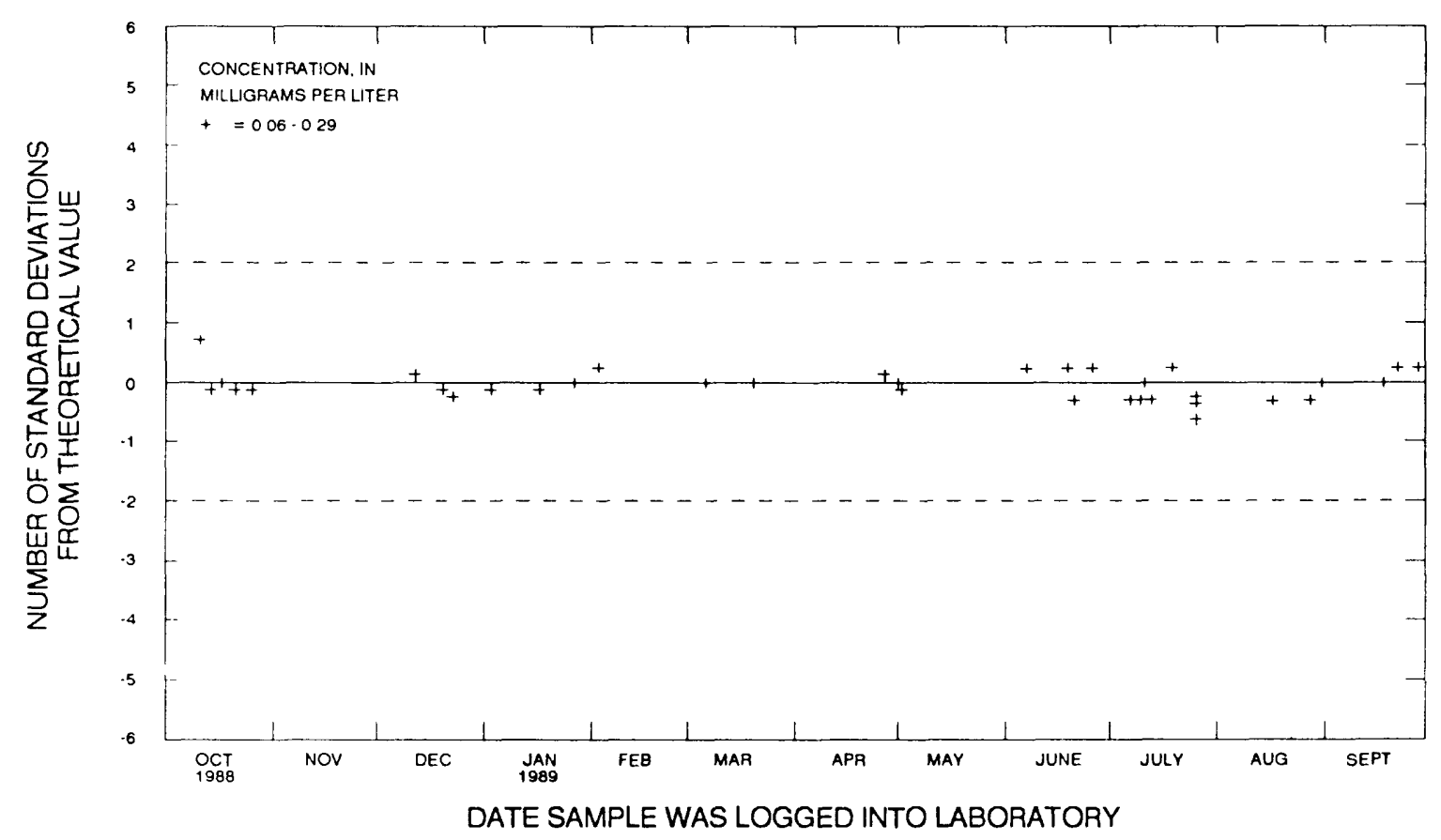

Figure 75.-- Nitrate plus nitrite as nitrogen, dlssolved, low lonic strength, (ion chromatography)

data from the National Water Quality Laboratory.

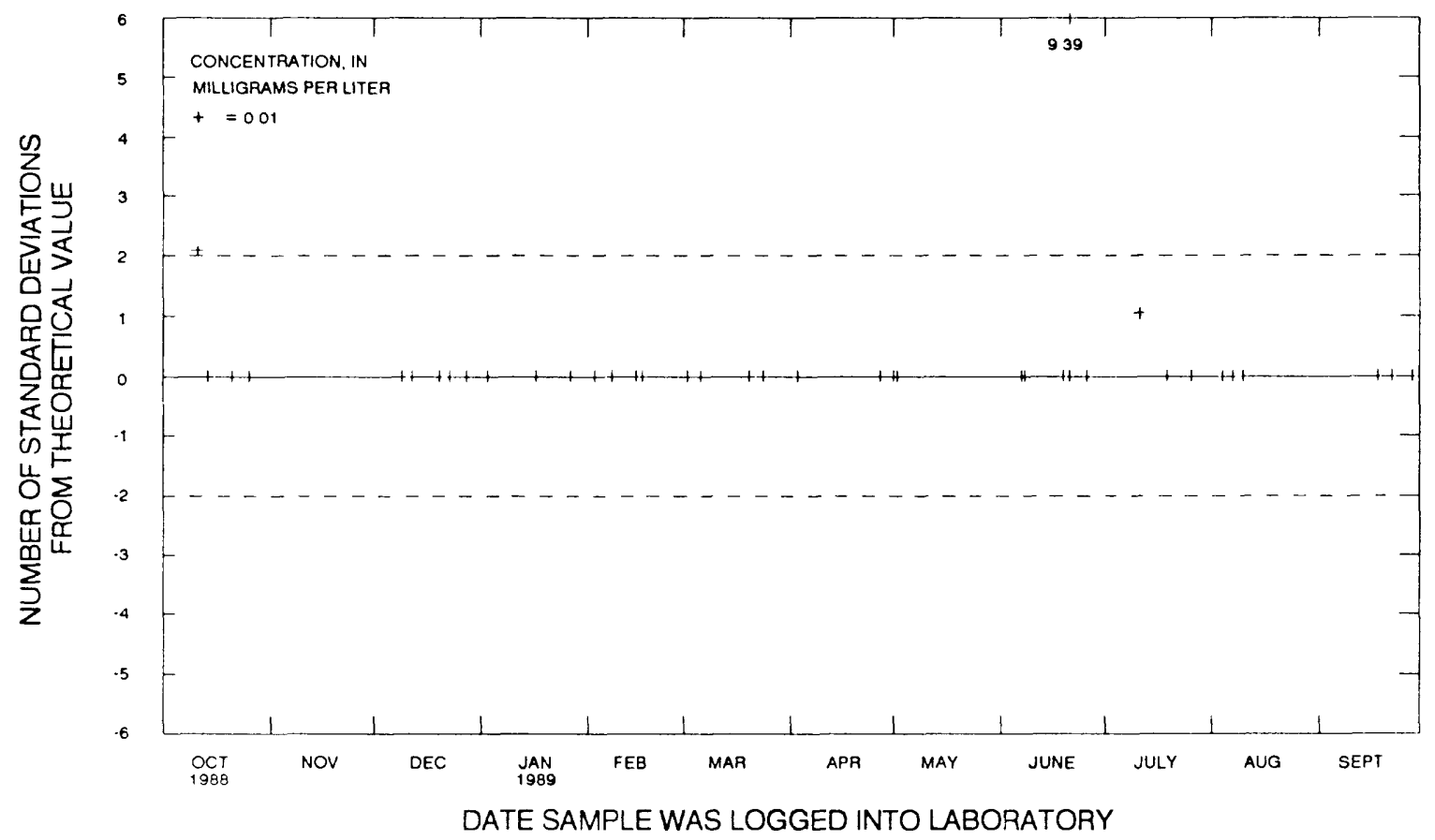

Figure 76.--Orthophosphate as phosphorus, dissolve 1 and total, low ionic strength, (ion chromatography) data from the Nationai Water Quality Laboratory. 


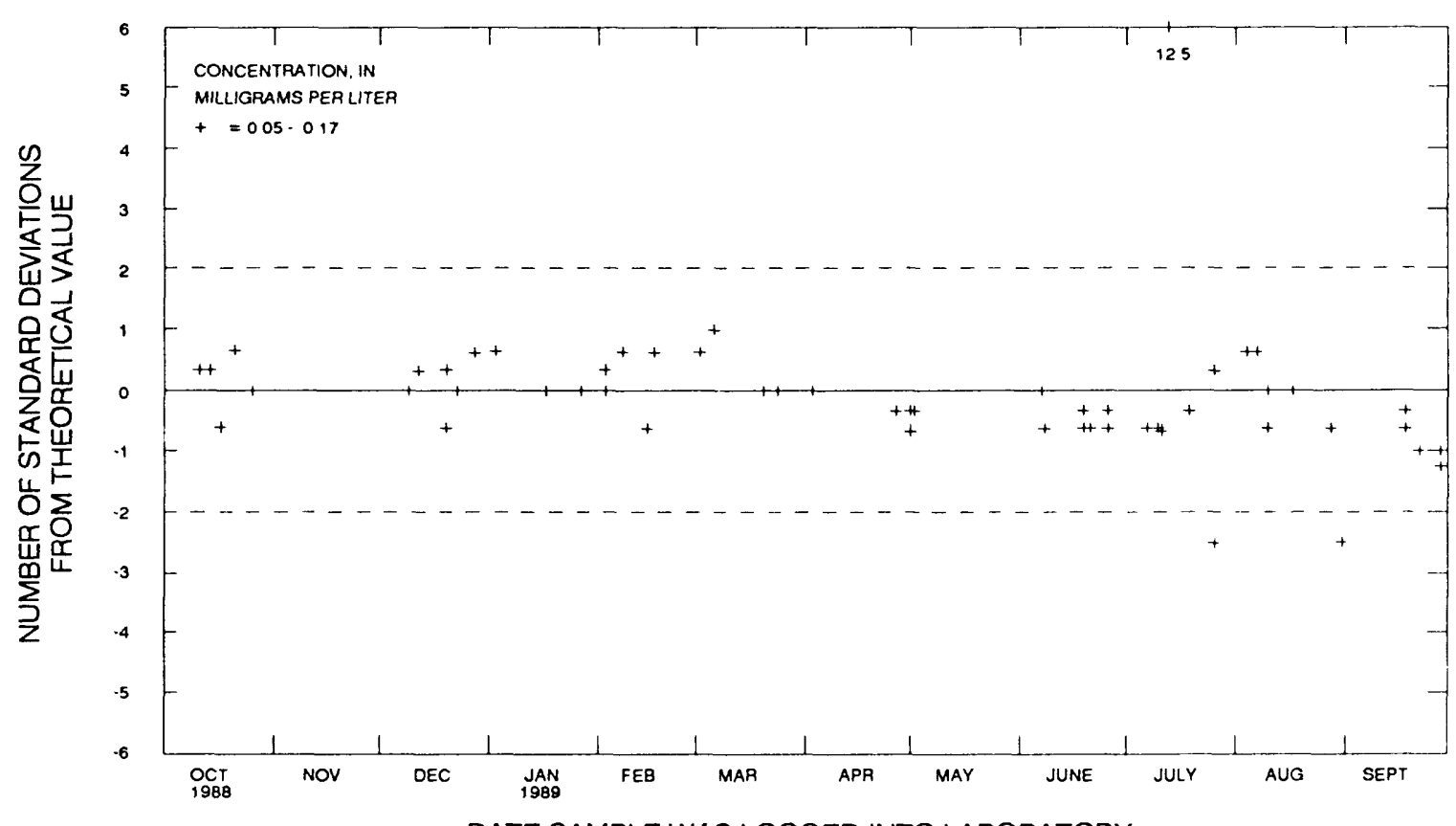

DATE SAMPLE WAS LOGGED INTO LABORATORY

Figure 77.--Potassium, dissolved, low ionic strength, (atomic absorption spectrometry) data from the National Water Quality Laboratory.

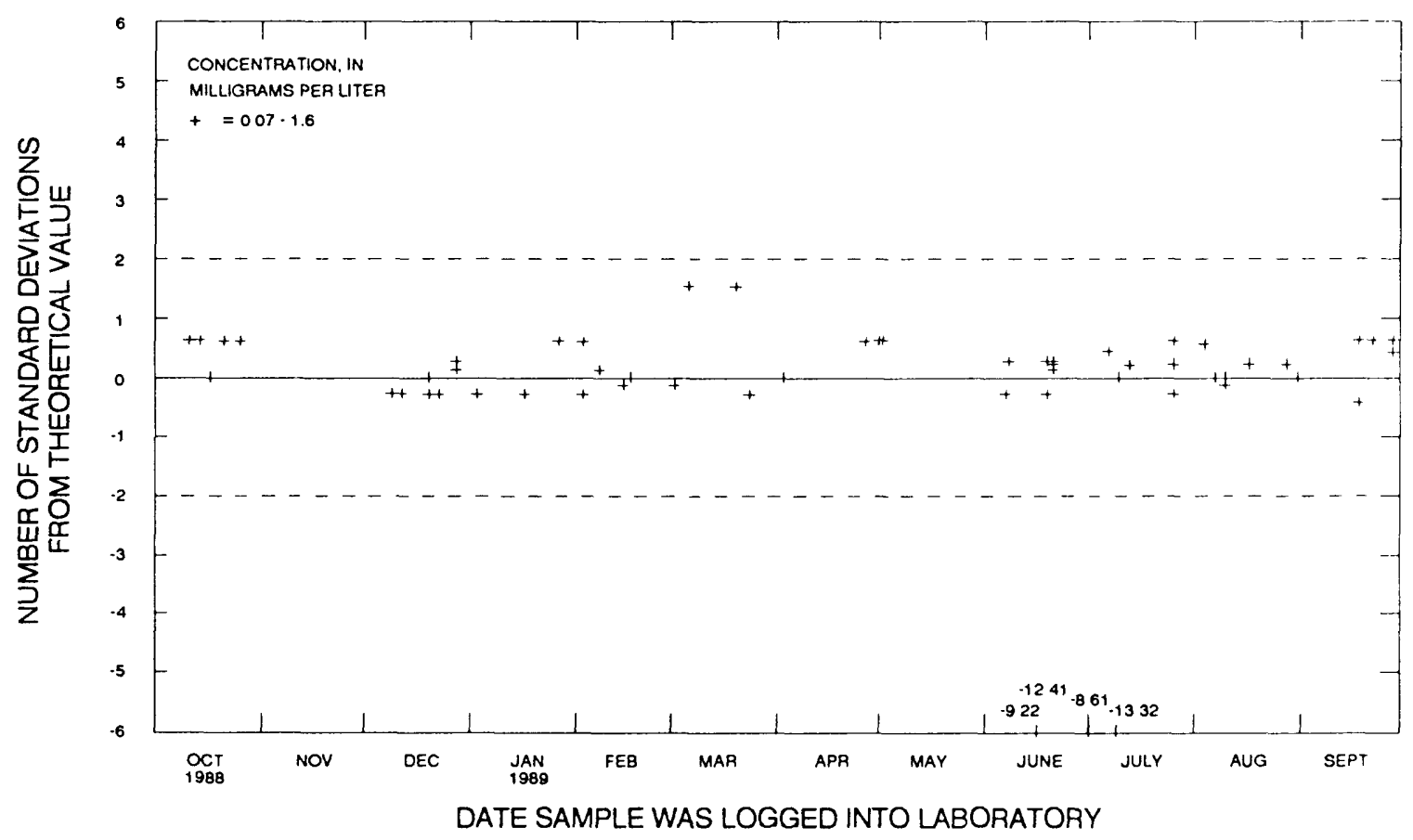

Figure 78.-- Sodium, dissolved, low ionic strength, (atomic absorption spectrometry) data from the National Water Quality Laboratory. 


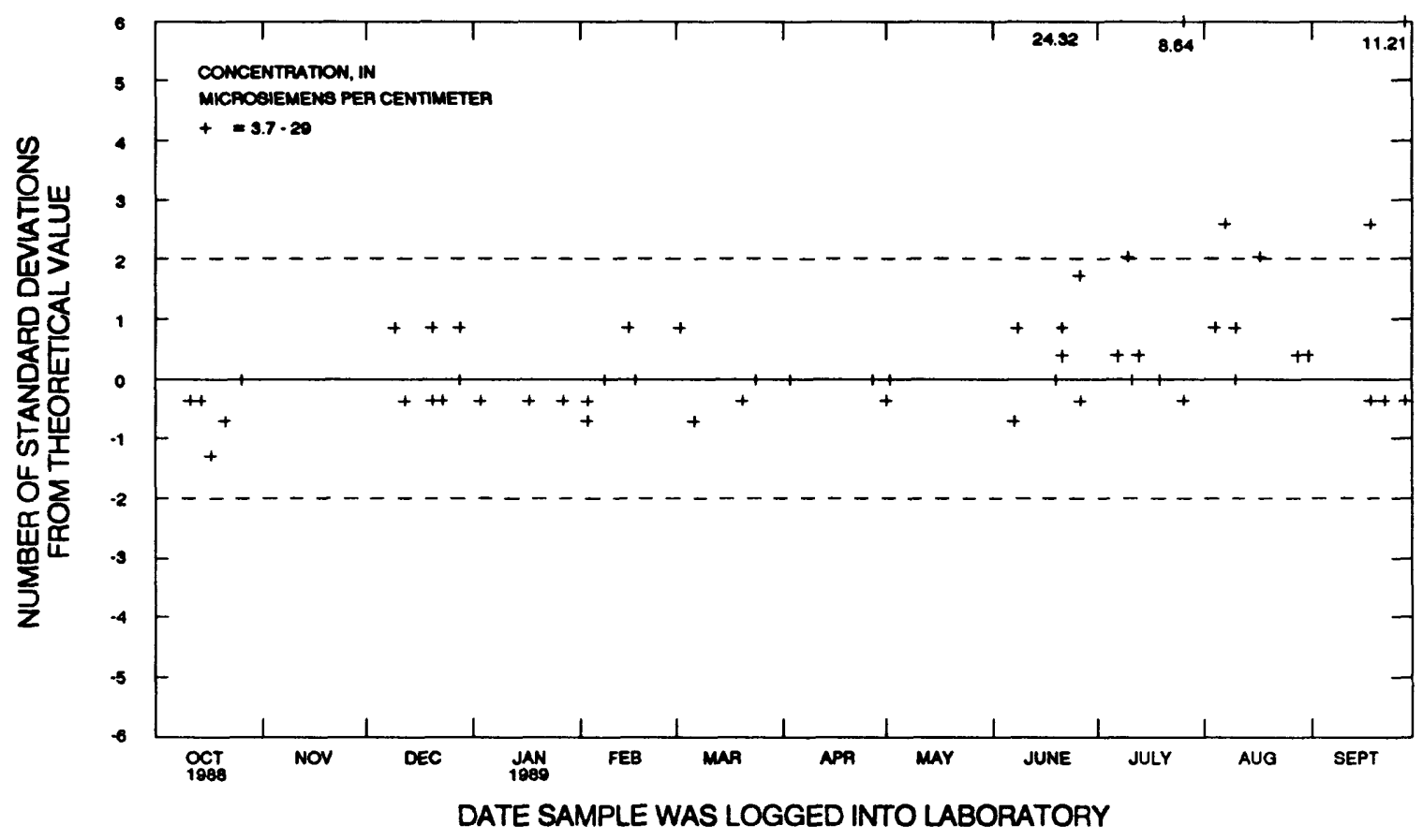

Figure 79.-- Specific conductance, dlssolved, low lonic strength, (wheatstone bridge)

data from the National Water Quality Laboratory.

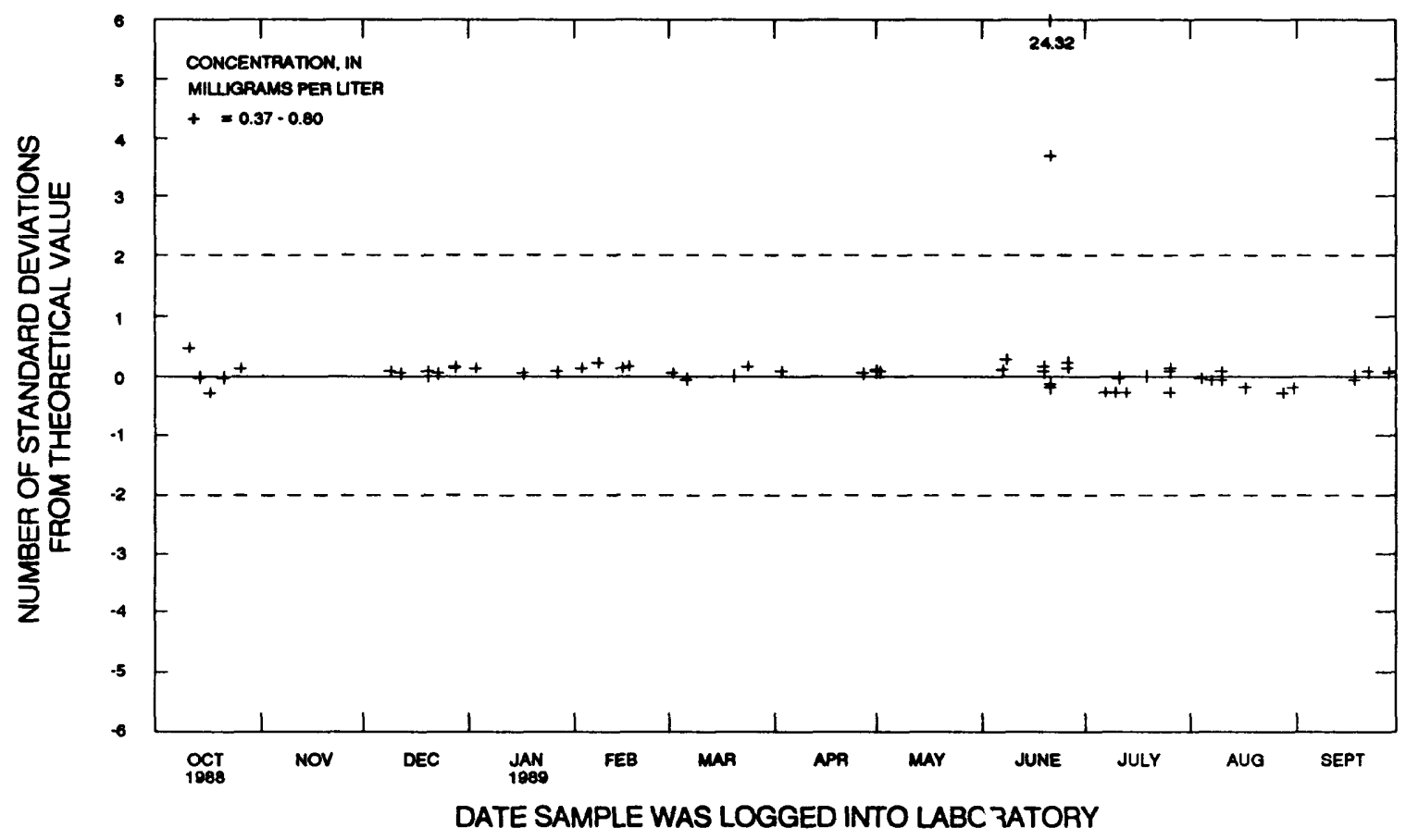

Figure 80.--Sulfate, dissolved, low lonic strength, (ion chromatography) data from the National Water Quality Laboratory. 


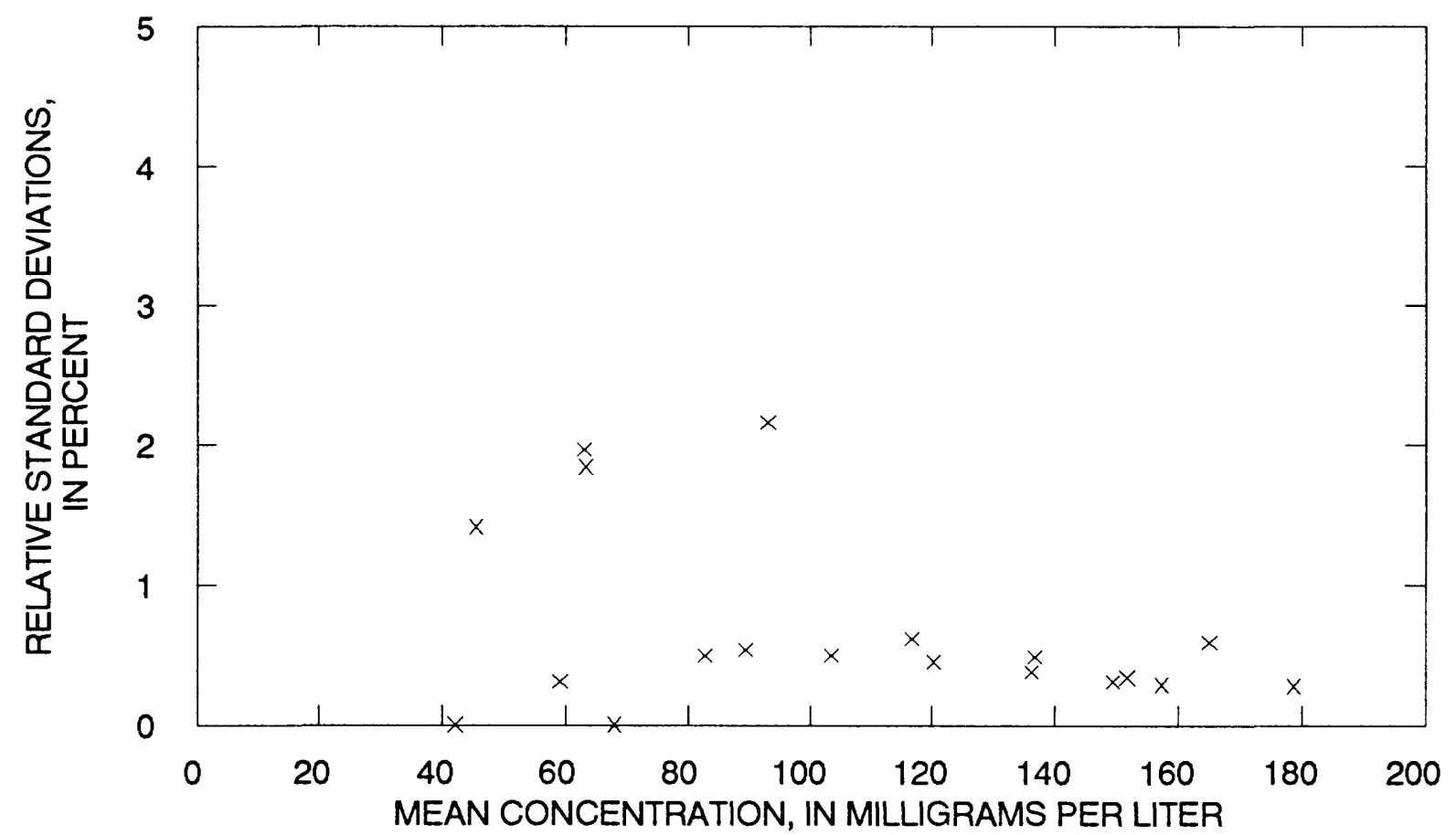

Figure 81.-- Precision data for alkalinity, total, (electrometric titration)

data from the National Water Quality Laboratory.

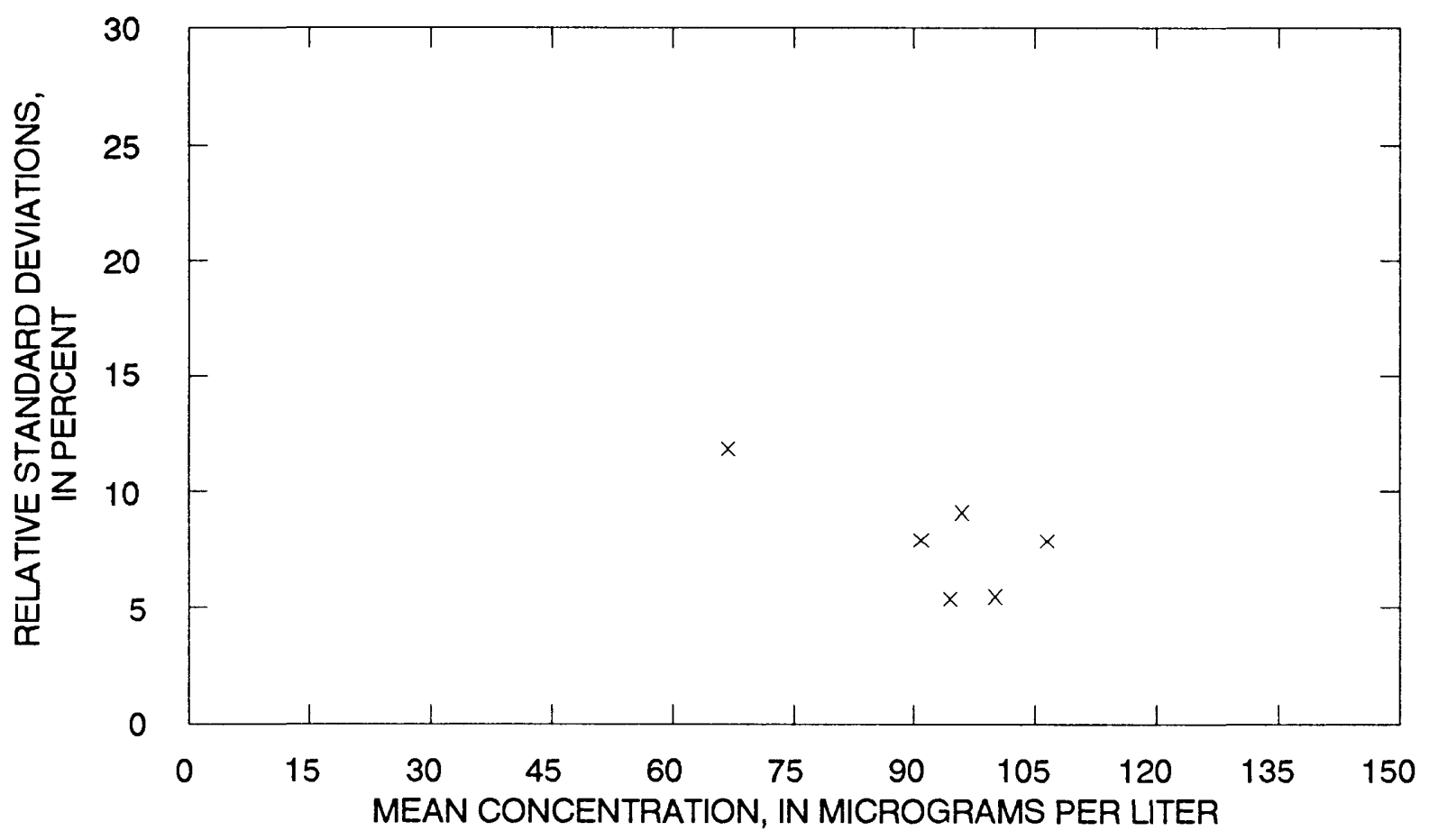

Figure 82.-- Precision data for aluminum, dissolved,

(direct current plasma emission spectrometry)

data from the National Water Quality Laboratory. 


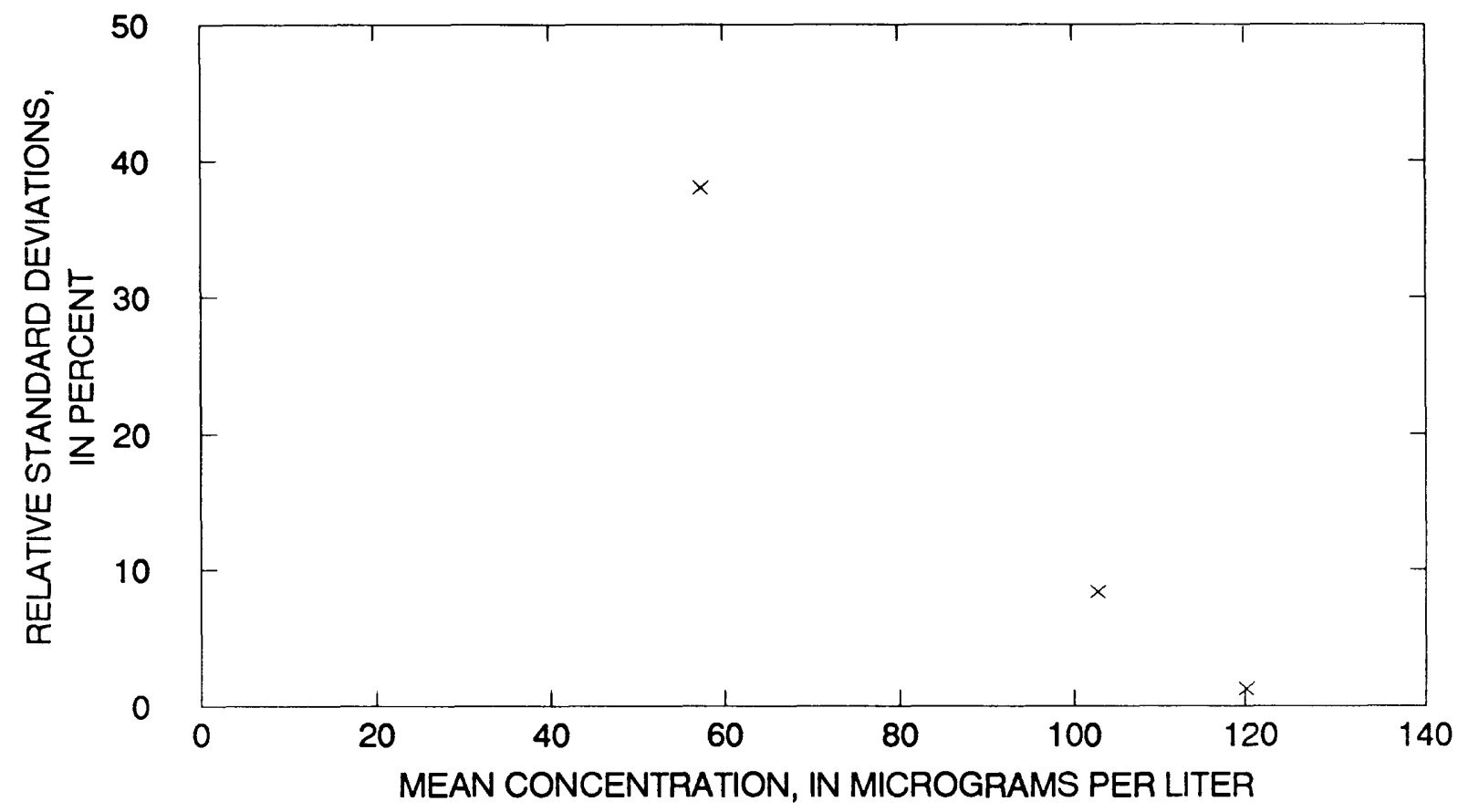

Figure 83.-- Precision data for aluminum, total, (direct current plasma emission spectrometry) data from the National Water Quality Laboratory.

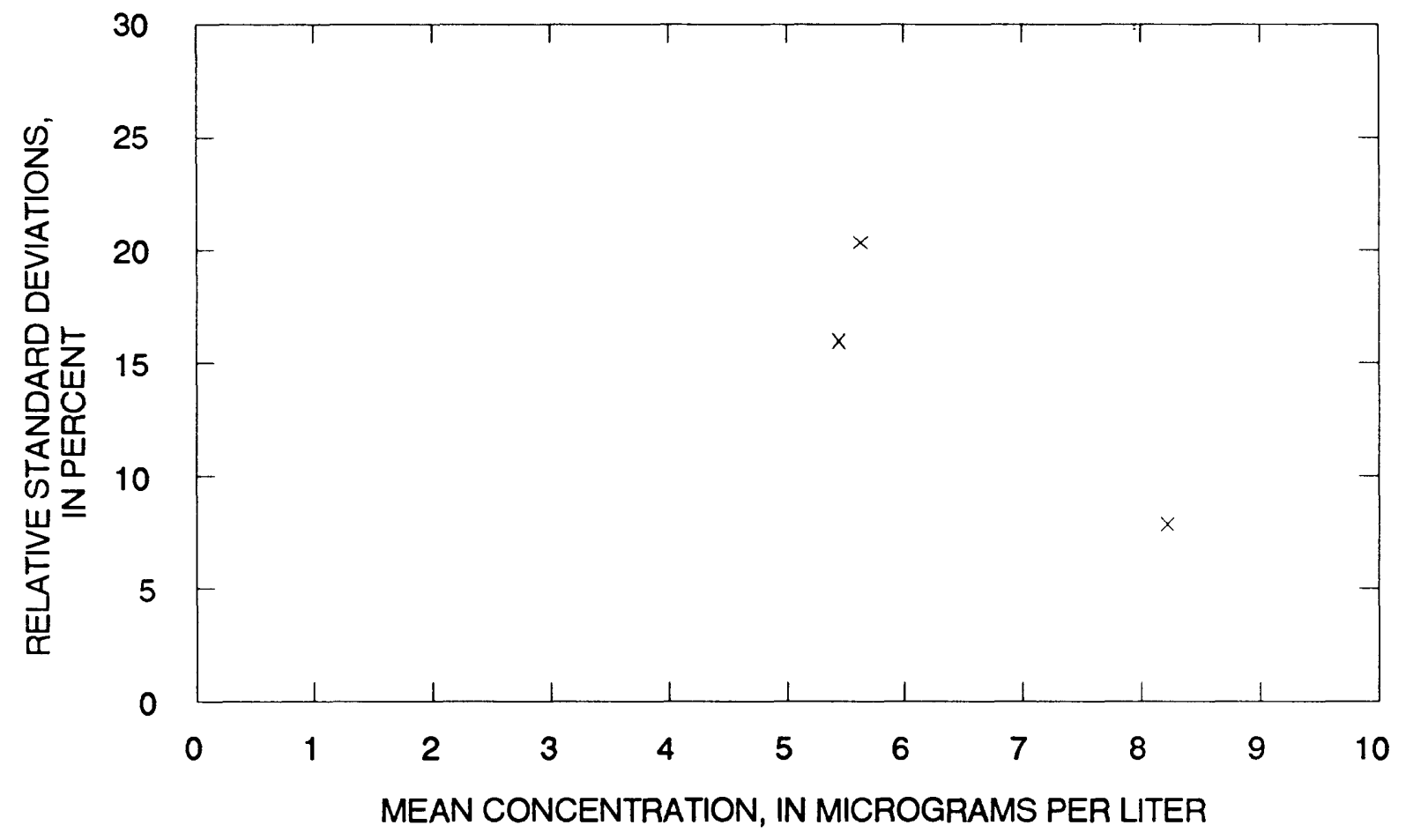

Figure 84.-- Precision data for antimony, dissolved and total, (atomic absorption spectrometry, hydride) data from the Natlonal Water Quality Laboratory. 


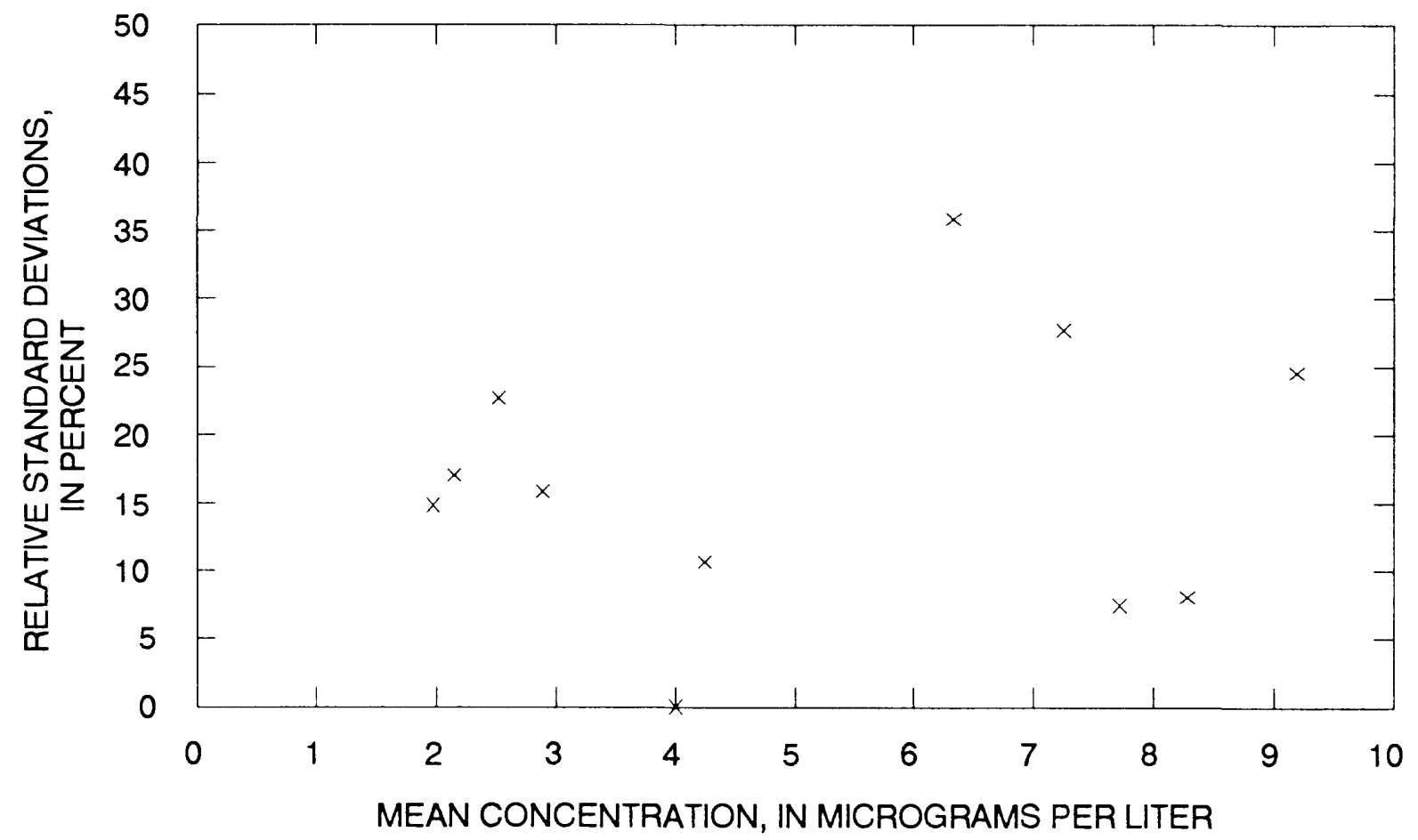

Figure 85.-- Precision data for arsenic, dissolved and total, (atomic absorption spectrometry, hydride)

data from the National Water Quality Laboratory.

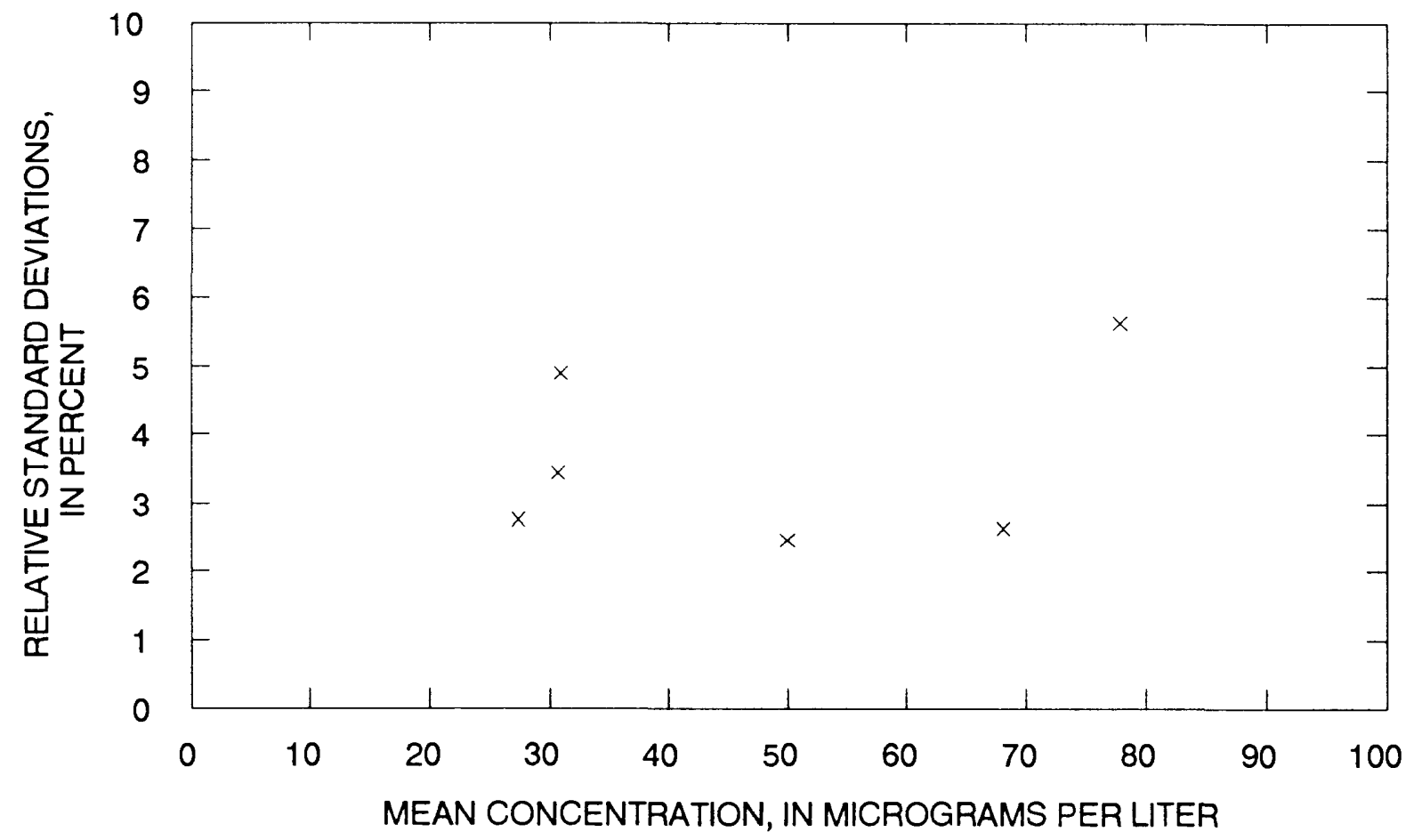

Figure 86.-- Precision data for barium, dissolved, (inductively coupled plasma emission spectrometry) data from the National Water Quality Laboratory. 


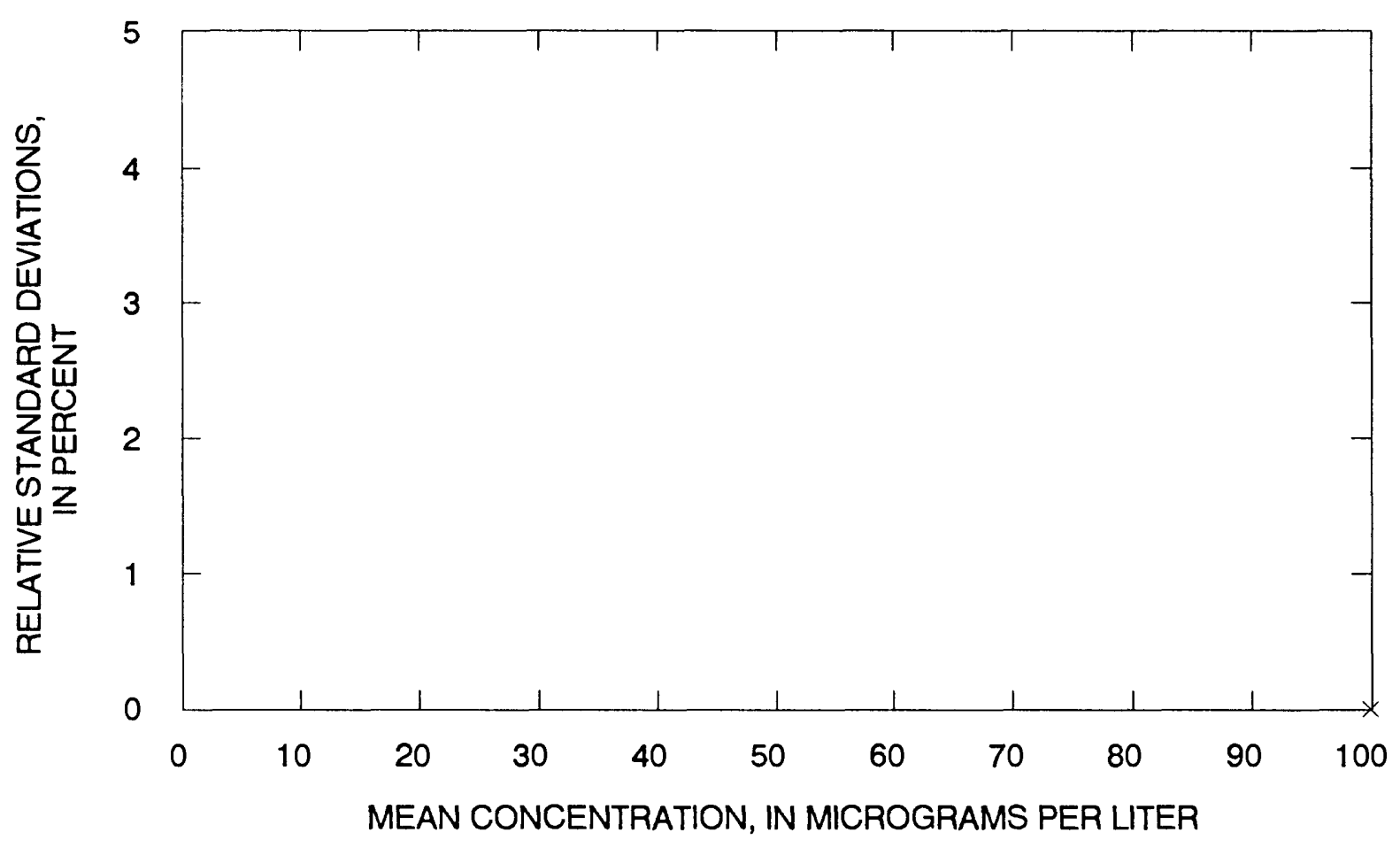

Figure 87.-- Precision data for barium, dissolved, (atomic absorption spectrometry)

data from the National Water Quality Laboratory.

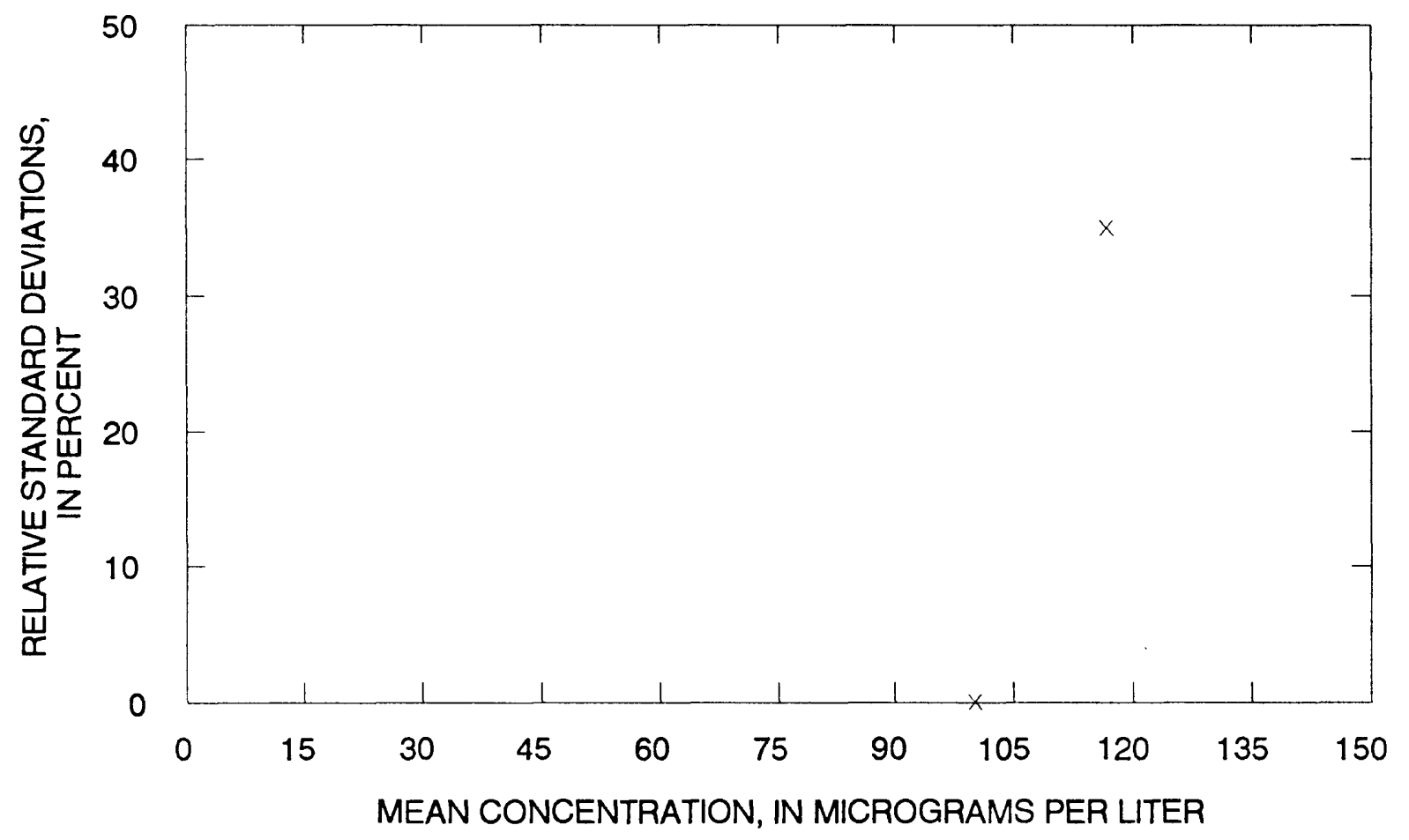

Figure 88.-- Precision data for barium, total recoverable, (atomic absorption spectrometry) data from the National Water Quality Laboratory. 


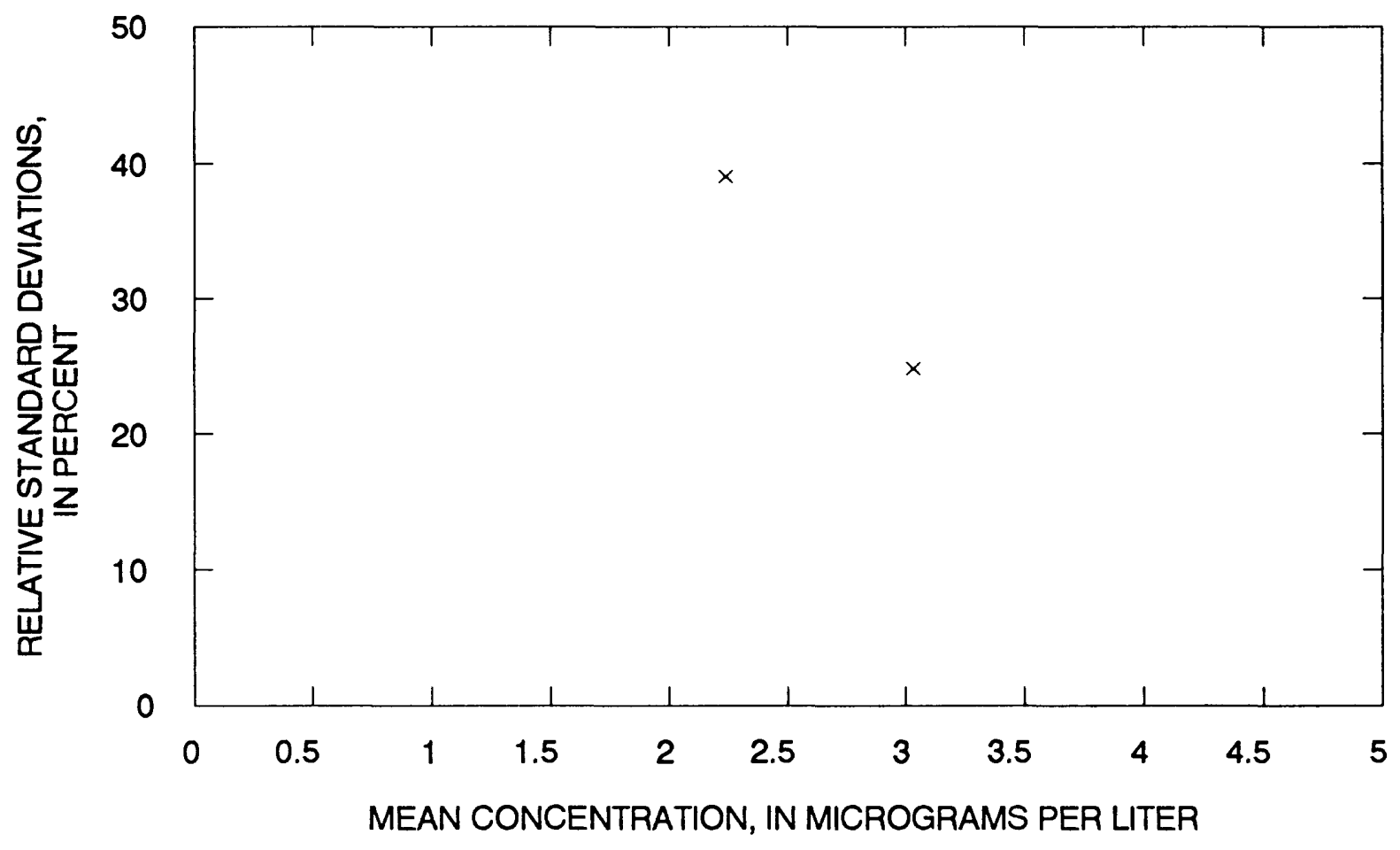

Figure 89.-- Preclslon data for beryllium, dissolved, (Inductively coupled plasma emlsslon spectrometry) data from the Natlonal Water Quality Laboratory.

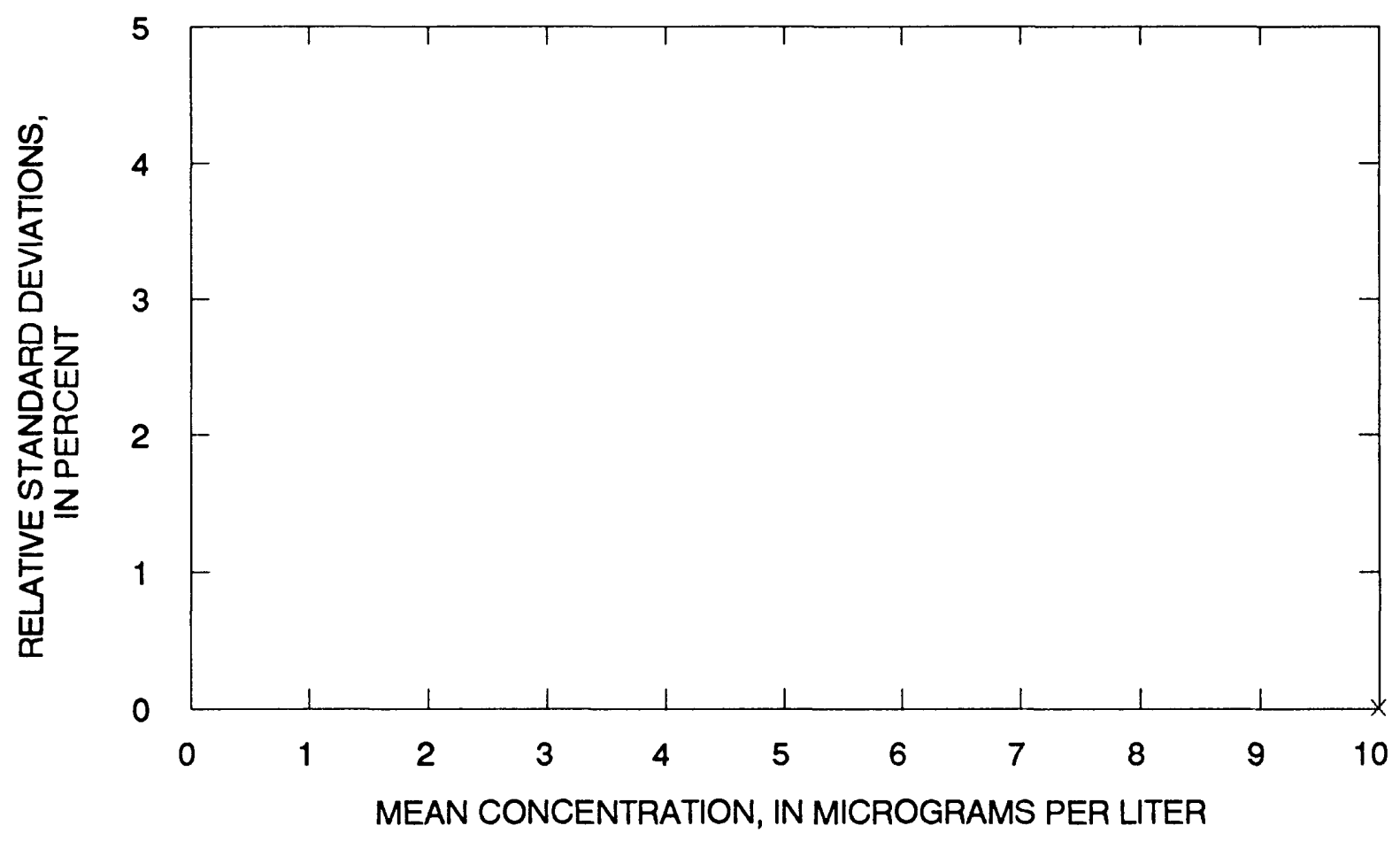

Figure 90.-- Preclsion data for beryllium, total recoverable, (atomic absorptlon spectrometry) data from the Natlonal Water Quality Laboratory. 

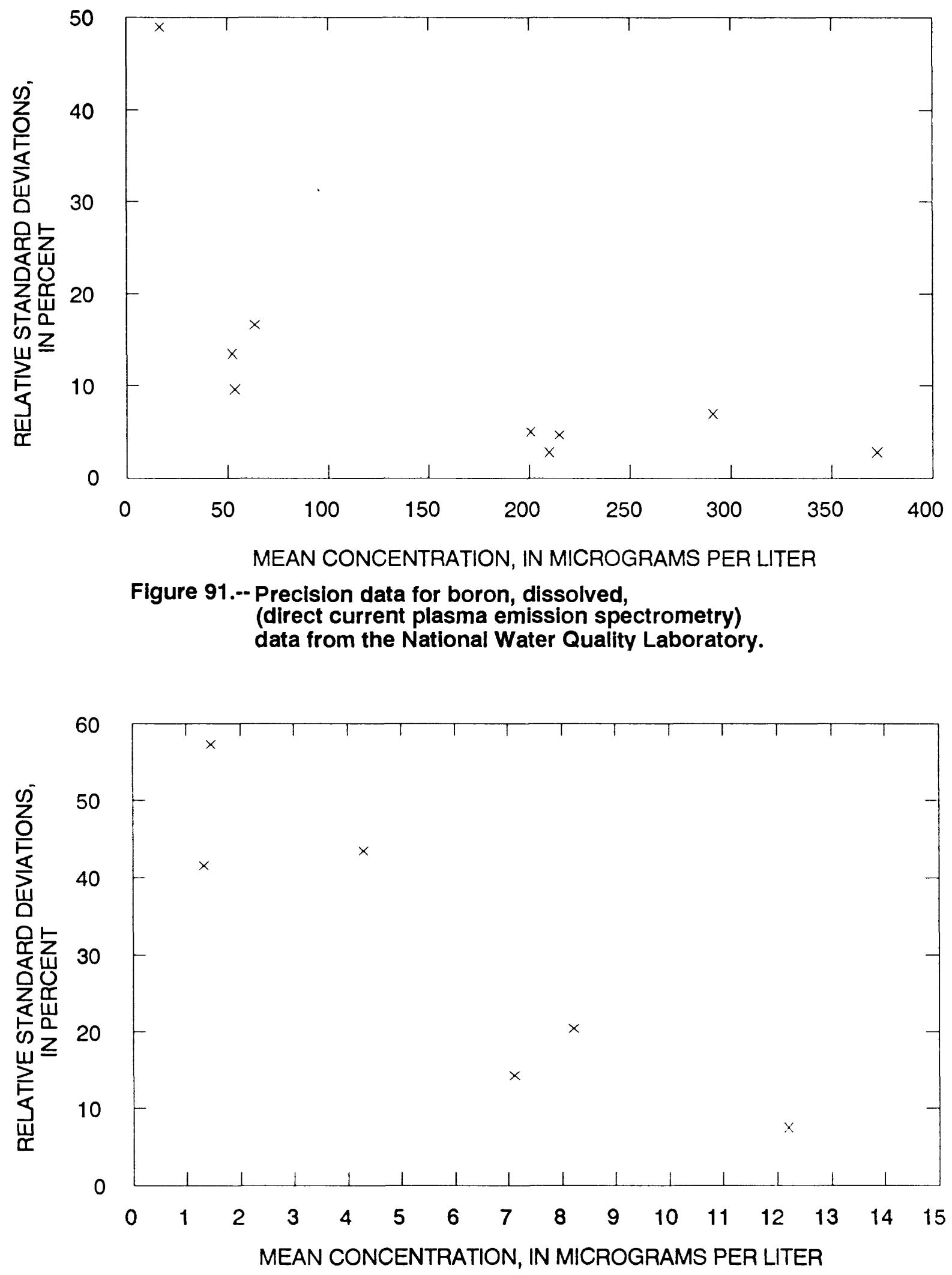

FIgure 92.-- Preclslon data for cadmium, dissolved, (inductively coupled plasma emission spectrometry) data from the National Water Quality Laboratory. 


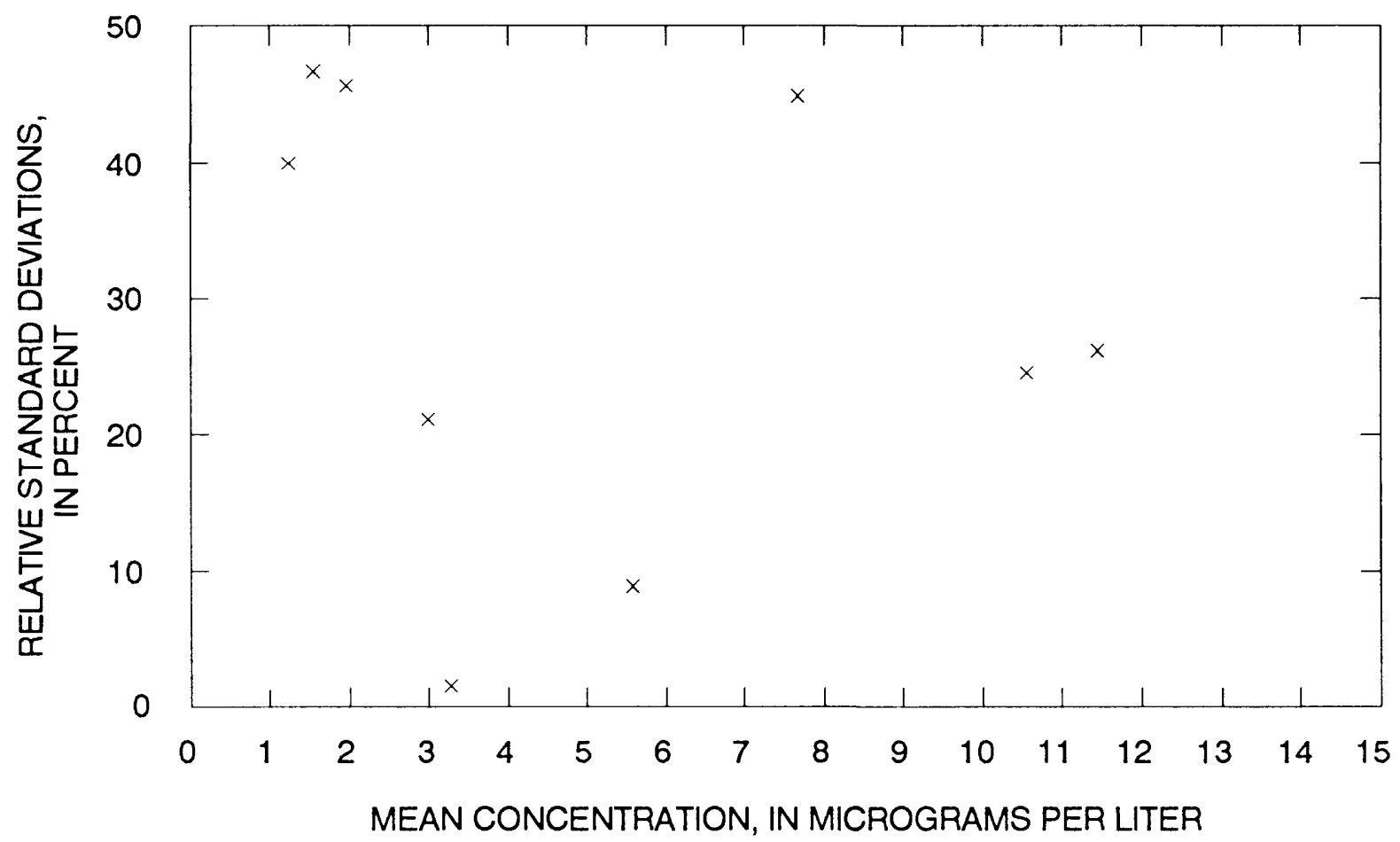

Figure 93.-- Precislon data for cadmium, dissolved, (atomlc absorption spectrometry; chelation-extraction and graphite furnace)

data from the National Water Quality Laboratory.

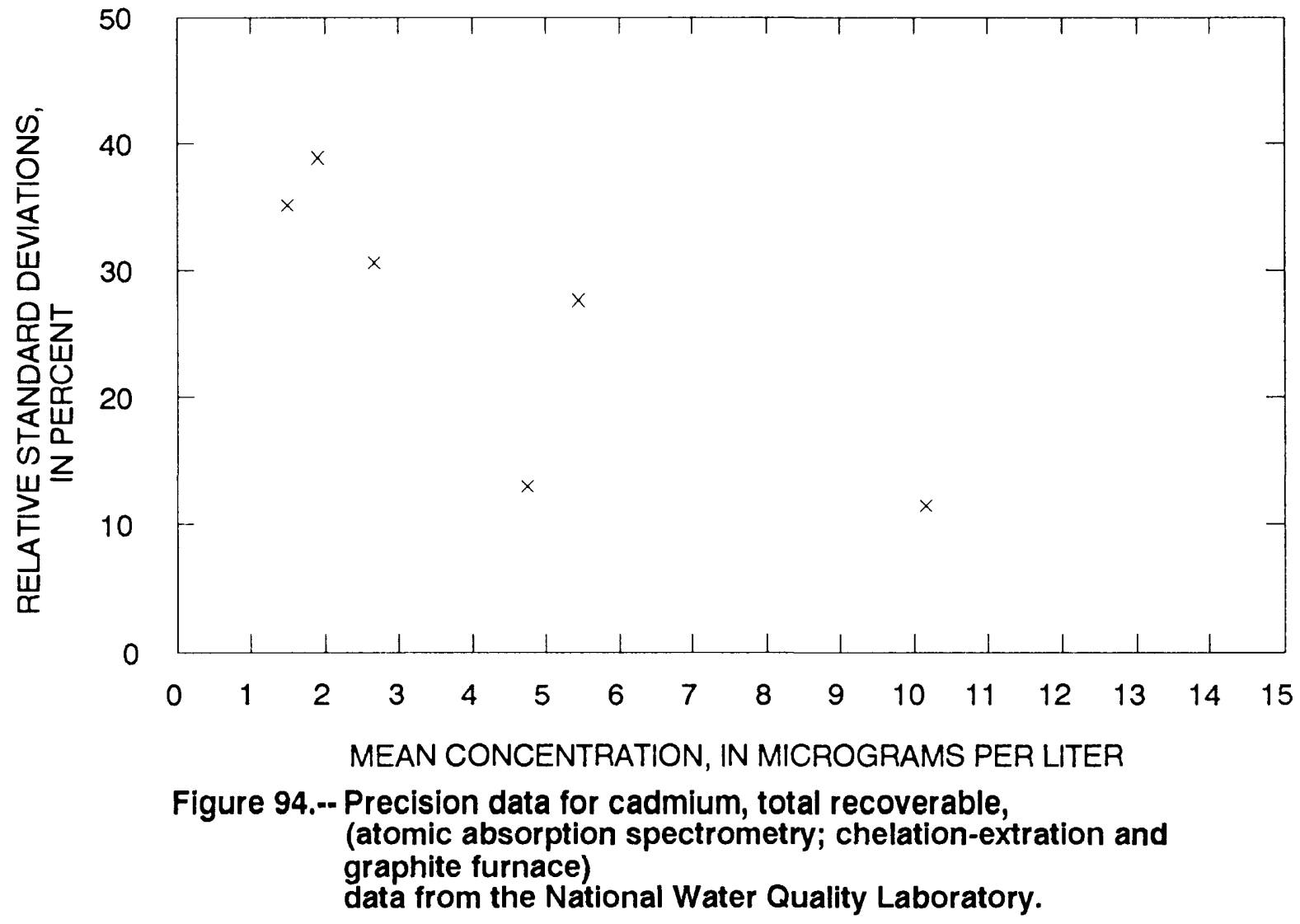




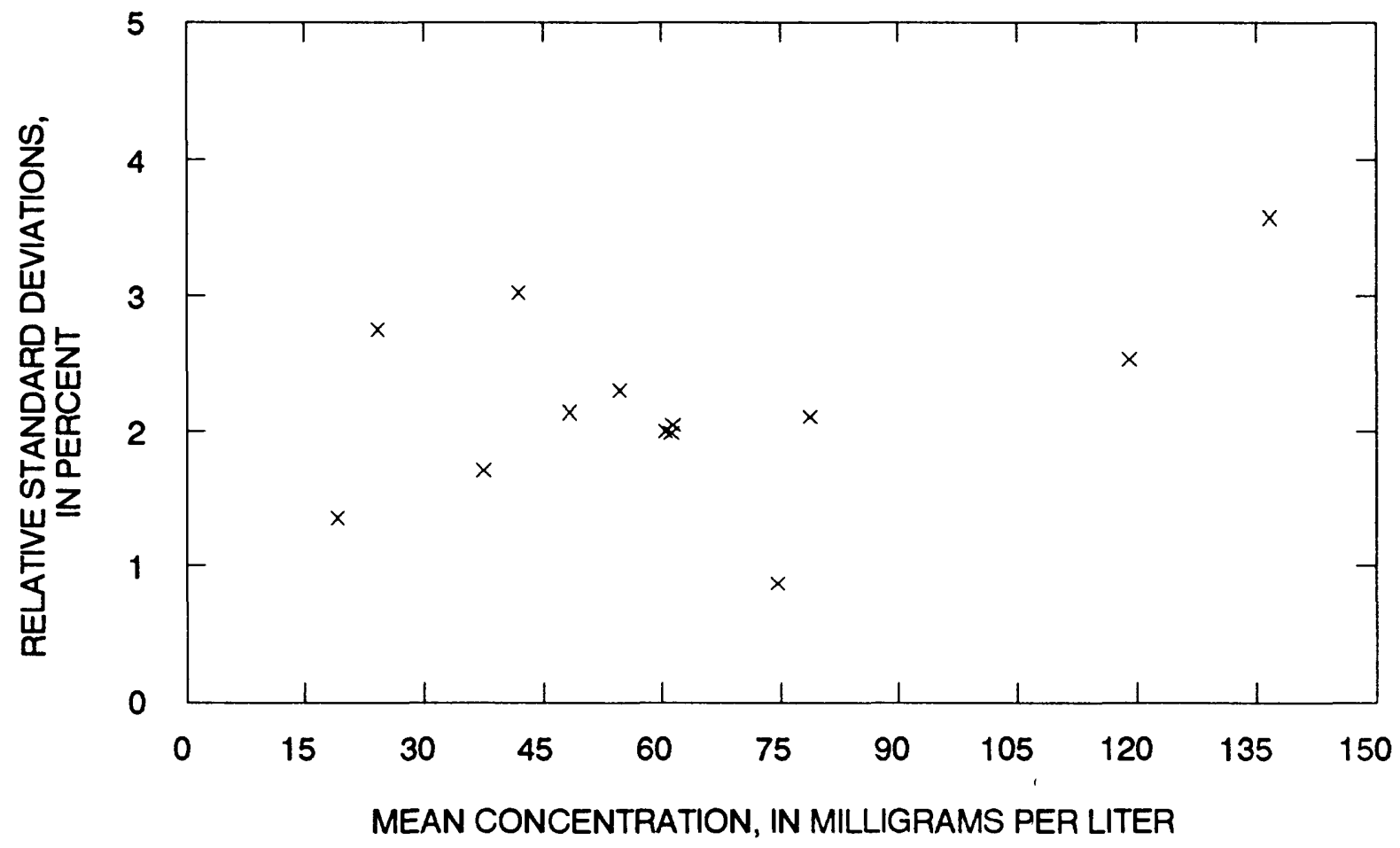

Flgure 95.-- Precislon data for calclum, dissolved, (Inductlvely coupled plasma spectrometry) data from the Natlonal Water Quallty Laboratory.

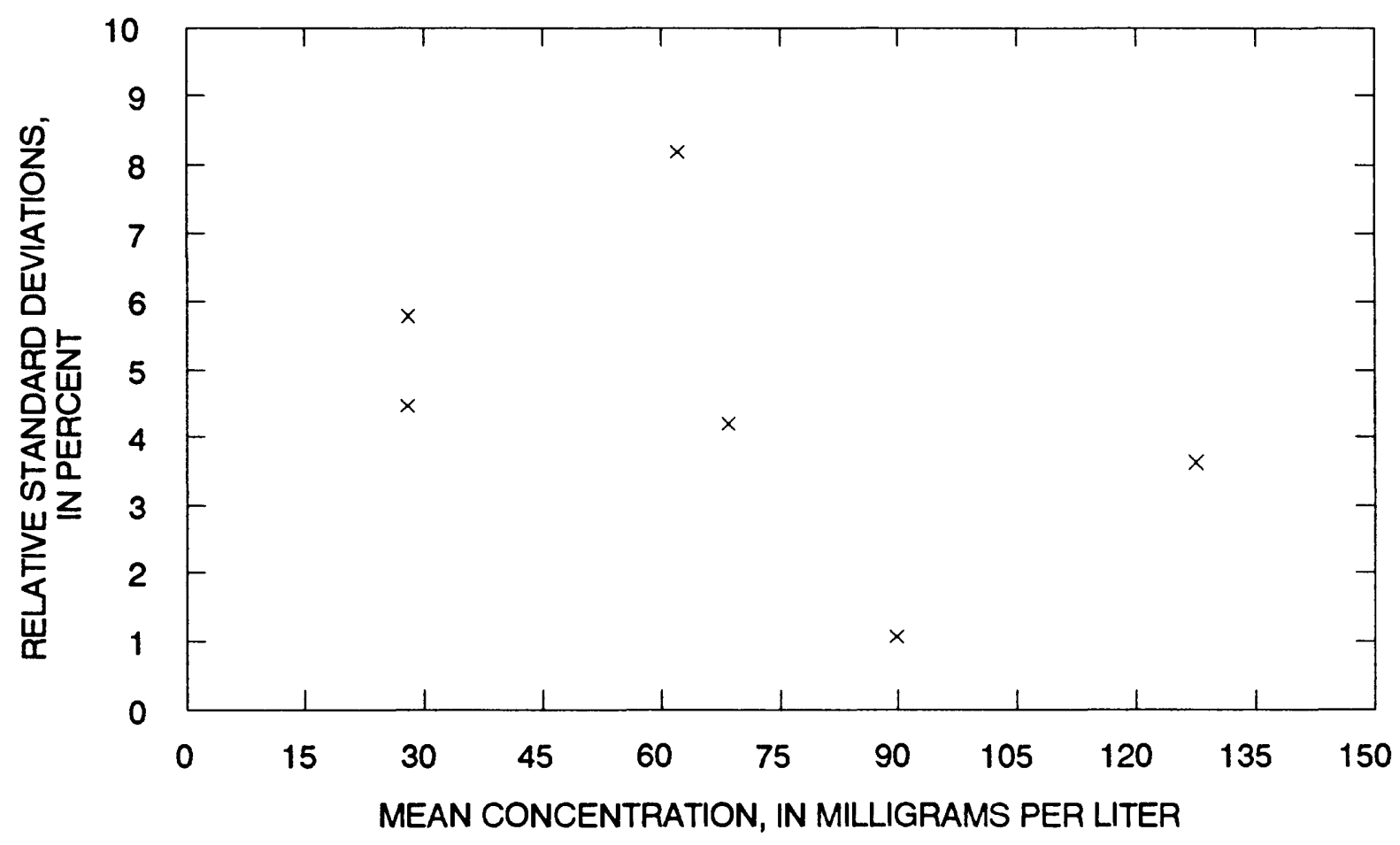

Figure 96.-- Preclsion data for calclum, dlssolved, (atomlc absorption spectrometry) data from the Natlonal Water Quallty Laboratory. 


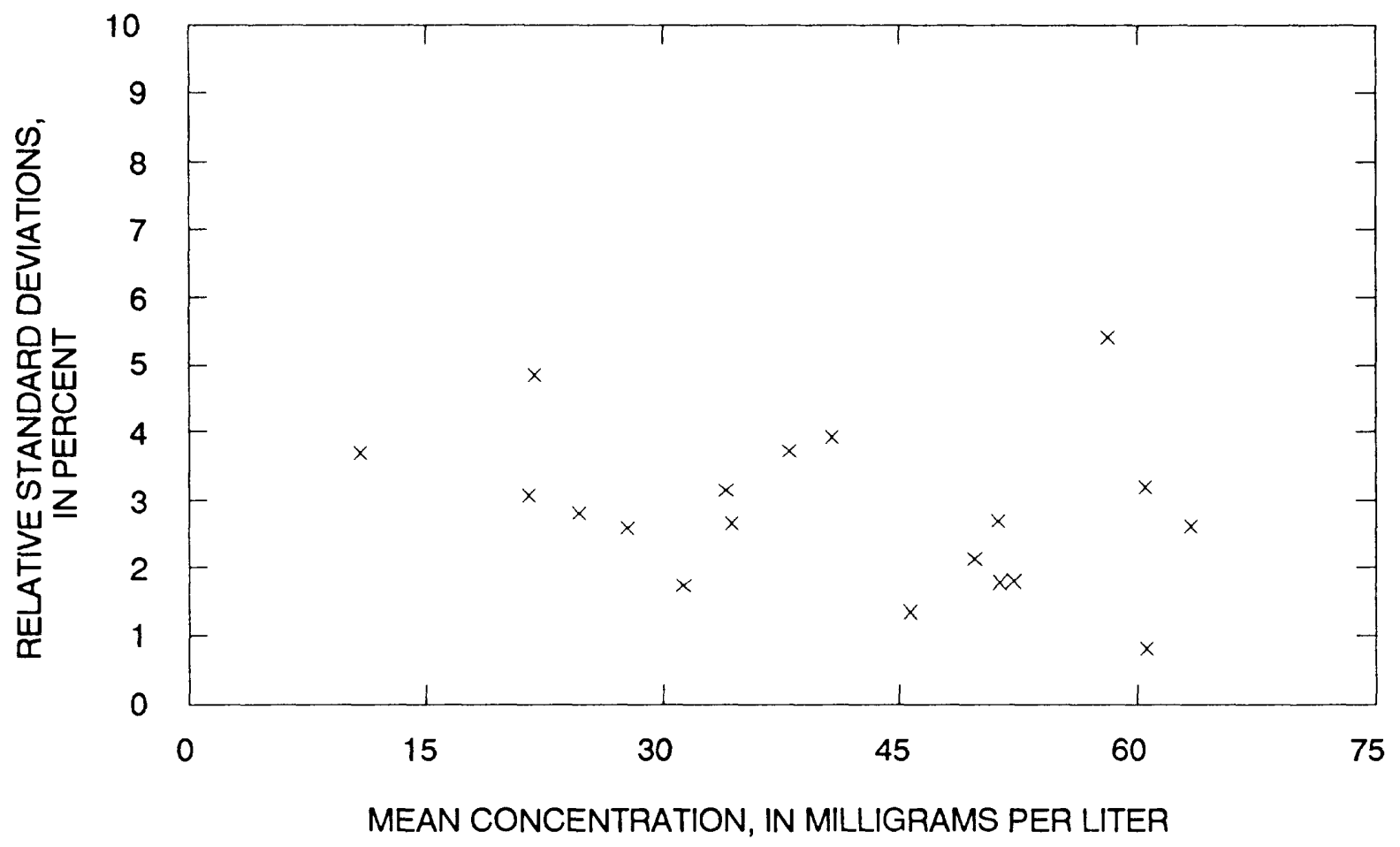

Figure 97.-- Precision data for chloride, dissolved, (colorimetric)

data from the National Water Quality Laboratory.

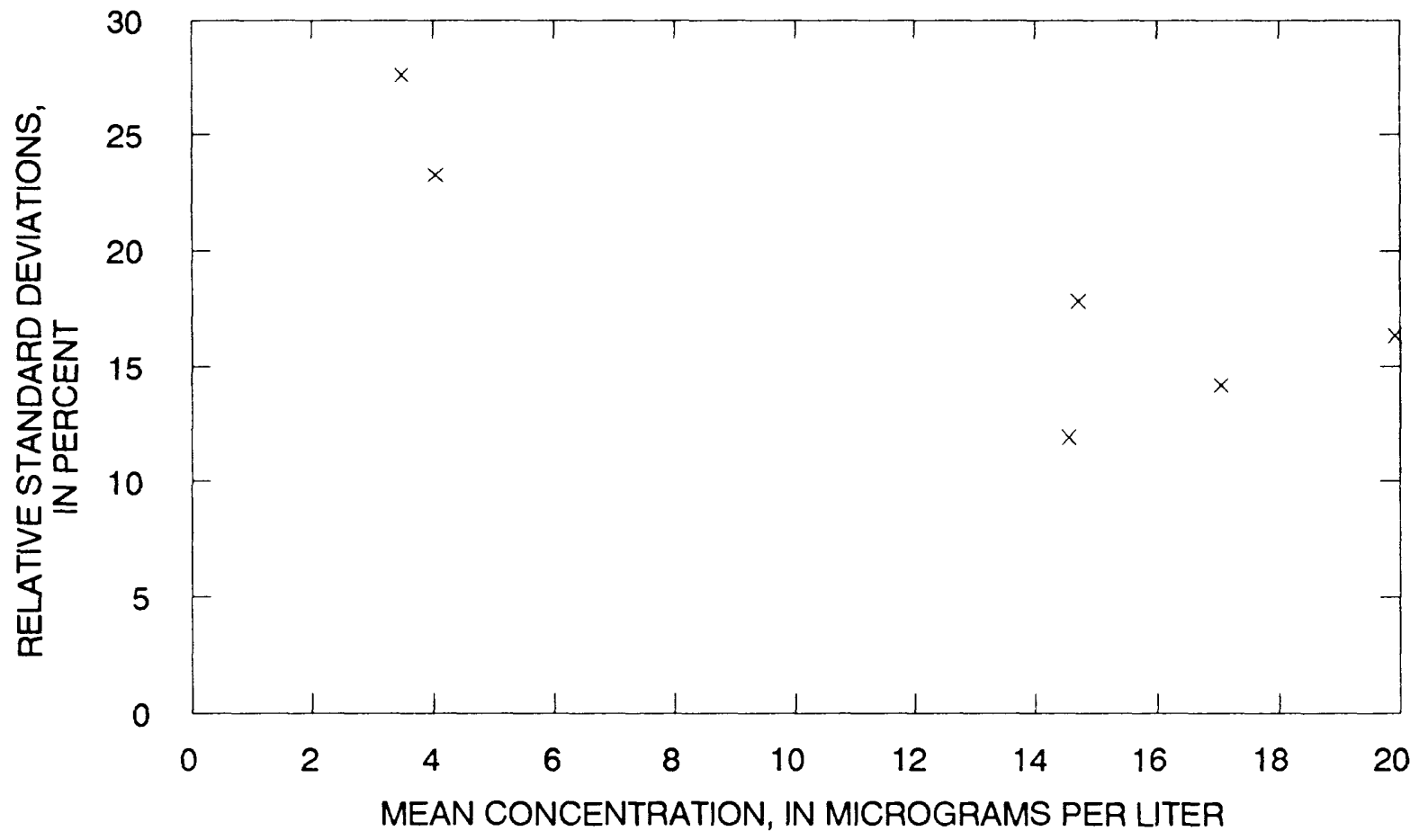

Figure 98.-- Precision data for chromium, dissolved, (inductively coupled plasma emission spectrometry) data from the National Water Quality Laboratory. 


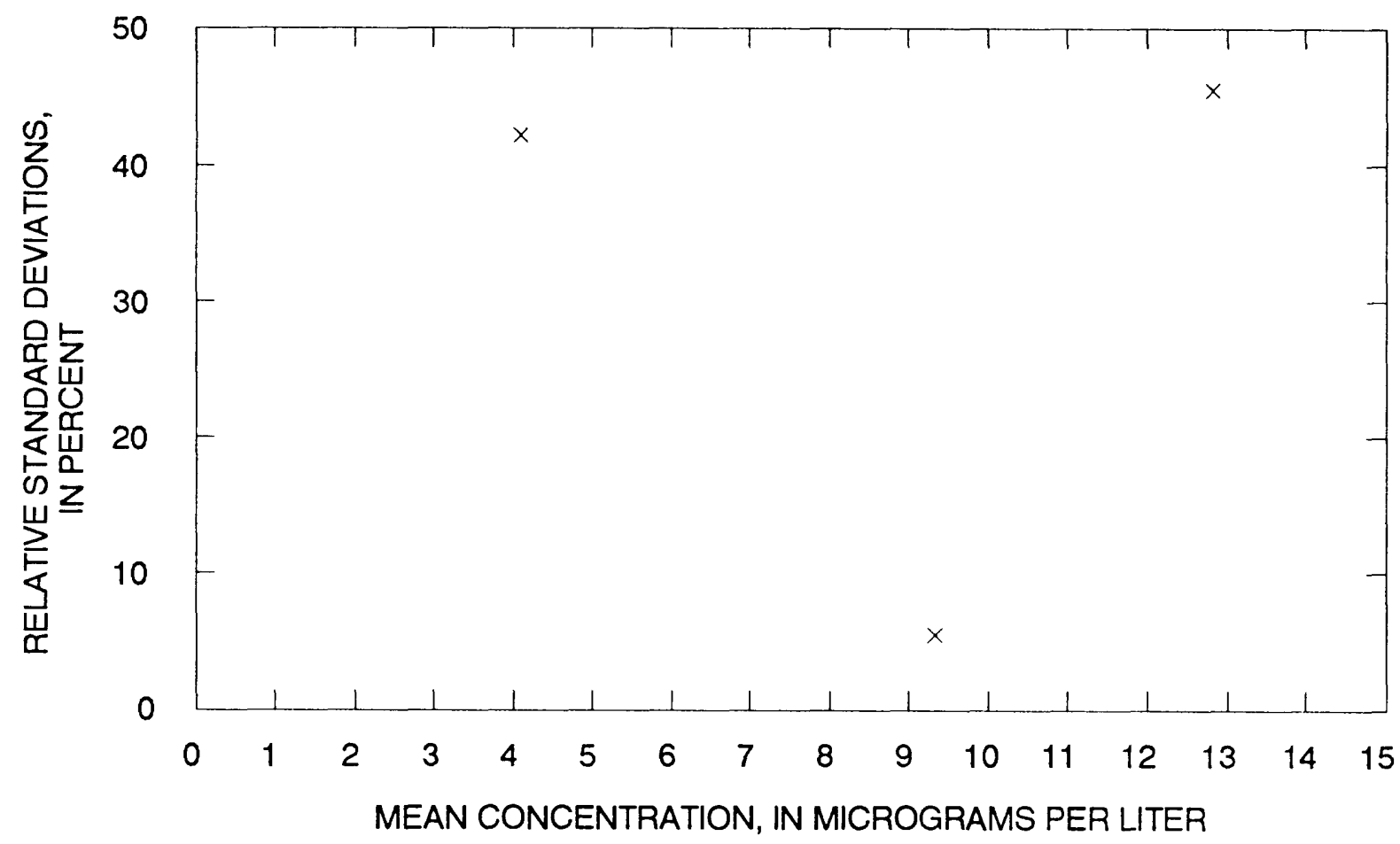

Figure 99.-- Precision data for chromium, dissolved, (direct current plasma emission spectrometry) data from the National Water Quality Laboratory.

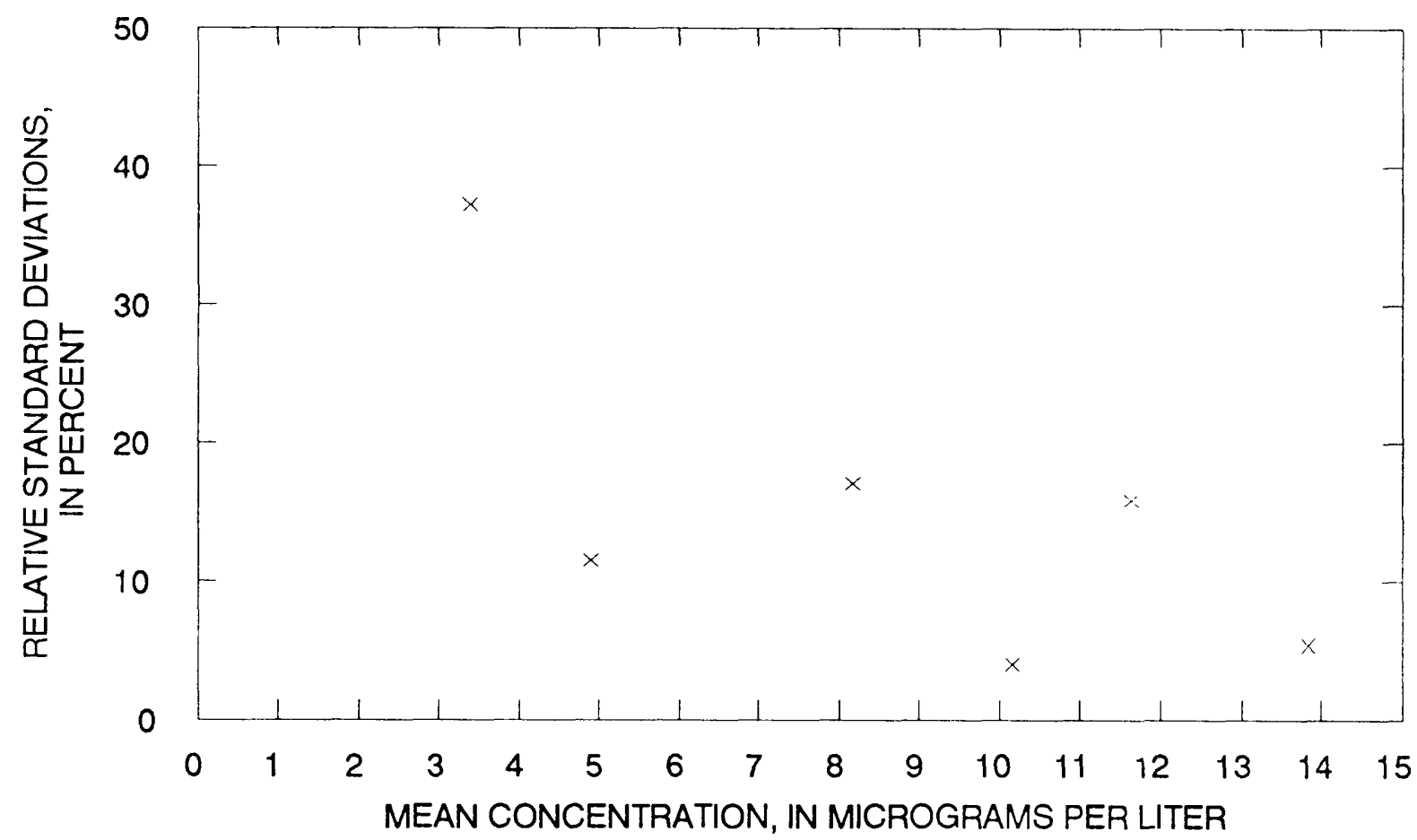

Figure 100.--Precision data for chromium, total recoverable, (direct current plasma emission spectrometry) data from the National Water Quality Laboratory. 


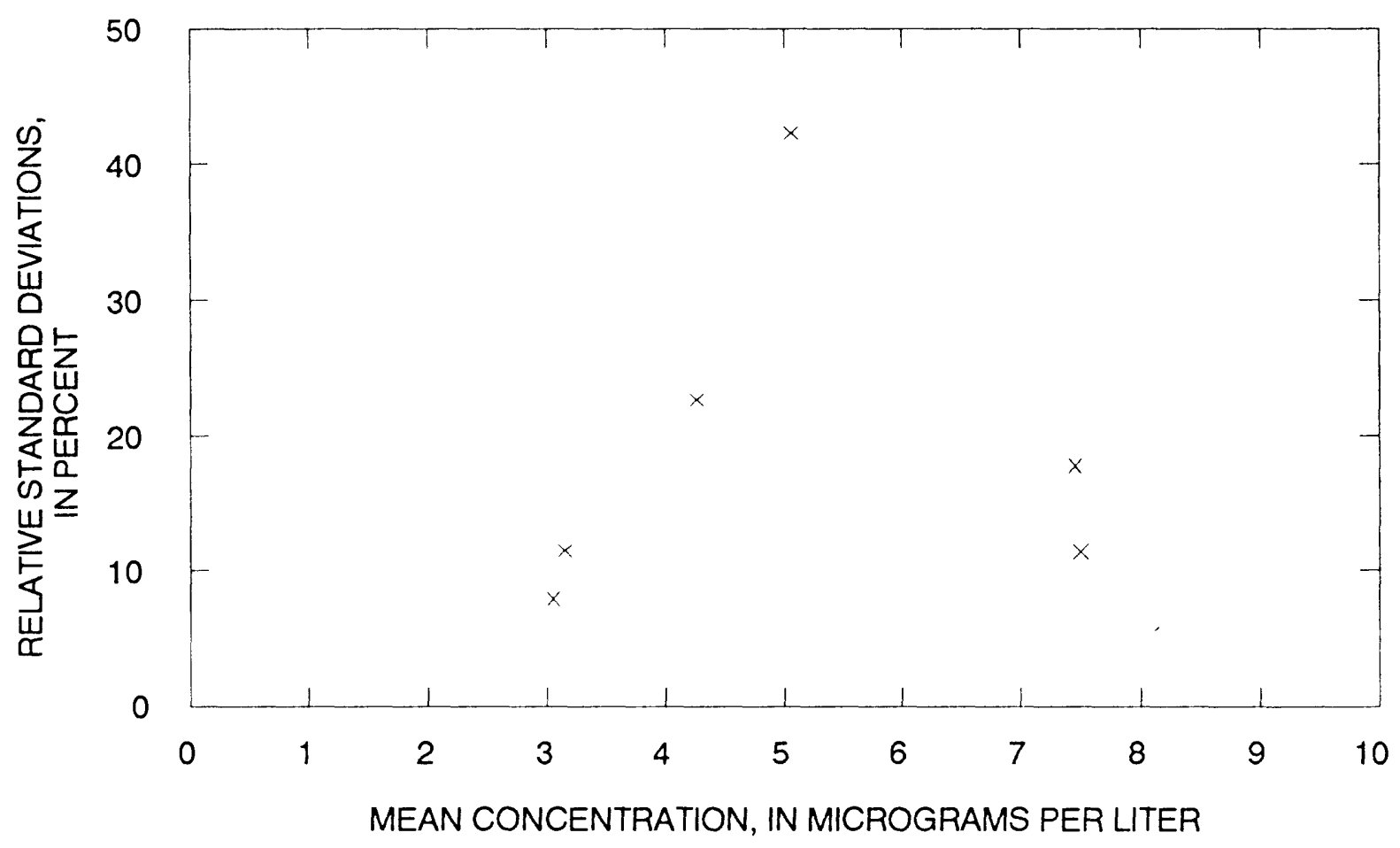

Figure 101.--Precision data for cobalt, dissolved, (inductively coupled plasma emission spectrometry) data from the National Water Quality Laboratory.

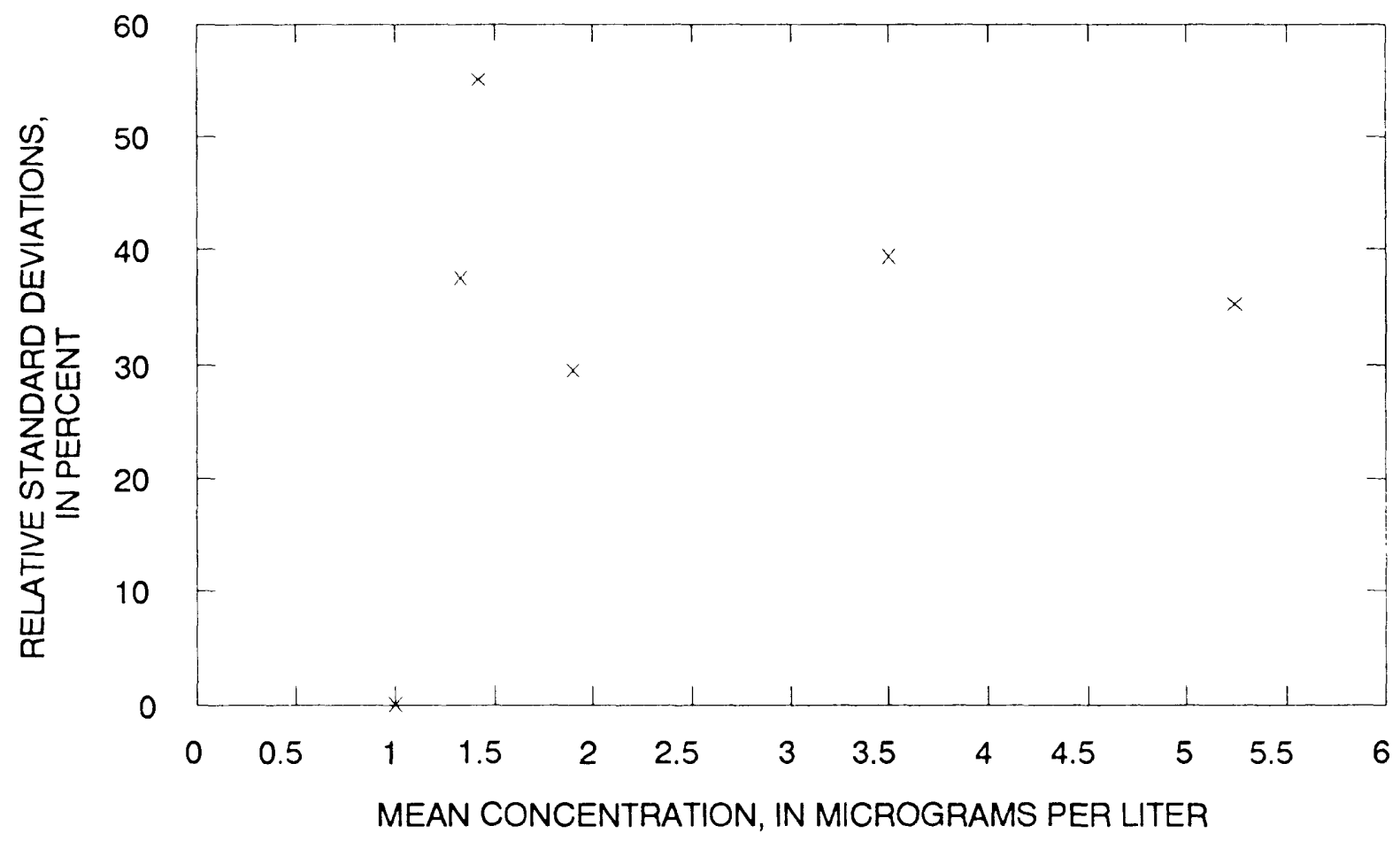

Figure 102.--Precision data for cobalt, dissolved, (atomic absorption spectrometry; chelation-extraction and graphite furnace) data from the National Water Quality Laboratory. 


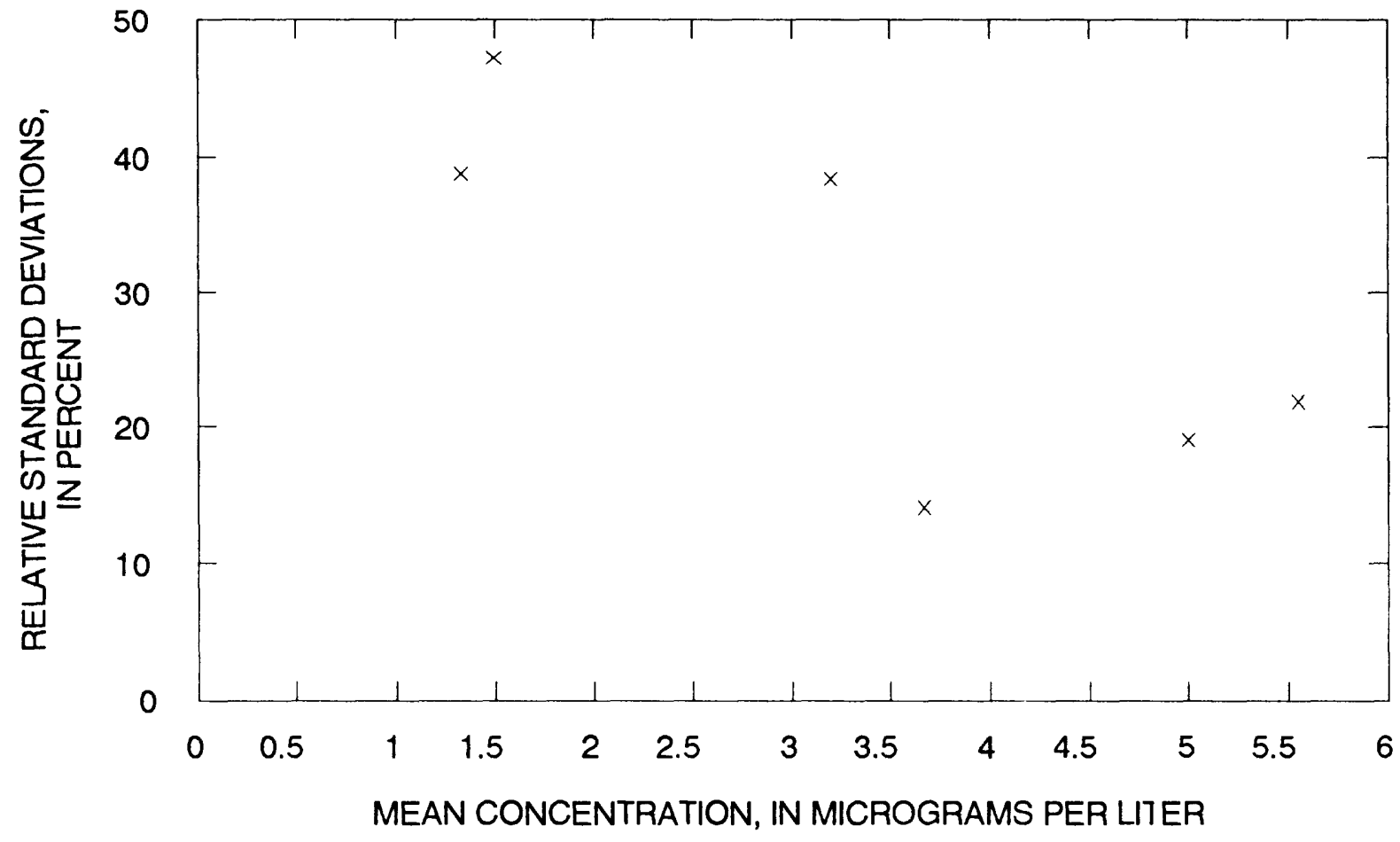

Figure 103.--Precision data for cobalt, total recoverable,

(atomic absorption spectrometry; chelation-extraction and graphite furnace)

data from the National Water Quality Laboratory.

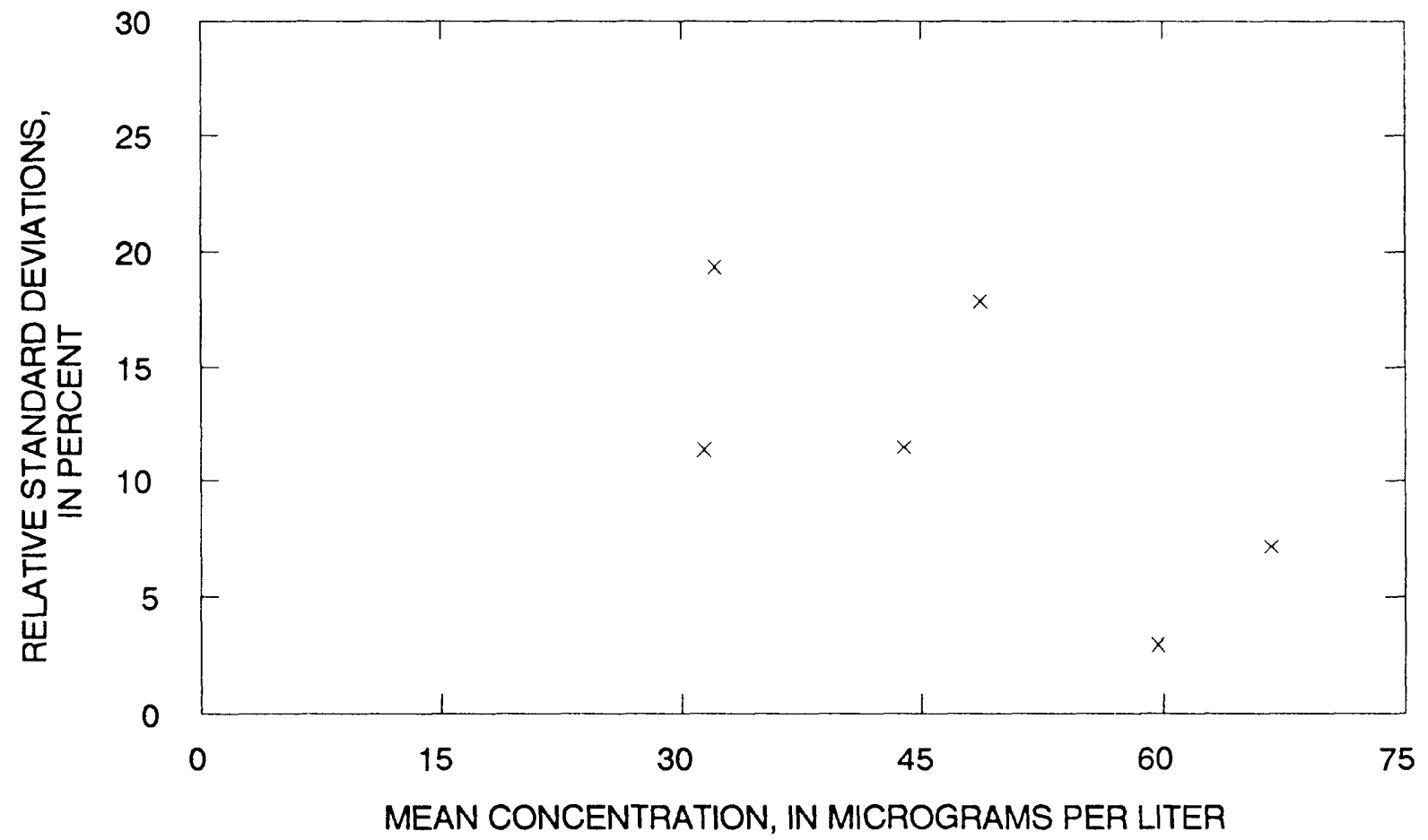

Figure 104.--Precision data for copper, dissolved, (inductively coupled plasma emission spectrometry) data from the National Water Quality Laboratory. 


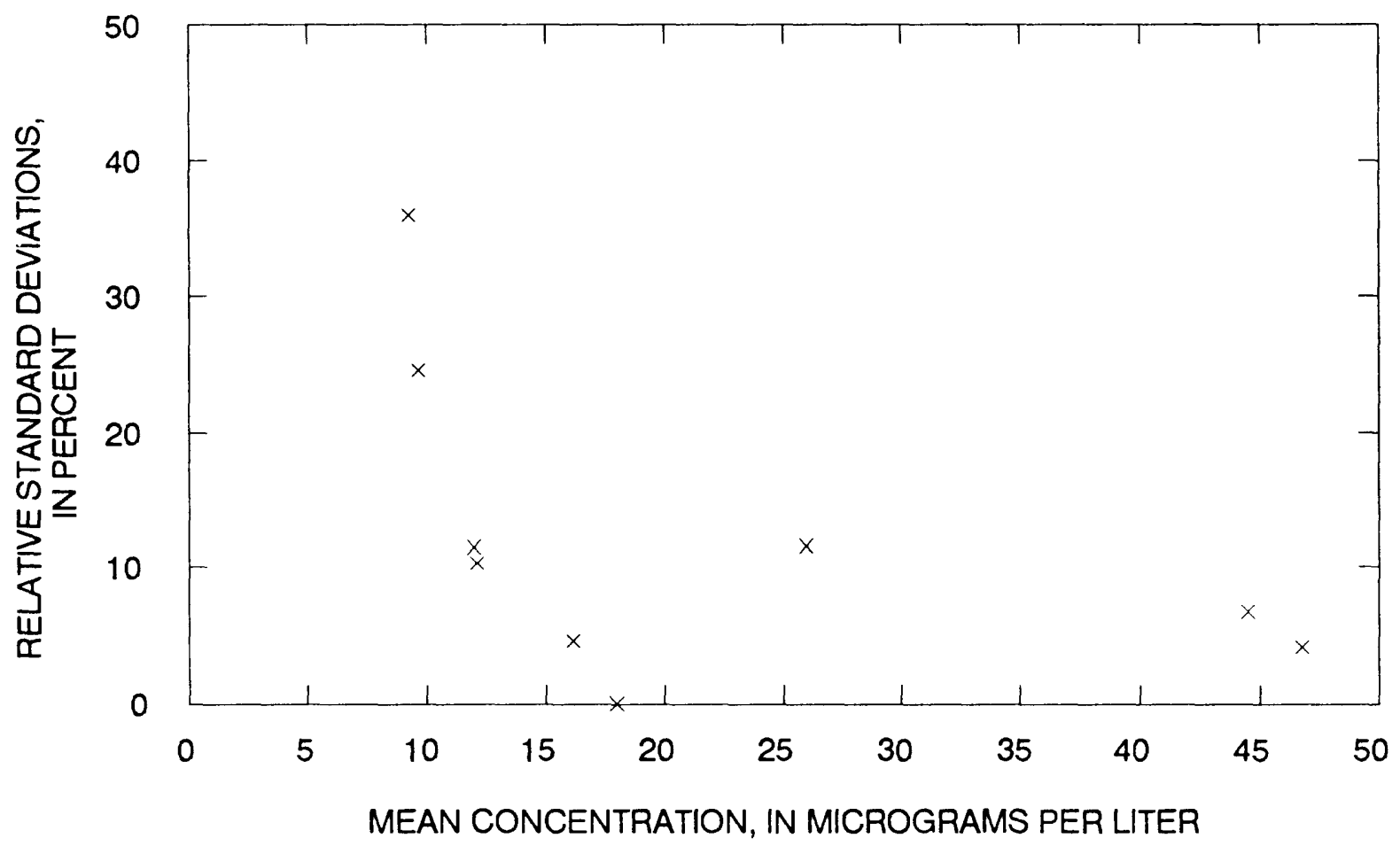

Figure 105.-- Precision data for copper, dissolved, (atomic absorption spectrometry; chelation-extraction and graphite furnace)

data from the National Water Quality Laboratory.

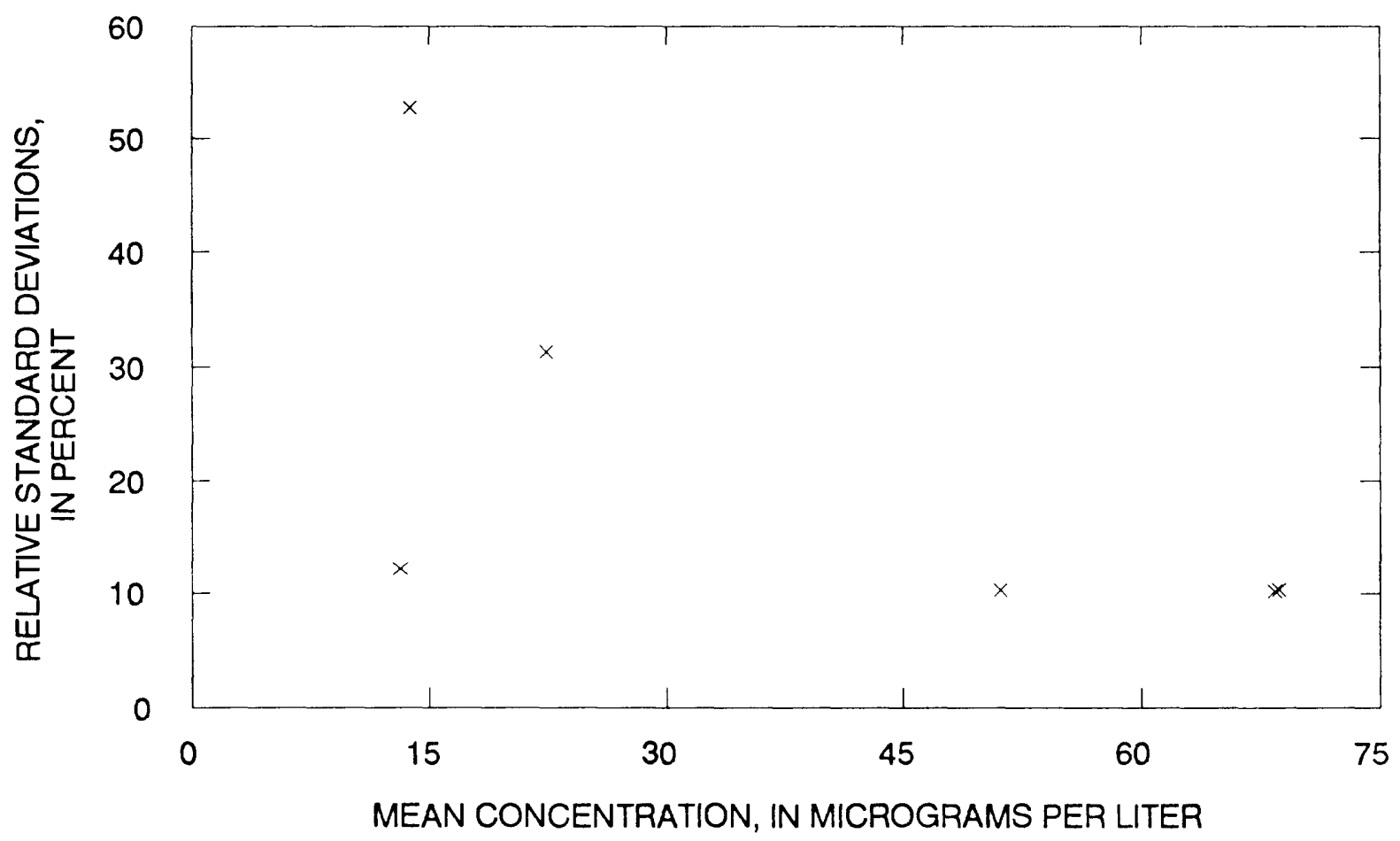

Figure 106.--Precision data for copper, total recoverable, (atomic absorption spectrometry; chelation-extraction and graphite furnace)

data from the National Water Quality Laboratory. 


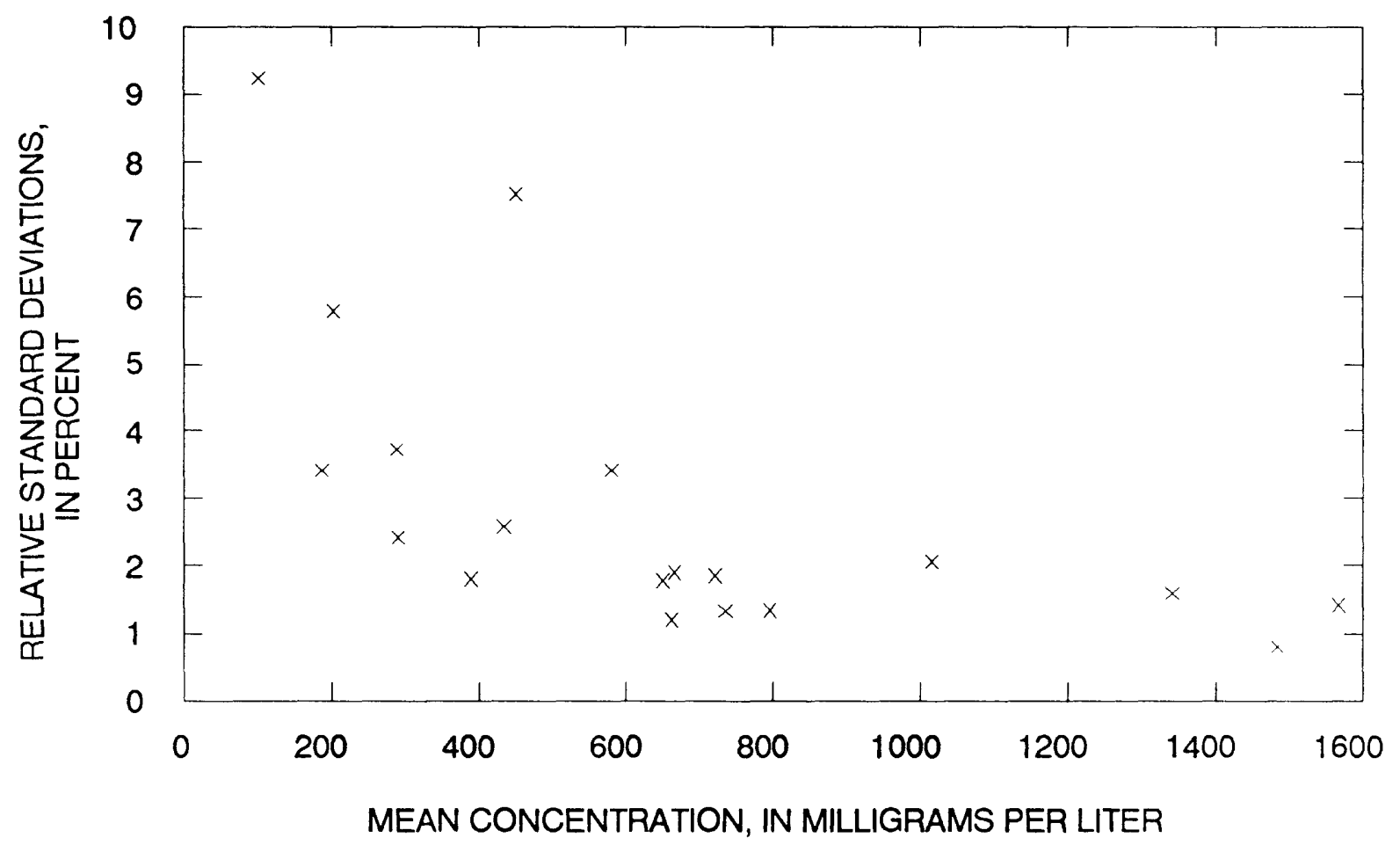

Figure 107.--Precision data for dlssolved solids, (gravimetric)

data from the National Water Quality Laboratory.

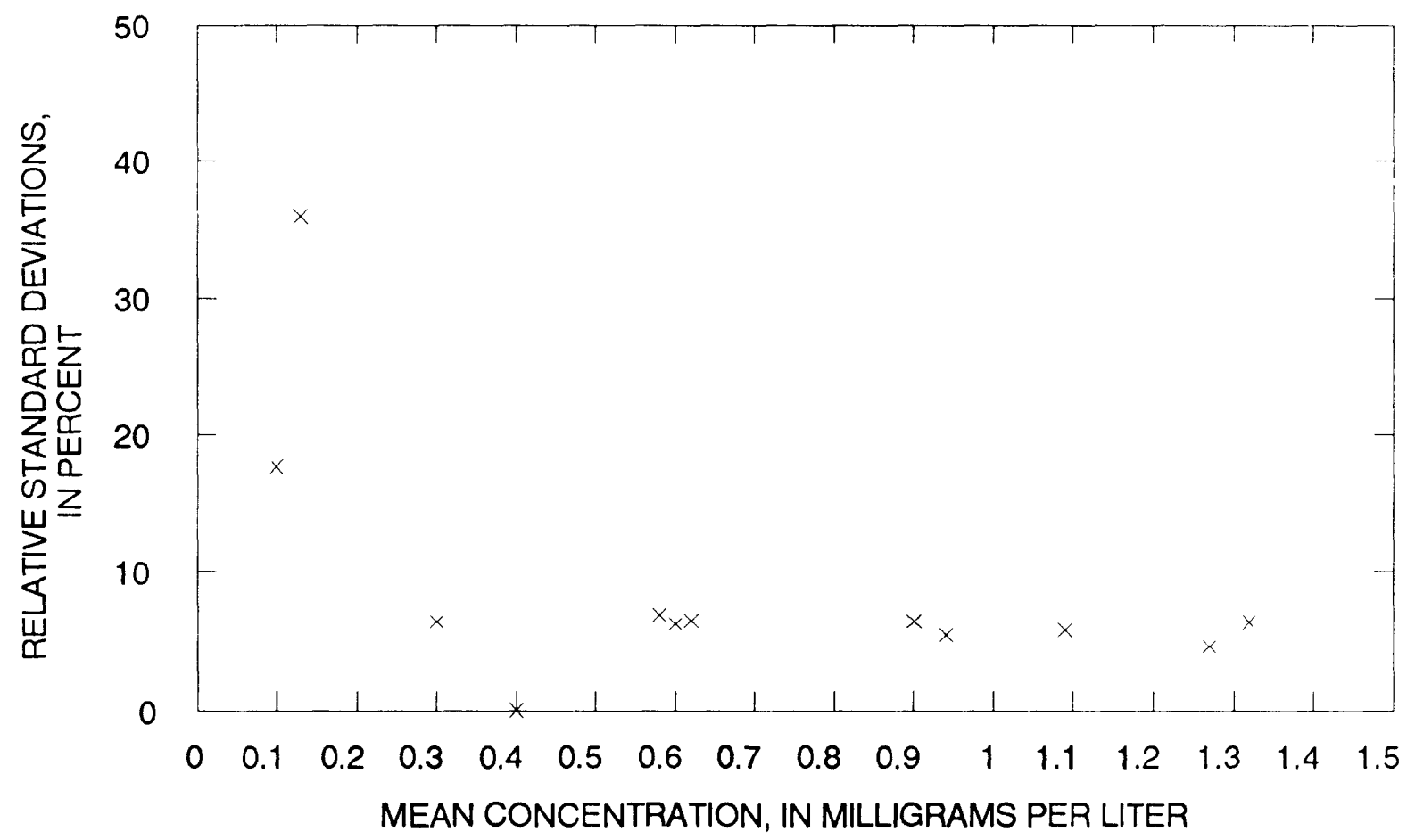

Figure 108.--Precision data for fluoride, dissolved, (ion selective electrode)

data from the National Water Quality Laboratory. 


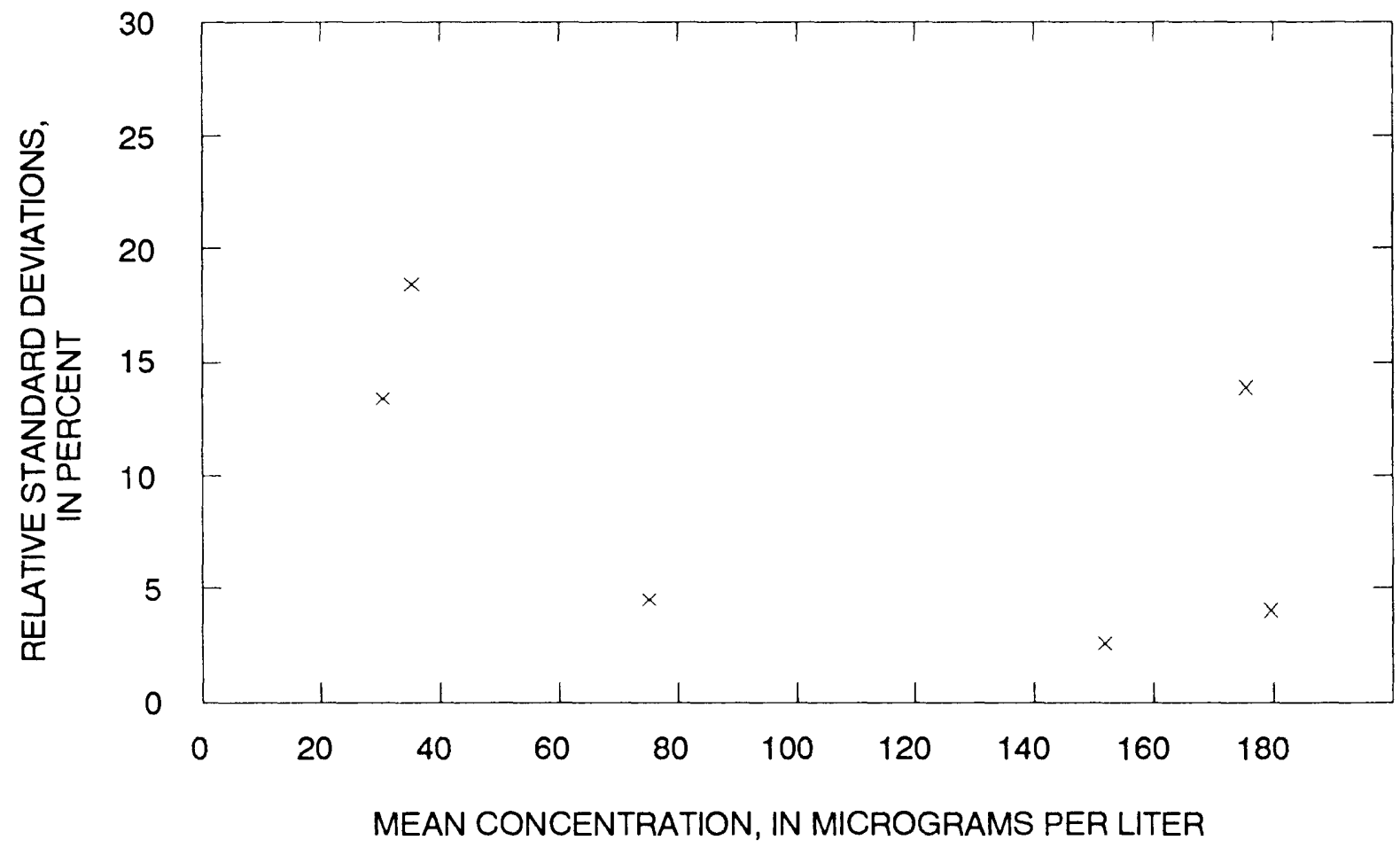

Figure 109.--Precision data for iron, dissolved, (inductively coupled plasma emission spectrometry) data from the National Water Quality Laboratory.

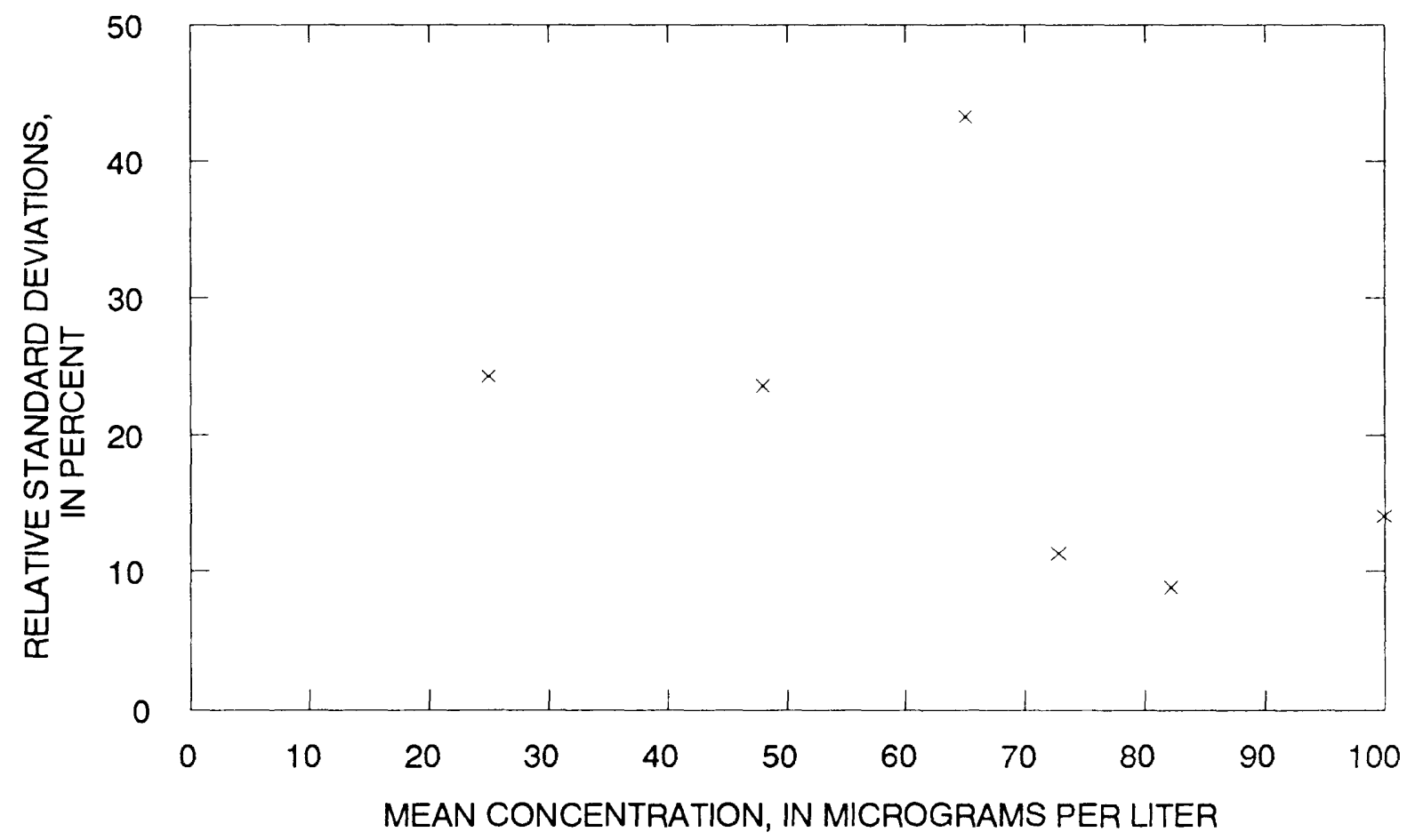

Figure 110.--Precision data for iron, dissolved, (atomic absorption spectrometry) data from the National Water Quality Laboratory. 


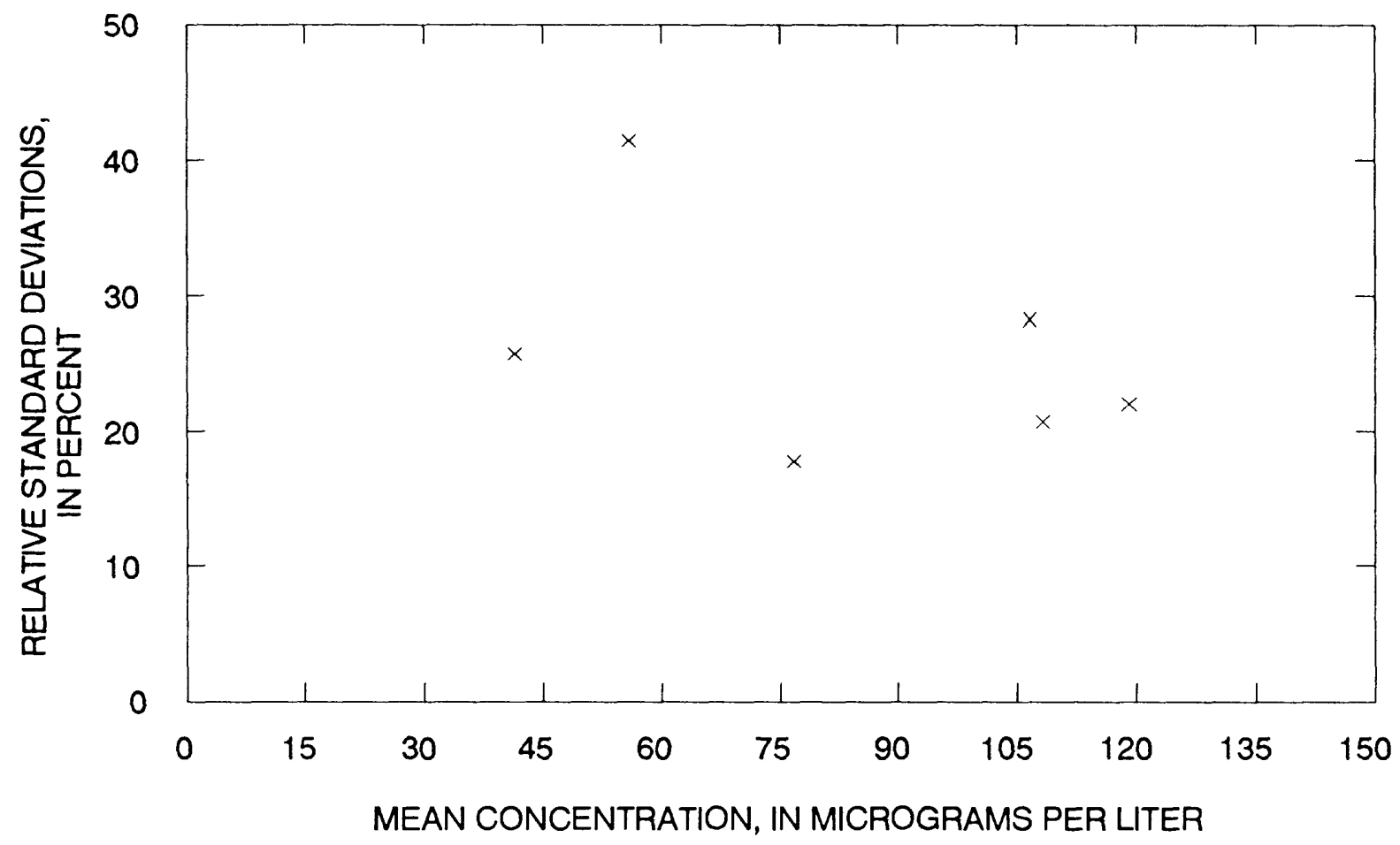

Figure 111.--Precision data for iron, total recoverable, (atomic absorption spectrometry) data from the National Water Quality Laboratory.

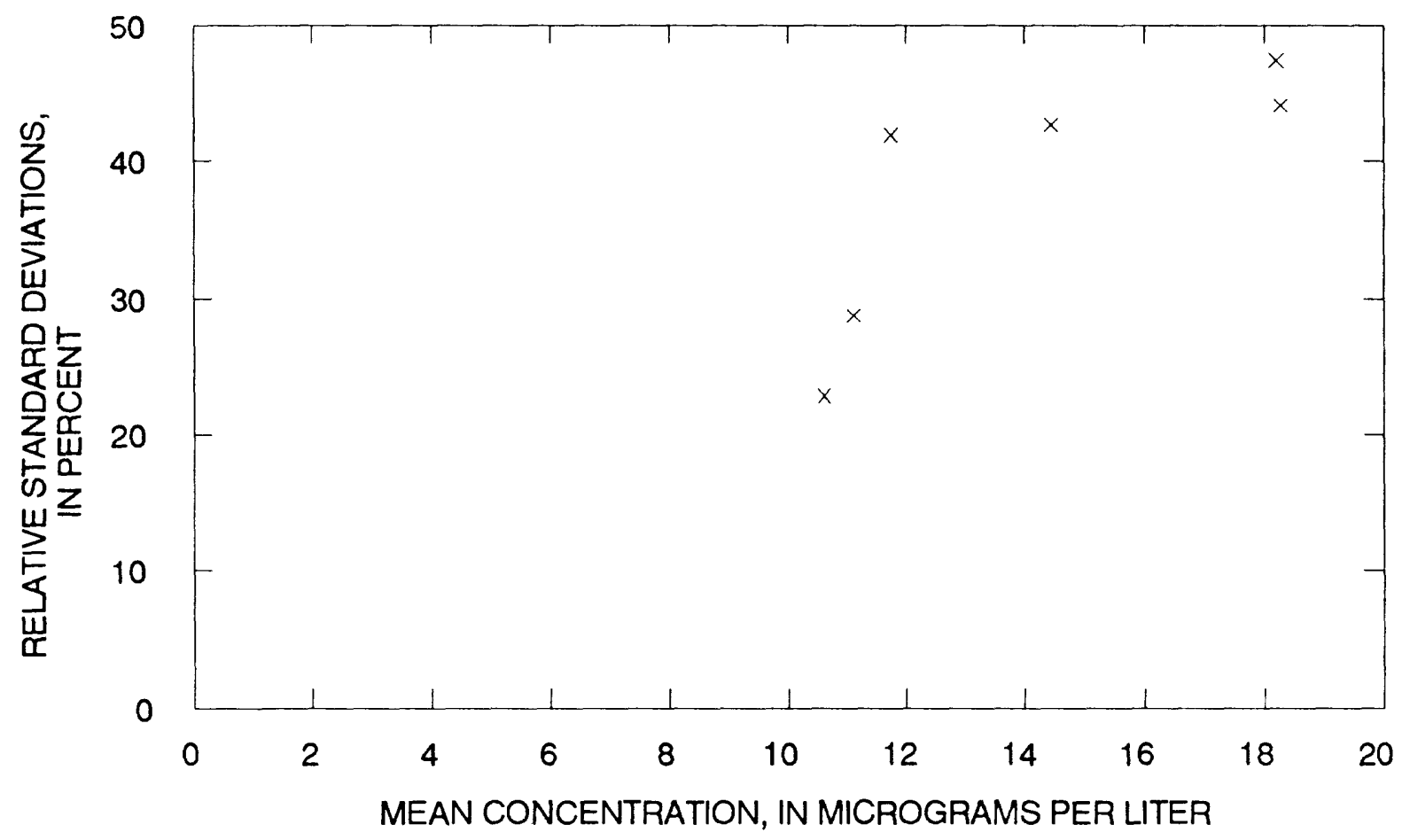

Figure 112.--Precision data for lead, dissolved, (inductively coupled plasma emission spectrometry) data from the National Water Quality Laboratory. 


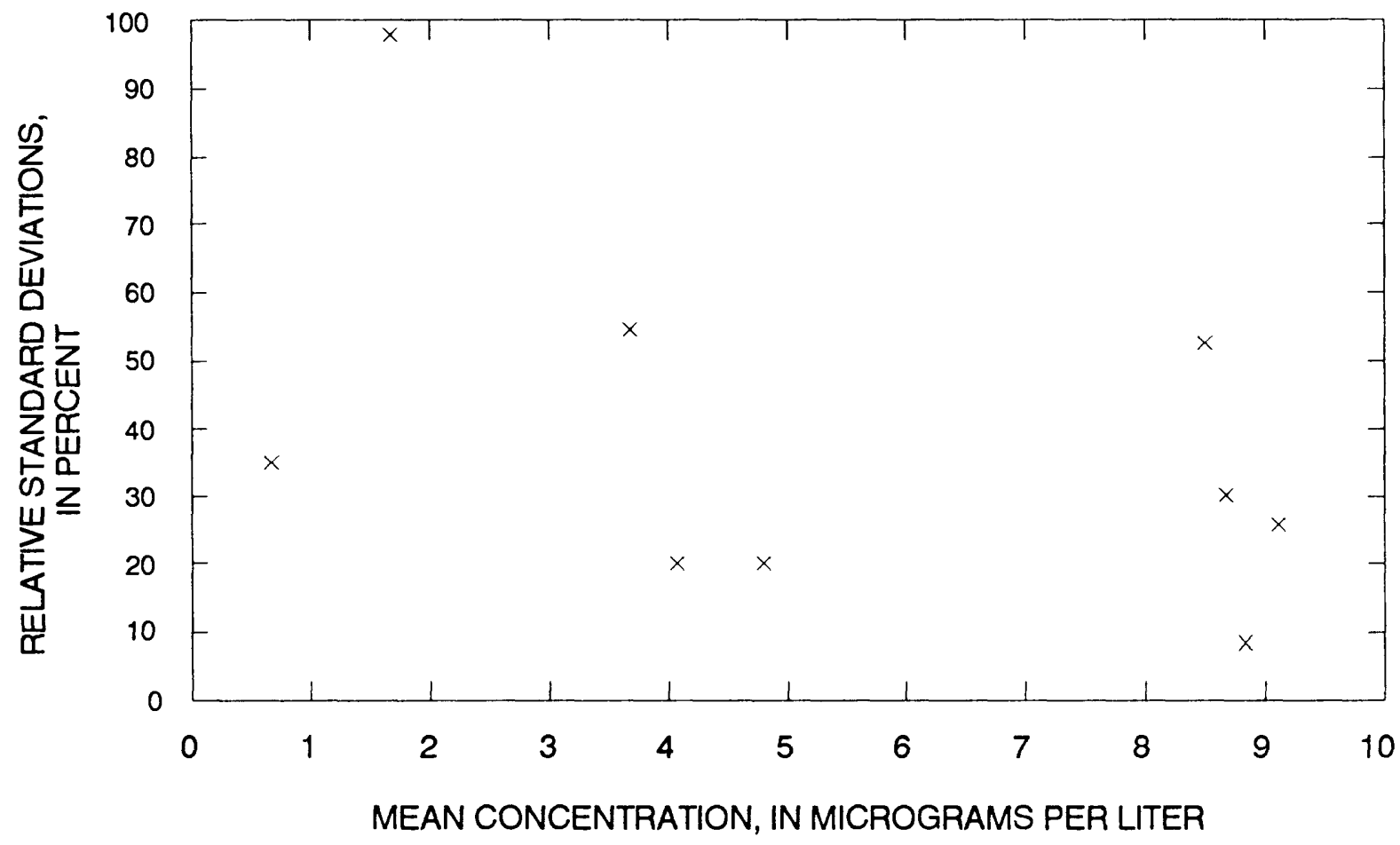

Figure 113.--Precision data for lead, dissolved,

(atomic absorption spectrometry; chelation-extraction and graphite furnace)

data from the Natlonal Water Quality Laboratory.

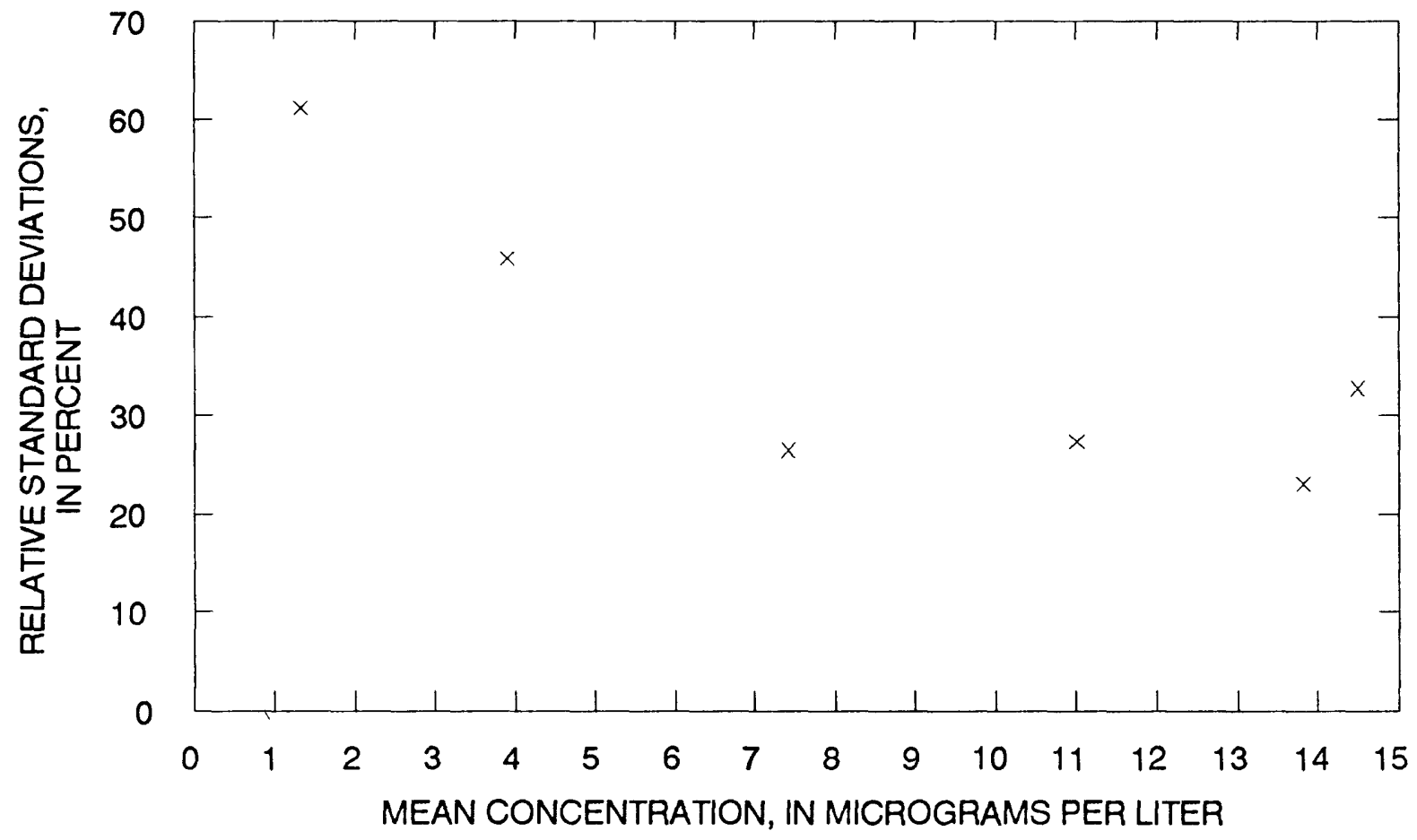

Figure 114.--Precision data for lead, total recoverable, (atomic absorption spectrometry; chelation-extraction and graphite furnace)

data from the National Water Quality Laboratory. 


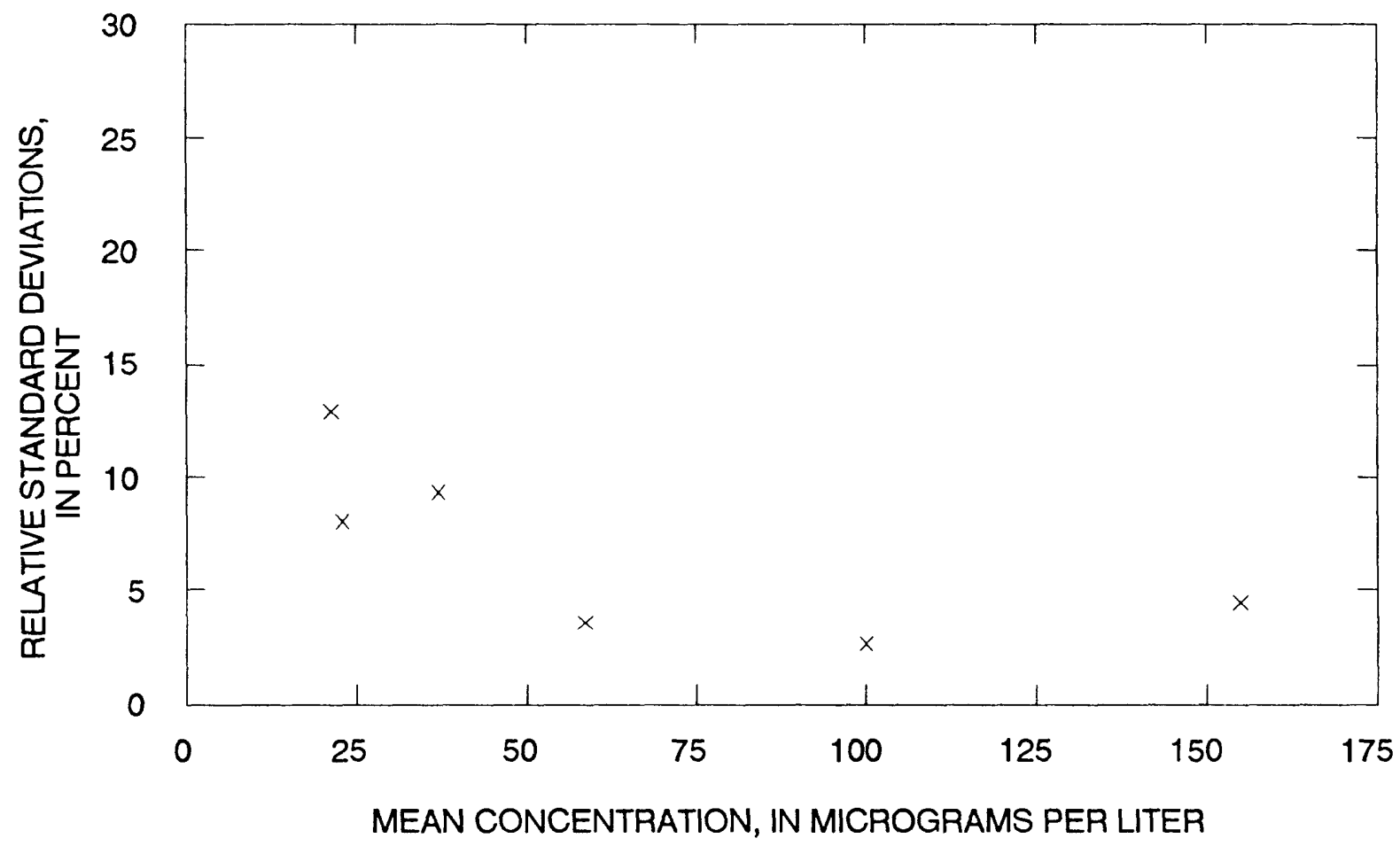

Figure 115.--Precision data for lithium, dissoived, (inductively coupied plasma emission spectrometry) data from the Nationai Water Quality Laboratory.

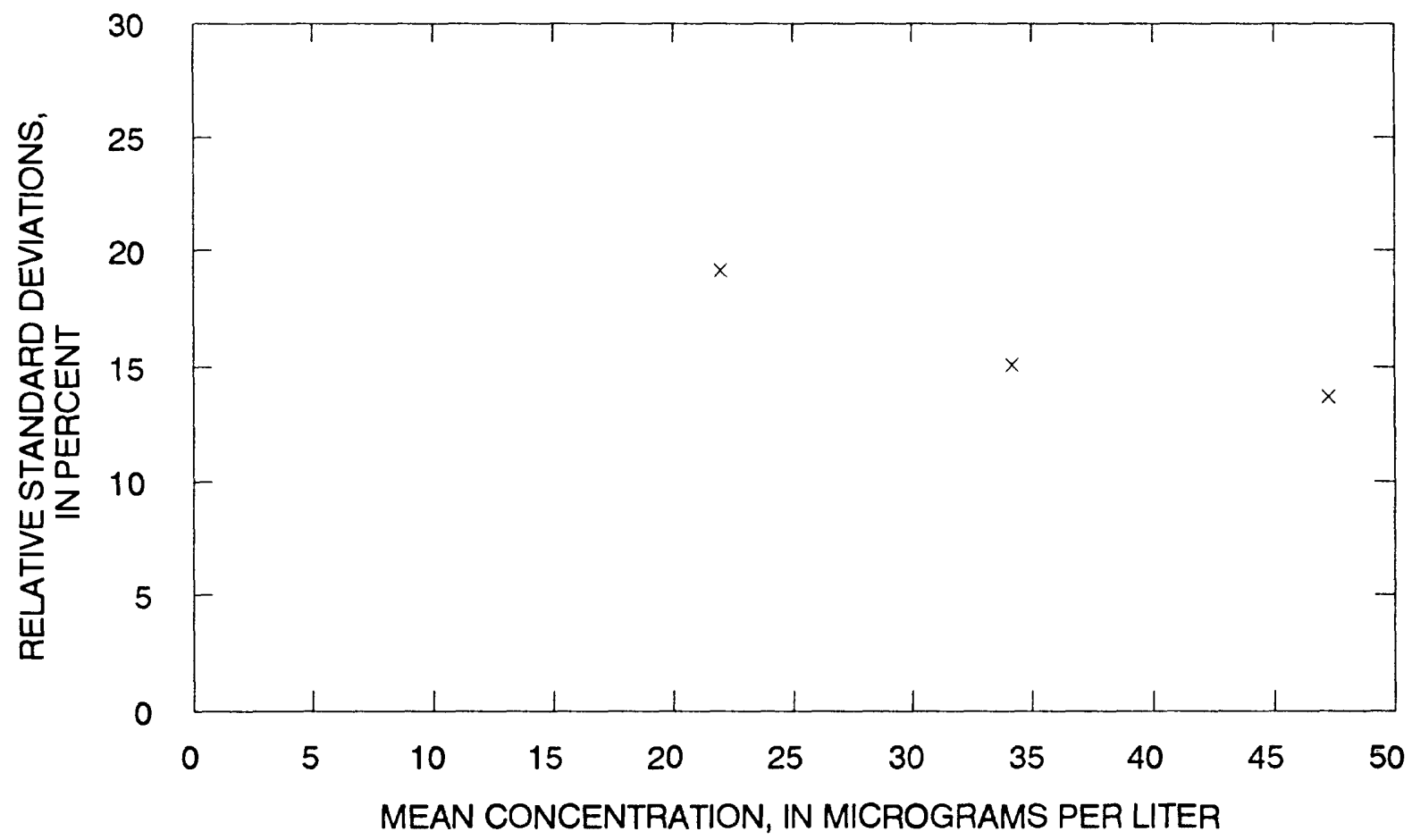

Figure 116.--Precision data for lithium, totai recoverabie, (atomic absorption spectrometry) data from the National Water Quality Laboratory. 


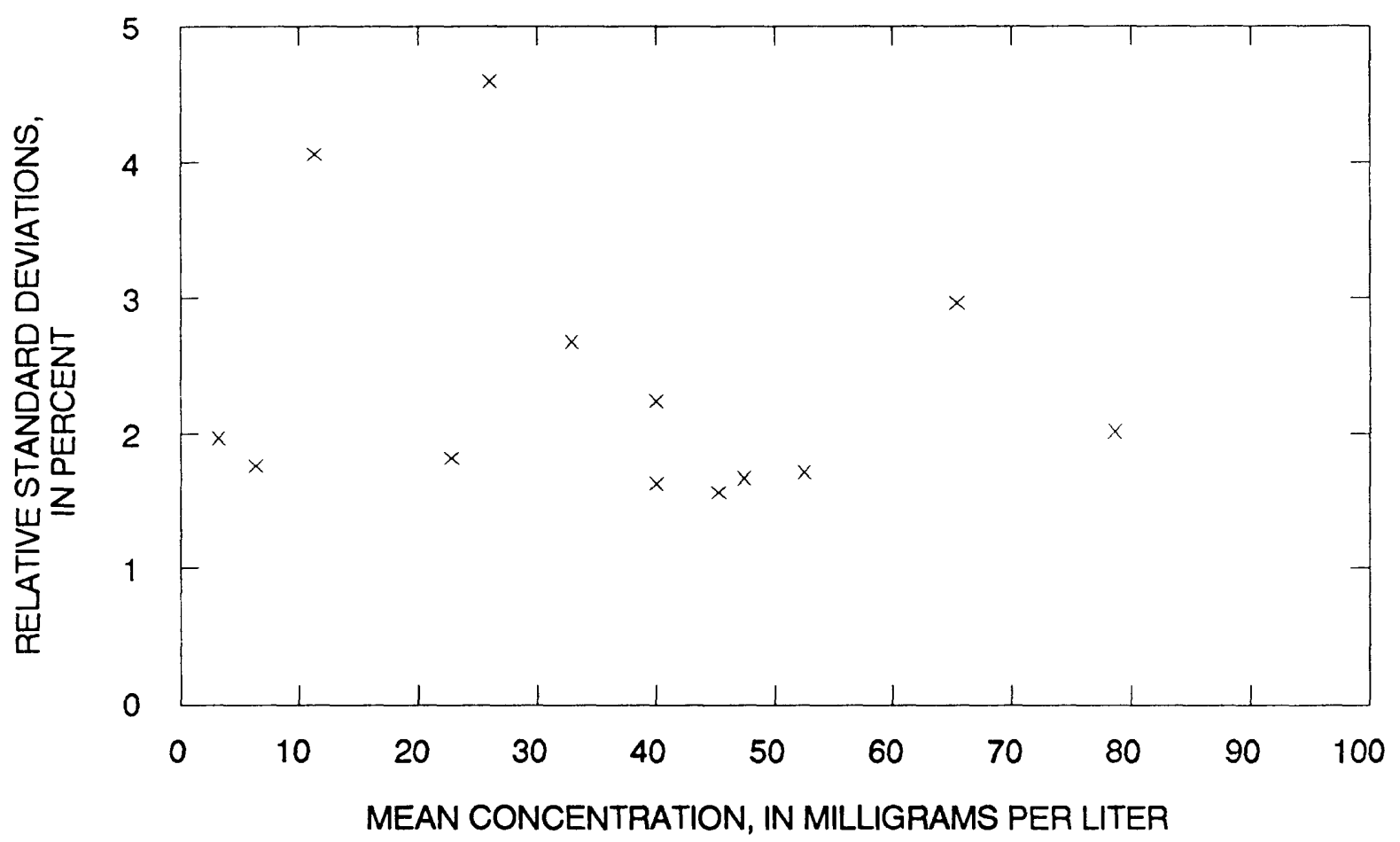

Figure 117.--Precision data for magnesium, dissolved, (inductively coupled plasma emlssion spectrometry) data from the National Water Quaiity Laboratory.

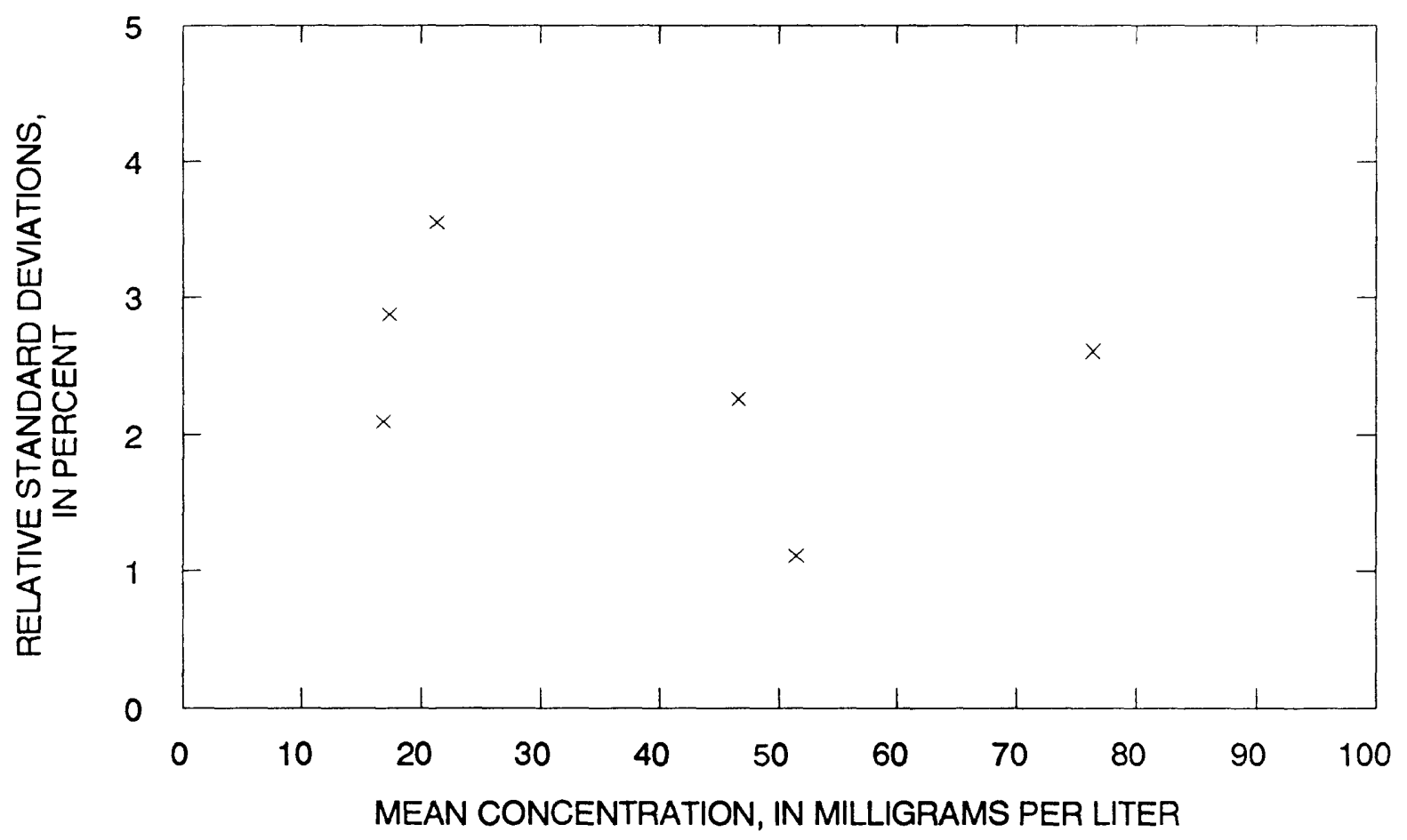

Figure 118.--Precision data for magnesium, dissolved, (atomic absorption spectrometry) data from the National Water Quality Laboratory. 


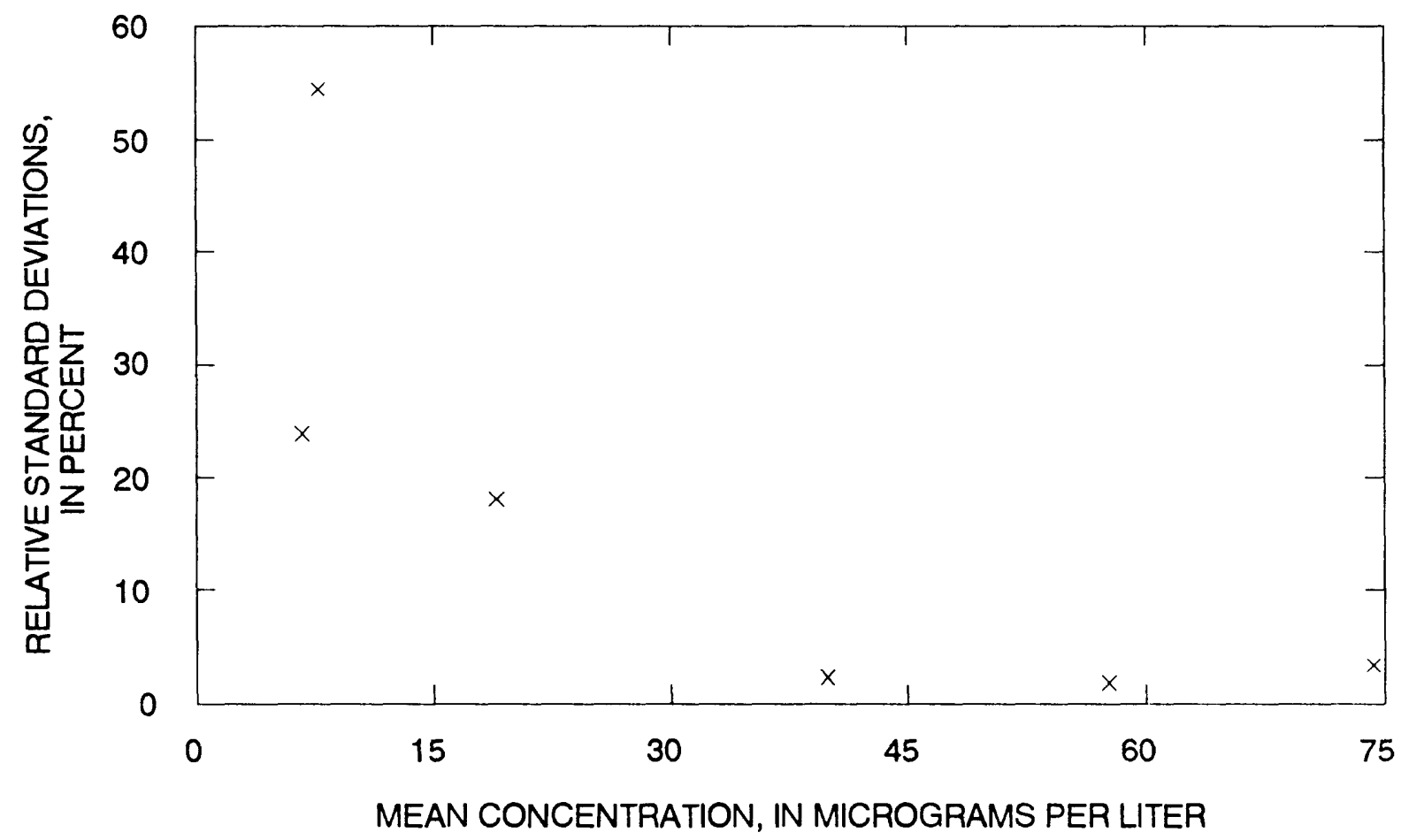

Figure 119.--Precision data for manganese, dissolved, (inductively coupled plasma emission spectrometry) data from the National Water Quality Laboratory.

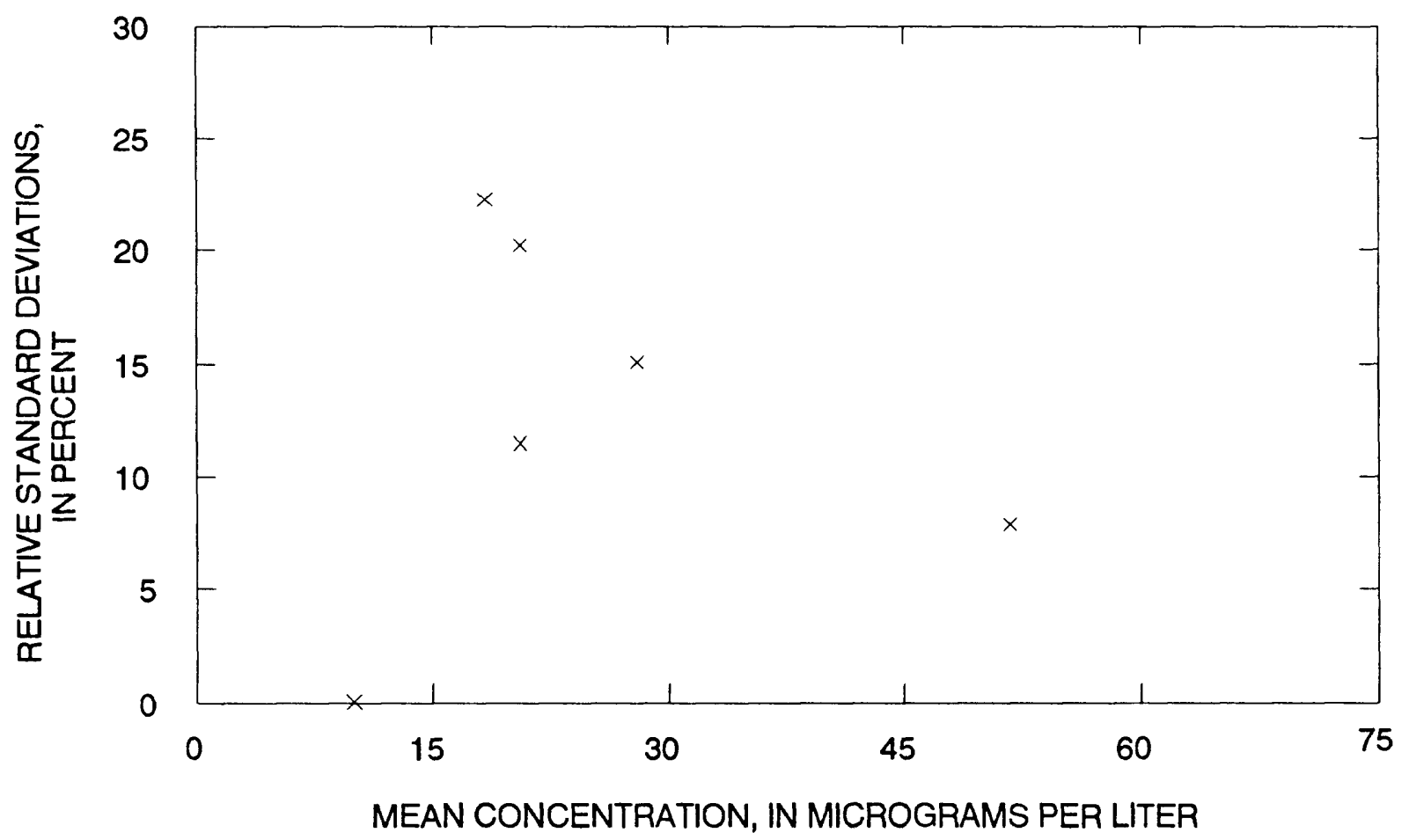

Figure 120.--Precislon data for manganese, dissoived, (atomic absorption spectrometry) data from the National Water Quality Laboratory. 


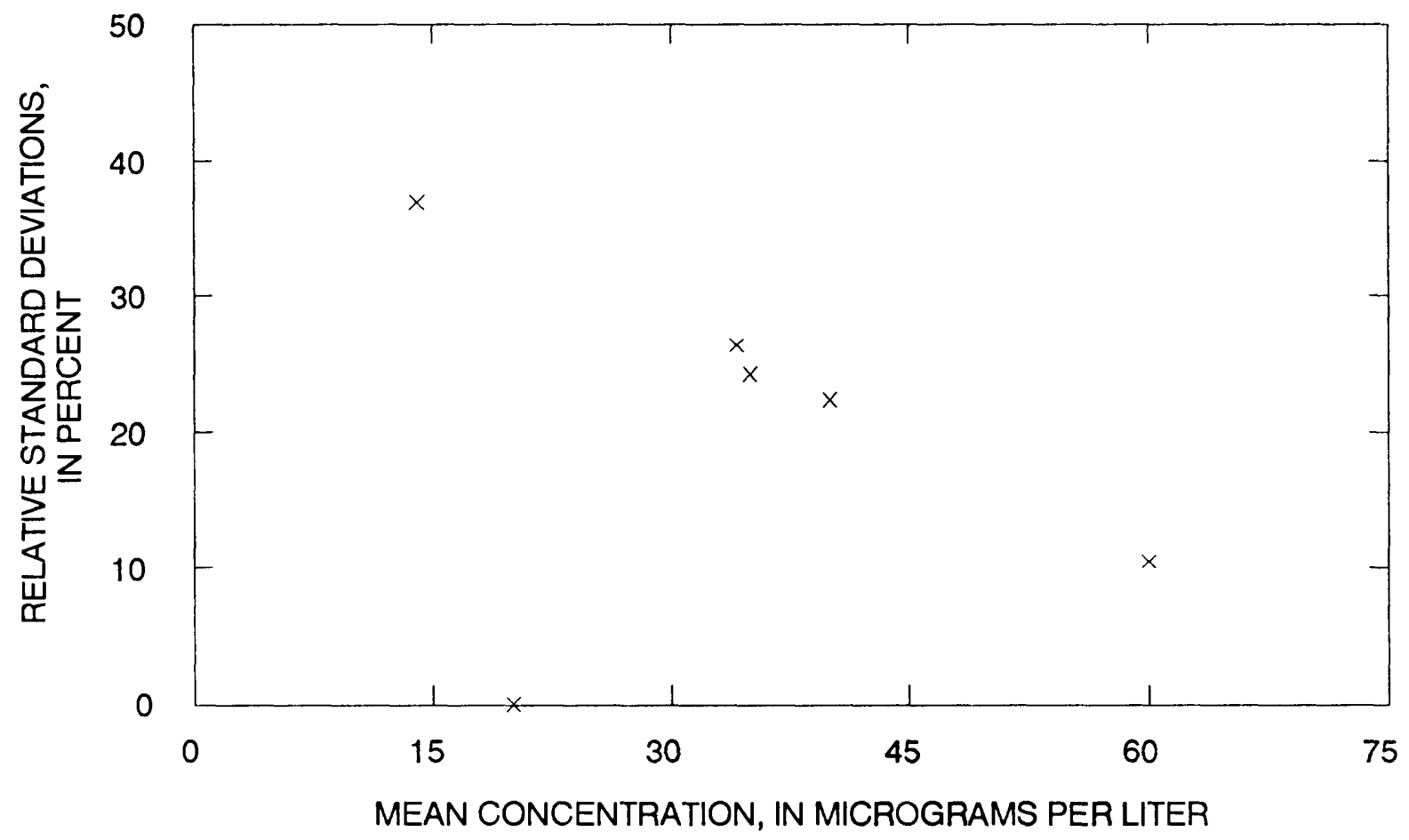

Figure 121.--Precision data for manganese, total recoverable, (atomic absorption spectrometry)

data from the National Water Quality Laboratory.

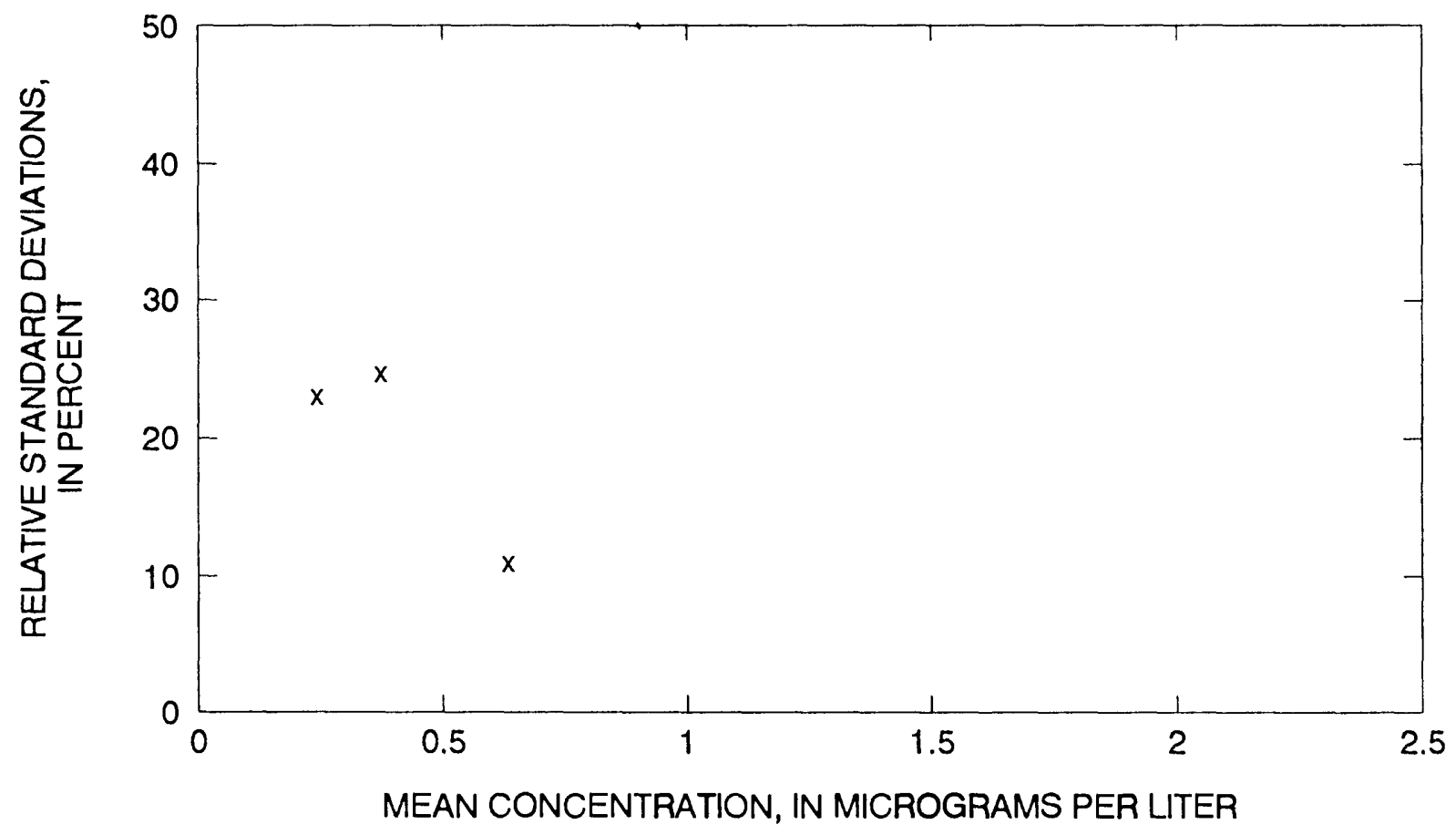

Figure 122.--Precision data for mercury, dissolved, (atomic absorption spectrometry)

data from the National Water Quality Laboratory. 


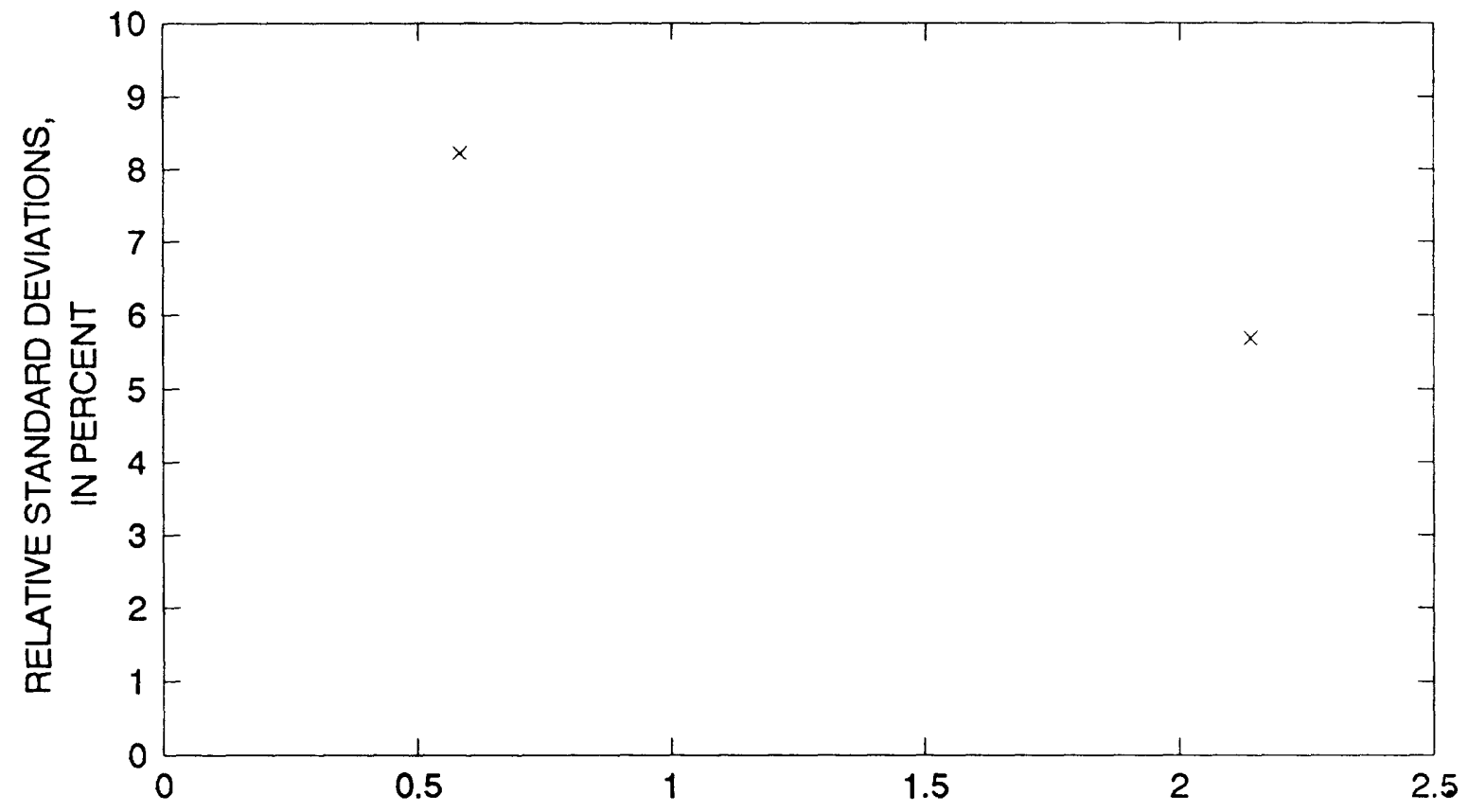

MEAN CONCENTRATION, IN MICROGRAMS PER LITER

Figure 123.--Precislon data for mercury, total, (atomic absorption spectometry) data from the National Water Quality Laboratory.

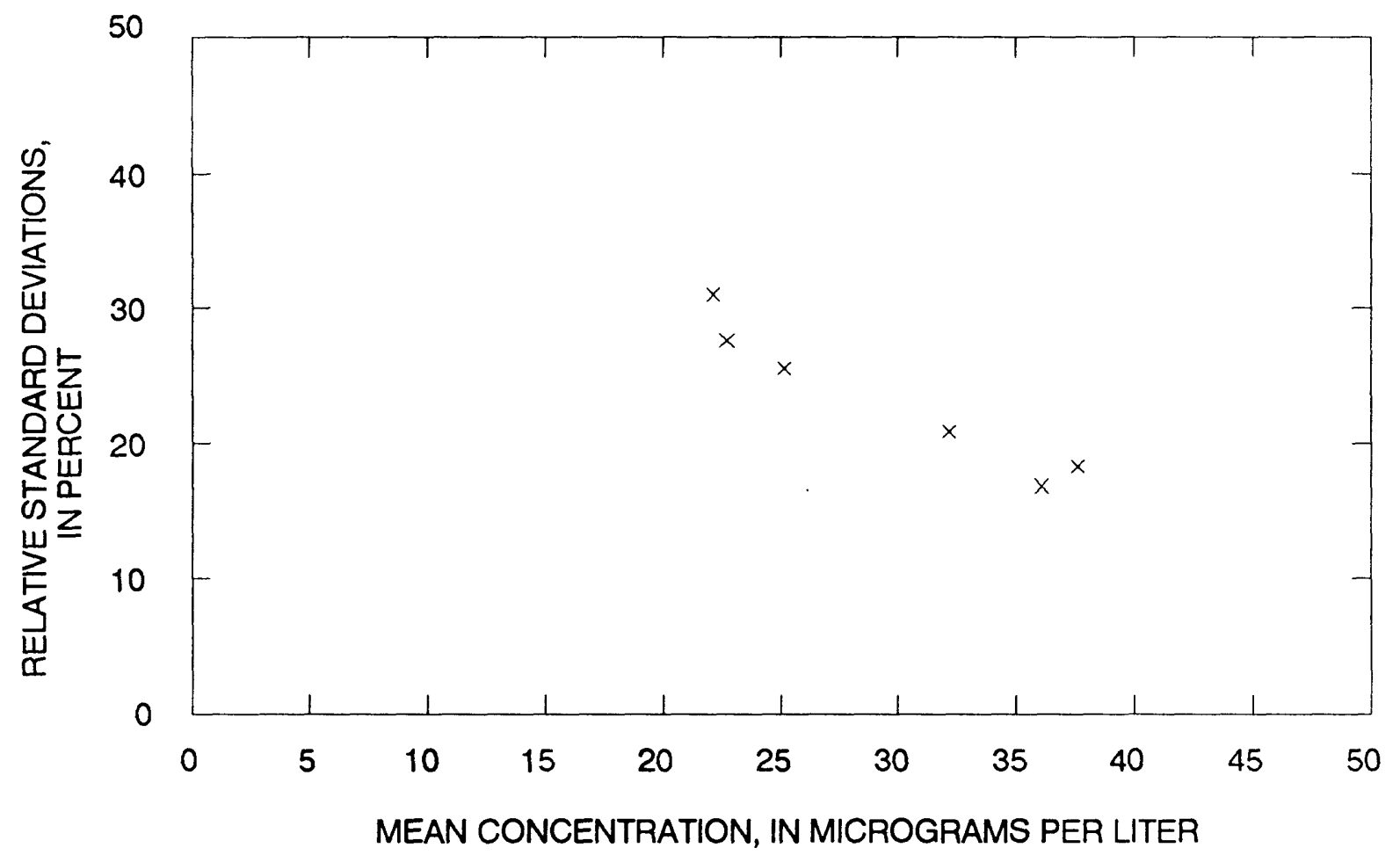

Figure 124.--Precision data for molybdenum, dissolved, (inductively coupied plasma emission spectrometry) data from the National Water Quality Laboratory. 


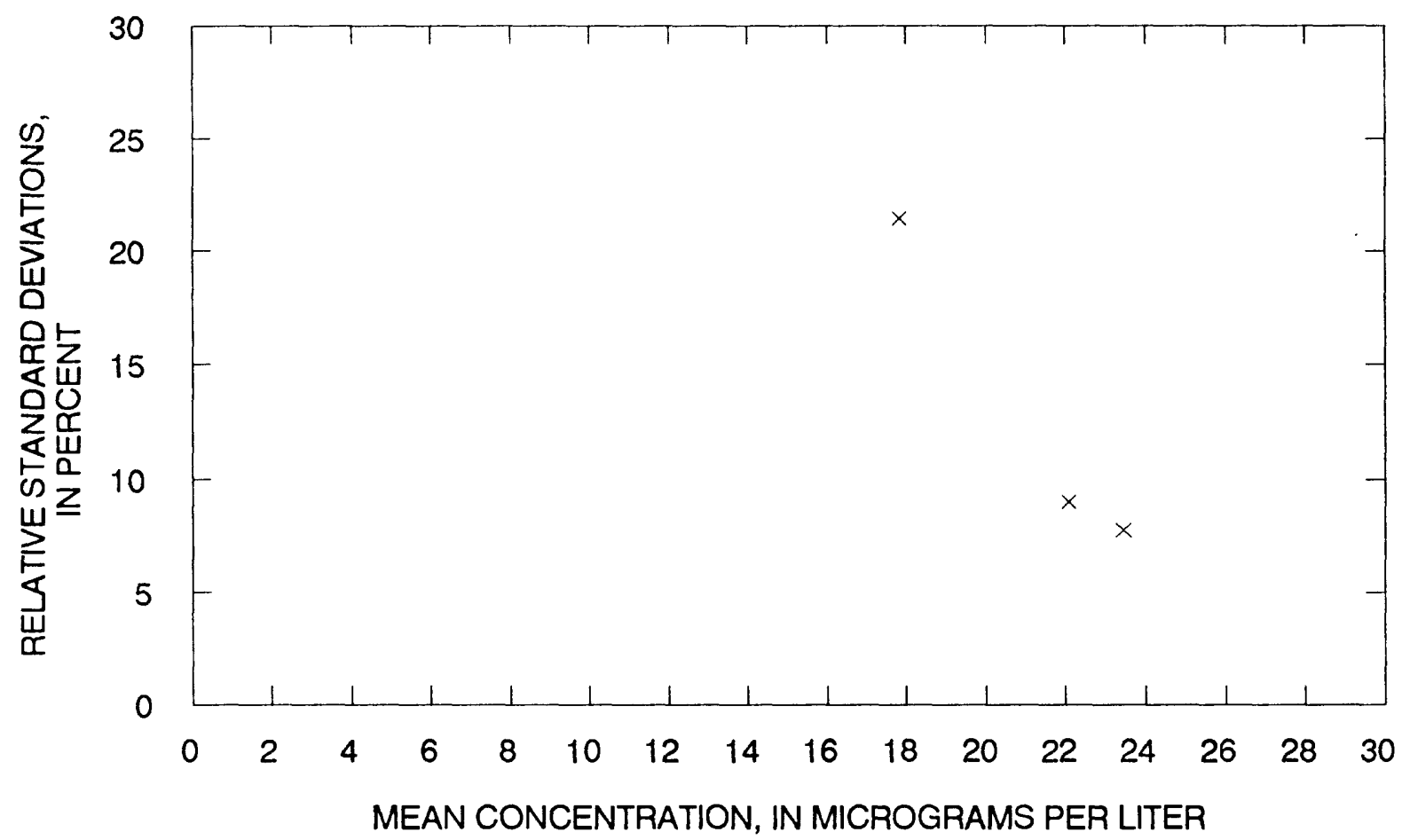

Figure 125.--Precision data for molybdenum, dissolved, (atomic absorption spectrometry) data from the National Water Quality Laboratory.

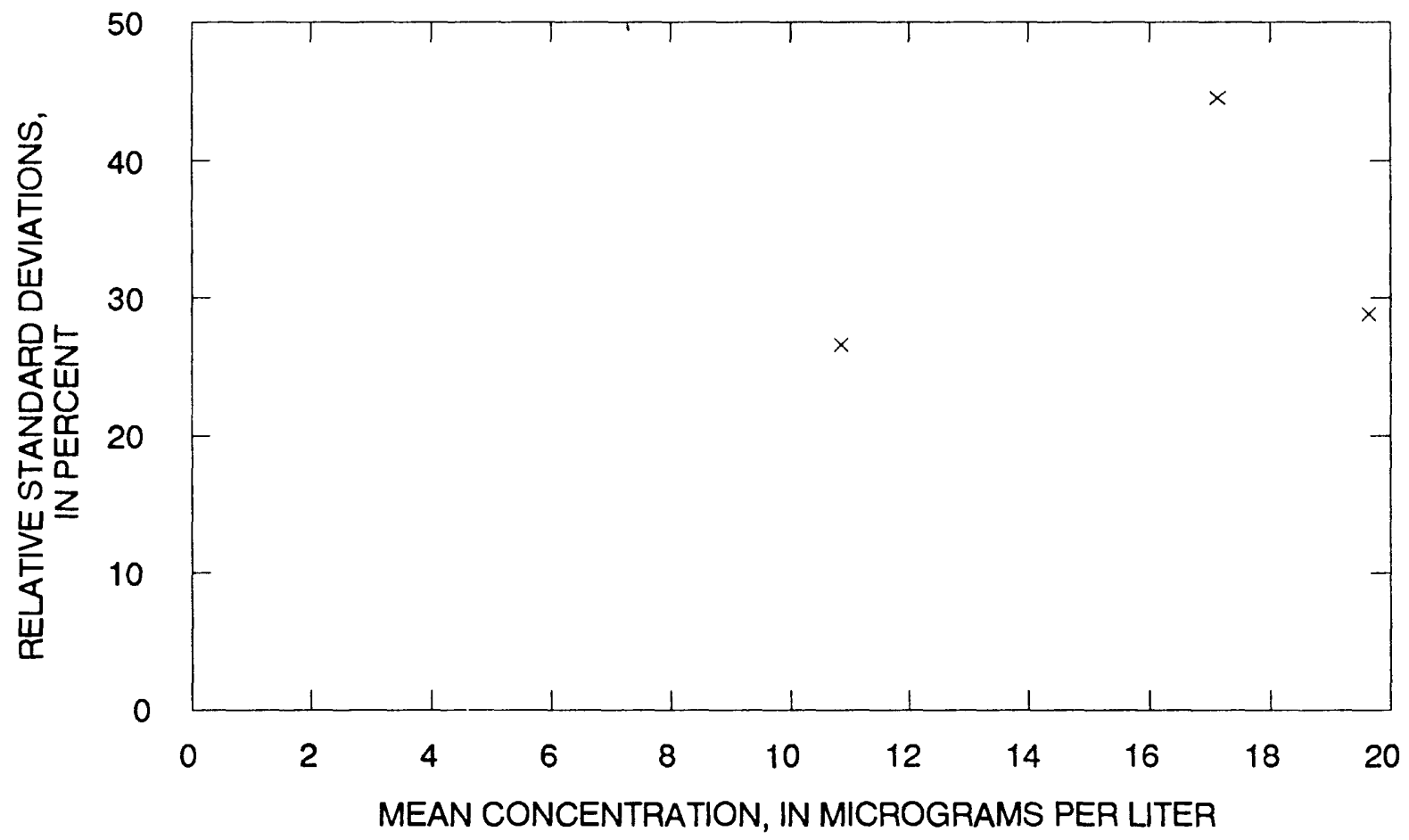

Figure 126.--Precision data for nickel, dissolved, (inductively coupled plasma emission spectrometry) data from the National Water Quality Laboratory. 


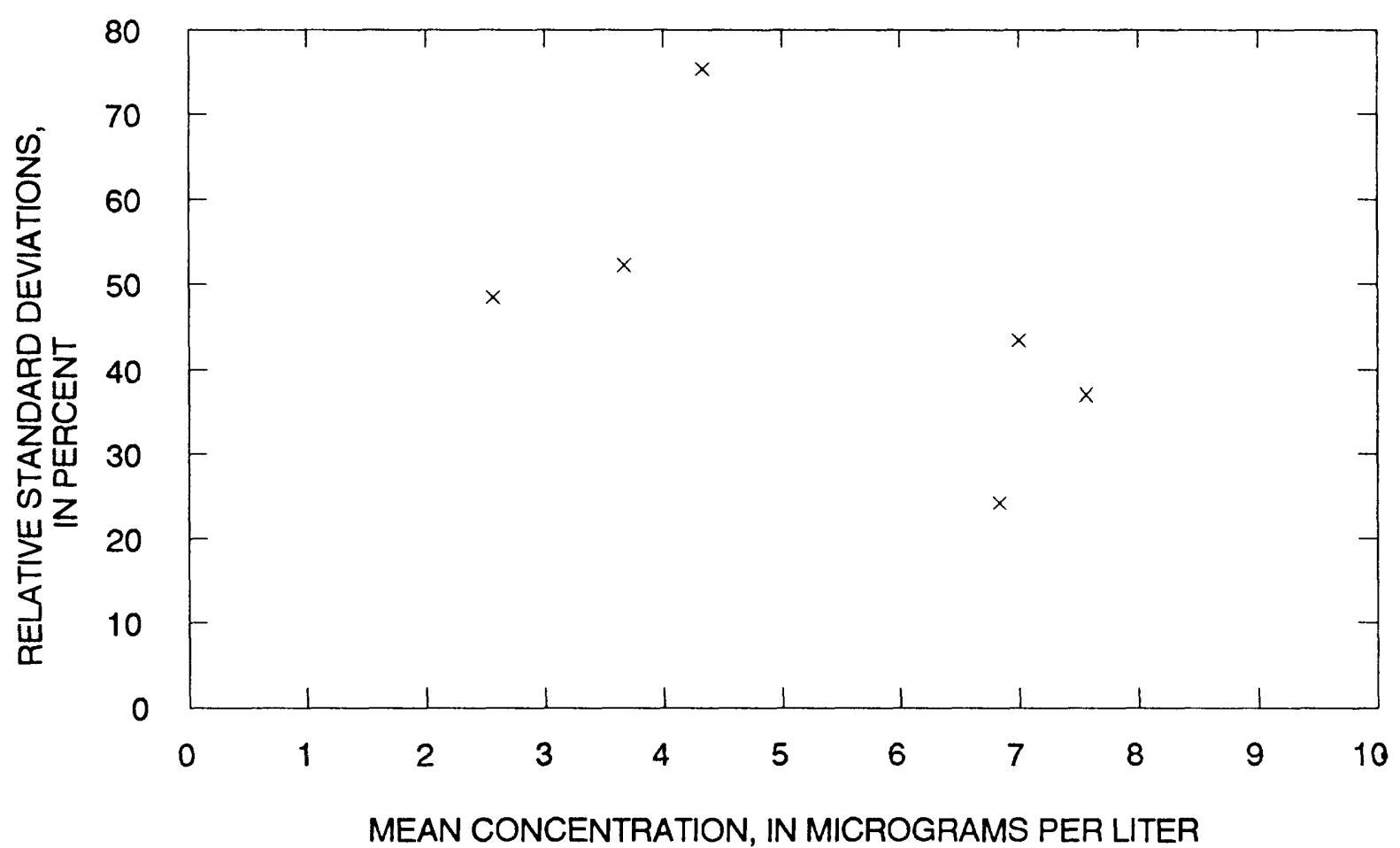

Figure 127.--Precision data for nickel, dissolved, (atomic absorptlon spectrometry; chelation-extraction and graphite furnace)

data from the Natlonal Water Quality Laboratory.

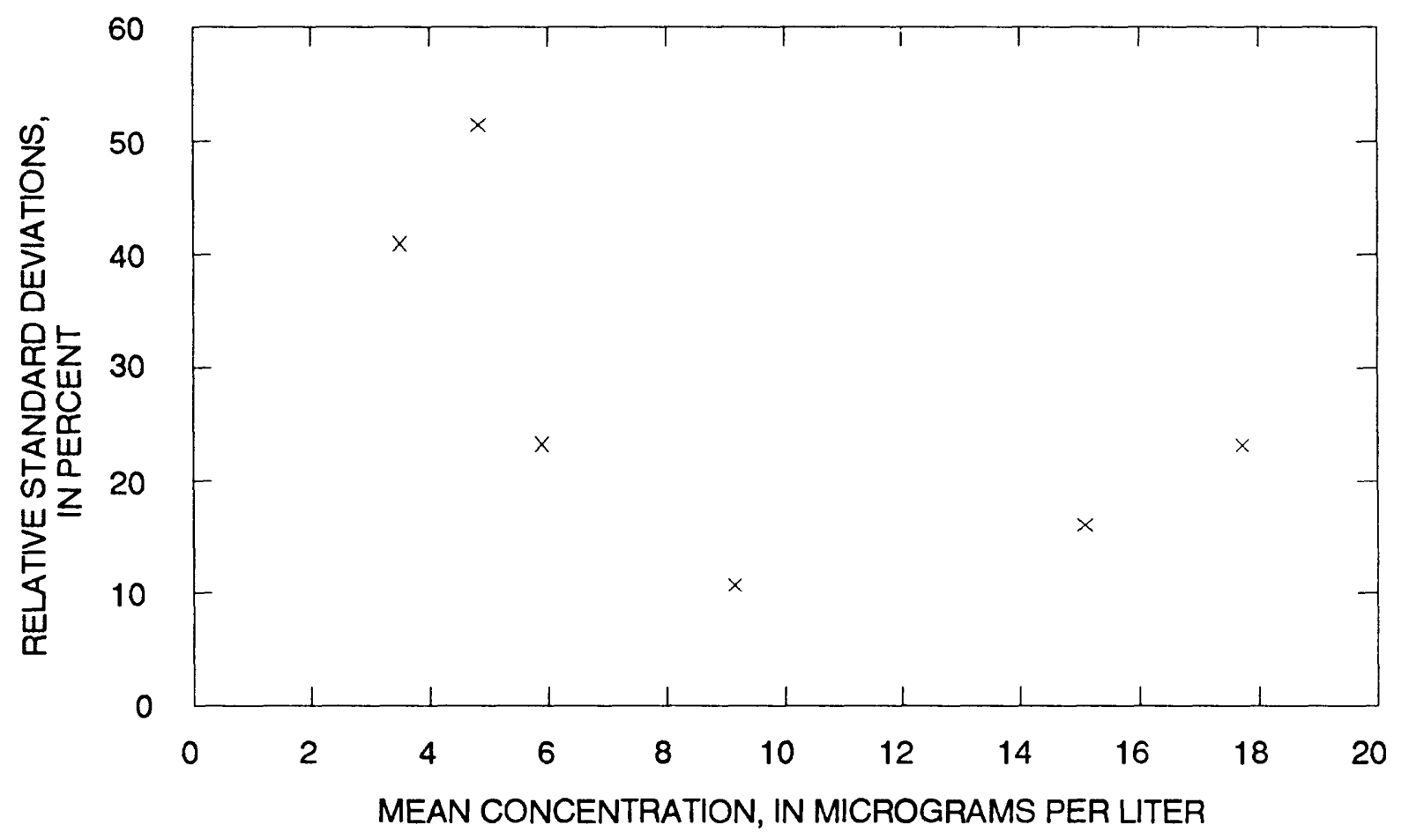

Figure 128.--Preclsion data for nickel, total recoverable, (atomlc absorptlon spectrometry; chelation-extraction and graphlte furnace)

data from the National Water Quaiity Laboratory. 


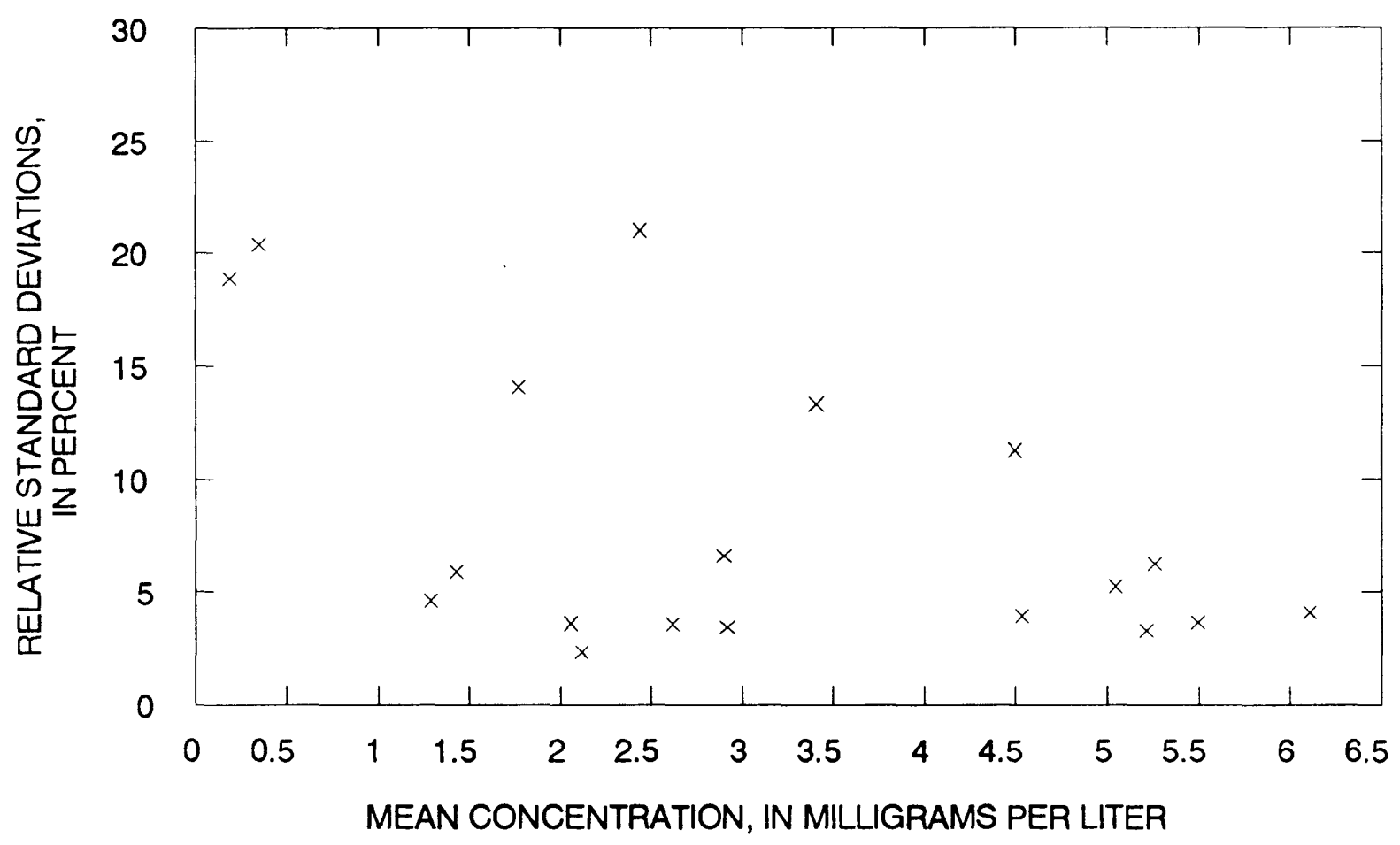

Figure 129.--Precision data for potasslum, dissolved, (atomic absorption spectrometry)

data from the National Water Quality Laboratory.

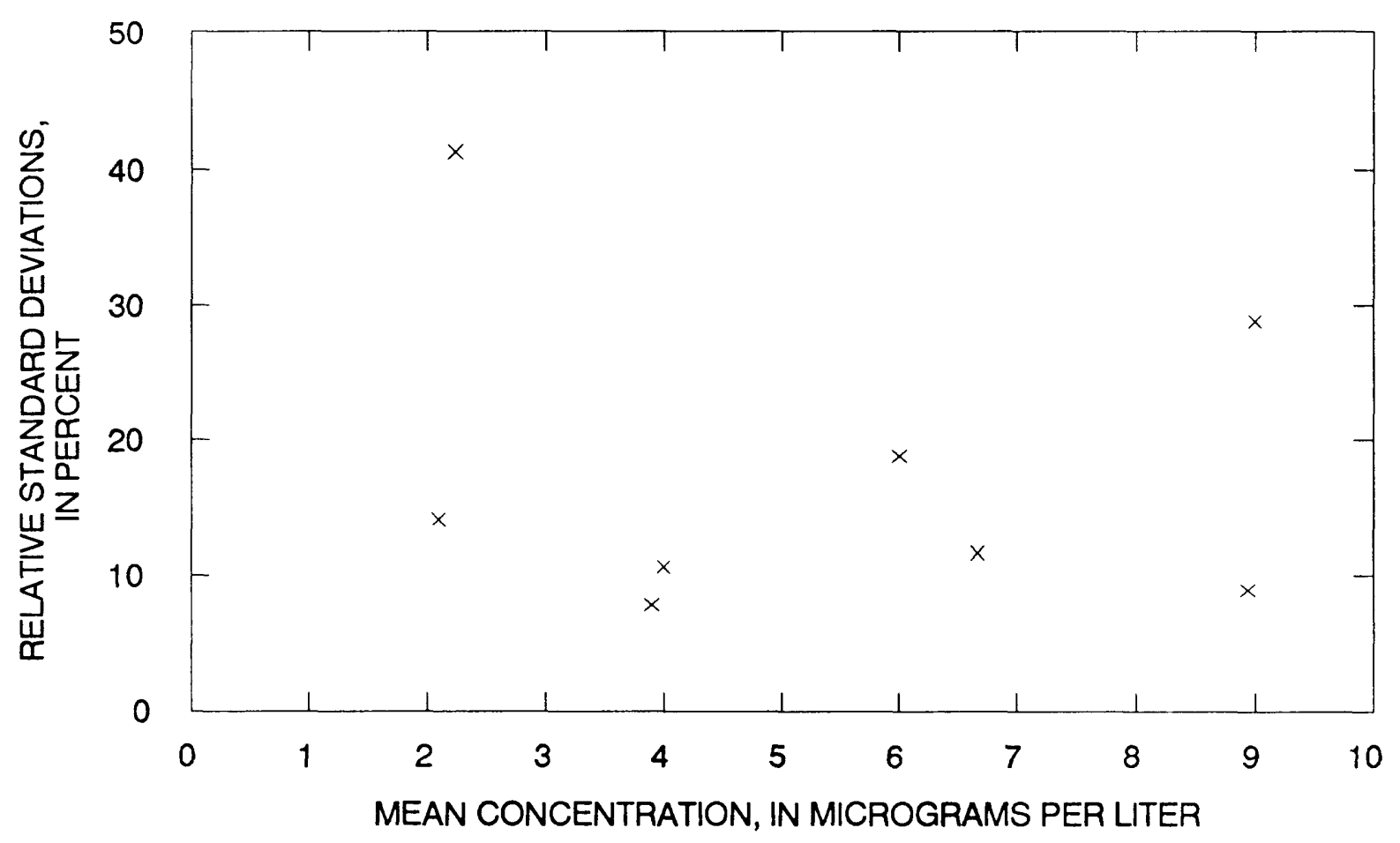

Figure 130.--Precision data for selenium, dissolved, (atomic absorption spectrometry, hydride) data from the National Water Quality Laboratory. 


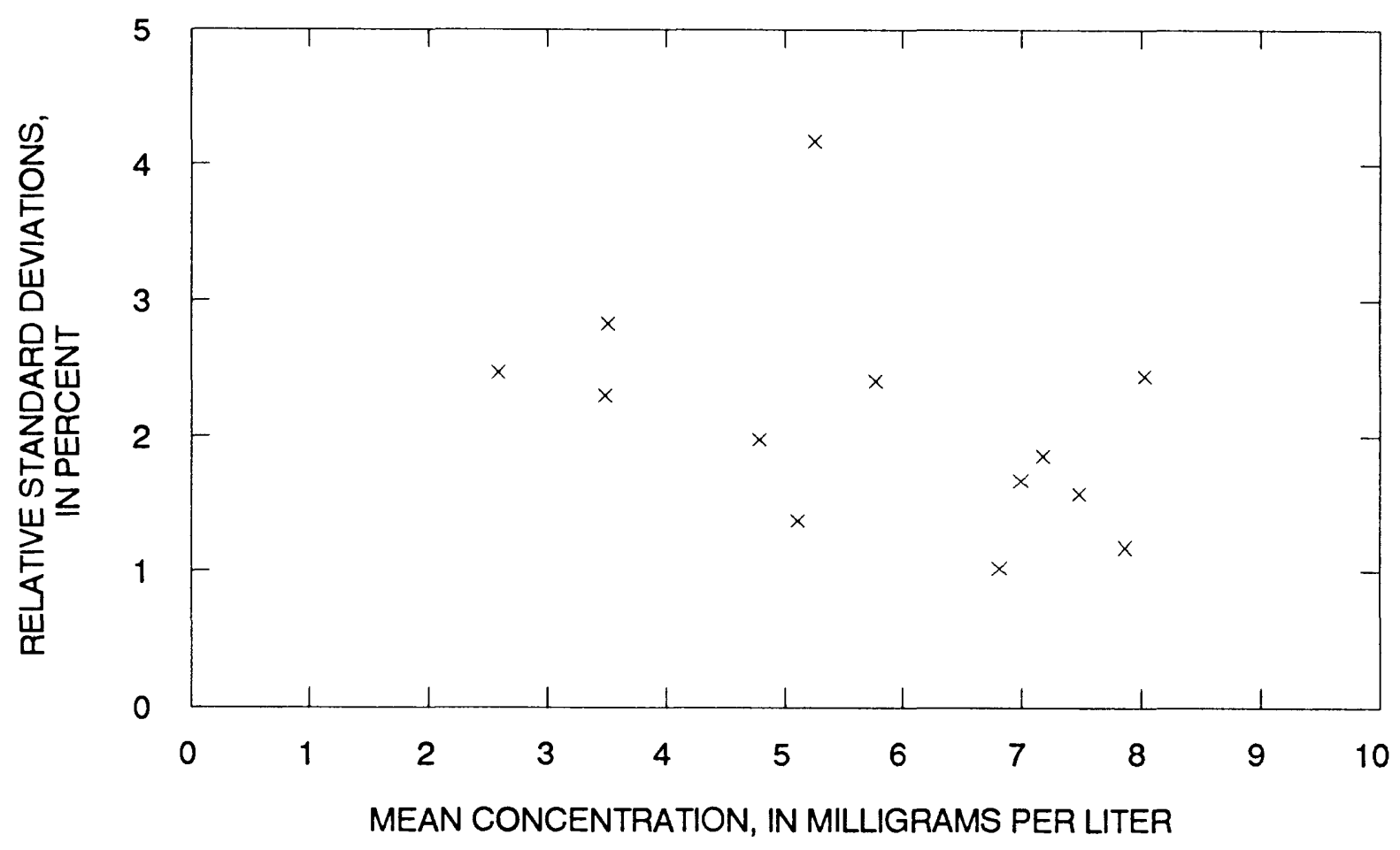

Figure 131--Precision data for silica, dissolved, (inductively coupled plasma emission spectrometry) data from the National Water Quality Laboratory.

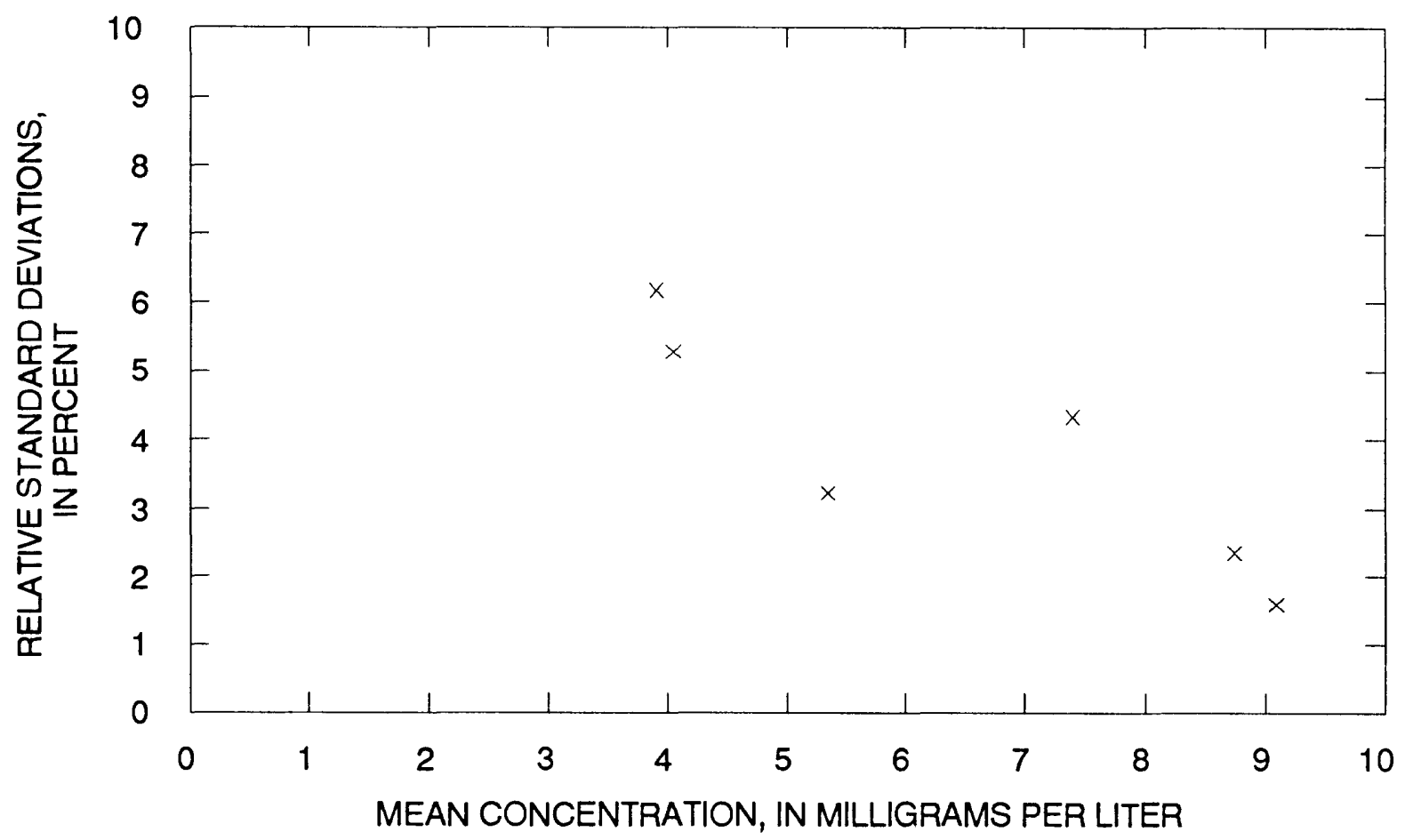

Figure 132.--Precision data for silica, dissolved, (colorimetric)

data from the National Water Quality Laboratory. 


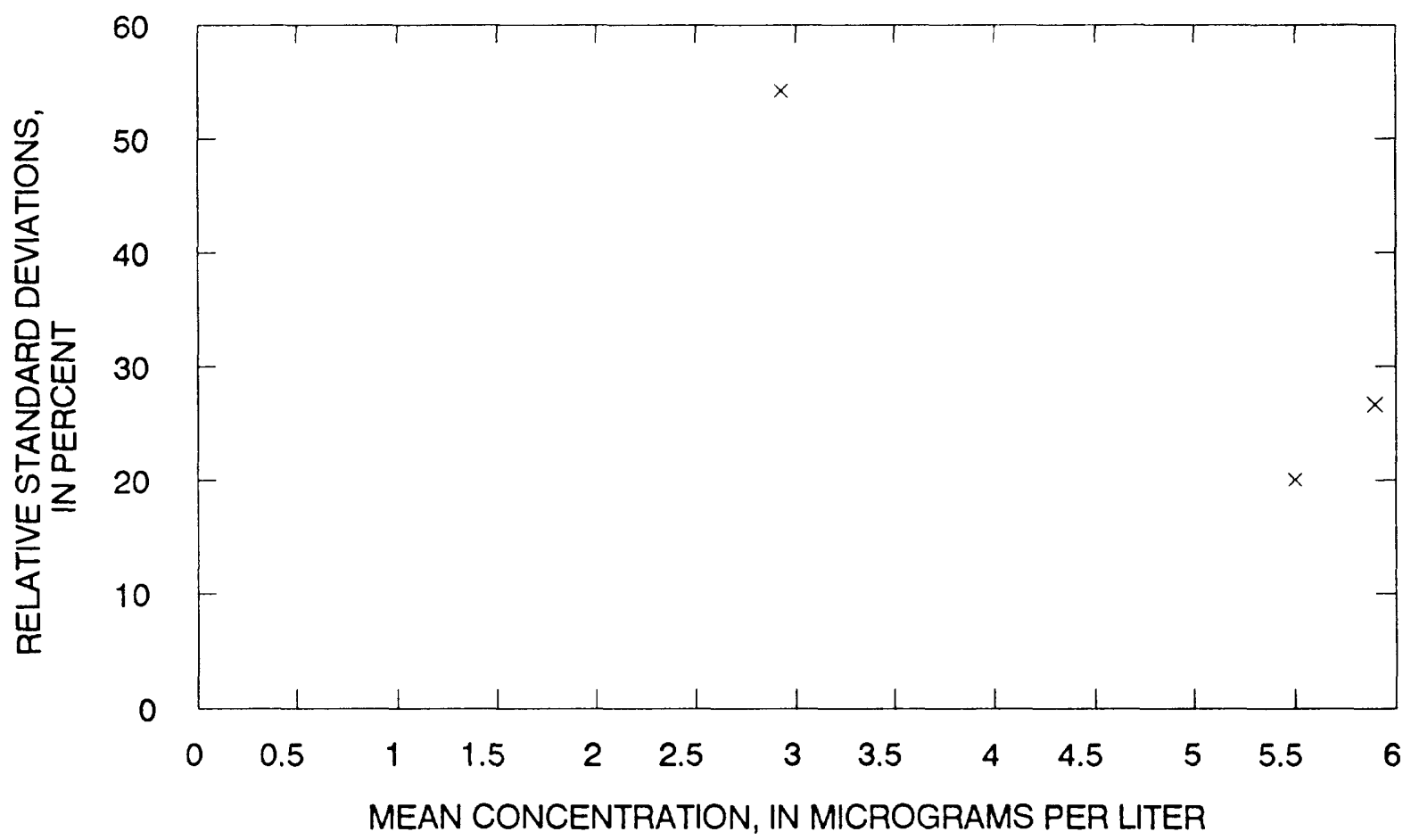

Figure 133---Precision data for silver, dissolved, (inductively coupled plasma emission spectrometry) data from the National Water Quality Laboratory.

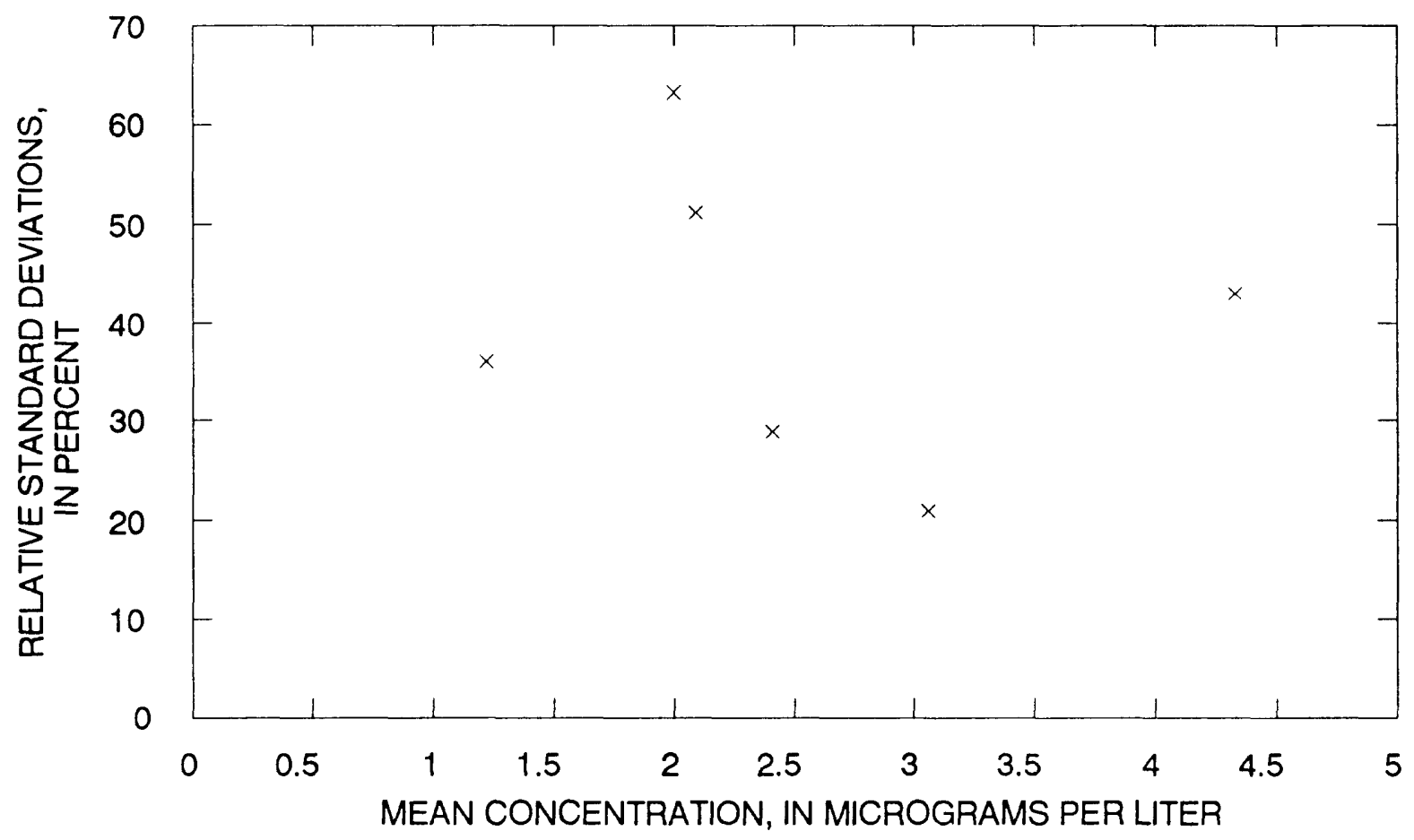

Figure 134.--Precision data for silver,dissolved, (atomic absorption spectrometry; chelation-extraction and graphite furnace)

data from the National Water Quality Laboratory. 


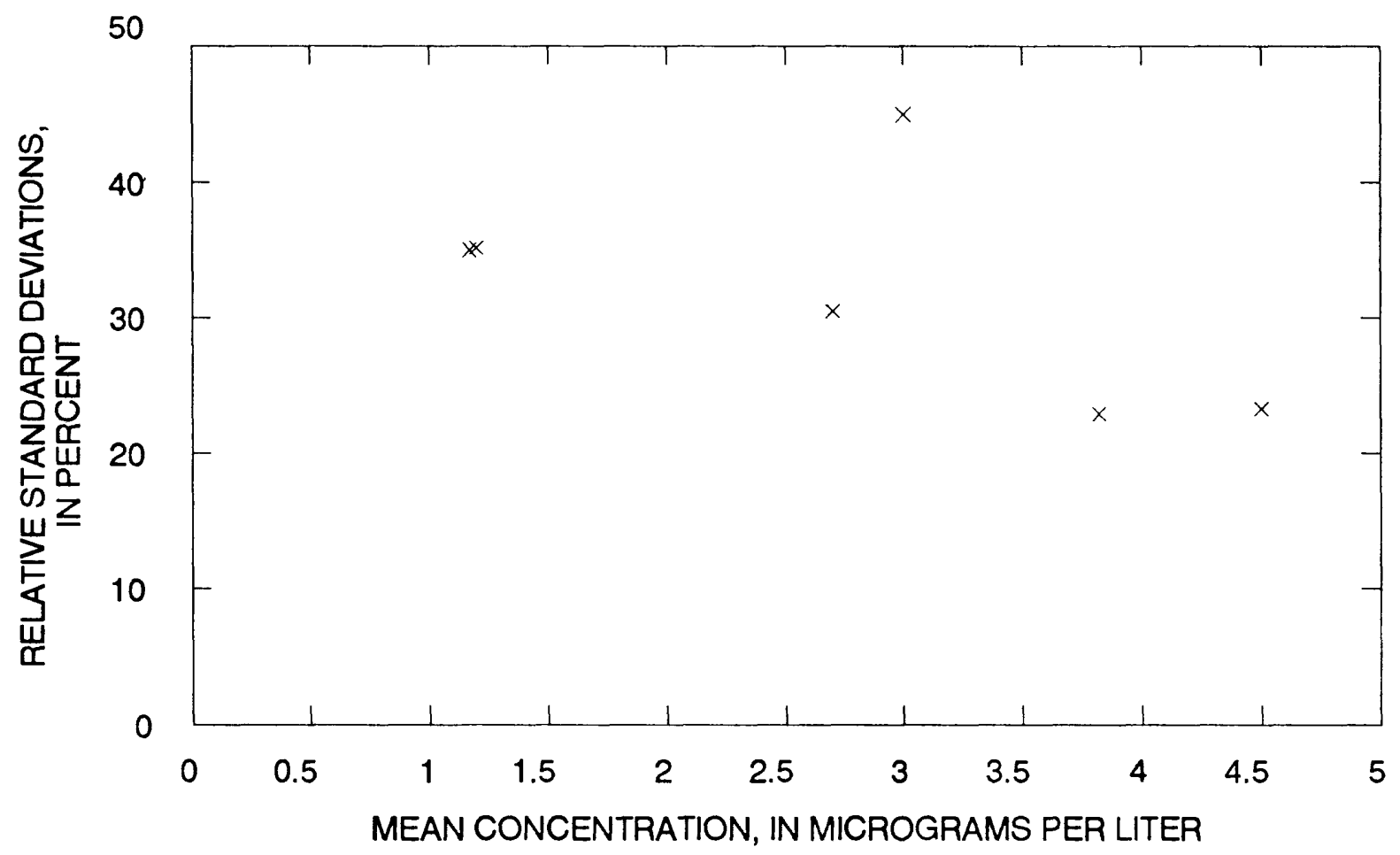

Figure 135.-- Precision data for silver, total recoverable, (atomic absorption spectrometry; chelation-extraction and graphite furnace)

data from the National Water Quality Laboratory.

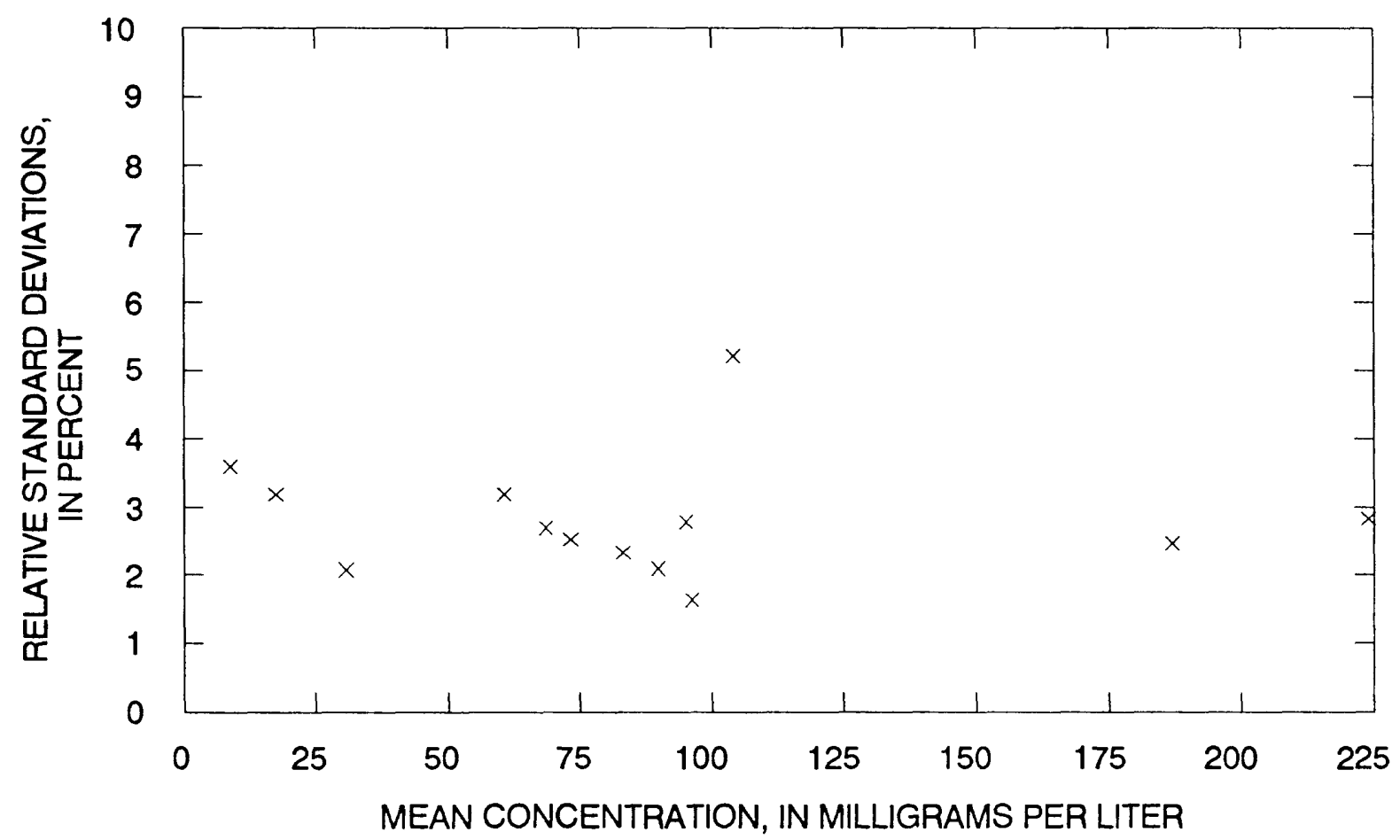

Figure 136.--Precision data for sodium, dissolved, (inductively coupled plasma emission spectrometry) data from the National Water Quality Laboratory. 


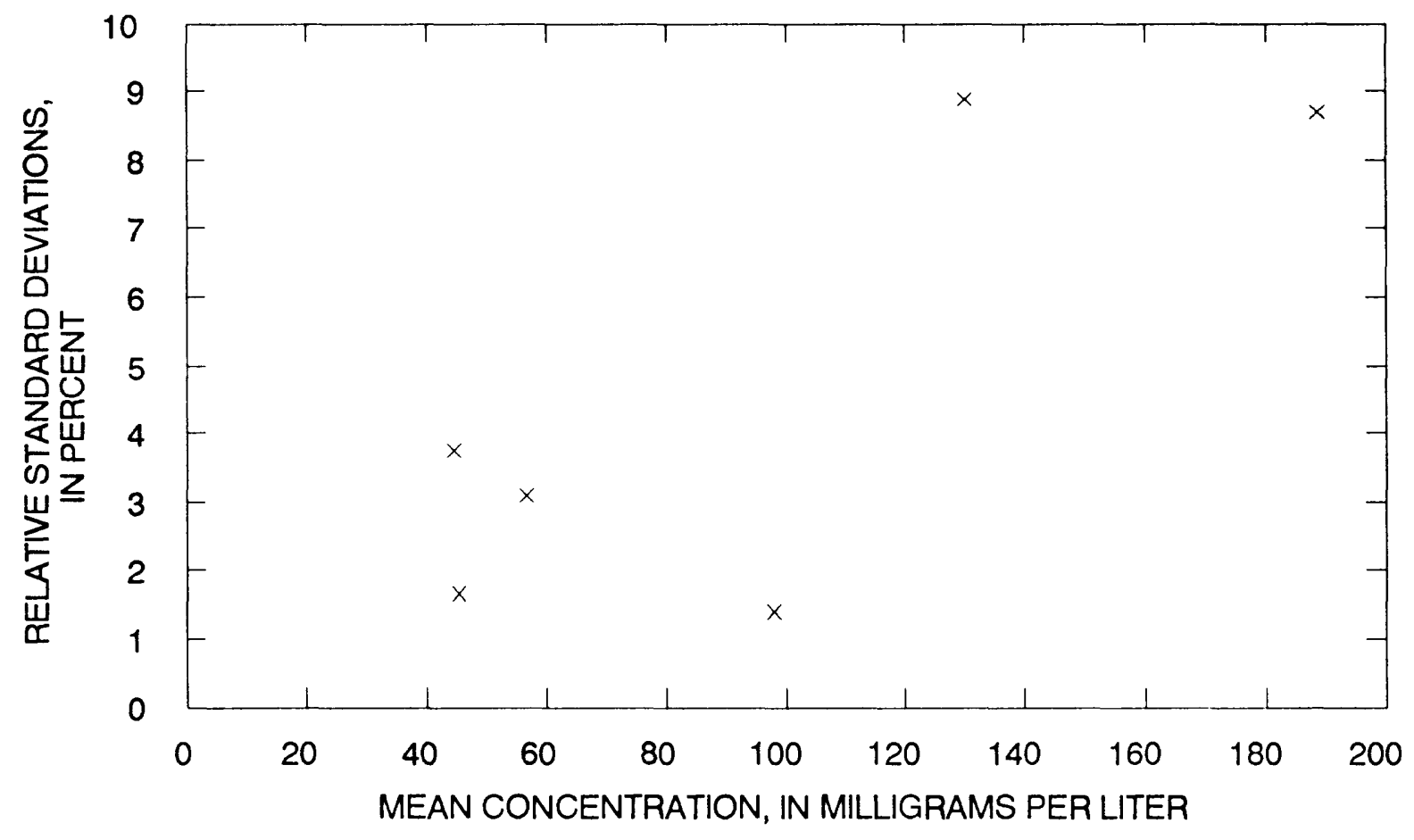

Figure 137.--Preclsion data for sodlum, dlssolved, (atomlc absorption spectrometry)

data from the National Water Quality Laboratory.

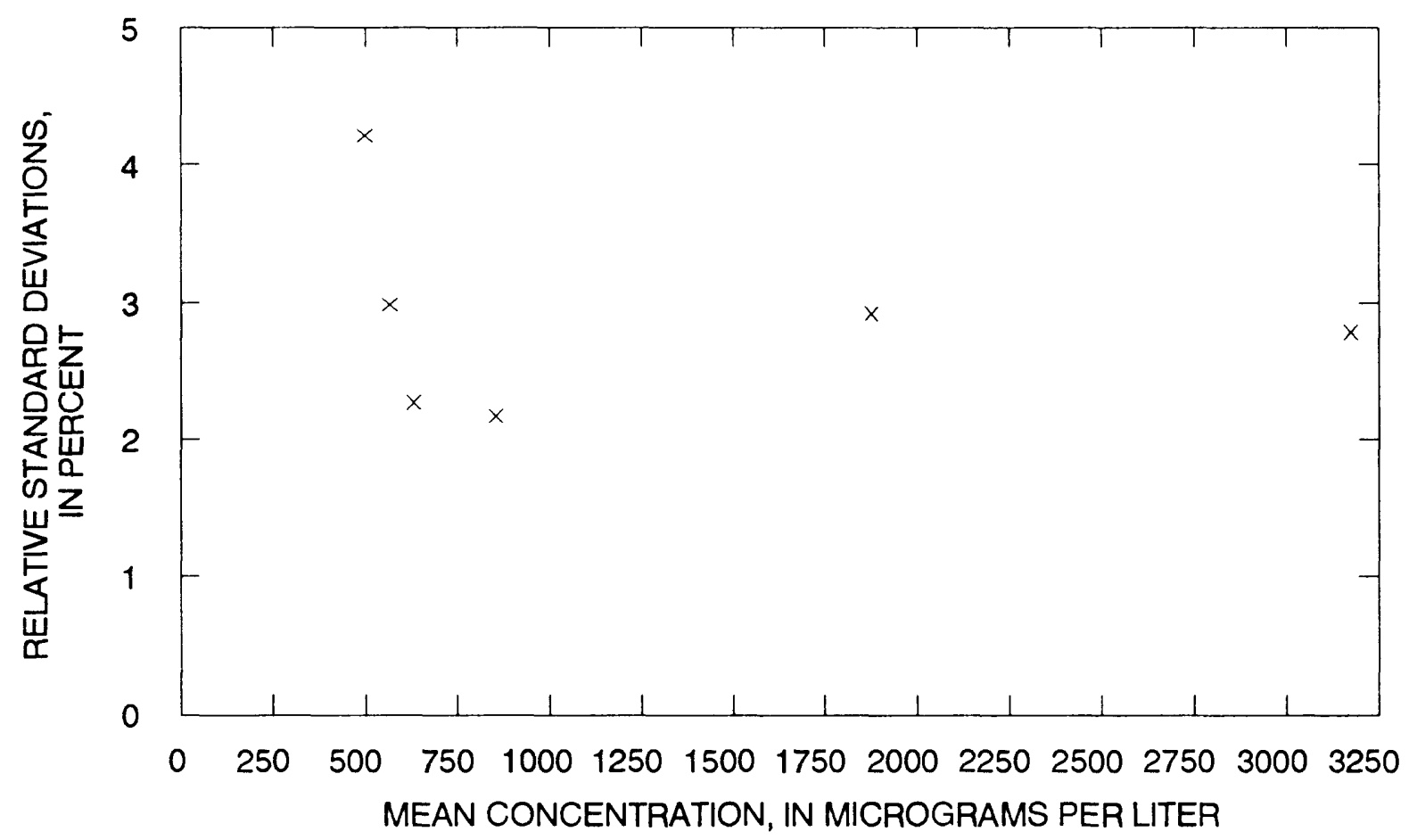

FIgure 138.--Preclsion data for strontlum, dissolved, (inductively coupled plasma emission spectrometry) data from the National Water Quality Laboratory. 


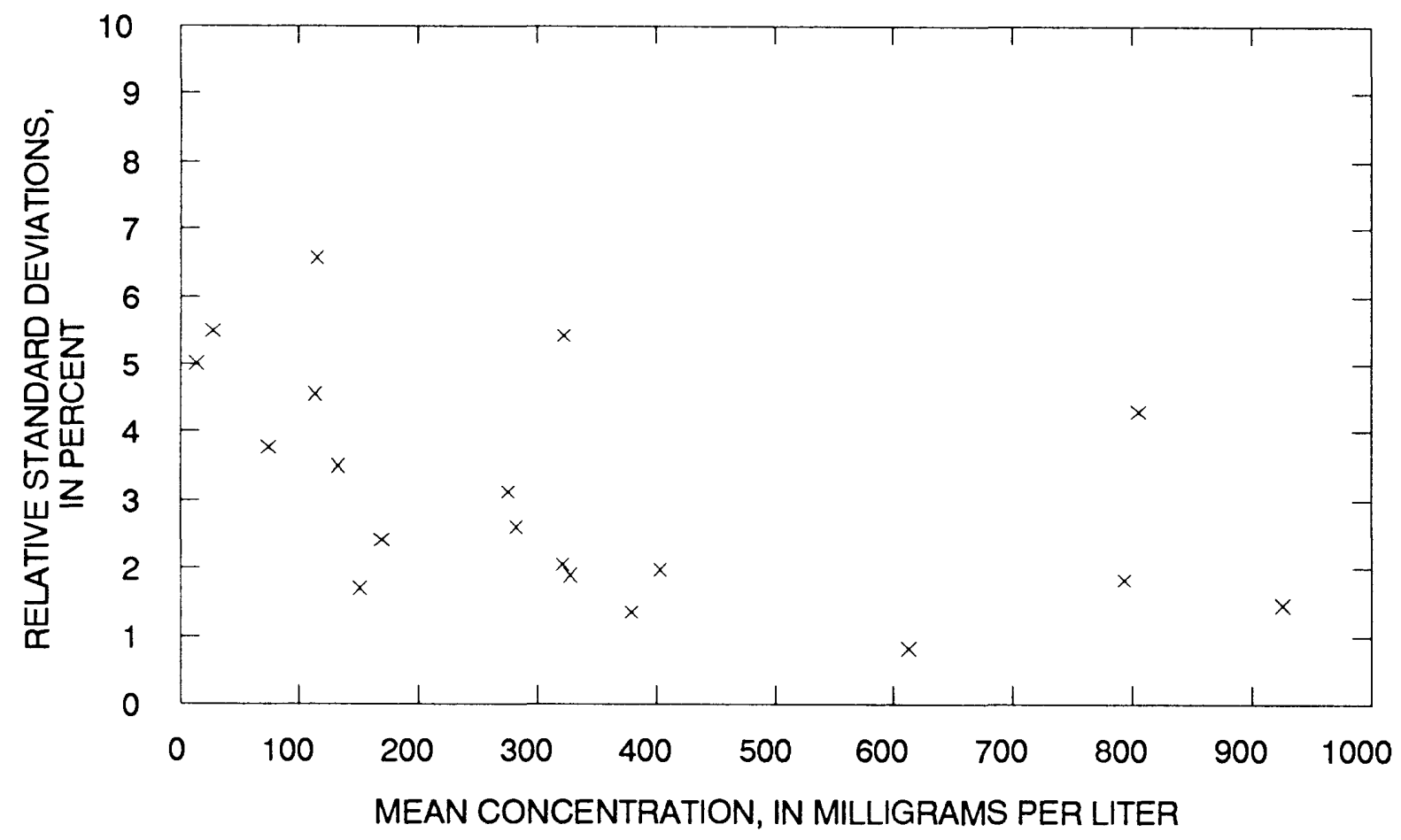

Figure 139.--Precision data for sulfate, dissolved, (turbidimetric)

data from the National Water Quality Laboratory.

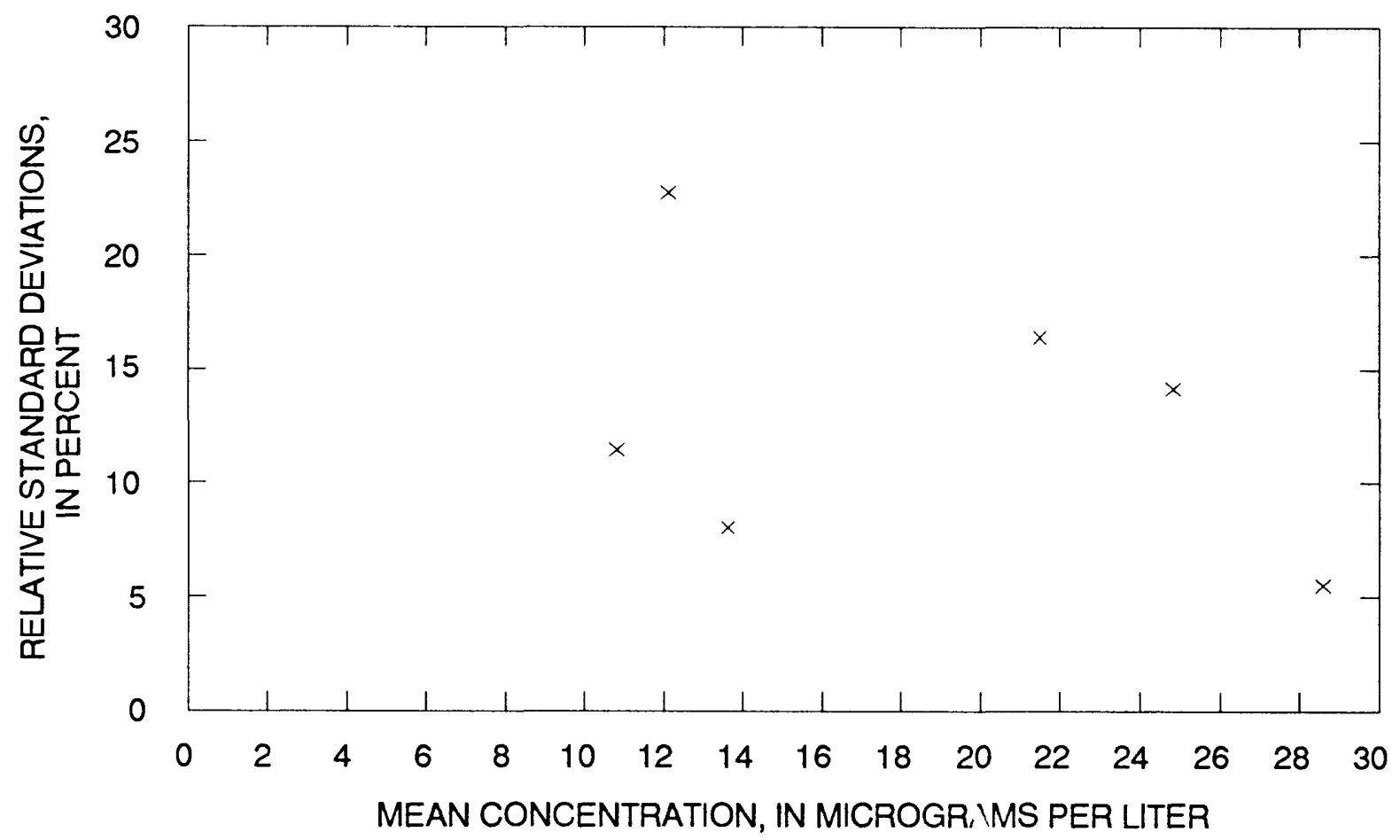

Figure 140.--Precision data for vanadium, dissolved (inductively coupled plasma emission spectrometry) data from the Natlonal Water Quality Laboratory. 


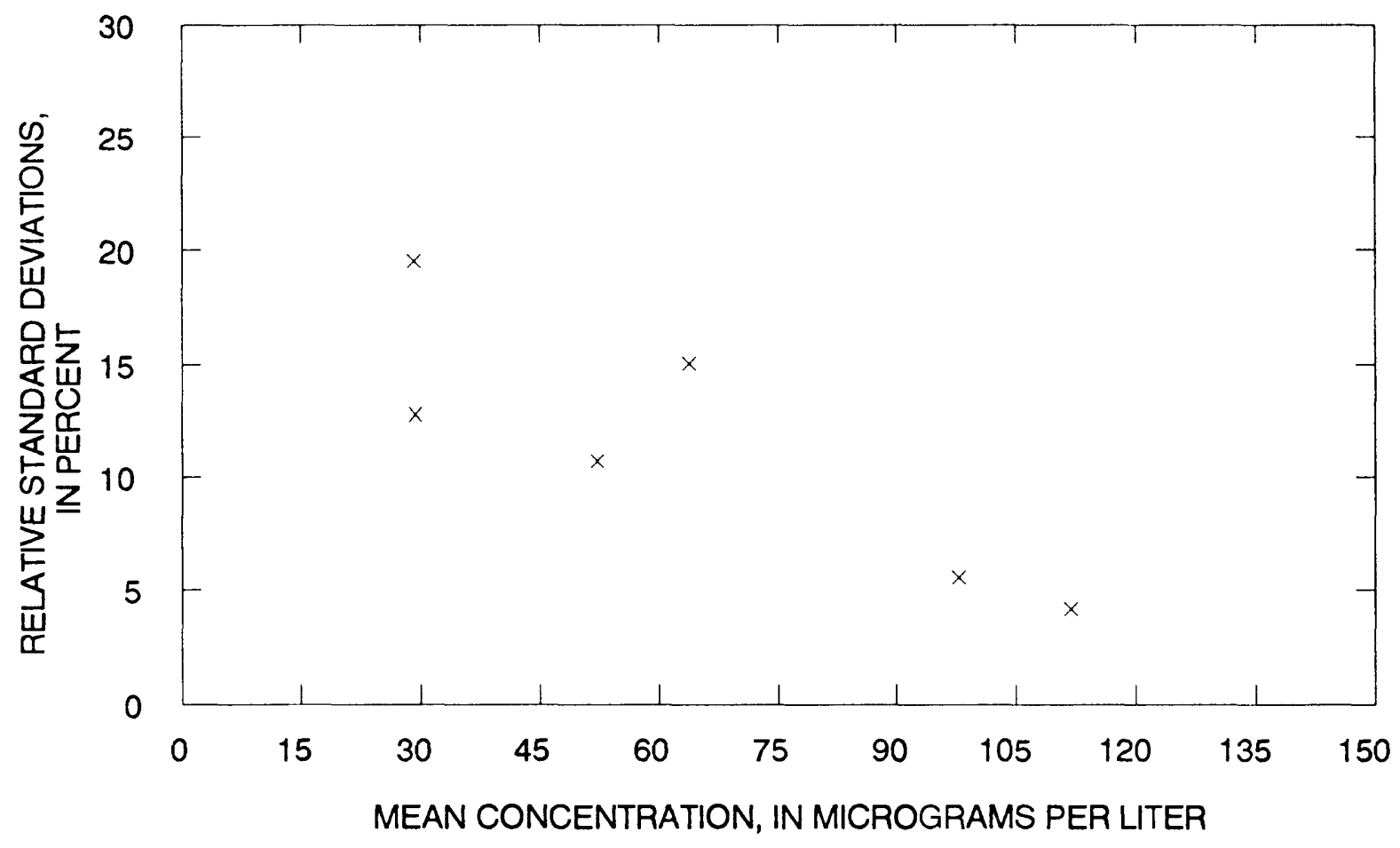

Figure 141.-- Precision data for zinc, dissolved, (inductively coupled plasma emission spectrometry) data from the National Water Quality Laboratory.

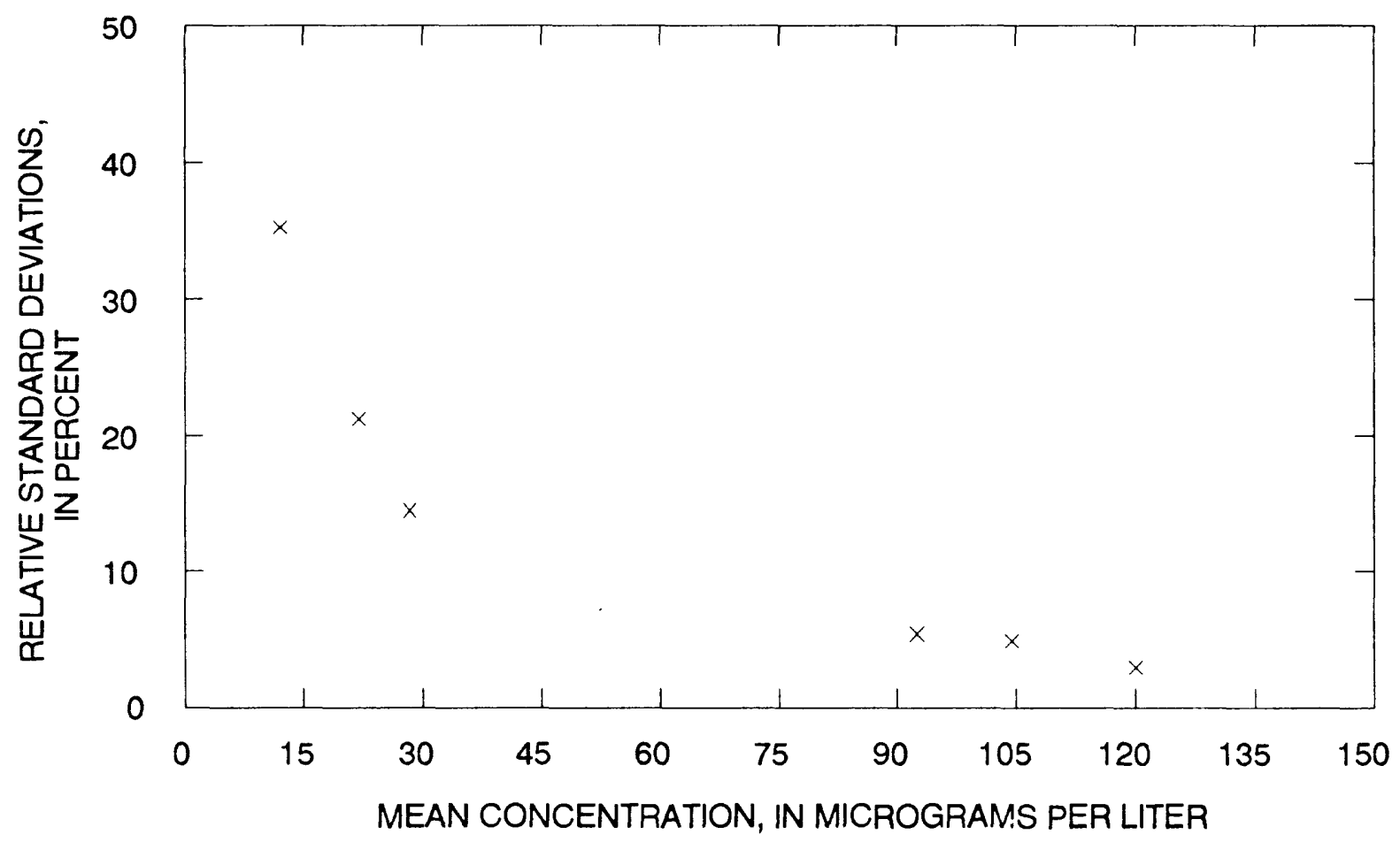

Figure 142.--Precision data for zinc, dissolved, (atomic absorption spectrometry) data from the National Water Quality Laboratory. 

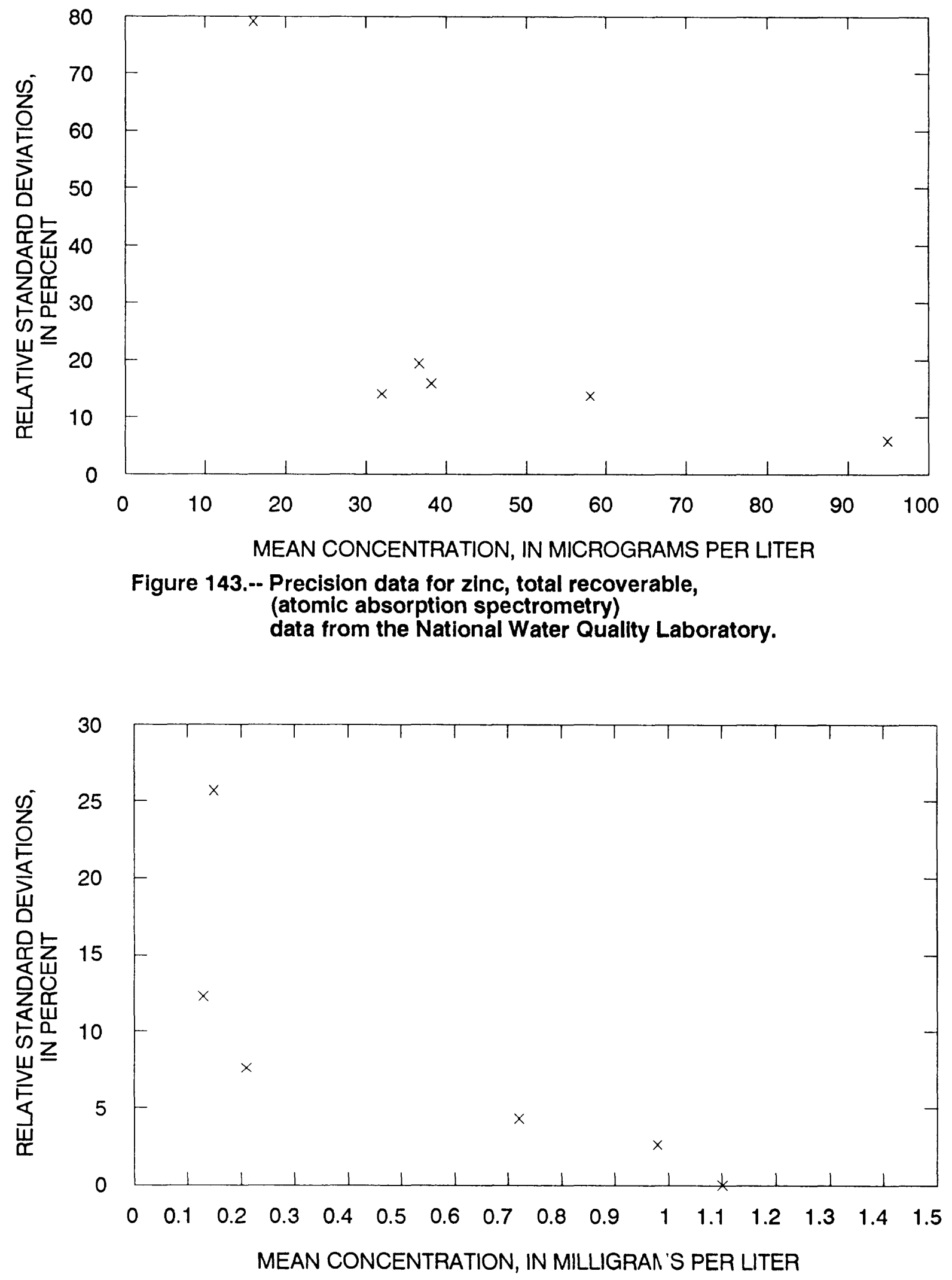

Figure 144.--Precision data for ammonia as nitrogell, dissolved and total, (colorimetric)

data from the National Water Quality Laboratory. 


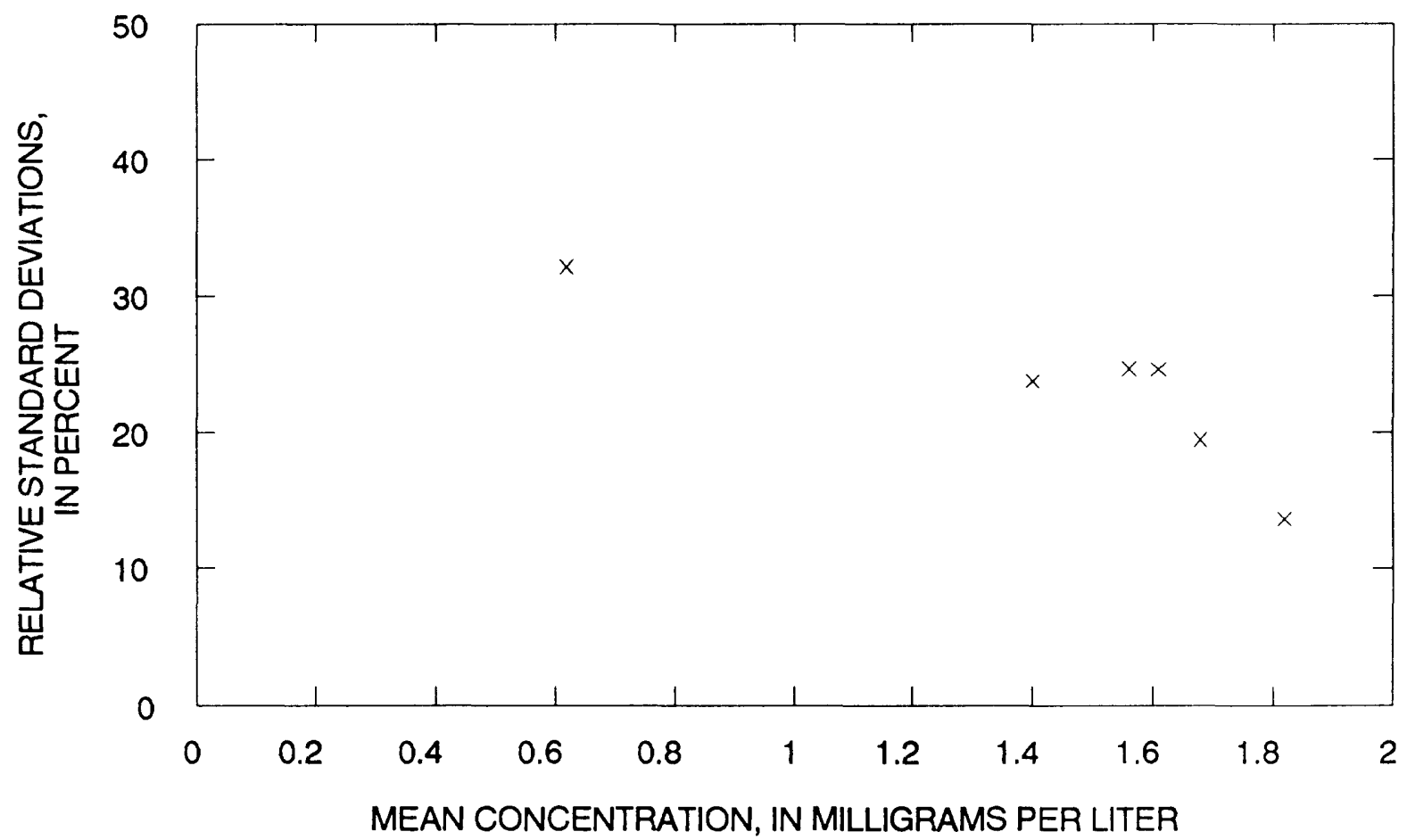

Figure 145.--Precision data for ammonia plus organic nitrogen, dissolved and total, (colorimetric)

data from the Natlonal Water Quality Laboratory.

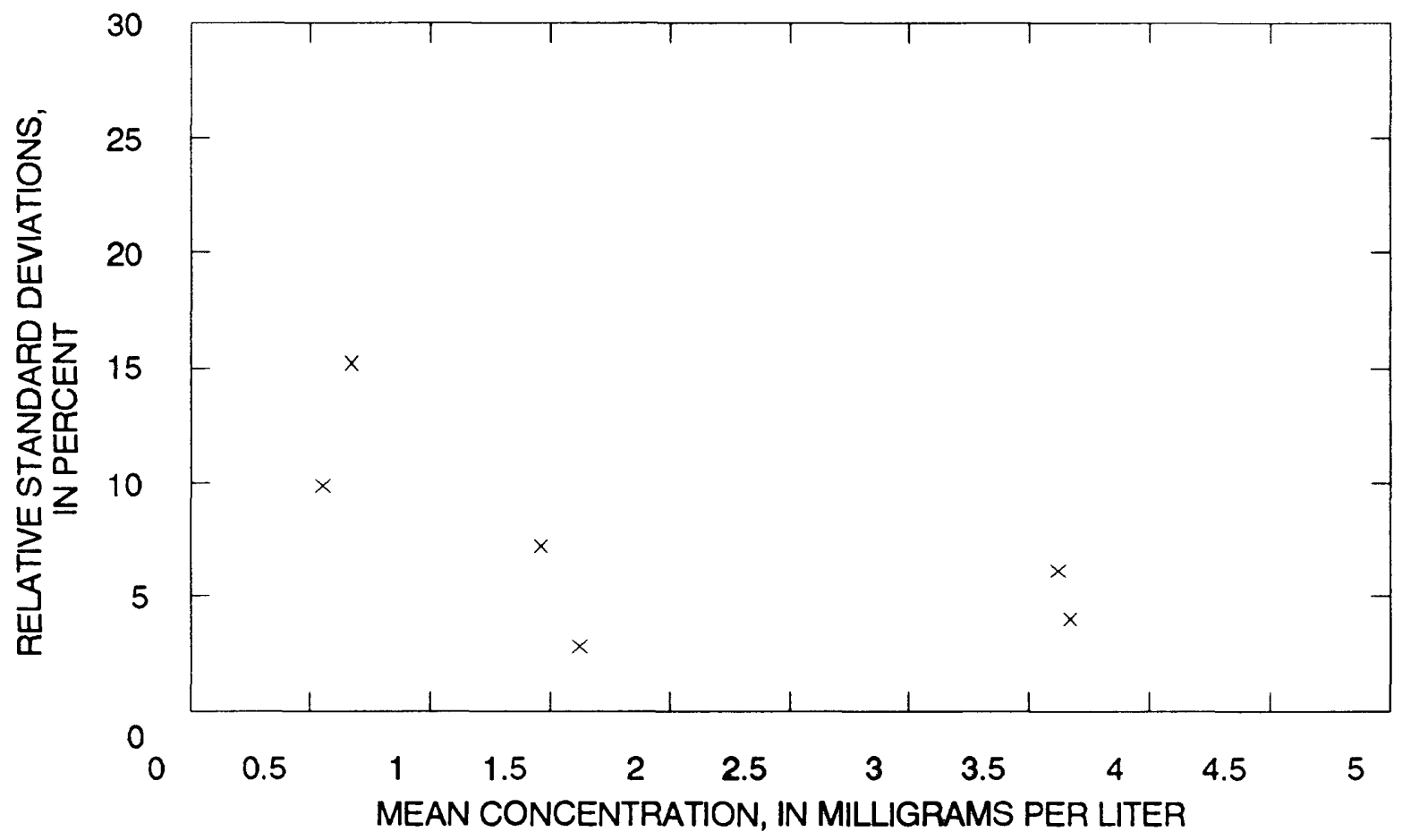

Figure 146.--Precision data for nitrate plus nitrite as nitrogen, dissolved and total, (colorimetric) data from the National Water Quality Laboratory. 


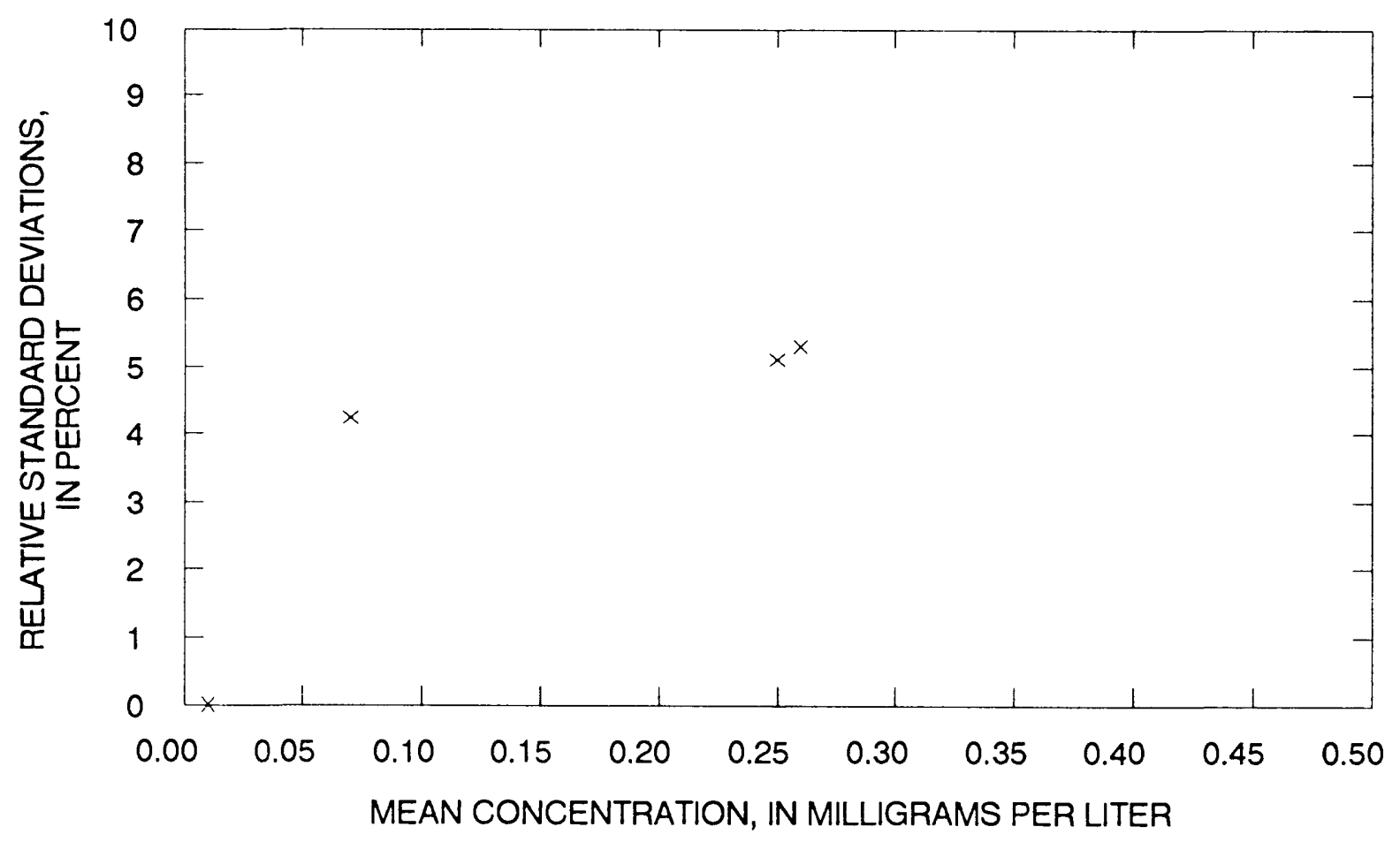

Figure 147.--Precision data for nitrite as nitrogen, dissolved and total, (colorimetric)

data from the National Water Quality Laboratory.

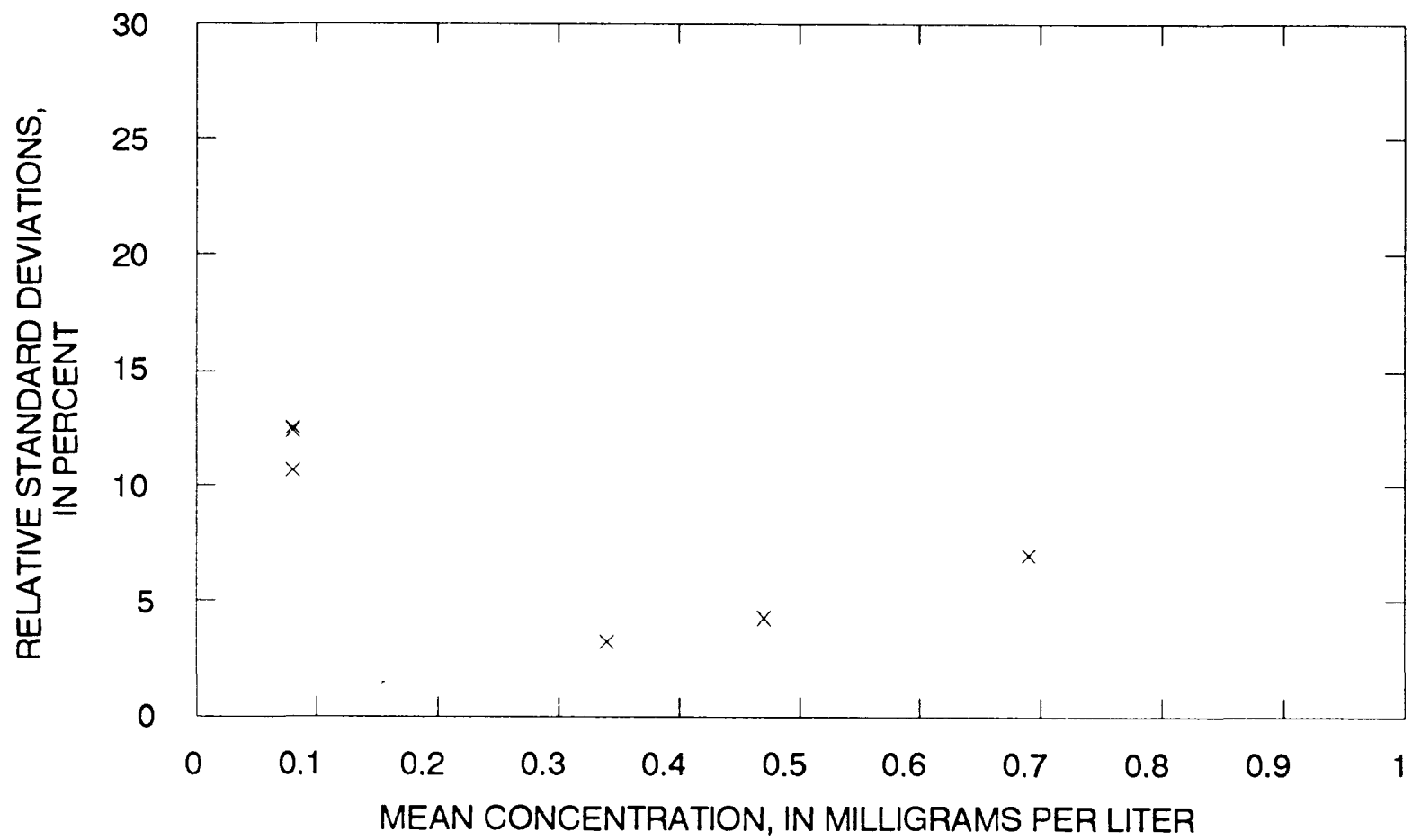

Figure 148.-- Precision data for orthophosphate as phosphorus, dissolved and total, (colorimetrlc) data from the National Water Quality Laboratory. 


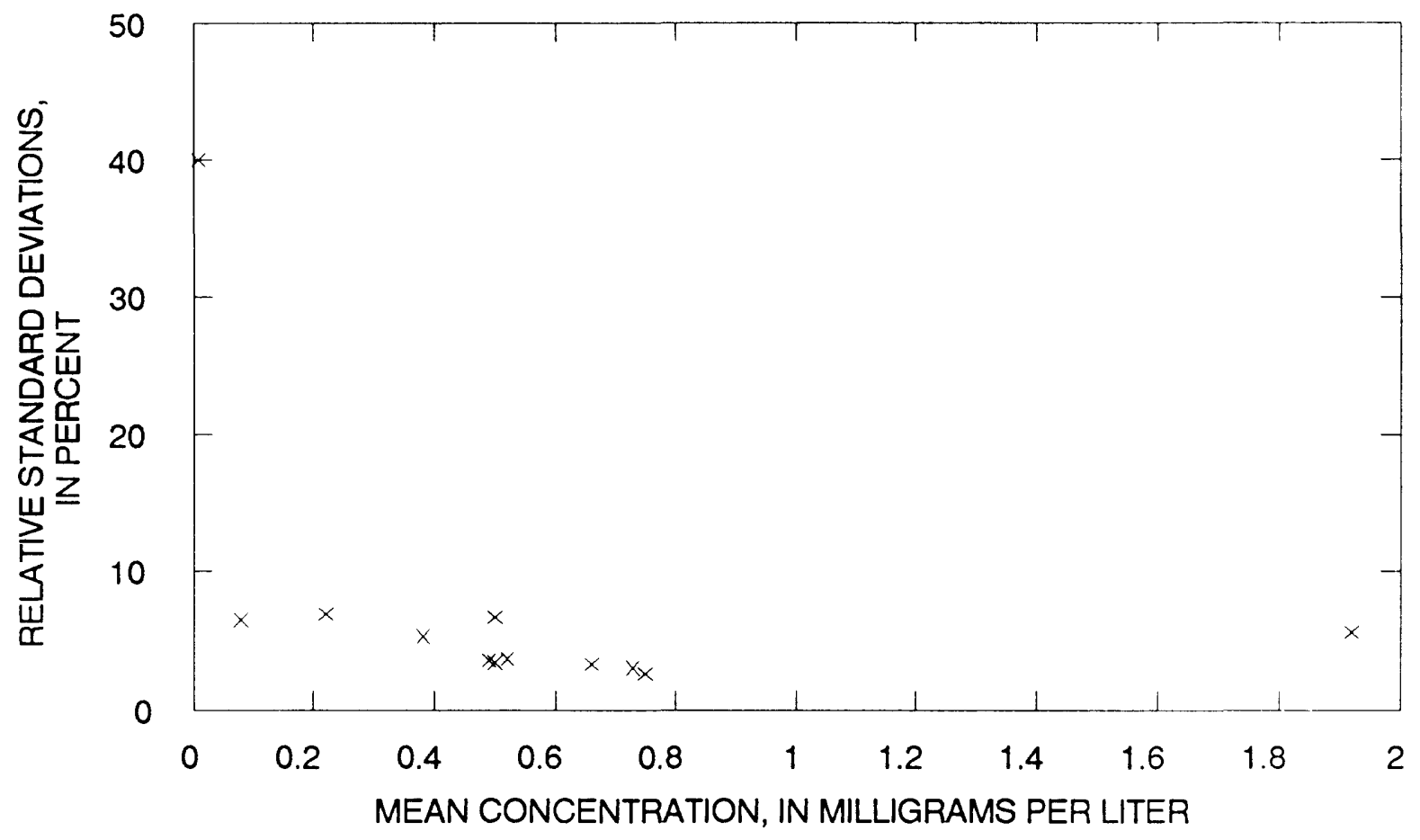

Figure 149.--Precision data for phosphorus, dissolved and total, (colorimetric)

data from the National Water Quality Laboratory.

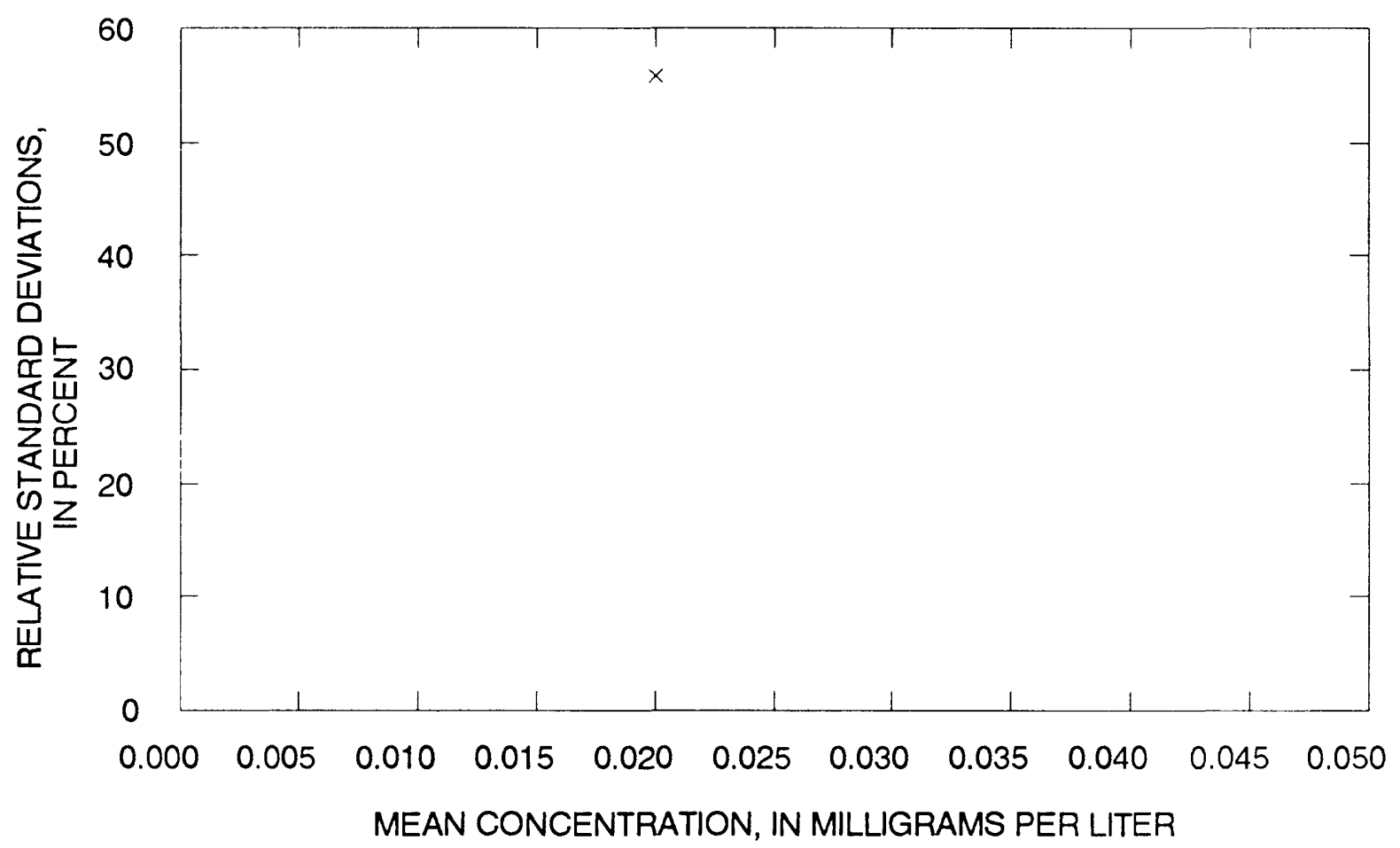

Figure 150.--Precision data for ammonla as nitrogen, dissolved and total, low ionlc strength, (colorlmetric)

data from the National Water Quality Laboratory. 


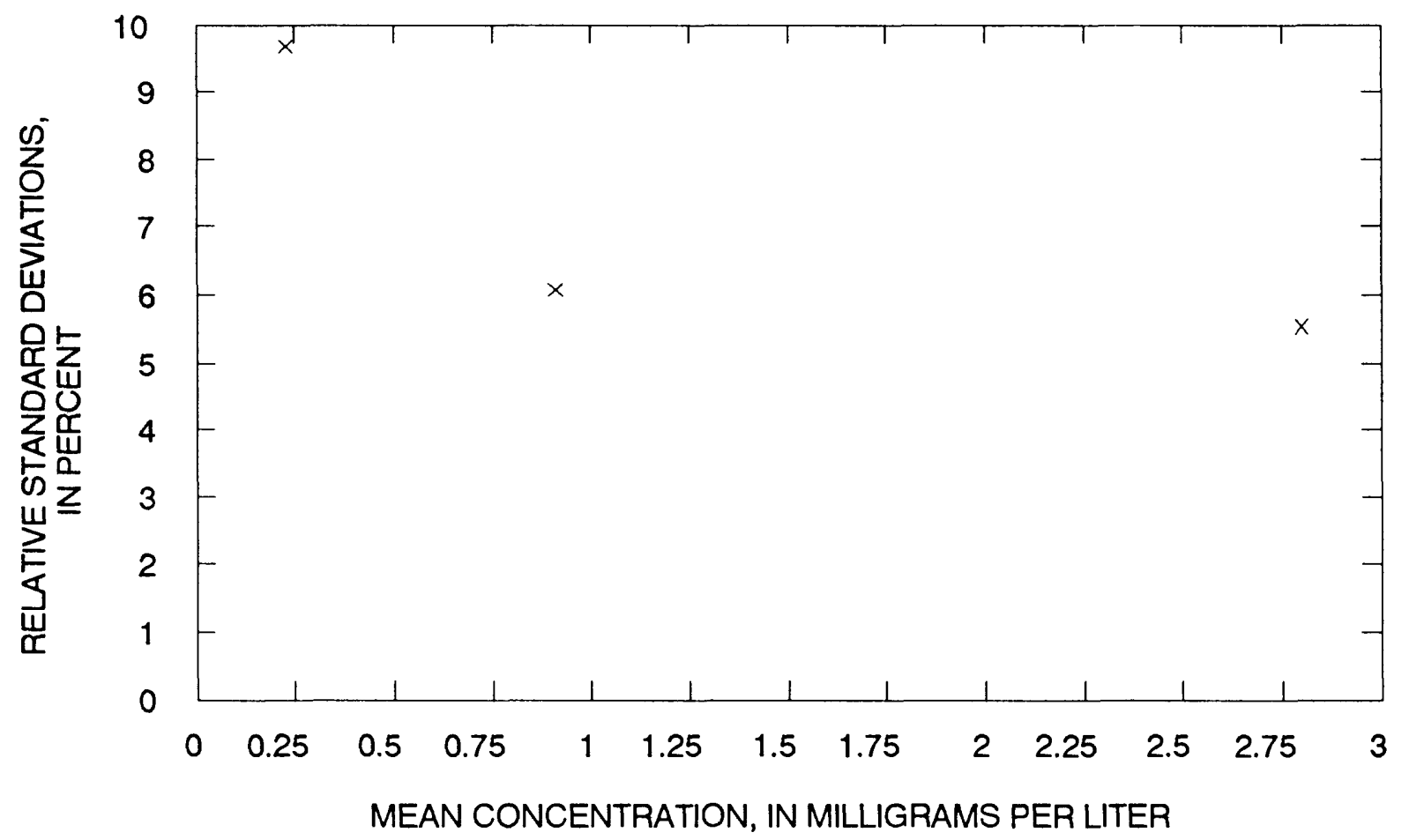

Figure 151.-- Precision data for calcium, dissolved, low ionic strength, (atomlc absorptlon spectrometry), data from the National Water Quality Laboratory.

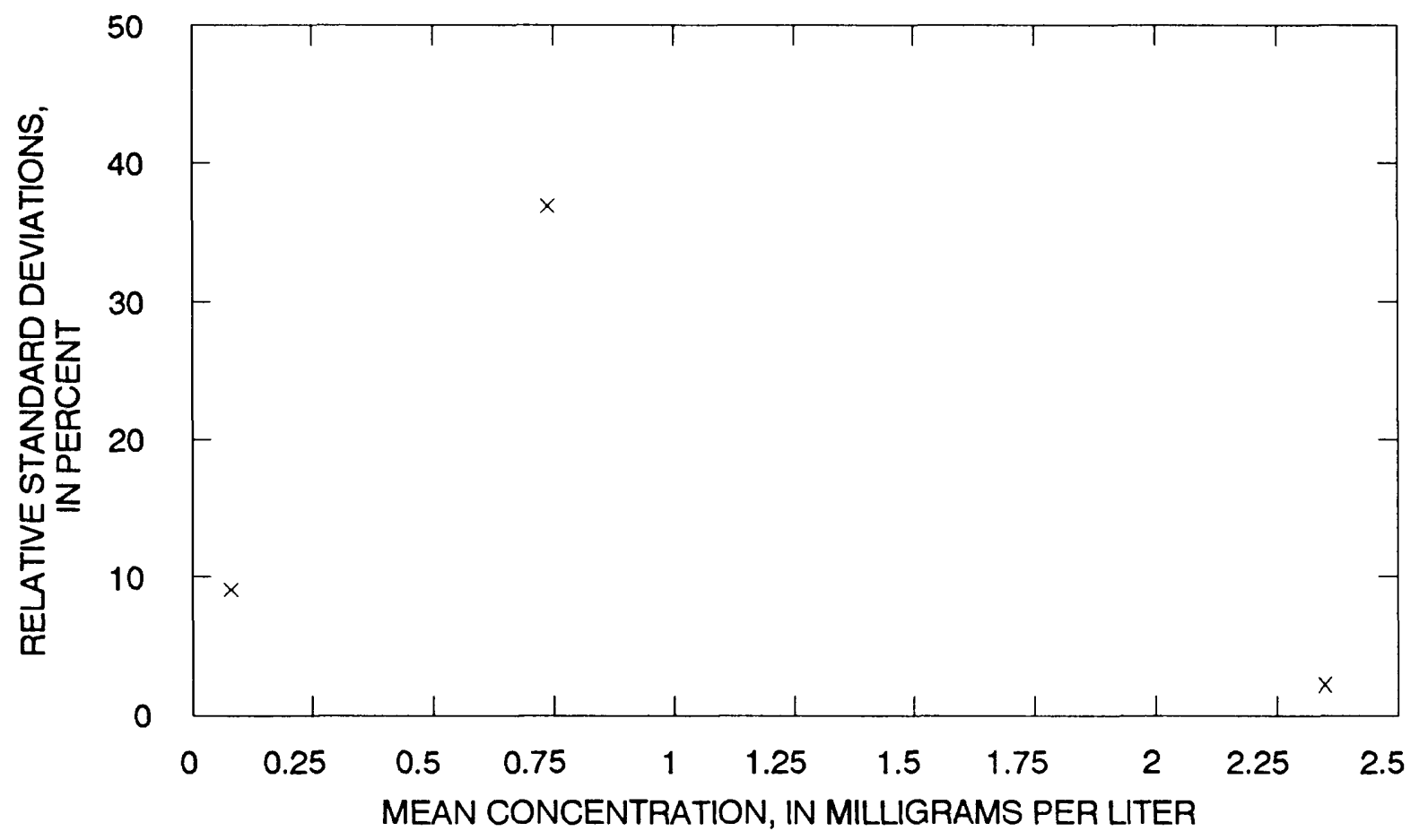

Figure 152.--Precision data for chloride, dissolved, low ionlc strength, (ion chromatography), data from the National Water Quallty Laboratory. 


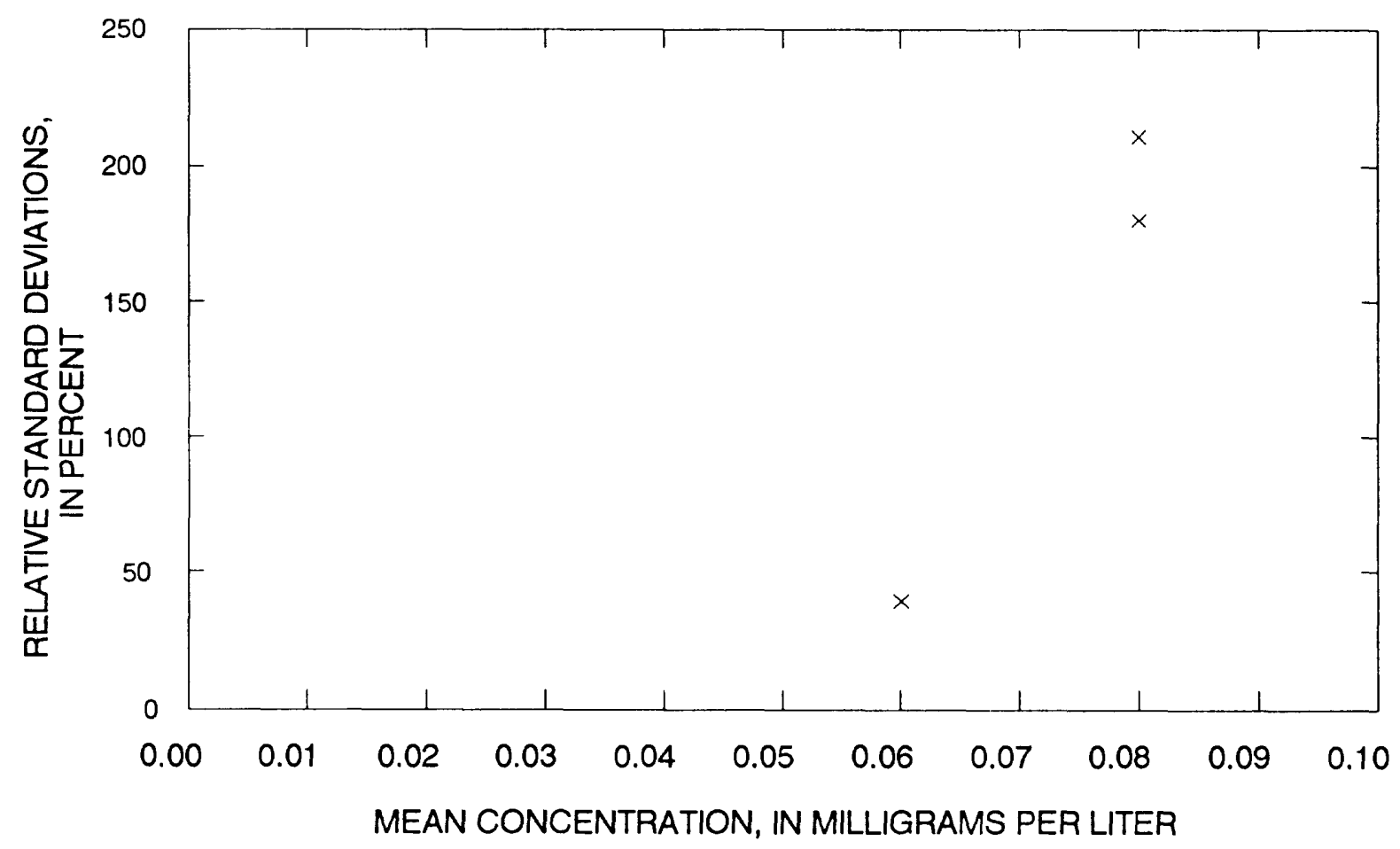

Figure 153.--Precision data for fluoride, dissolved, low ionic strength, (ion chromatography), data from the National Water Quality Laboratory.

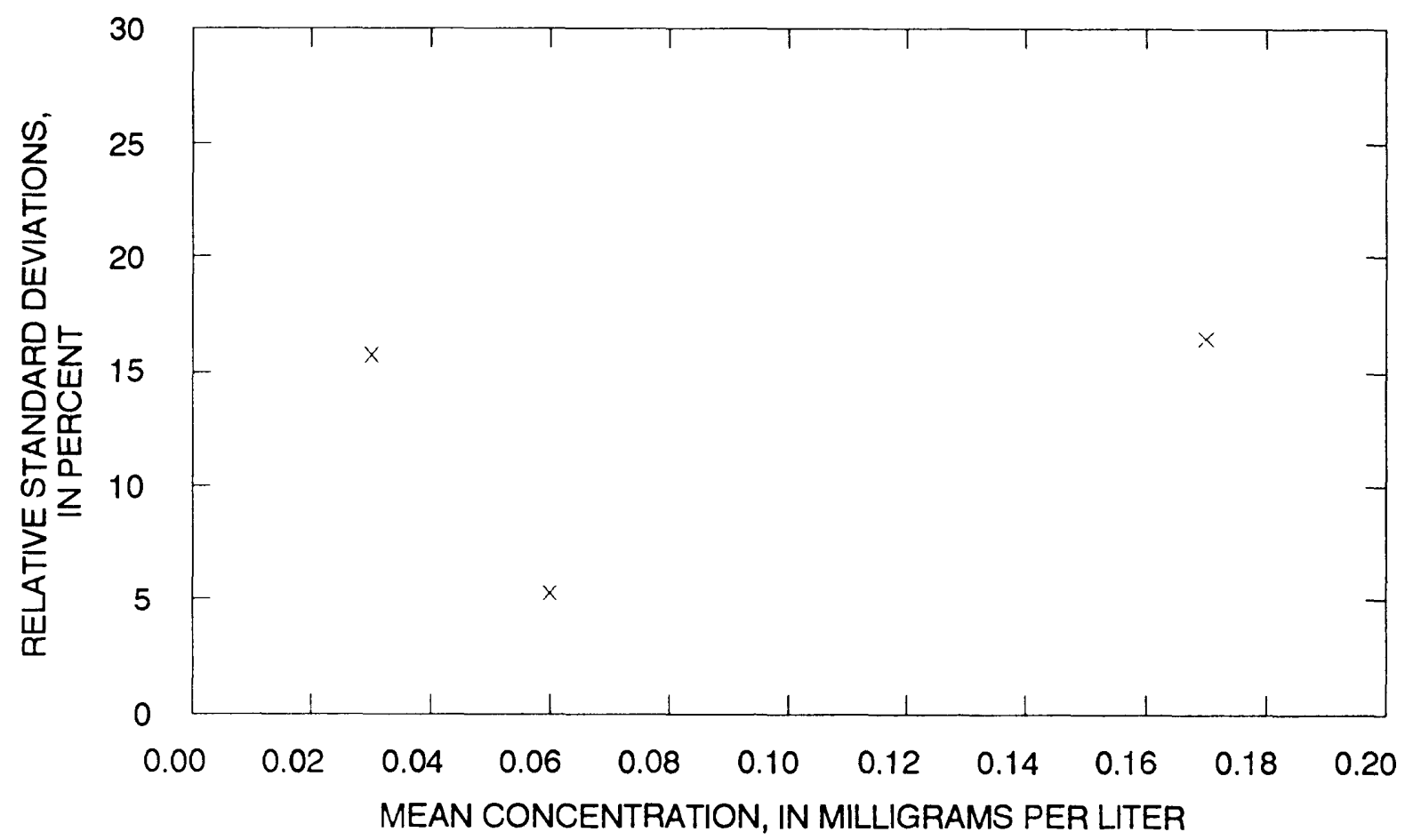

Figure 154.--Precision data for magnesium, dissovled, low ionic strength, (atomic absorption spectrometry) data from the National Water Quality Laboratory. 


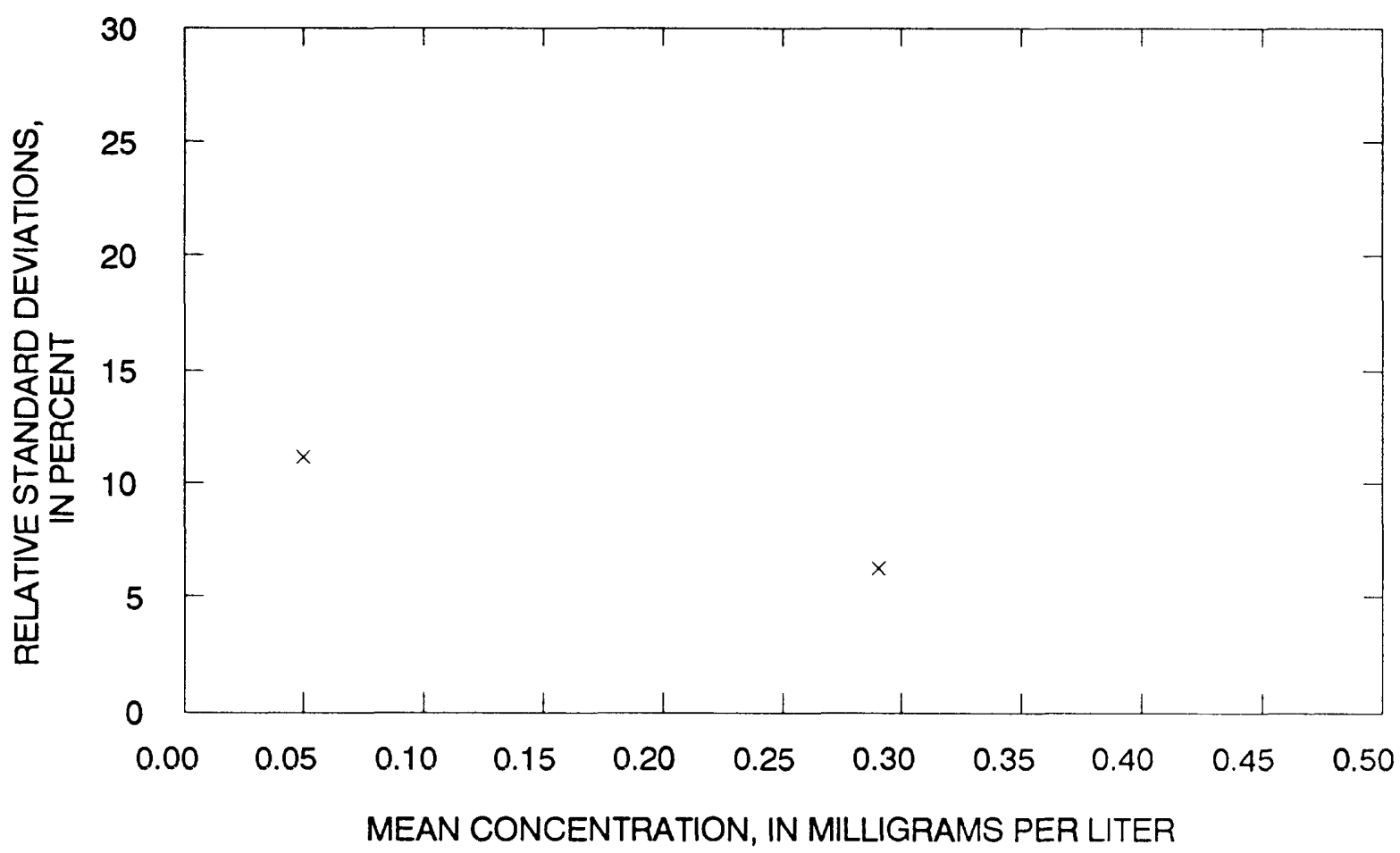

Flgure 155.--Preclslon data for nitrate plus nitrite as nitrogen, dissolved and total, low lonic strength, (Ion chromatography) data from the National Water Quality Laboratory.

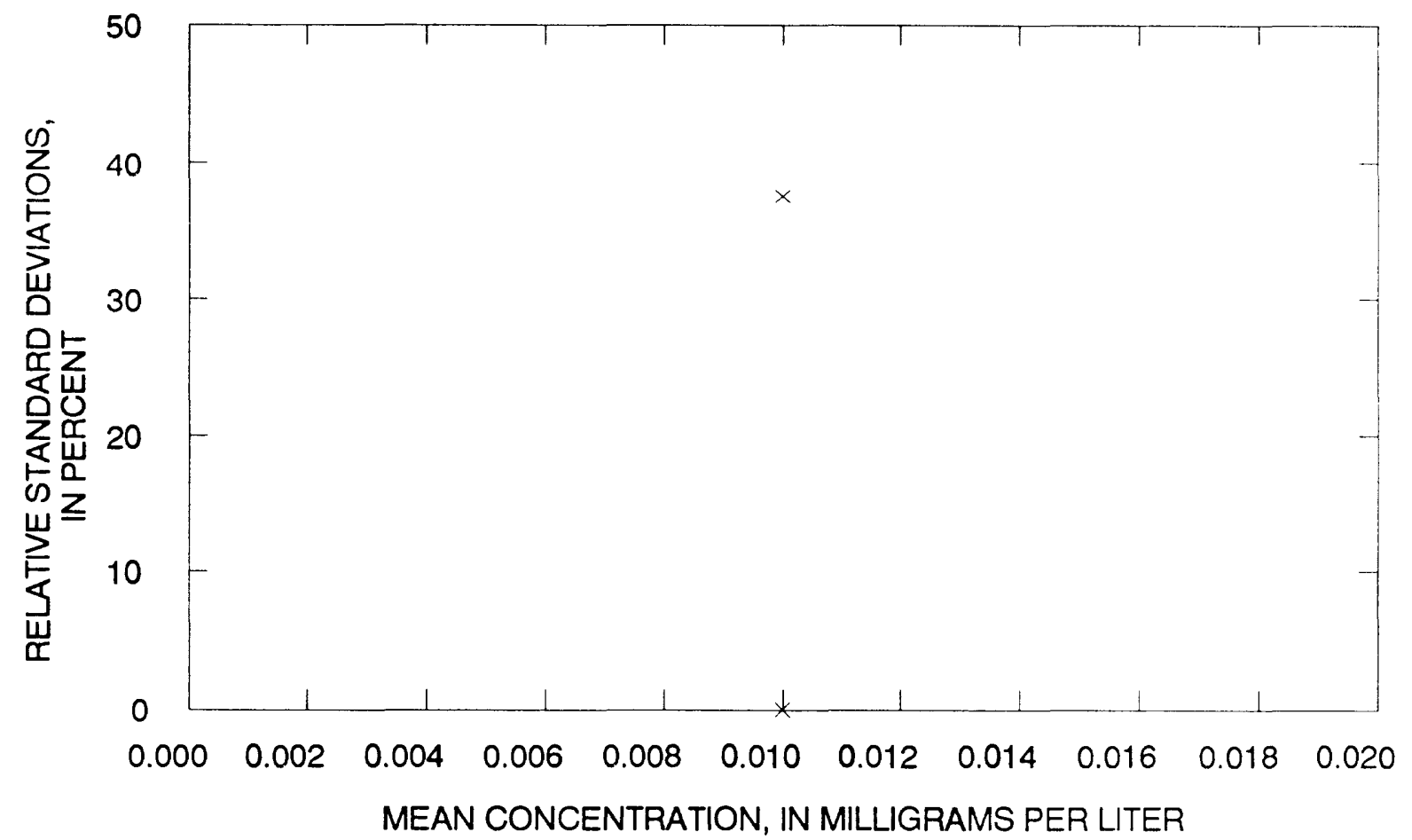

Figure 156.-- Precision data for orthophosphate as phosphorus, dissoived, low lonic strength,

(ion chromatography)

data from the National Water Quality Laboratory. 


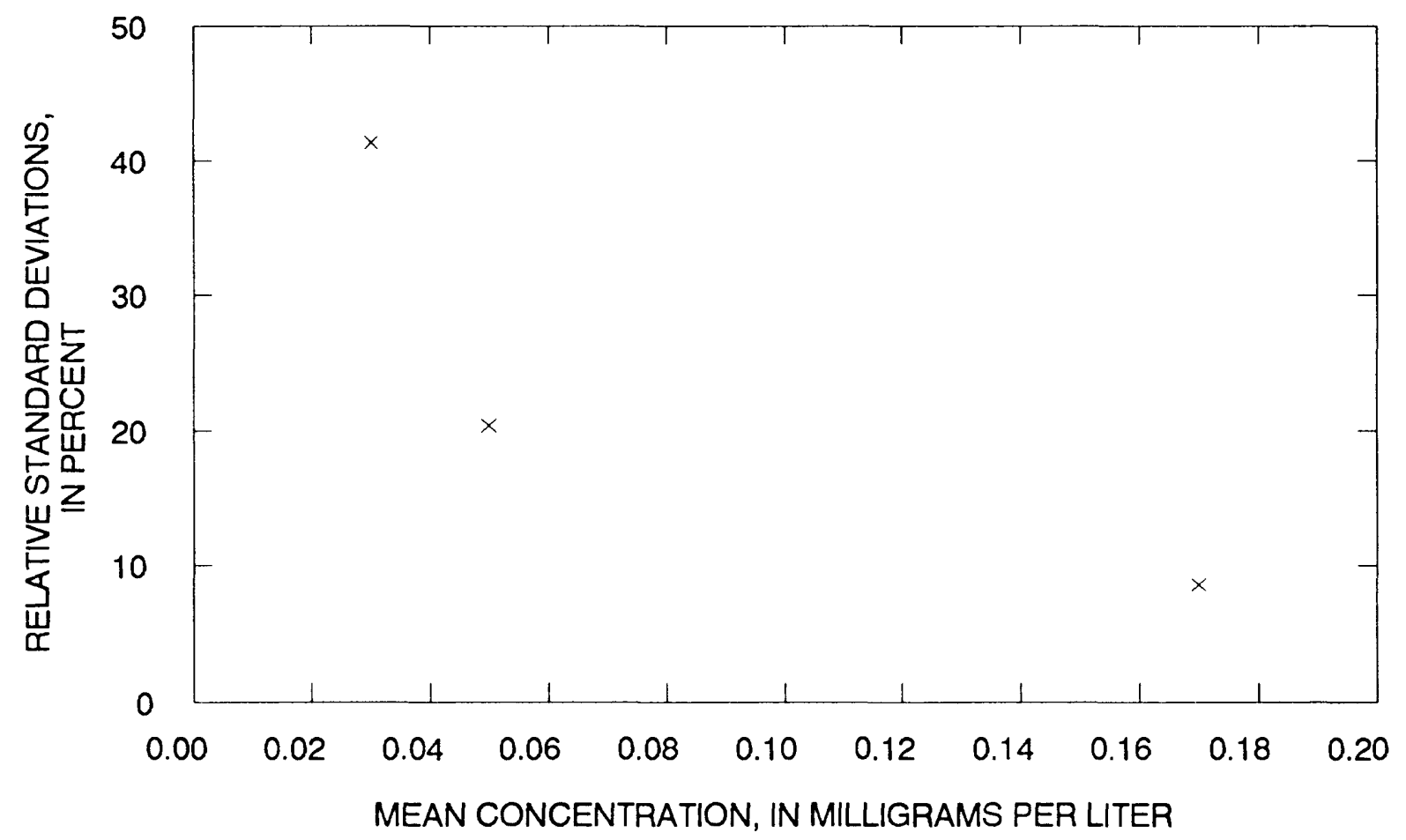

Figure 157.--Precision data for potassium, dissolved, low ionic strength, (atomic absorption spectrometry)

data from the National Water Quality Laboratory.

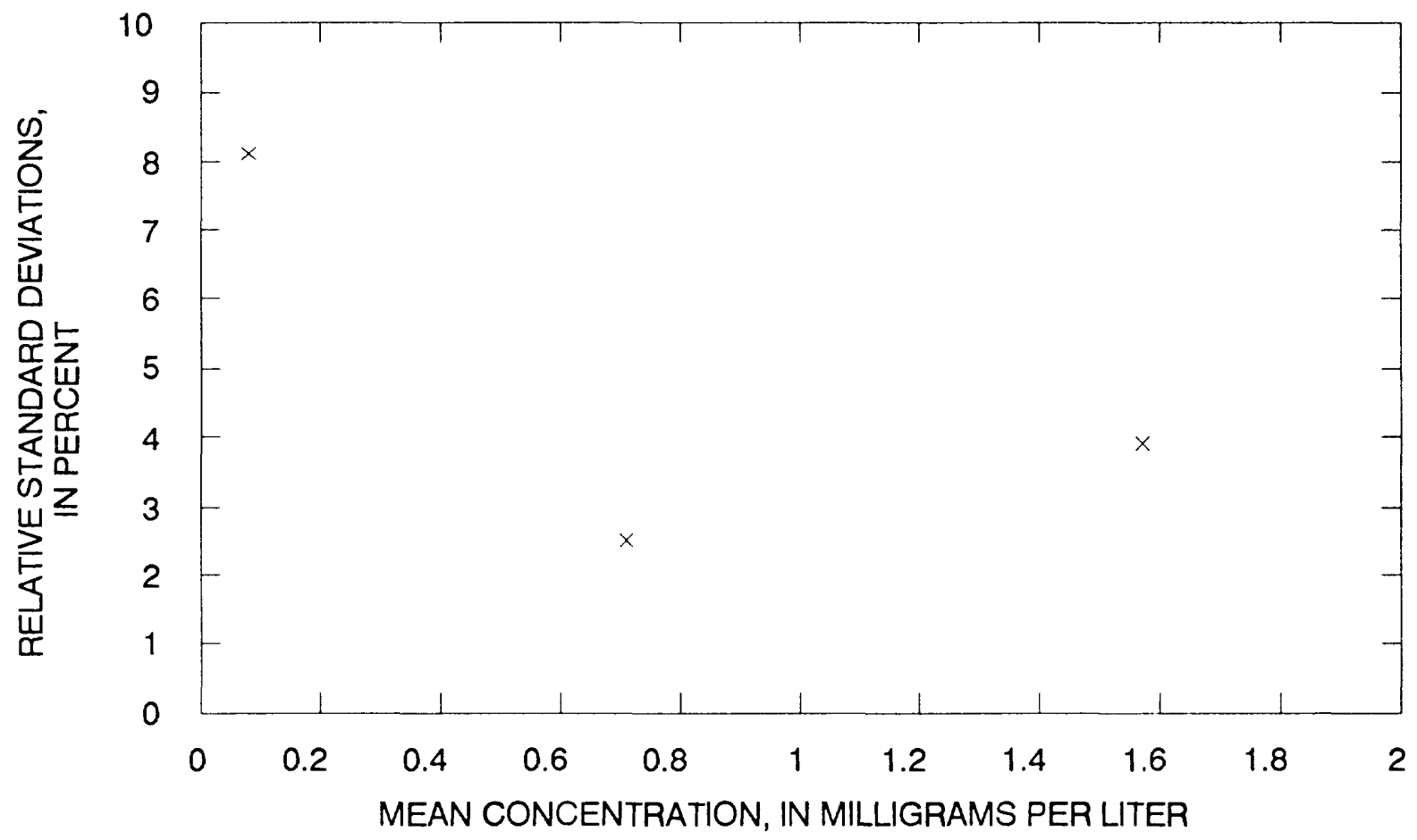

Figure 158.--Precision data for sodium, dissolved, low ionic strength, (atomic absorption spectrometry) data from the National Water Quality Laboratory. 


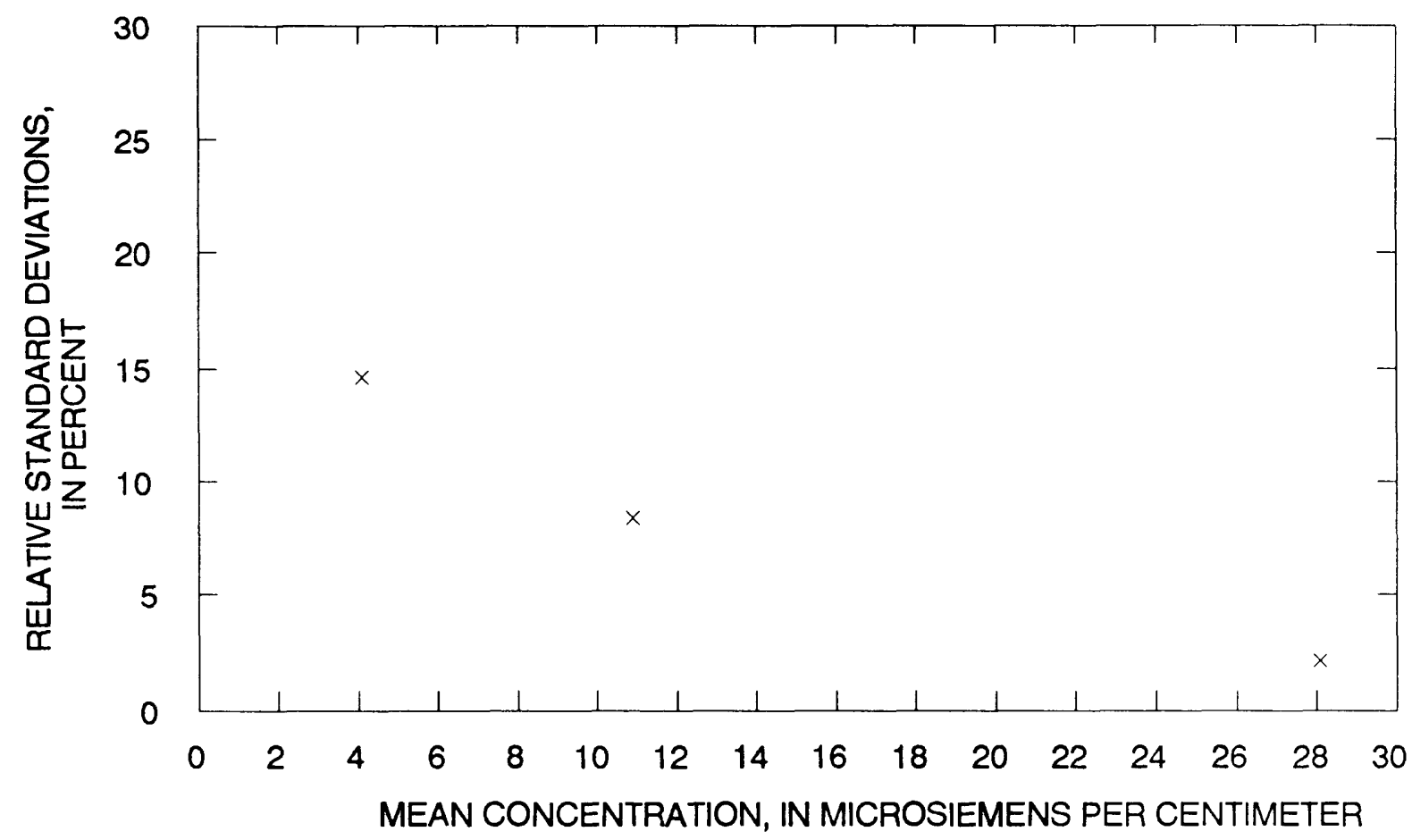

Figure 159.--Precision data for specific conductance, low ionic strength, (wheatstone bridge) data from the National Water Quality Laboratory.

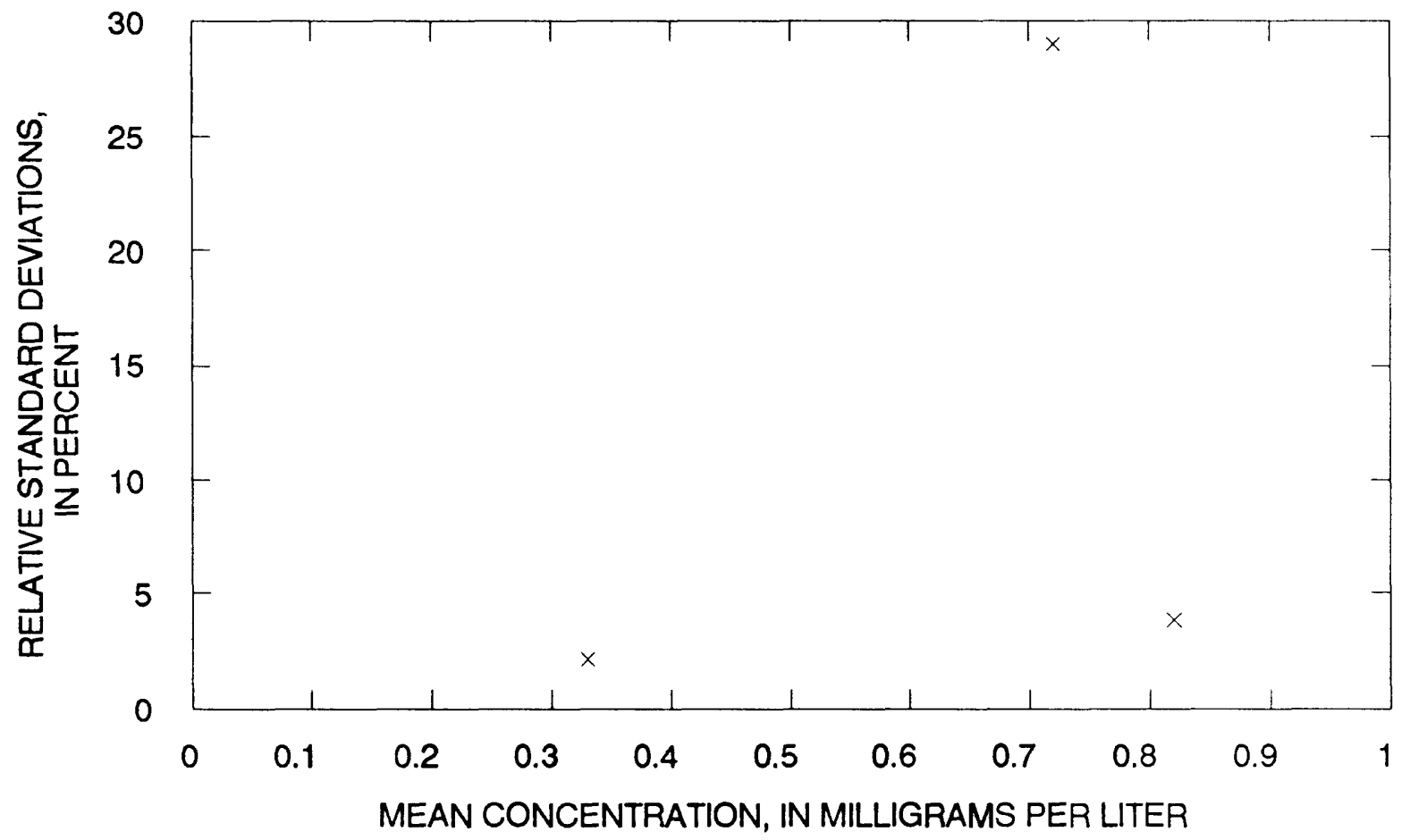

Figure 160.--Precision data for sulfate, dissolved, low ionic strength, (lon chromatography) data from the National Water Quality Laboratory. 